University of Louisville

ThinkIR: The University of Louisville's Institutional Repository

Electronic Theses and Dissertations

8-2014

\title{
"My watch begins" : identification and procedural rhetoric on second screens and social networks.
}

K. Shannon Howard

University of Louisville

Follow this and additional works at: https://ir.library.louisville.edu/etd

Part of the English Language and Literature Commons

\section{Recommended Citation}

Howard, K. Shannon, "'My watch begins" : identification and procedural rhetoric on second screens and social networks." (2014). Electronic Theses and Dissertations. Paper 642.

https://doi.org/10.18297/etd/642

This Doctoral Dissertation is brought to you for free and open access by ThinkIR: The University of Louisville's Institutional Repository. It has been accepted for inclusion in Electronic Theses and Dissertations by an authorized administrator of ThinkIR: The University of Louisville's Institutional Repository. This title appears here courtesy of the author, who has retained all other copyrights. For more information, please contact thinkir@louisville.edu. 


\title{
"MY WATCH BEGINS": IDENTIFICATION AND PROCEDURAL RHETORIC ON SECOND SCREENS AND SOCIAL NETWORKS
}

\author{
By \\ K. Shannon Howard \\ B.A., Presbyterian College, 1997 \\ M.A., University of South Alabama, 2010

\begin{abstract}
A Dissertation
Submitted to the Faculty of the

College of Arts and Sciences of the University of Louisville in Partial Fulfillment of the Requirements

for the Degree of
\end{abstract} \\ Doctor of Philosophy \\ Department of English \\ University of Louisville \\ Louisville, Kentucky
}

August 2014 
Copyright 2014 by K. Shannon Howard

All rights reserved 

"MY WATCH BEGINS": IDENTIFICATION AND PROCEDURAL RHETORIC ON SECOND SCREENS AND SOCIAL NETWORKS

By

K. Shannon Howard

B.A., Presbyterian College

M.A., University of South Alabama

A Dissertation Approved on

March 3, 2014

By the following Dissertation Committee

Bronwyn T. Williams, Dissertation Director

Karen Kopelson

Stephen Schneider

Matthew Biberman

Ellen B. Harrington 


\section{ACKNOWLEDGEMENTS}

I thank my dissertation director, Dr. Bronwyn Williams, for his helpful suggestions during the dissertation process. He was generous with his time during the research and writing of this dissertation, even when on sabbatical in England. I thank Karen Kopelson, Stephen Schneider, Matthew Biberman, and Ellen Harrington for their invaluable suggestions on what to abridge, explain, and/or expand. Karen was such a valuable second reader and supporter of my work throughout my dissertation and before it. I was lucky to have her as a professor and a director of graduate studies during my time at Louisville. Stephen helped me through the trying process of finding a tenure-track position and believing in this work as a future book. Debra Journet was also helpful in the early stages of this project. I had a positive experience working with these scholars and hope to make them proud with this work.

I thank my friends who listened to my obsessions with care and respect as I explored identification in fandoms, and I particularly thank Stellmarys Lopez for her help in the final chapter. Meeting you was a benefit to this project but, more importantly, to my life. 


\title{
ABSTRACT \\ "MY WATCH BEGINS": IDENTIFICATION AND PROCEDURAL RHETORIC ON SECOND SCREENS AND SOCIAL NETWORKS
}

\author{
K. Shannon Howard
}

March 3, 2014

Digital rhetoric creates opportunities for examining rhetoric as it evolves daily. This evolution may be described in terms of network circulation and immediate opportunities for publishing and creating. This project analyzes mobile applications and live feeds used during television broadcasts, where rhetoric is closely tied to the work of identifying with another point of view. Producers and designers of dual-screen applications prompt us to answer how we would act if we assumed the role of protagonist and saw the world through her or his eyes. These questions support the idea that identification is not just a relative of empathy or a way to engage emotionally with the text but also a way to approach problems and sharpen observation.

From this dissertation's findings we may reconsider the work of seeing and perspectival shifting as part of a sophisticated procedure of reflexive role play and public intellectualism. In addition, the analysis provides information about how mobile devices and second screens work to support consensus and a preferred reading (viewing) of popular narratives and group performances, thereby calling into careful consideration 
how we use such devices to influence others. Finally, the dissertation's work helps us understand new forms of viral communication and the velocity (Ridolfo and DeVoss) at which they are transmitted. Consequently, we may approach textual artifacts as "living documents" and consider how such "living" properties may change our perceptions of authorship and composing.

In Chapter One, "My Watch Begins: Complex Narrative, Transmedia, and Point of View," I begin by offering an overview of my methodological approach to these applications. I situate the work of identification on mobile devices within the larger conversation surrounding transmedia and how it encourages viewers to participate in contemporary television narratives. This section provides explanations of how the terms procedural rhetoric (as introduced first by Ian Bogost), prosopopoiea (from ancient rhetoric), and point of view (from narrative theory) will function in this project, with most of the attention given to procedural and rhetorical studies of the various programs and websites associated with audience writings. This chapter also calls attention to the difference between empathy and perspective shifting. An example from contemporary culture that helps illustrate this difference and provides space for conversation is the viral blog post "I Am Adam Lanza's Mother." This editorial, written in the aftermath of the Sandy Hook shooting in 2012, features identification techniques used as persuasive tools but does so in a problematic way that might be better handled with a nuanced and careful study of how identification operates in other settings.

Central to this project are questions addressing how we discuss and document the acts of viewing/seeing/looking, and in what ways the process of seeing from multiple perspectives is currently being lauded in society and the academy. In Chapter Two, "If 
You See Something, Say Something: Syncing Audience Viewing and Response," I reveal two opening examples that illustrate these premises: one from a Walking Dead advertisement that features the protagonist's eye and one from a Department of Homeland Security ad — "If You See Something, Say Something.” These examples dovetail into a specific analysis of syncing devices, or dual screen viewing experiences, and the actual rhetoric accompanying the requests to see from multiple perspectives ("If you were Rick, you would __"). I also call attention to shows where the act of identifying with the protagonist raises questions about the limitations of perspectives. To be specific, I suggest that the white middle-class male is the paradigm of identification exercises for shows that encourage participation from viewers. Examples from television suggest that women and minorities are less likely to be the characters with whom we align our interests; therefore, I argue we should interrogate this trend and think reflexively about the act of identifying.

In Chapter Three, "Choreographing Conversation through Tagging, Tokens, and Reblogs," I argue that analysis of audience reactions via live feeds and blogging platforms shows that textual artifacts, through increased circulation, promote a certain form of identification through consensus. This consensus reveals the tendency of viewers to gravitate toward preferred readings (viewings) of narratives and to identify with characters closely resembling themselves. By constituting viewers in a rhetoric specific to each fictional world, producers encourage identification and help secure appropriate and largely positive viewer behaviors through conversations online. Specifically, digital activities like "checking in" to a show and writing with specific hashtags become markers of narrative involvement. Producers, in turn, engage in reciprocal action by promoting or 
displaying fan activity on their own feeds, thereby sponsoring the work of the audience. While such activity often leads to conformity, I argue that these moments of group consensus may act as springboards for future conversation about other perspectives and narrative outcomes.

In Chapter Four, “Texts as Bodies, Bodies as Texts: Tumblr Role Play and the Rhetorical Practices of Identification,” the rhetorical analysis of these online sites and mobile applications then leads to questions of how we perceive embodiment during identification. In this section I look closely at the writing found on the microblogging site Tumblr, where viewers of television narrative engage in role playing their favorite protagonists and creating dialogue with fellow role players. This practice, operating outside the jurisdiction of producer-designed apps, reveals new patterns of the work of identification. With attention to the ideas of Katherine Hayles and Deleuze and Guattari, we may reconsider how text, once circulated, acts as an extension of and a replacement for the physical body. Still, the work of these bloggers demonstrates that identification is still a personal investment that refers to and gives credit to the person behind the computer screen. This chapter reveals a productive tension between the embodied author's work and the nature of writing as it moves through networks.

In my conclusion I explain how these applications and online tools have implications for the writing classroom. Students are frequently told that good writers and thinkers must see a problem or an issue from multiple perspectives. This project focuses intensely on the work of shifting perspectives and how those perspectives are represented in writing. Its implications for teaching productive source integration and research may be applied to the first-year writing classroom but also the graduate class curriculum, 
where novice scholars learn to extend, oppose, and ally themselves with the scholars who have come before them. 
TABLE OF CONTENTS

PAGE

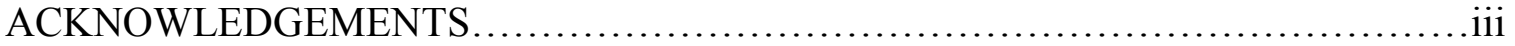

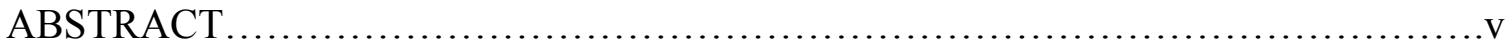

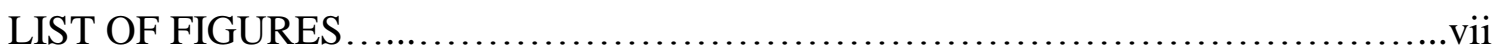

INTRODUCTION: IMAGINING MULTIPLE PERSPECTIVES ....................

HISTORICIZING POINT OF VIEW IN POPULAR CULTURE AND DIGITAL

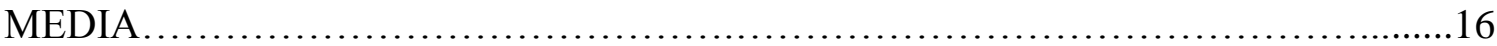

"IF YOU SEE SOMETHING, SAY SOMETHING": SYNCING, WRITING, AND

PERSPECTIVE SHIFTING IN TELEVISION NARRATIVE.......................54

FOLLOWING THE LEADER: CHOREOGRAPHING CONSENSUS AND

CONVERSATION IN LIVE TWEETING...........................................101

TEXTS AS BODIES, BODIES AS TEXTS: ROLE PLAY AND THE PROCESSES OF IDENTIFICATION ......................................................... 151

CONCLUSION: IDENTIFICATION AS A RHETORICAL STRATEGY AND CONSIDERATIONS FOR THE WRITING CLASSROOM.........................193

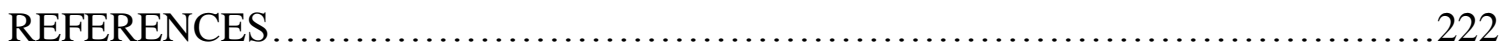

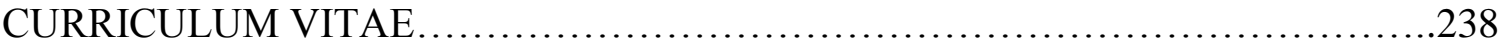




\section{LIST OF FIGURES}

\section{FIGURE}

PAGE

1. Screen shot from Weather Application for Game of Thrones..................1

2. "My Watch Begins" Campaign for Game of Thrones............................27

3. NCIS: LA Connect App: "Listening" to Live Broadcast........................56

4. Advertisement for the "If You See Something, Say Something" Campaign....59

5. U. S. Navy Advertisement during The Walking Dead Story Sync..............67

6. Interactive Puzzle Game on Falling Skies App during Commercial Airing.....67

7. Quiz Question for Fans from AMC Mobile's The Walking Dead Story Sync...68

8. Facts about Production on Falling Skies App.............................. 70

9. Facts about Production on The Walking Dead Story Sync......................70

10. Live Feed during Story Sync of The Walking Dead.........................74

11. Audience Polls for The Walking Dead Story Sync.........................81

12. Evaluation Question from Story Sync of The Walking Dead..................84

13. Evaluation Question from NCIS: LA Connect App.......................85

14. "Audience Poll: Decide" for Story Sync of The Walking Dead................86

15. "Audience Poll: Decide" for Story Sync of The Walking Dead...............89

16. "Test Your Knowledge" on the NCIS: LA Connect App.....................92

17. Showtime Sync for Nurse Jackie's "Luck of the Drawing"

18. My Conversation with Producers from Fox Television...................... 101 
19. Vikings Check-In Sticker from GetGlue.....................................112

20. Hannibal Check-In Sticker from GetGlue.................................112

21. Bonus Hannibal Sticker from GetGlue......................................113

22. Reblogging and Liking a Post on Tumblr..................................118

23. Trending Topics: The Walking Dead hashtag "fighttheliving".................121

24. Tumblr Microblog Entry about Tagging and Popularity......................122

25. "Dash, you stop that," by thehobbesgirl on Tumblr..........................124

26. Actress Jennifer Carpenter's Query about Live Tweeting.......................127

27. Showtime's Response to Carpenter...................................... 128

28. Opening Writing Prompt for Vikings on Twitter.............................132

29. Conversation with Producers and Showrunners about Hannibal ....................134

30. Reflection Question after Live Broadcast of Hannibal.........................136

31. Producers of Hannibal Participating in Forward Friday on Twitter.............138

32. Showrunner Bryan Fuller's Conversation with Role Playing Fan...............140

33. NBC Hannibal Tumblr Page with Parodic Tagging...........................142

34. Tumblr Page of Dr. Who Role Playing Blogger..............................143

35. Promotional blog entry of role playing community for the sitcom Friends.......151

36. The Walking Dead "Dead Yourself" Application...............................155

37. Role play between razielangelofsecrets and bibliophileangel on Tumblr........158

38. Rate Your Professor profile of Walter White from Breaking Bad......................162

39. Example of Magic Anon Writing Prompts from UR Lmichiferangst............170

40. URL little-shrike reblogs URL drlecterpsychiatrist's fan mix for Hannibal .....180

41. Blogger fefarielle praises English language learners on Tumblr...............181 
42. The roleplayerscoffeeshop blog indicates that their blog will be on hiatus.......184

43. A "shoutout" post dedicated to role players from the Heroes fandom.........185

44. Studio promotion on Twitter of the Starz series The White Queen..........186

45. Role player somnambulisms promotes role player uniquecocktail on her dash......187

46. Advanced Search on Twitter for Hashtag Information.....................216 


\section{INTRODUCTION}

\section{IMAGINING MULTIPLE PERSPECTIVES}

Above all else, join us in trying to surprise and delight users. Show them their world in innovative ways, and let them interact with it like never before. In our experience, users really respond to polish, both in functionality and user interface. Go the extra mile. Give them more than they expect. And take them places where they have never been before. - Apple iOS Developer's Guide

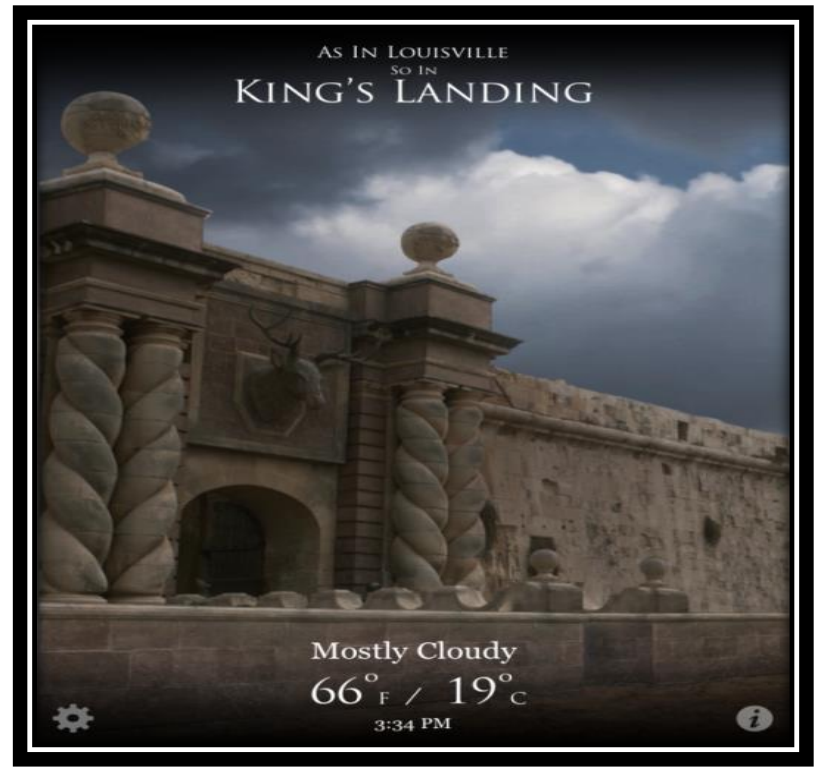

Fig. 1: Screen shot from Mobile Weather Application for Game of Thrones

The screen shot above is from an app called "Ice and Fire," and it refers to the story world of HBO's television program Game of Thrones. Available through the App store on any Apple brand mobile device, a user on iPad or iPhone can download this weather app in order to check the temperature and time in her/his location during the day. What is perhaps intriguing (or banal, if you are Jean Baudrillard writing about our "screenified" culture of simulated realities) is the simplicity of what we see. The 
application does nothing more than tell the weather. It gives a time in Fahrenheit and Celsius, and it gives the accurate minute and hour of the day, but there is little participation involved in opening its contents. The user views the given information and closes it.

Yet if one clicks on the lower case italicized "i" in the bottom right hand corner, a description of the city mentioned on the screen will appear. The description gives the viewer a sense of what life is like in the city of King's Landing, and who lives there. The Song of Ice and Fire book series by writer and television producer George R. R. Martin, upon which the television series Game of Thrones is based, features alternating points of view among a large cast of characters. In doing so, each character, living in different parts of the story world, reveals, through their daily adventures, a new part of the Seven Kingdoms and a candidate for king of the realm.

Therefore, the app reflects this large set of perspectives and settings; and, depending on the day of the week or the weather, we see a different fictional town's weather highlighted. For instance, when Louisville received its first three inches of snow, the scene of the app changed to reflect those icy conditions and feature the coldest region in Game of Thrones. The screen showed a landscape, complete with an animation of falling sleet, based in the far Northern town of Winterfell. While this app is simple in design, it achieves its first goal - to announce and market the third season of Game of Thrones — by making us as users of the app view our world from a more imaginative point of view. Because the weather changes, the interface changes to reflect what might be happening in the world of Game of Thrones at the same time. Details about the setting, including the economic and social class of the citizenry, the climate conditions, and the 
major industries of the area are often added to this process of checking the temperature because such information thickens the observation process; that is, it makes the city of King's Landing function as more than just an idle reference to a literary or television mythos.

This practical weather app seamlessly merges worlds, inviting continual check-ins that connect the real world to the virtual one. Not only does it work toward dissolving the boundaries between real and virtual sites of being, but the changing pictures, animations, and even locations featured on the screen are part of why Apple, on its website, refers to such applications as "living documents." As a term from the world of business, a "living document" typically means that it is a document subject to change. Here, the term takes on a different meaning when considering how many scenes and points of view change on the app itself. ${ }^{1}$ When revisiting the quotation that opens this chapter, it is easy to see how this app fulfills Apple's mission for operating system designers. The instructions advise that an app should "take the [users] places they've never seen before." "Ice and Fire" certainly simulates places we've never been, and it helps us see things from a different, and fantastical, point of view.

But most applications are more complicated than the one described in the above paragraphs and image. This project is a rhetorical study of these apps and their associated social networks, both the complicated and the simple ones, as "living documents" of persuasion: how they shape narrative meaning for viewers, and the ways in which they use character identification or point of view to ensure deep engagement. From these texts

\footnotetext{
${ }^{1}$ A "living" document like an app may also be subject to periodic updates as designers work to "debug" the software associated with its presentation. Through the App Store, a user may download updates to the app as it develops.
} 
we can find ways that empathy and attention to shifting points of view are becoming a more integral part of how we conceptualize meaning in our world.

\section{Rationale}

This project is driven in part by the major question of what it means to see, and, more specifically, what it means to see from more than one point of view. Disciplines in the Humanities approaches this question in different ways. Psychology, Philosophy, Anthropology, English Literature, Theatre, and Composition and Rhetoric all bring this question into view through different tools of analysis. Most are interested in what it means to engage in intersubjectivity, or dialogue and understanding of different mind sets. Because we live our lives within the realm of one conscious mind, people believe that we are either limited in our understanding of what happens around us, or we are capable of imagination and cognitive ability to transcend that so-called boundary of the self and understand other perspectives.

My approach to the question of what it means to see from more than one point of view is grounded in a study of the digital rhetoric surrounding pop culture narratives. The digital artifacts presented here are designed to accompany the fictional world(s) of television dramas that have aired in the twenty-first century. They include the second screen applications, social networking sites, and role play activities generated by both producers of a narrative and the fans who follow them. Within the purview of this project are the narrative-inspired writing activities that promote the act of perspective shifting as a laudable trait.

Before examining this data, I must explain what I believe to be true. First, I do think we are capable of knowing the world and understanding it beyond our own thoughts 
and ideas. We possess the cognitive ability to see from multiple perspectives and to harness that ability to think more critically about the writing and reading that we do. Second, perspective shifting is not just reactive, as is the case when we empathize after someone confronts tragedy, but proactive and appropriate in logically working through a problem. I suggest we have not yet mined the possibilities of understanding the difference between what it means to empathize and what it means to shift perspectives. Third, the writing artifacts we produce in relation to these perspectival shifts take on a sentience and rhetorical power of their own, once circulated and read by greater numbers of people. Understanding how these processes work is vital to our work as critical thinkers contributing to living digital archives.

Storytellers, I would argue, also believe these points to be true, or they would not traffic in ideas and the dissemination of them with such joy and possibility. This is why I rely on narrative--particularly fictional narrative--when arguing we are capable of seeing from multiple perspectives in ways we have not fully articulated yet. Storytelling allows more than one possible version of what could be. It poses what Jerome Bruner calls a number of possible worlds. In Stephen King's memoir On Writing, he recalls the moment when someone first told him to "make up his own story." He describes it accordingly: I remember an immense feeling of possibility at the idea, as if I had been ushered into a vast building filled with closed doors and had been given leave to open any I liked. There were more doors than one person could ever open in a lifetime, I thought (and still think). (King 28) 
In other words, storytellers do not offer a fictional view of the world just for transitory entertainment purposes. They also offer countless possible ways of experiencing and reimagining life, and this approach is central to how we write and read.

This idea especially plays out in the creative use of the mobile technologies discussed in this project. Phones, tablets, and other devices enable us to write and read while physically active and to perform multiple tasks at once. The idea of experiencing narrative does not have to be confined to one armchair or one television in a living room. Now we take living stories with us, literally, wherever we go, and enjoy them as we perform the mundane chores of day to day life. Here we see the mundane and the creative worlds not only brushing up against each other but bleeding over into each other. In other words, the spread of new technological supplements to storytelling (second or dualscreen applications, for example) are breaking down binaries that once seemed ossified: it is hard to draw the line now between mobility and immobility, consumer-driven or producer-driven design, and material and non-material communication. I will confront each of these binaries more fully in my forthcoming chapters.

This very dissolution of the fictive and the real as opposites becomes important to my analysis of what it means to see from multiple perspectives. But what do alternate perspectives provide? Some might say they only confuse our system of values by multiplying the possible ways to approach any problem. Others might comment on the relativity that seems to accompany the multiplication of points of view: if everyone has a point of view, how can one of those views be essentially the "right" or "moral" one in a given situation? (see Booth's Critical Understanding). Yet in most classrooms at my home university I find posters hung on the walls that laud the act of "considering a 
problem from more than one point of view" as part of what education strives to do. Whether or not we trust the statements found on such posters and the people who write them is not as interesting as the fact that they keep appearing and that the rhetoric surrounding them continues to evolve. Similar rhetoric, focused on the persuasive power of an individual's point of view, has even bled into the overall national climate in the past decade. The Department of Homeland Security's own campaigns to prevent terrorist activity here in the United States_- "If You See Something, Say Something"-reasserts the importance of sharp observation skills being essential to maintaining public safety (more to come on this campaign in Chapter Two).

Still, some might say that it just is not possible to see outside of ourselves, even through the use of storytellers as models for considering multiple worlds or doors (as King would say) to reality. They would say, and perhaps rightly so, that even when we entertain an alternate vision of what the world could be, we choose the character within that vision who best represents who we already are and how we have navigated the world. We may imagine different perspectives all we like, but ultimately that imaginative process reflects who we ultimately want to be. It does not pay serious attention to what it means to be alien or other. I will address this point in Chapters Two and Three more fully.

\section{Connections to Previous Studies}

While Chapter One provides a full literature review of the scholarship preceding this project, I highlight the part of this review that addresses gaming because it may be a question already rising in the reader's mind: why study perspective shifting when we know new media studies and its focus on video games has already done most of this 
work? Why must we even devote time to perspective shifting when gaming already demonstrates the use of an avatar who experiences a different world through procedures of play? One need only Google "game studies" to find dozens of links to articles and online journals on gaming and how it relates to the learning processes in our schools. Cynthia L. Selfe and Gail E. Hawisher published an edited collection in 2007, called Gaming Lives in the Twenty-First Century, inside which scholars analyzed how games fostered literacy, agency, and cultural connections in student learning. Also, in 2008, Matthew S. S. Johnson edited a special edition of Computers and Composition within which authors like Kevin Moberly describe gaming as a rhetorical and complex process: "As players enact, revise, and refine the rhetorical strategies that form the core of their characters' identities, they initiate a narrative process of attack and counter attack." (293). He goes on to say that games like World of Warcraft "reward[] players for the prowess with which they compose their characters (and thereby write the game) by granting them ever-increasing access to the game's symbolic vocabulary" (293). Moberly's argument highlights the composing work that occurs when we work on changing identities. While we are not writing alphabetic text, our construction of identity still works as a procedure based in audience awareness and rhetorical strategy. Steven Johnson also reminds us that of all forms of pop culture narrative, games are the media that require us "to decide, to choose, to prioritize" our actions, all of which are important to intellectual growth and seeing problems from a different vantage point (41). Recent scholarship even discusses the parallels between the readings in game manuals and textbooks, where the authors of such manuals "consciously ask players to examine the way they might engage the game and from what perspectives" they might play it before even pressing the "start" button 
(Matthew S. S. Johnson 69). Most notably, James Paul Gee, author of What Video Games Have to Teach Us about Learning and Literacy, argued that young students are learning how to solve problems through repetition of simulated obstacles. With their "unmet potential to create complexity by letting people experience the world from different perspectives" (158), he says, games allow users of all ages to try on different characters in a virtual world where they may practice literally changing their vision of an obstacle or problem every time they reenter or replay a scenario. The word "perspective" is peppered throughout the above scholarship, revealing a major facet of what games have to offer: an exploration of multiple points of view.

Although similar to such games, the apps and social networks I discuss here frequently act as "second" screens that "sync" live with the master narrative on the first screen, or television. These apps provide an interface for viewer live-feed conversations and role play activity (to be discussed in more detail in Chapter Four). Experiencing such guided narrative is a form of transmedia-- or storytelling across multiple platforms ${ }^{2}$-- that does not merely supplement a mythology but monitors and simultaneously directs it. To be clear, "Ice and Fire" need not be "synced" with Game of Thrones as it airs live. I use that app to open discussion because it shows how seeing from new perspectives is central to its design. "Ice and Fire" is more like the practice of gaming because, as Debra Journet

\footnotetext{
${ }^{2}$ For more elaboration on transmedia from a media studies perspective, see Christy Dena's 2009 dissertation: "Transmedia Practice: Theorising the Practice of Expressing Media in a Fictional World across Distinct Media and Environments." Although I introduce transmedia more fully in Chapter One, I should first say that Dena makes a valuable distinction between two approaches to transmedia analysis: "transmedial narratology" and "media studies theory of transmedia storytelling" (17). She uses the latter to interrogate the processes of fictional world building from a lens of creative practices, but not one rooted in structuralist ideologies of how narrative functions beyond the page or screen. These creative practices, in Dena's work, are discussed not in terms of how stories work but how the platforms in transmedia work together. In my project I hope to establish a bridge between these two approaches with rhetoric as the main disciplinary lens. In doing so, I look at both the media and the narrative working together to persuade or communicate.
} 
explains in her study of narrative in the game Myst, "one of the greatest and most intense pleasures in playing these games came from the gradual way they move[] [us] from one wondrous place to another" (103-04). With most apps, the role playing we are asked to do is not gradual but occurs synchronically with actors playing those same roles on television. The apps all appear to share one feature in common: using character identification to deepen understanding of an already established mythos. Our identification process with these fictional television characters begins while their narratives are still being shaped and the show is still continuing from season to season.

In terms of choosing apps, I focus on both the "syncing" applications and the apps like "Ice and Fire" because I believe they are relevant to how we will be reading, viewing, and composing meaning in the future. To say that the mobile devices upon which we use these apps will always remain off or silent during large public events is no longer a given. While it may not surprise us that dual-screen viewing is part of events like the Super Bowl or the Oscars, where viewers are gathered in parties to watch television, review and stream their favorite plays or fashion trends on smartphones, and talk their way through the event, it is also a part of traditionally "silent" activities on the part of audiences - university lecture halls, theatre events, conferences--happening in larger spaces with many people in the same room. Some lecturers ask their students to "tweet" via the microblogging service Twitter questions that they have about the material being discussed; such a practice is typically called "backchanneling." I have even attended a live musical performance whose marketing staff allowed the audience to keep mobile phones out to tweet their reactions to the show. And, perhaps most pervasive on a daily basis is the new version of Facebook that mimics dual-screen and backchanneling 
processes: one screen is the collection of status updates and pictures users are publishing, and the other is the ticking real time news feed of activity. Even blockbuster movies like Les Miserables offer "study guides" that can be downloaded on iBooks for free, although they have not yet made the transition to "syncing" in the movie theatre yet.

A benefit of dual-screen technology is the ability to work with language and social identity as "living" processes that possess what Jim Ridolfo and Danielle DeVoss call "rhetorical velocity." Rhetorical velocity takes into account the speed at which information is exchanged and interpreted, so users or viewers at all times must make decisions about how they will present their ideas in order to predict how they might be remixed by others. The way viewers engage with an app that features "live conversation feed" could be applied here. While Ridolfo and deVoss highlight multimodal designs as their main examples of items being communicated at such speed, I would extend their idea to include items as seemingly mundane as a sentence mocking a fictional character in a television show that a viewer posts on Twitter. In an earlier time, viewers expressed such opinions in a vacuum, even forgetting they expressed the thought, but now with producers of narrative hosting their own websites and social media, each statement has the potential to be retooled or used by a network to market the franchise. Composing thoughts about narrative has become a "living," speedy transmission that, depending on where we post or publish, establishes dialogue among not only other fans, but potentially the creators, writers, and actors of a given narrative world. Viewers gain practice retooling their communication for various audiences within minutes: a narrative twist in a TV show, one lasting only seconds, may grant an instant opportunity to post a reaction witty enough to be reposted or retweeted by hundreds of other viewers, or even the 
producers themselves. Language and interaction on these apps and in other online spaces remains ever on the move, always living, always changing, especially where fictional worlds are being discussed and debated.

\section{Upcoming Structure}

In Chapter One, I will explain why seeing from multiple perspectives is important to the growth of a discerning public. I will introduce specific tools that changed visual forms of narrative in important ways. I show how, throughout the history of different forms of media, using an app, an online game, or a website associated with a fictional world creates opportunities for decision-making to happen frequently enough to allow for meaningful revision and rethinking of alternate solutions to any given situation, fictional or real. These exchanges make a narrative experience come to life in ways that we had previously not experienced. I provide an overview of the particular histories, particularly in pop culture and media, associated with seeing narrative as a living, evolving process. I also explain the methodology I adopt to interpret these digital artifacts and how "thick descriptions" of this data will form the basis of the project as a whole.

In Chapter Two, I look carefully at the items on syncing applications that ask viewers to assess the ethical and moral decisions of characters placed in difficult and dramatic situations as they watch the show. I will contend that by making viewers answer specific questions designed by producers, we are engaging in a somewhat formalist enterprise of analyzing what Wayne Booth famously called the ethics of fiction, or "the company we keep." I will explain how point of view is central to understanding what Story Sync asks of us as viewers. Finally, I will consider how imagining ourselves in similar situations as characters creates a form of guided reading or viewing that 
repeatedly asks viewers to pay attention to what Jason Mittell has called in his online essay "core narrative." That is, viewers are directed, as Mittell metaphorically argues, to "drill down" inside the canon of a story world instead of "spread out" their interests or activities. This practice suggests a shift in how fan activity is monitored and perceived by those in power because rather than fans creating the raw material through which they will make themselves socially connect with others, the material is reinforcing what the studio wants viewers to attend to and learn in depth.

I will focus then, in the third chapter, on the directive that tells viewers to "join the conversation," which is written at the top of the screen on many discussion forums attached to the story sync application. By adding this request for writing and conversing, the applications are engaging in the backchanneling practice typical to microblogging sites like Twitter. I will examine how these apps guide viewers to participate in a kind of choreographed interchange that is both creative but also, as I will argue, heavily guided and influenced by producers. Within this chapter, I will contextualize the "join the conversation" directive, which I take to be a literal command, within the larger figurative use of the word "conversation" in the rhetoric of theorists like Kenneth Burke, who see conversation as a metaphor for the drama that occurs around the exchange of knowledge. In essence, I hope to answer the question: what cultural work does "joining the conversation" in these apps actually do for viewers? What relationship, if any, does this idea of "conversation" on the apps have with more formal uses of the term in academic circles? In what ways do small messages, made up of 140 characters, create powerful dialogue that may compete with that found in lengthy pieces of writing? And how might 
consensus and normative constructions of characters be hindering us from identifying with those who are not white, male, or middle class?

In Chapter Four, I analyze the role play activities of users who create blogs dedicated to the portrayal of their favorite fictional characters from television narratives. Using such technologies in social spaces allows people to work together to interpret narrative and make it live beyond the screen. As we engage in this social interchange of knowledge about narratives we enjoy, Anne Francis Wysocki says we explore "identity formation, exercise of power, and the negotiation of new social codes" (51). Here, clearly, role-playing activity takes on its most literal manifestations. I show how such activities become disembodied in the process of circulating throughout online spaces and then return to the author to reconstitute her or him as a new being whose role play practices alter the way the person conceptualizes the world. Consequently, we enter what James Porter calls a "digital economy" where "capital resides . . .in your ability to deliver and circulate texts in ways that make them accessible and useful to others and in your ability to collaborate with others, to share files, to co-create meaning in social spaces" (188).

The viewer/user of these social networks and apps has opportunity to reflect on how interacting via a second screen benefits her/himself, the producers, and the other fans with whom s/he comes in contact. Sometimes the answer points most often to how the producers benefit. It is their story world that benefits most from viewer appreciation and support. Yet beyond this truism--that money does play a large role in the production and dissemination of televisual narrative, and much depends on its growing amount — are significant practices that ask us to see from multiple perspectives and participate in 
making fiction live beyond its allotted time on the air or screen. Bronwyn T. Williams and Henry Jenkins both cite the power of what Pierre Levy calls "collective intelligence." On such social networks there are more opportunities to engage in what Williams calls in Shimmering Literacies the "communal making of meaning" (39). As Gee announces in his work on gaming and in his work with the New London Group, the key to transferring knowledge is the ability to think on a "design" level (126), to see how information may not only be learned but how it may be put to use.

But beyond those elements of collective intelligence is another message embedded in the framework of these examples of media: the message that seeing a world from multiple perspectives and imagining alternate realities is a positive, worthwhile pursuit. This dissertation strives to articulate how and why this is so. 


\section{CHAPTER ONE}

\section{HISTORICIZING POINT OF VIEW IN POPULAR CULTURE AND DIGITAL}

\section{MEDIA}

No need to enter into the idea of the virtual double of reality, we are already there-the televisual universe is nothing more than a holographic detail of global reality. All the way up to, and including, the most daily parts of our existence, we are already within a situation of experimental reality. And it is precisely from this that we have the fascination, by immersion, of spontaneous interactivity.

- Jean Baudrillard, Telemorphosis

In this chapter I provide an overview of recent commentary on the ability to see from more than one perspective, articulate my methodological approach, and then conclude with a literature review of how this ability has been incorporated into televisual narrative and digital media--the world that Jean Baudrillard describes in his quotation above. However, before reviewing the instances of "spontaneous interactivity" and "holographic detail" of narrative as they unfold on television, it helps to see how people in our culture today view the act of being able to walk in another person's shoes as important to forming a discerning and ethically sound public.

In May 2013, Joel Stein's cover story and scathing critique of today’s Millennial generation in Time Magazine, titled "The Greatest Generation," included comments about how today's young people are so focused on becoming "microcelebrities," he says, they are not interested in anyone else's experience other than their own. His exact words were controversial for many readers: "Not only do millennials lack the kind of empathy that allows them to feel concerned for others, but they also have trouble even 
intellectually understanding others' points of view." In other words, they are not capable of doing what Michael Jinkins at The Huffington Post describes as the ability to "imagine others' ideas from within" in order to "live generously and with integrity in a pluralistic society." This generation may value collaboration, according to Stein, but they are too narcissistic to imagine themselves in other people's shoes.

What the article makes clear is that a world where others lack the ability to see from other perspectives is not a happy place. Nor is it a productive or rational one. Whether or not we side with Stein or others who attempt to generalize behavior about today's college students, we know that the words empathy and perspective are loaded ones that promote the hard to define but frequently used term critical thinking. Kenneth Burke also states in the oft-quoted passage from The Rhetoric of Motives that identifying with others is "the simplest case of persuasion" (55), or, rather, the main vehicle through which rhetors (or in my case storytellers) communicate with audience members. Irvin Peckham, building on the ideas of Pierre Bourdieu, has also said, critically speaking, that being able to see from multiple points of view is a direct result of being in a higher social class, where traveling and exposure to different cultures helps us become discerning citizens (73). According to cognitive psychologist Jerome Bruner, our minds can, through the experience of narrative visualize "the world not univocally but simultaneously through a set of prisms each of which catches some part of it" (Actual Minds 26). Bruner goes on to say that "as we grow to adulthood (at least in Western culture), we become increasingly adept at seeing the same set of events from multiple perspectives or stances and at entertaining the results as, so to speak, alternative possible worlds" (Actual Minds 109). His perspective is one of optimism, highlighting the many ways the human brain 
continues to surprise us with its capabilities. The work of these scholars points toward a genuine concern that the thinking public has about how well we discern and recognize different points of view and what kind of world might be possible if we all mastered the process.

Michelle Ballif revives the ancient Greek term "metis" in her scholarly work, and focuses on how people might approach rhetoric in the twenty-first century by attending to qualities related to shifting identities. If Baudrillard, Jameson, and Lyotard's theories of postmodern life are true in any sense (and most of these theories are dark, pessimistic indictments of consumer practice and capitalism's failure to bring stability to our world), she suggests that we learn to adapt to this type of simulated, commercial environment by facing it with cunning rather than fear. She says, "At our current stage of simulation [contemporary life], we need simulators, not philosopher kings-we need artisans, like Hephaestus. This forging, at once artifice and artisan, is the work of metis, the work of the Cyborg, the work of Hephaestus" (65). While Ballif does not mention role play or perspective shifting specifically, the skills required to act rhetorically in contemporary society that has been characterized as "simulated" resemble these abilities and intersect with them. Building on a rhetorical foundation dating back many centuries, Ballif stresses our need to learn how to shift and simulate our reality rather than accept it passively.

Instructors in ancient Greece often included exercises in shifting perspective to train their rhetors to become comfortable depicting another person's character so that they might best use that skill in public argument. This skill was and is now still called 
prosopopoiea (or ethopoiea, depending on the specific usage) ${ }^{3}$, although we find references to it today to be synonymous with the term personification in literary studies. Sharon Crowley and Debra Hawhee, in their textbook Ancient Rhetorics for Contemporary Students, explain the skill of character building in this way: In other words, students using this exercise were to construct a characterization of some person, real or fictional, living or dead. In modern schools, this exercise, along with description and narration, is often taught by creative writers - persons who make their living writing poetry and fiction. But the ancients made no sharp distinctions among the composing skills required by rhetors, poets, historians, or novelists.

Historians need to know how to depict character just as novelists and poets do. Furthermore, the establishment of a rhetor's character amounts to an important kind of proof in rhetoric. (238)

Crowley and Hawhee's book makes lucid what initially sounds like a confusing technique. Indeed, prosopopoiea is also used to refer, as Patricia Bizzell and Bruce Herzberg say in The Rhetorical Tradition, to "investing abstractions or inanimate objects with human qualities, emotions, or abilities, especially the power of speech" (513). In this same anthology, the editors provide an excerpt from medieval poetry scholar Geoffrey of

\footnotetext{
${ }^{3}$ According to Kennedy's translation of Hemogenes' exercises, "[e]thopoiea is an imitation of the character of a person supposed to be speaking; for example, what words Andromache might say to Hector. It is called personification (prosopopoiea) when we personify a thing ... where 'The Sea' addresses the Athenians" (84). The progymnasmata often use these terms interchangeably, with the term ethopoiea occurring more frequently in scholarship and in records of training exercises. I use prosopopoiea due to its semantic relationship to person-making and personification, and since my project is centered on role play more than on the matter of ethos (although both are certainly related), I find it fits my purposes better for this work. Derivations of the term ethos (like ethopoiea) in Rhetoric and Composition often end up in discussions about credibility of the speaker, and my project is not as concerned with credibility as it is with creativity and the ability to simulate characters other than the speaker's own.
} 
Vinsauf, who addresses prosopopoiea in this fashion: "Come, Prosopopoiea, fifth helpmeet in extending the journey [of creating poetry]. To a thing which has no power of speech, give the power lawfully to speak, and let license endow it with tongue" (513).

He addresses the concept of prosopopoiea as a vital force that makes poetry transcend the ordinary events of human life in order to give voice to things usually perceived as voiceless.

In George A. Kennedy's translation of the progymnasmata, a series of composition exercises designed for students in ancient Greece, prosopopoiea prompts rhetors in training to consider "What words would a man say when leaving on a journey? Or a general to his soldiers in time of danger?" In some cases the character personified is a historical figure already known to the student, so the student would also be charged with imagining "what words would Cyrus say when marching against the Massagetae? Or what would Datis say when he met the king after the battle of Marathon?" The rhetor would have to imagine and accurately portray “the speaker's age, the occasion, the place, [and] the social status of the speaker" (Kennedy 47). This work resembles the same task set before those using an app that asks users to picture life in King's Landing, only that task is, in the case of these applications, designed for us. However, some syncing applications query the user to determine if s/he has the ability to imagine her/himself as the leader of a gang of survivors during an apocalypse, as is the case in television's The Walking Dead. More on this in Chapter Two.

The new media of today creates another opportunity, one used previously in poetry and in oratory in ancient times, to link role play with persuasion. However, most people, when imagining point of view or person making in new media or elsewhere, do 
not think of the process as creative and purposeful, as Geoffrey of Vinsauf does. They may think of the idea of role play as an undisciplined display of mockery (in the case of imitation) or trauma (depicting the pain of others).

\section{Empathy vs. Perspective Shifting}

Indeed, it would be difficult to examine the idea of multiple points of view without also discussing the term empathy, which invokes ideas about the ability to imagine what another person experiences, especially in situations of danger or trauma. Two Rhetoric and Composition dissertations by Erik Leake and Janet Lucas in 2011 include interrogation of the definitions, limitations, and advantages of being able to empathize with others as a rhetorical act in and outside the writing classroom. Although my work is not a pedagogical project, I am indebted to their review of current literature on the topic, which includes but is not limited to Keen's theory of narrative empathy; scholarship on Rogerian argument by Lunsford, Corder, and Lassner; rhetorical listening with Heilker, King, and Ratcliffe; and rhetorics of proximity by Lynch. These theories on empathy and even on the problematic nature of reconceiving communication and argument as "emergence toward the other" (Corder 26) cannot help but be included as part of the theoretical grounding for a project on the ability to see from multiple perspectives.

While my project differs in scope and focus from Lucas's and Leake's works, we share the initial exigency for our projects in common. For example, it is not surprising to note that when we try to role play or empathize with others, with or without the aid of technology, something can and often will go wrong. To illustrate this idea, I show how a woman's attempt at empathy in 2012, shortly after the violent shootings at Sandy Hook 
Elementary School in Newtown, Connecticut, backfired and inadvertently illustrated the pitfalls of thinking we all possess the skill to role play, or effectively imagine ourselves in other people's shoes, as the saying goes. In writing about her own son's mental illness, she made what many would consider mistakes in shifting from her own subjective view of reality to the view of a larger and more judgmental public audience. Her attempt to draw an analogy—not too unlike "As in King's Landing, So in Louisville" (although grounded in reality since this shooting was no fiction)—created such controversy that she became infamous over social media and national news outlets.

A blogger and mother from Idaho, Liza Long wrote an essay after Adam Lanza killed twenty-six children and adults in Newtown, giving candid examples of her thirteen-year-old son's antisocial and violent tendencies toward herself and others. In her plea for more open discussion of how we might best address mental illness in children and prevent future tragedies like the one in Connecticut, she wrote the following statement: "I am sharing this story because I am Adam Lanza's mother. I am Dylan Klebold's and Eric Harris' mothers. I am James Holmes' mother. I am Jared Loughner's mother. I am Seung-Hui Cho's mother. And these boys - and their mothers-need help." Once Long published this essay online, it was picked up by publications like the San Francisco Chronicle, from which I quote the lines above. People became incensed over the horrific comparisons between an aggressive child and the list of documented teen mass murderers and spree shooters, stating, not too surprisingly, that while Long had used a pseudonym to discuss her son, she had not used one to protect herself, nor had she prevented readers from linking to her personal blog: "Anarchist Soccer Mom." As such, 
people across the country would know her son for the future killer he would become, and it would be unlikely for him to ever shake the essay's impact on his character. ${ }^{4}$

Alexandra Petri of The Washington Post wrote a rebuttal to the angry mothers, asking them to remember that the "I Am Adam Lanza's Mom" essay was written to open discussion about mental illness, not to start a "mommy war." Petri stressed how easy it was for Long's detractors to lose sight of the main argument in their vehement outcry over children's privacy on the Internet. While I side with most of these angry mothers and feel that Long's son has a right to privacy, I do acknowledge the need for national conversation on mental health and children. More importantly, I question the rhetorical moves made by Liza Long in her attempt to bring us to that national conversation. She uses empathy in shocking ways, asking us to imagine what it must be like for mothers of these shooters to seek answers and never find any. While her claim of being Adam's mother got attention, some of that attention ultimately hurt her argument, as readers visited her blog and began to mock the strange tales she shared about her family and her lack of patience with them. Her ethos was damaged when she failed to make her desire for empathy translate into a logical argument for better resources for mental health care.

Some might dismiss this piece as a common occurrence in online discussion, one where people merely vent their frustrations about family or health care or children. Yet the problem of making the "I" connect to the "other" in an effective manner still lurks

\footnotetext{
${ }^{4}$ In sum, Long used a very public medium through which to explore her feelings of empathy: the Internet. While I mentioned earlier that I wanted people to find a "safe" space to explore the process of seeing from multiple perspectives, I did not mean that new media in all its forms is "safe." The apps that will be the focus of my study are not used primarily as ways to communicate publicly; although data is often gathered and polled from users, these people choose to remain anonymous. Most importantly, however, the comments that do "go live" are about fictional people, not real ones. There is little space provided for confessions of mental illness about family members.
} 
beneath the various arguments that sprung up around the essay. The movement from "I" to "Adam Lanza's mom" seems fraught with miscommunication and misunderstanding between audience and writer.

I return to the idea we may infer from Stein, Jinkins, Burke, and Bruner: that being able to see from multiple perspectives is a cognitive skill worthy of our cultural attention at this time in history. It is not to say that such a skill was not valuable in other times, for it would certainly be easy to lament the absence of empathy in historical events as tragic as the Holocaust. But at a time when seeing from multiple perspectives is a skill often mismanaged dangerously in public, especially in online platforms, as is the case with Liza Long, we might seek new models of rhetoric through which to explore and thicken our understanding of the processes of how point of view is shaped or simulated. I believe these apps, however commercial and banal they initially appear to the critical eye, may help us productively interrogate these processes in ways a purely theoretical approach may not be able to accomplish.

\section{Methodology}

Trafficking in matters of point of view and empathy includes a confusing research road through fields of narrative theory, literary criticism, anthropology, rhetoric, communication studies, and even national politics. While drawing on concepts from anthropology and other fields is somewhat unavoidable, I still find new media to be the best field in which to anchor my argument as a whole. I believe that things like apps on a tablet have the power to "fictionalize the audience's own space" (Wardrip-Fruin and Harrigan 3) and provide a valuable testing area for our always evolving powers of observation. Before I begin in earnest to describe how these apps engage in such work, 
however, it is helpful to consider the setting, or to review the scholarly and cultural observations on today's television narratives and their accompanying transmedia.

Like new media theorists before me who have referenced rhetorical frameworks like the five ancient canons and/or Kenneth Burke's pentad in their analysis of digital communication tools (see Brooke; Lunsford; DelaGrange; Sosnoski and McAlister), I invoke terms from rhetoric, such as Burke's use of “identification” from The Rhetoric of Motives to help make the argument that the new media artifacts I am studying are persuading and communicating in ways that are surprisingly but also remarkably similar to older forms of persuasion like prosopopoiea. I see rhetoric and new media as partners in making narrative "living documents" that may encourage us in innovative ways to see from different perspectives. Products like the apps discussed here directly engage in some of the most common rhetorical questions, which Wayne Booth lucidly presents in his primer on rhetoric as: "When should I change my mind? How can I really get you to change yours?" (Rhetoric of Rhetoric 59). ${ }^{5}$ As we identify with characters on screen, we shift our understanding from a personal view of the world to a fictional one, but the shifting itself helps us "to develop ethos, to recognize the importance of audience, to be able to see from multiple perspectives, to accept and celebrate difference in an increasingly global society, to become active and productive citizens" (Matthew S. S. Johnson 69). Certainly producers limit this activity in specific ways by creating a closed code of meaning that is proprietary in design, and I will explain in more detail in Chapter

\footnotetext{
${ }^{5}$ In the field of Rhetoric and Composition, the notion of seeing from multiple points of view often becomes part of a conversation on argumentation. In argument, most of us now recognize (thanks to decades of Carl Rogers' influence) that a helpful way to engage an opponent in discourse is to imagine, listen to, and/ or predict what the person would be thinking in response to our statements. To get someone to change a mind, we must imagine how that mind operates.
} 
Two what impact this knowledge has on the study of these apps. For now, I will simply say that the work being done in these social exchanges between viewer and producer still invites examination of how shifting perspectives is becoming more important in narrating experiences that are both real and virtual.

My approach to understanding the processes involved in manipulating point of view is to provide thick descriptions ${ }^{6}$ of new media artifacts, or case studies of specific narratives and applications accompanying them that Ian Bogost would refer to as “discursive analysis" (515). By thick descriptions, I mean, as Clifford Geertz has said, it is important to know everything about a place or a group of people and how it or they make meaning. To understand artifacts in a culture we must immerse ourselves in their use and any existing records of their reception. In discursive analysis we focus primarily on how writing and communication in general contextualize the artifacts we find. Close observation and analysis remain benchmarks of intellectual enterprise throughout many fields, and Rhetoric and Composition is no exception. Rather, this field features a magnified study of writing and communicating as "living," or changing processes, all subject to the perspective of the rhetor and audience involved. While it might be easy to dismiss, at least initially, this project on transmedia applications as just another example of consumer manipulation (we want viewers to use our app to become even more hooked on our program and be faithful to a particular brand of narrative), I wish to dig deeper

\footnotetext{
${ }^{6}$ Thick description, made famous by Clifford Geertz, actually originated in an essay that deals primarily in the skill of perspective shifting: "What is 'Le Penseur' [the thinker] Doing?" Author Gilbert Ryle differentiates between thin and thick description by using the example of a wink. We might observe that someone contracted an eyelid, but in some cases that contraction of the lid was motivated or contextualized by the circumstances surrounding the action. Saying that somewhat closed the lid but not offering any further remark would be an instance of "thin" description. This 1968 essay is currently available online through the University of Saskatchewan.
} 
(again, borrowing from ideas of Geertz and anthropology) and see how such apps are changing the way stories are told.

To provide one example of how this method will work, I demonstrate how the term identification as defined by Burke gives me a way to explicate the design and rhetoric of a website (once again tied to the television series Game of Thrones). This marketing site, tied to the release of Game of Thrones's Season 2 DVD release, is called mywatchbegins.com.

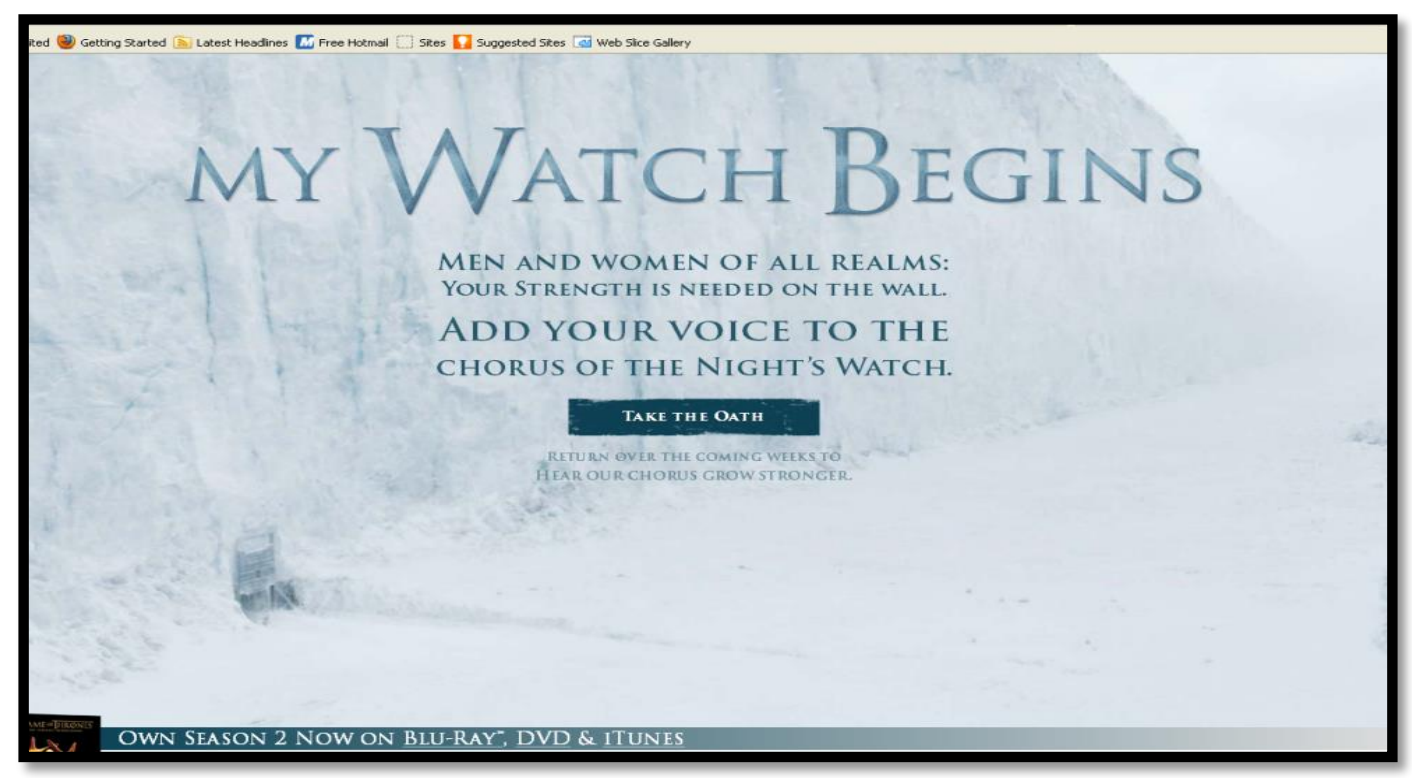

Fig. 2: "My Watch Begins" Campaign in Support of DVD Release of Game of Thrones

On the website featured above in this screen shot a viewer can upload a voice recording of her/himself reciting the oath of the men of a group called the Night's Watch: a tribe of men who are charged with guarding the Seven Kingdoms from dangers in the North. Like their title suggests, their main goal is to "keep watch" over the land. Jon Snow, a character from the show, recites the words to the oath and flashes them on the screen so that participants will know the exact words. Once the viewer recites them with Snow, the recording then "syncs" with other audience members who have recorded the 
oath before them. Then, on the website, visitors are asked to "return in the coming weeks to hear our chorus grow stronger."

The notion of a stronger chorus, a team of supporters, or a legion of followers keeping the narrative alive through their participation shows a definite trend toward helping viewers identify with the building and maintenance of a fictional world. Kenneth Burke says in The Rhetoric of Motives, "You persuade a man only insofar as you can talk his language by speech, gesture, tonality, order, image, attitude, idea, identifying your ways with his" (55). Not only are viewers identifying with Snow, however, but they are "syncing" their contributions to make one master soundtrack of involvement that can be accessed by anyone at any time. Identification works here as a series of processes in which we are "creatively participating" and "collaborating" (Burke 58) in the making of narrative. By recording the oath, we (the truly royal "we") literally speak from Jon Snow's point of view and then adopt that point of view as our own. As an added bonus, the word "watch" is once again invoked as an action that has prosocial and productive meaning for our culture today. More appealing is the fact that viewers do not have to assume the role in earnest; instead, they may simulate, if only momentarily, a fantasy world.

In other words, such a website is linking the processes of identification and communication in a way that makes it easy to see that mywatchbegins.com is grounded in the power of rhetoric. If, quoting Cicero, Burke says that a basic definition of rhetoric is "speech designed to persuade" (49), the oath of the Night's Watch operates on two levels: to persuade users to play the role of guards against evil in the fictional world and join this worthy but imaginary cause, and to persuade users to sync their understanding of 
the narrative with others to demonstrate allegiance to the fictional world. Of course, the website itself does not create true spiritual allies of the Night's Watch. It does the opposite by encouraging media involvement that acts in opposition to the Night's Watch and its cause. The very material world that the Night's Watch eschews as part of its mission is embraced through this activity. Yet the main point I wish to emphasize here (using this site metonymically for my argument as a whole) is the coming together of hundreds of voices, which is the very process of how identification operates. Burke says that identification's counterpart is "division" (23). If so, the work of the Night's Watch website is unification of different subjectivities under the umbrella of one love: if not for Jon Snow or the Watch, a love for Game of Thrones.

While it seems, at first glance, that this process is based on affective reasoning or emotional responses to a show's characters, the strategic establishment of a dialectic, something Burke is always careful to note in criticism, is implicit in this activity of “joining the Night's Watch." To join the watch, users must decide to "take the black," thereby leaving their old life behind and wearing black cloaks that will mark them as members of this ascetic troupe of characters. But to stand with the Night's Watch is to stand against whatever is threatening the world of the Seven Kingdoms. Furthermore, the oath represents a life that is grounded in service, not one grounded in worldly pleasures. Those who are members must live single lives, separate from their families and all loved ones, refuse any association with royalty, and give their entire lives to the cause. In other words, the website encourages users to, put simply, live like monks in a fictional world. Whether users agree with such a lifestyle or not, they may find themselves persuaded by the imagery involved in taking the vow, imagery that invokes contrasts between good and 
evil, light and dark: "I am the fire that burns against the cold, the light that brings the dawn." To be a member is to "be the shield that guards the realms of men."

Such a dialectic may, according to Burke, "invite[ ] participation regardless of the subject matter." He goes on to say that when such a dialectic presents itself in rhetoric, you "will find yourself swinging along with the succession of antitheses, even though you may not agree with the proposition that is being presented in this form" (58). The form, as Burke says, is what persuades us: in this case it is the ceremonial process of syncing ourselves with other allies of a certain narrative world. Its repetitive nature and simplicity drive viewers and fans toward a consensus, too, which I will interrogate in Chapter Three.

This website's series of steps, or distinct procedure of involvement—listen to the oath, then recite it and record it in your own voice, then sync it with former users-makes not only the concept of "identification" in rhetoric come to life in Burkean terms but also the idea of a certain type of rhetoric not defined by Burke but rather more recently defined by Ian Bogost in Persuasive Games: "procedural rhetoric." Bogost uses "procedural" separately from its typical use associated with coding or programming in computer science; instead, procedural rhetoric "is the practice of using processes persuasively, just as verbal rhetoric is the practice of using oratory persuasively and visual rhetoric is the practice of using images persuasively. It uses both "expression" and "persuasion" to create spaces where the depiction of "the way things work" is central to building an argument or influencing user behavior (58). Not all procedural rhetoric is graphically or programmatically obtuse or complicated, and it does not require participatory activity to be worthy of its name. The "Ice and Fire" app, because it takes 
the temperature and time of day into account and translates it into images and texts that reflect the world of Game of Thrones, could be considered one example. Its persuasive power comes from its ability to gather certain information and process it into a fantastical perspective, thereby altering the user's original view of reality, if only momentarily and conservatively.

Also, emphasis on processes in procedural rhetoric helps establish a distinction between what it means to empathize and what it means to see from multiple perspectives. While the two are similar in some ways, there are also key differences. As Dolf Zillmann has said, "Perspective taking is, of course, deliberate empathy, accomplished by focused cognitive efforts" (43). Bogost uses the term deliberation frequently to describe what happens to players in Persuasive Games: they are called on to weigh outcomes, consider disruptions in the status quo, and adjust their vision of the world according to the data they input during the game. Something about dissecting the machinations of programs where sequential steps are the norm suggests that we are, more often than not, engaging in rational activity of a sort. However, as I will discuss in Chapter Four, deliberation does not discount emotion or pathos in its occurrence, and such a narrow way of defining procedure would not take into account the changes in players' thinking as they alter their perspectives in a given scenario. But while empathy and point of view are similar in many regards, my use of point of view in this project deals primarily with rational, cognitive processes that, while often helping us create a deep, emotional bond with a narrative, increase our storehouse of communication tools and ability to recognize the persuasive power of simulating other perspectives. At times pathos and sentiment are bracketed off to allow more focus on how these processes potentially enable us to 
become better problem solvers, observers of our surroundings, and, even manipulators of our own realities. Also, I argue that the ability to see from multiple points of view is proactive, while the feeling of empathy is often triggered by actions already completed. For example, I might empathize with a person who has endured a great loss, but to do so places me at the back end of the experience, at the moment of damage control. Being able to imagine someone else's point of view, however difficult that process is, means that I am, hopefully a part of something from the start. ${ }^{7}$

Because my project investigates the processes of character identification and the process of how we view reality, I have chosen the mundane but appropriate term point of view to represent what I call the embodiment of one person's perspective in any given situation, and I use the word perspective as a frequent synonym. To be clear, terms like slant, focalization, perspective, and so forth have been bandied about by both narratologists and narrative theorists, and some studies of these concepts have been helpful (while also obsessively focused on matters of defining a phenomenon that often eludes easy definition). H. Porter Abbott says, for example, that the term focalization is especially helpful because it, unlike point of view, "refers specifically to the lens through which we see characters and events" (73). Yet this study of television apps does not work with the idea of the "lens" as much as it deals with the rhetoric associated with different persons and their experiences. For good or ill, point of view, as Abbott illustrates, is often accompanied by the term "person"- first person or third person point of view, respectively (70-72) —and, therefore, it better characterizes the idea of role play and

\footnotetext{
${ }^{7}$ It is dangerous to assume we can ever fully know someone else's perspective, especially since the process brings to mind the egotistic view of mastering other people's thought processes rather than being open to their experience (see Ratliffe on "rhetorical listening" and the notion of "standing under" instead of "understanding").
} 
character identification, since roles in my project will be most often in human form. I also use the point of view and person terminology to remind us that today's television narratives and their audiences engage in what Mo Ryan, Erik Adams, and Myles McNutt in 2013 describe as a "relationship" ("State of the Industry"). While media is not embodied physically, it is often anthropomorphized and invoked in terms of human connections. Point of view or character identification are, therefore, regularly employed to help readers or viewers get the most out of a narrative world.

\section{Early Examples of Complex Narrative and Point of View: $M * A * S * H$ and St.}

\section{Elsewhere}

While point of view is only one ingredient of what makes narrative more complex, it works in tandem with difficult subject matter and serial narration to create a new age of television some have labeled a "golden" age. ${ }^{8}$ When considering the history of television programming, many people have opinions about when television became "golden" (most refer to this era as the "third golden age of TV") or started getting "complex" in terms of narrative. Steven Johnson, author of Everything Bad is Good for You, explains that television became complex when it started "marry[ing] complex narrative structure with complex subject matter" (68). With Johnson, the word complex is used frequently but with some degree of circular reasoning; that is, the definition of complex often includes the very word complex to illustrate its meaning. Jason Mittell, a noted television scholar, made a more common definition of complex television narrative through his research in which he says that complex narrative "employs a range of serial

\footnotetext{
${ }^{8}$ For more information and a more in-depth discussion of why this time is labeled a "golden age," see the 2011 series America in Primetime, which features showrunners like Alan Ball, Shonda Rhimes, David Shore, Vince Gilligan, David Simon, and others. In particular, Gilligan and Shore contend that production of television rivals and even surpasses the creative efforts of Hollywood movie making in today's culture.
} 
techniques, with the underlying assumption that a series is a cumulative narrative that builds over time, rather than resetting back to a steady-state equilibrium at the end of every episode." Such narrative "is not as uniform and convention-driven as episodic or serials norms - in fact, its most defining characteristic might be its unconventionality."

Critics and scholars highlight different eras as being responsible for making television "complex" in form and content. Mittell dates the beginning of experimentation in the 1970s, while Steven Johnson hails Hill Street Blues, which aired first in 1981, as the prime ancestor of complexity (65). In his work uniting the fields of Rhetoric and Composition and television studies, Bronwyn T. Williams mentions shows from the 1990s like $E R, N Y P D$ Blue, and The X-Files as examples of shows that "require attentive and sophisticated rhetorical work to interpret" (Tuned In 58). David Lavery uses different terms than complex narrative to describe the cultural scene of television in the past two decades; his article on "Lost and Long-Term Television Narrative" includes words like flexi-narrative, neo-baroque, and hybrid and Dickensian narrative to characterize today's shows (313-14). His focus on the show Lost illustrates his belief in complex television being most common in the 2000s.

It is important to establish when television writers first became enamored with the prospects of highlighting subjectivity and making narrative complex. I will suggest that this increasing attention to subjectivity foregrounded the need for dual-screen applications that make this process accessible to viewers in future years. I do not suggest that apps were developed because of my specific examples discussed here. Instead, I wish to better explain some of the television narratives that startled the public with their use of point of view. If we as viewers are meant to be careful observers of the texts 
surrounding us, then these television narratives challenged viewers' ability to do so. This discussion accomplishes two goals: it helps me set the "scene" that will lead to use of TV applications, but is also provides an additional framing of the literature surrounding some famous pop culture narratives and an overview of how subjectivity has been famously depicted across the years.

In 2012, blogger Brendan Keogh published a piece called "A Certain Point of View" within which he discussed the show $M^{*} A * S^{*} H$ and one of its more memorable episodes. In Season Seven, the episode "Point of View" highlighted how narrative changes dramatically when the camera shifts to show a wounded soldier's perspective on the action. Keogh describes his reaction as a viewer:

It feels so weird, so constrained to not be able to follow them [the cast members] as I would in any other episode. Regardless of how familiar everyone and everything in the 4077 [army hospital] is to me as the viewer, being bound to and trapped inside outsider's body makes me feel like an outsider. Even the usually familiar face of Captain Pierce is terrifying and alien as he stands over my body while I lie splayed on an operating table.

While Keogh begins by simply watching, he ends his experience by envisioning himself on the operating table in place of the soldier. He also feels keenly the effects of being an outsider and the feeling of seeing a familiar world turn alien. By taking this different perspective, Keogh says he felt like he "was playing a videogame" as he "experience[ed] another body that is not [his] own." He takes this analogy farther, saying that he wished video games had pushed him toward the experience of being wounded because he had 
always wanted, when playing such games, "to feel like a body in a world — even a damaged and unusable one." Television for Keogh introduced him to an experience that gaming had not shown him.

While Keogh describes an immersive and exciting process of shifting point of view, I fast forward now to a more negative moment in television history in 1988. Just as in Winterfell on my "Ice and Fire" app, this example starts with a confusing close up on the setting of falling snow. Only this time, the snow is inside a globe, where the hospital building St. Eligius is being blanketed with flakes as a child shakes a glass globe's contents, and the credits role on the sixth and final season of one of television's most famous series. Not only did the medical drama St. Elsewhere (1982-1988) push the boundaries of storytelling by adding multiple storylines and treating serious subjects, it also took a huge risk in ending by suggesting that the entire narrative happened from the point of view of a working class autistic child. In other words, the ending made a strong case for the possibility that the adventures both in and outside the hospital featured in the show were actually the imaginings of one person, and we as the audience were privy to each fantasy as they aired weekly for six years.

What had once been mainly true in works of fiction or large screen art cinema was now true for a small screen: characters had "inner worlds of their own, inner worlds that can, in turn, leech out into the shifting emotional and intellectual atmosphere that pervades and even extends beyond the time-space of narrative" (Abbott 164). Jerome Bruner would concur, for he says that "the greatest feat in the history of narrative art was the leap from the folktale to the psychological novel that places the engine of action in the characters rather than the plot" (37). According to the wiki entry on St. Elsewhere 
(public broadcasts of the show are not available due to copyright infringement) ${ }^{9}$, one of the final quotations from St. Elsewhere echoes this very element of storytelling when Tommy's father says, "I don't understand this autism. I talk to my boy, but . . . I'm not even sure if he ever hears me. . . Tommy's locked inside his own world. Staring at that toy all day long. What does he think about?" 10

To consider just how far the mystery of autism goes in terms of St. Elsewhere, one need only perform an internet search for "Tommy Westphall." The boy with the snow globe, according to media conspiracy theories, is responsible, through his point of view, for creating a "multiverse" of television fantasies, since St. Elsewhere did feature some crossovers with other programs like Homicide: Life on the Street, and Homicide featured crossovers with others. What is important to see here is that when experimenting with complex narrative and point of view, radical subjectivity creates the kind of doubt that keeps audiences from placing their trust in those who tell them stories onscreen. Ned Beauman blogged on The Guardian in 2007:

Back in 1988, of course, no one knew that television programs (apart from Star Trek) would ever be subject to such thorough and merciless scrutiny. But in the age of the internet, when television writers play a trick, they have to think about the consequences--because if they don't, somebody

\footnotetext{
${ }^{9}$ At the time of this project's completion, an excerpt of the final scene was finally available on YouTube. The clip was/is called "Tommy Westphall Snow Globe Ending."

${ }^{10}$ Conveniently for this project, rhetoricians Paul Heilker and Jason King connect autism to the ability to practice rhetorical listening, and their words also indicate where Tommy and the audience may have parted ways: "Since many of the earliest diagnosed cases of autism involved individuals who did not speak, ... people on the spectrum have historically been spoken for. . . . Their silence was a blank screen onto which we projected numerous fears, values, and misconceptions" (119). The "rhetorical effects" that Heilker and King describe seem to point toward the complete breakdown of communication between the non-autistic and the autistic, and the depiction of a young boy as the figure head for St. Elsewhere's origin further complicates how the narrative and the audience shockingly parted ways.
} 
else certainly will. If that cramps their creativity, then so be it. Tommy

Westphall is like HP Lovecraft's Cthulhu - you look into his eyes, and he destroys your faith in reality. Television can't take another monster like him.

Although the word monster is certainly hyperbolic, it illustrates the strong feelings associated with delving into point of view to confirm or deny the existence of a narrative world in which others became invested. What is interesting is how Keogh reacts in frightened but, overall, supportive terms to the experience of seeing from the soldier's point of view, while viewers of St. Elsewhere had been more critical of what they saw as a "cheat" in the finale of the hospital drama. It seems that point of view experimentation works best as a temporary exercise, one that lasts an episode, as in Keogh's example, but does not involve readjusting the reality of an entire narrative.

Of course, other shows had experimented with point of view. The drama thirtysomething sometimes engaged in point of view manipulation in its more "antirealist" moments (Feuer 87), and in 1986 the eighth season of Dallas was apparently all the dream of one character. ${ }^{11}$ Yet these examples, perhaps, had not been as pronounced as the "snow globe" finale was in throwing the entire reality of a series into

\footnotetext{
${ }^{11}$ David Lavery explains that Dallas featured this narrative twist of making the season a product of character Pam Ewing's world because it enabled the producers to rehire Patrick Duffy, an actor whose role had been killed off the previous year (316). As such, it isn't really a product of point of view experimentation as it is a retroactive continuity ploy to reverse previous events. As far as thirtysomething is concerned, Feuer goes on to note that multiple perspectives are featured in the first season when a fight is replayed from the two different points of view of Nancy and Elliot (88). The notion of fighting being represented from two sides has obvious persuasive connotations in that the audience feels they have received all the information and may judiciously pick which side they favor in the narrative. Around the mid-1980s, other fantasy and science fiction shows were experimenting as well, although their artistic choices were not as surprising due to the nature of the genre. For example, Steven Spielberg's Amazing Stories featured one episode entirely from the point of view of the family dog.
} 
question. Various online entertainment sites that consistently rank St. Elsewhere's finale, called "The Last One," as one of the Top 10 or Top 5 worst television finales in history. To be sure, St. Elsewhere aired its controversial series finale during an age when researchers were commenting on the lack of "suspense," or unpredictability in episodic television series (Kozloff 73). Most television shows were able to balance stand-alone episodes with some form of overall seasonal arc of narration. A person could start watching a show during the second or third year of a show's airing and still become acclimated to the fictional world. While Kozloff characterizes television of the late 1980s and early 1990s as featuring some "multiple storylines intertwined in complex patterns" it was still typically bound by "formulaic" narrative and "reliable" narrators (93), storytellers we could trust. Most drama and comedy alike, attempted to restore the narrative equilibrium established at the show's opening during its conclusion. ${ }^{12}$ Closure usually occurred in predictable final moments of the airing of any episode.

Certainly some shows, like $M * A * S * H$, dealt with differing points of view and still managed to retain the trust of the viewer, or at least spark fascination in place of, or at least in addition to, anger. Watching David Lynch's Twin Peaks in 1990 and 1991 often left viewers wondering if what they witnessed on screen was happening in the "real world” or happening in Special Agent Dale Cooper's mind. A decade later in Buffy the

\footnotetext{
${ }^{12}$ Scholars of the late 1980s did laud St. Elsewhere's entire run as a product of complex narrative. One episode in particular that David Barker studies- “"Time Heals"--traces the hospital's history from the 1930s to the 80s in a series of flashbacks that feature overlapping character chronologies, which demonstrated that the drama serial of that time may indeed "be negotiated as the intersection of multiple 'histories' resonating together with great complexity" and that close analysis of TV might resemble "archaeological excavation" of sorts $(34,44)$. Alan Sepinwall describes the show as one that proved that "your characters, your stories, and your world didn't have to be confined to a familiar box" (13, my emphasis). This narrative, although physically confined to the TV set at this time in the 1980s, was seeking extensions into our lives that would alter the way we participated in making meaning for ourselves.
} 
Vampire Slayer, the sixth season episode "Normal Again" featured flashbacks to a mental institution where the heroine has imagined herself with special powers and is living in an alternate universe. At the episode's end, the camera remains at the hospital where Buffy's family is saying "We've lost her," thereby allowing viewers to imagine that perhaps this universe, too, may be a product of someone's fantastical point of view. ${ }^{13}$ In 1998 the comedic X-Files episode "Bad Blood" from Season Five featured half of the narrative told from the female FBI agent's perspective and the second half from the male's perspective, allowing the audience to synthesize the information at the end and judge which narrative seemed the most plausible. In $E R$, which first aired in 1994, the eighth season opener was "Four Corners," which asked the audience to not only juggle two perspectives of a man and woman but four perspectives in all: the perspective of a young, rich doctor; a middle-aged lesbian, a doctor with brain cancer, and a black surgeon who had just completed his residency.

While most of the above examples are from drama, perspective shifting did occur in comedy, too. JoEllen Fisherkeller observes that the 1990s situational comedy Herman's Head, while hardly featuring complex narrative, also experimented with point of view in a way that made viewers rethink their own problem solving techniques. Fisherkeller describes a student she interviewed, Marina, whose love for the narrative of Herman's Head helped her see the value of her own conflicting thoughts and how to manage them intelligently. As Fisherkeller relates, the show suspends narrative time

\footnotetext{
${ }^{13}$ Another notable episode from Buffy that experiments with point of view is season four's "Superstar," during which an insecure and unstable young man casts a spell on the cast and supposedly on us, too, the audience. This spell causes us all to see the television show as being about a new hero named Jonathan, rather than about Buffy. Even the opening credits are altered to show Jonathan as the series' main hero. I see this shift as being quite similar to what happened with the soldier in $M^{*} A^{*} S^{*} H$ : a world viewers thought they knew, as perspective shifted, became an alien one.
} 
when the main character Herman faces a significant problem or crisis because four imaginary characters, representing different parts of his personality, appear on screen to debate the outcomes with him (43). Rather than present their narrative as a tidy linear package, the writers of this program gave viewers a chance to see "the chaos and turmoil of the voices of human consciousness" (Fisherkeller 43). Such glimpses of interiority postpone endings in favor of explorations of character point of view and the nuances associated with problem solving.

Alan Sepinwall says that shows of the 1980s and 90s were trailblazers of later complex narratives (11). In particular, he says that St. Elsewhere's ending, in which Tommy finally sets the snow globe on top of a television set (13), could have been a critique on what Baudrillard called a "screenified" culture: in other words, "some fans were dazzled by it; others felt it was the show judging them harshly for having watched it all these years." Writer Tom Fontana moved forward with point of view experimentation, having a full career after St. Elsewhere. He brought experimental point of view storytelling to HBO's $O z$ when he used an African-American con man in a wheelchair, named Augustus Hill, as his narrator in that show. Augustus didn't just narrate the events as they happened within the prison; he also "address[ed] the audience directly multiple times in each episode, musing on problems universal to the prison experience, or to life outside the walls of Oz" (23). If a white autistic child was hard to relate to, then Augustus was also a risk, since most audience members, if white middle class in status and racial background, would have trouble seeing beyond their own perspectives into a world of crime. 


\section{Blending First Person Embodiment with a Shocking Finale: The Case of Tony}

\section{Soprano}

One example combines both the characteristics of the $M^{*} A * S * H$ episode, with embodiment figured into the viewer's experience, and the St. Elsewhere finale, during which the ending of a narrative leaves many questions. Almost exactly twenty years after St. Elsewhere ended, HBO's The Sopranos' final scene of the series in 2007, luckily still available on the web, features the protagonist Tony Soprano sitting with his family in a diner but then abruptly cuts off before we know what happens to him. B. Malen, author of a blog in which the finale is parsed in such minute detail that every moment is discussed in terms of camera placement, uses the words "point of view" to describe what we see and how David Chase, creator of The Sopranos, a show that ran for six seasons, would want us to experience the suddenness and horror of what he believes to be Tony's death scene. Tony eats at the diner while a few unknown characters suspiciously eye him from a distance, giving the viewer the sense that he is being watched by dangerous foes. Then, as each person from his family arrives, Tony looks up from the jukebox, which is currently playing Journey’s “Don’t Stop Believing” after he places a coin in the machine, and makes eye contact with each person entering the restaurant. Yet the final moment when he looks at his daughter Meadow, we see his gaze greet her, and then abruptly the camera cuts to black. Malen explains the ending in these words:

Remember, Tony Soprano is the main character the viewer has followed all of these years. We have been inside his head in multiple dream sequences and have intimate knowledge of his personality and fears through his visits to Dr. Melfi. It makes sense to put the viewer in Tony's 
$P O V$ at the time of his death. Once Tony is dead, there is no show. If Tony was to die it had to be the last moment of the series. The show ends where Tony's consciousness ends.

So the last shot of the series is from Tony's POV. Tony does not hear the bullet as it was shot from close range and traveled faster than the speed of sound (i.e. the bullet hit his brain before his brain could process the sound). Tony never heard it coming. No chance to reflect or react. The bullet shattered his brain and there was instantaneous death. Just a void of blackness and nothingness. (emphasis mine except for "had") Malen doesn't stop with a casual discussion of POV angles. He provides the information necessary to decode the finale and convince us Tony died. He explains that each time Tony hears the front door diner bell, he looks up, and then the camera cuts to see whoever is entering the door to the diner. This sequence-bell ringing, looking up, cutting to the person entering - is repeated in full four times. The fifth time, when Tony's daughter Meadow enters the diner, the sequence consists of the bell ringing, looking up, and blackout when Tony starts to visualize Meadow. If we follow the sequence through to its logical conclusion, we should have had more time to see Meadow, but not if Tony's world ends immediately as he is shot.

Malen's tutorial on his website walks the viewer through the camera's shots, one by one. He links the images together with his textual explanations of why one follows the next. Whether or not we agree with Malen, we can concede that his careful attention to shot composition and point of view seems to transcend visual rhetoric's purview and open up the possibility, as I stated earlier, for procedural rhetoric to take hold here. More 
than image, sound, or moving image alone, this interpretation is based on a process of repetition that has to be understood by the audience member in order to work. It seems that although we aren't required to see reality as Tony does or to role play his thoughts, the finale, according to Malen, requires that we at least role play the process of, if not emotionally, physically placing ourselves in his shoes in order to gain literal understanding of the events that conclude the series. This moment offers us new insight into how empathy or identification may be evolving: possibly we no longer have to emotionally connect with the protagonist. Instead, we have to be able to imagine or simulate a temporary body swap of sorts, and realign our perspective with his own. Such a skill requires we understand the process of perspective taking, if not the ethical dimensions it entails when we allow ourselves to identify with others.

Like Tom Fontana before him, David Chase endured the anger of fans only to refuse to answer their questions about the ending. He only said, "It comes from your emotions, from your unconscious, from your subconscious. . . . I try to let my unconscious act out. So why did I do it that way? I thought everyone would feel it. That, even if they couldn't say what it meant, that they would feel it" (qtd. in Sepinwall 54). Here Chase returns to the area of emotional empathy to describe his job as showrunner. He seems to be directly alluding to the process of empathy or identification with his narrative. Our ability to understand the last moments of this narrative was somehow based on how well we could not only see from Tony's perspective but from David Chase's perspective. It seems too early to dismiss the affective, or emotional components of identifying with Tony. 
Of course, Malen's blog is only one of many online sources that claims to have the ending solved, and Sepinwall himself (who has also admitted to reading Malen's notes) has argued the inverse, that Tony lives on, unable to escape his sad and unfulfilling life (58). Yet my interest in Malen is his focus on POV, or point of view, camera angling and how it does convey the suddenness and tragedy of, well, if not death, then the end to our involvement or TV "relationship" with this Soprano family of mobsters. Other theories abound on discussion forums, where some visitors claim that, like in the case of Tommy, the entire show of The Sopranos was happening inside Tony's head. Either way, point of view returns here with a vengeance to trouble any easy answers to complex narrative conclusions.

The conclusion I will make throughout this project is not that point of view experimentation requires good role players, although it is hard to avoid that possibility sometimes, but that role playing as a skill seems to be more and more prevalent among creative teams who shape our stories. Whether or not we excel at it is just what apps like "Ice and Fire" seem to address.

\section{Point of View and Transmedia Applications}

Transmedia creations speak back to the fan whose viewing of the canonical episodes of television just isn't sufficient enough to account for an enriched viewing experience, but it also guides understanding of what narrative experience we should have. In Convergence Culture, Henry Jenkins defines transmedia as "a new aesthetic that has emerged in response to media convergence- one that places new demands on consumers and depends on the active participation of knowledge communities" (21). On his personal website "Aca-Fan," Jenkins further clarifies that transmedia does four things: 
- Offers backstory

- Maps the world

- Offers us other characters' perspectives on the action

- Deepens audience engagement

While investigation into transmedia practice has been done before (besides Jenkins, see also Deuze; Dena; Journet) the third item in his list above has received less attention than one might initially suspect. In this project I will be discussing producer-generated transmedia featuring other character perspectives, the kind designed by marketing advisors of television's complex narratives in order to ensure fan and viewer understanding and entertainment with a given series. Studies of fan transmedia and activity as a literacy to which we should pay attention already exist (see Black; Williams; Journet; Jenkins; Harrigan and Waldrip-Fruin), but not as many scholars have focused on producer-generated media of this kind. For years fans have gathered around their own digital discussion forums and fan-authored tales of their favorite narratives. We have seen fans decorate their social networking pages with quotations, images, and clips of favorite music from TV, movies, and books they enjoy (see Williams's Shimmering Literacies for examples). For this project's purposes, it is important to look at producer-generated content because it is a form of guided reading or viewing, and guided interpretations of the narrative often raise questions about the people we are asked to identify with in the context of the plot. What interests me is how perspective taking or character identification is central to the process here in the apps designed for these narratives. The focus I wish to establish is one where we consider the active role playing of protagonists and antagonists a rather curious requirement for showing loyalty to a fictional world. 
Transmedia existed in limited producer-generated forms during the early 1990s, in the years following the St. Elsewhere finale. The widespread use of the Internet helped make transmedia a more visible tool for narrative. Chris Carter's The X-Files became one of the first shows designed to be explored both on screen and on the Internet. Carter and other producers would actually log on to the official website Inside the $X$ to answer fan questions after each episode aired. Fans also had the opportunity to enjoy a movie adaptation - The X-Files: Fight the Future (1998) — that extended the narrative already in progress on television (Gillan 29-31). Soon the web began to feature narrative extensions on its host sites, as a sort of hybrid of Fight the Future and Inside the X, so that those fans of NBC's Homicide: Life on the Streets (Tom Fontana's domain) were the recipients of a program called Second Watch, during which nine episodes "continued the storyline of the precinct by focusing on the shift that followed the one dramatized on-air," thereby stressing "content creation and viewer interaction so that viewers would feel like they were 'creating a new narrative"' (Gillan 35-36). After the website simulated a press conference for fans, Fontana is quoted as saying, "The people tapping into the Web site were playing the part of the reporters. It really told me a lot about the future of this whole thing. It's not just about watching. It's about participating and getting into the role playing of it. That's a whole different experience than turning on a television set" (qtd. in Gillan 37).

Yet clearly these forms of entertainment were not "syncing" with the live broadcast but enjoyed during breaks between seasons. The first attempt at some form of "syncing" activity was Dawson's Desktop, designed to "maintain the fiction that the storyworld continues between Dawson's Creek episodes" within a single season (Gillan 
39). Cornel Sandvoss would label such an experience "constant audienceship" as we engage in the act of reading in an "intertextual field" (31). On this website, fans imagine that they are actually using Dawson's real computer online and "peruse Dawson's fictionalized personal computer screen, sneak a look at Dawson's multimedia journal and homework files, surf his bookmarked Web sites and listen to his CDs. They can read characters' e-mails and chats and go through their trash bins. They can e-mail and chat in real-time with characters (whose input is supplied by writer Arika Mittman)" (Botwin). Producers want, through such designs, to help fans stay connected to the narrative even when it is not airing live. Had apps or even mobile devices been available at that time, the desktop would have been an ideal application to "sync" with the onscreen narrative.

Yet viewers weren't quite ready for that. Despite these fan activities being available, many viewers, especially die-hard fans of The X-Files, for example, considered the weekly airing of a new episode sacrosanct; that is, they would have never pictured distracting themselves on the web or doing what would later be called "syncing" an app while watching the show. Will Brooker says that for most fans, watching a show like that is a "symbolic pilgrimage" that includes unplugging phones and turning off lights (156). During the "symbolic pilgrimage," the emphasis is on the spiritual connection with the one screen, the television screen, not multi-tasking activities or supplementing narrative with any outside help. Here is one way television had earned its bad reputation for being a "drug" that hypnotizes its audiences into a state of submission (although such attention to the mythos was rarely a passive experience for anyone on the "pilgrimage") (Brooker 157). Fans would deconstruct and discuss their favorite scenes online after the episode ended on various forums, but only then. 
But while no apps existed yet, fans began to amass their own collections of researched material that overlapped with the main corpus of a show. Fans of Twin Peaks, as Henry Jenkins has discussed, analyzed scenes of that show in great detail over early news groups. In addition, fans did not always seek answers in digital ways: they had producer daughter Jennifer Lynch's book The Secret Diary of Laura Palmer, a copy of the Twin Peaks soundtrack, and a collection of David Lynch's favorite films (and those he directed and/or produced) to animate and extend the world of that show (Poachers 110). These forms of transmedia, created or produced by the Lynch family, were considered necessary materials for researching answers to Twin Peaks's famous murder case, the central plot involving the death of a teenager in a small town. Rumors persisted that David Lynch himself discovered this fan research by occasionally visiting the news groups, causing those fans to wonder if they were inadvertently "writing [their] own show" by posting intricate theories about the various mysteries in the narrative (Jenkins 110). The idea that the fan activity would be self-sponsored but also monitored by a showrunner would foreshadow later developments in transmedia of the twenty-first century.

By the twenty-first century, literacy scholars were taking note of how narrative transcended the small screen and pervaded all aspects of viewers' lives. Bronwyn T. Williams's description of the television phenomenon of NBC's drama Heroes (2006-10) typifies what is possible for fans of a TV show in today's world:

The narrative of Heroes is not confined to what is broadcast each week. If I go to the official website, I can find the usual accompanying material such as trailers, interviews with the writers and actors, and character 
biographies. But I can also read a graphic novel about the characters that offers new story lines and information not in the broadcast series, I can watch videos made for the web with new characters, I can play an online game involving the characters that reveals information not seen on television. (121)

This catalogue of opportunities to view, read, role play, and write new ways into a given mythology is always growing. Like scholars before him, Williams is intent on showing how this kind of immersion in narrative is not a practice of "cultural dupes" or "couch potatoes" being hoodwinked into a consumer culture of franchise material (33); instead, viewers are digging more deeply into analysis and debate with other fans than they have in previous eras and are simultaneously quite savvy about the level of their involvement intersecting with commercial interests (see also Newkirk; Jenkins; Johnson; and Bury for classic examples of how fans remix materials given to them by producers).

Debra Journet discusses how ABC's Lost was a product of the convergence of video game narratives and complex narrative: each season opened up a new dimension of the setting that could be explored by both the characters stranded on the mysterious South Pacific island and for the audience watching at home (202-03). Lost made the practice of shifting perspectives a requirement for watching the show, since each week a different character from the ensemble was featured as the protagonist. Viewers also had to shift from past, present, and future moments in each character's past, which further complicated the process of viewing. While Lost did not feature dual-screen technologies in the moment of its airing, it created a show that allowed both characters and audience members to see themselves as players in a game, where they participated in "identifying 
patterns, solving logical puzzles, and mapping mazelike spaces" (203). When viewers finished an episode, they often reviewed and closely analyzed each episode in order to solve the mythology that seemed to expand every year. Yet as Jennifer Gillan explained, "the only way for a casual viewer to catch up [with the increasing mysteries]was via an alternate delivery platform" (137). Gillan is referring not only to transmedia outlets like websites but also to streaming TV sites like Hulu, ABC.com, and iTunes, where episodes could be consumed multiple ways and times.

Although fan wikis, forums, and Lost-centric websites remained numerous and have been studied as admirable examples of close reading and analysis of narrative (see Journet), producer-generated transmedia also made the show a true success. The Lost Experience online game connected viewers to websites of companies like Oceanic, the airline the castaways were flying when they crashed, and the Hanso Foundation, a fictional research company featured in later seasons of the show (Gillan 170). The idea perpetuated on the web was different than the one established with Homicide's Second Watch series. The difference with the clues and information on The Lost Experience was that transmedia attempted to perpetuate the truth of the mythology, "never breaking out of the fiction" (174). The idea was that fans could eventually entertain the thought that the conspiracies behind the island's mysteries bled over into the real world and knew no boundaries. This kind of transmedia kept fans occupied during the long hiatuses between seasons. Gillan says that this form of telling stories has given television programs "a dual existence," one featured on the TV screen and one "detached from the networkdetermined scheduling grid" (179). The next step would be uniting the two efforts rather than seeing them as separate processes. 
Films like The Matrix, The Blair Witch Project, and A.I. also featured large campaigns of transmedia (games, online sites, etc.) through which producers convinced viewers that the world of the narrative could transcend the large screen and enter their own homes through all of the techniques mentioned in previous paragraphs. Christy Dena cites examples from television as well as other forms of media that have famously used transmedia to ensure fan loyalty and participation in fictional worlds. She examines children's cartoons both here and abroad, the Olympic Games sponsors, movies, and even music. Of note is her example of the band Nine Inch Nails's transmedia that spanned across live performance, compact disc, alternate reality game, t-shirts, and even USB sticks left in restrooms. Nine Inch Nails used the concept of an apocalypse called Year Zero (also the name of his album) to enhance the fan experience of listening to their new music. Fans even gathered at a secret location once they decoded the clues on the USB files, and they were pleased to discover the location was a private live concert of the band, complete with people disguised as SWAT team members who would eventually break up the concert and quell the "resistance" gathering (Dena 49-50).

More uncommon to these various forms of media and narrative is the dual-screen technology, although that may be coming sooner than we think. Many theatres are reserving seats for patrons who, during the live performances, write their impressions of plays and musicals on Twitter as the narrative unfolds onstage. Movie producers are issuing free guides to download on tablets, and DVDs, as we already know, have introduced director, actor, and designer commentary to accompany the viewing of a narrative. Still, most producers in film, music, and other storytelling platforms have not yet prompted audiences as a whole to sync their experience with a narrative study guide 
that specifically employs two different devices. Television is the primary media form that is experimenting with this process now, and I will demonstrate how this process works in the next chapter.

Whether role playing is explicit or implicit in the design of such applications, I will argue that the idea of "identification" pervades the enhancement of narrative today, particularly in new media. Such use of "identification" now has the ability to transcend fictional worlds and be useful to us in our own classrooms, work, and civic life.

Although transmedia and commerce are closely related, this project looks beyond financial motives of producers to see what kinds of rhetoric persist in these new forms of participatory culture, and how such rhetoric manifests itself in the real world as well as the fictional one. 


\section{CHAPTER TWO}

\section{"IF YOU SEE SOMETHING, SAY SOMETHING": SYNCING, WRITING, AND PERSPECTIVE SHIFTING IN NARRATIVE AND SECOND SCREENS}

When two men collaborate in an enterprise to which they contribute different kinds of services and from which they derive different kinds of profit, who is to say, once and for all, just where "cooperation" ends and one partner's "exploitation" of the other begins? (25)

In being identified with B, A is "substantially one" with a person other than himself. Yet at the same time, he remains unique, an individual locus of motives. Thus he is both joined and separate, at once a distinct substance and consubstantial with another. (21)

--Kenneth Burke, Rhetoric of Motives

The tag line for the second half of the third season of The Walking Dead is "An Eye for an Eye," which references the villain's injury in that narrative from the third season. The advertisement that uses this tag line features the two main characters of the show, standing apart but also staring intently at the audience. The villain's eye is covered by an iconic patch. His eye, destroyed in a fight with another character, compromises his vision on a physical level. The character to the right of him--Rick Grimes, the protagonist and hero-is featured with only one eye but has remained physically whole. While he has not suffered any physical loss or injury to sight, Rick hallucinates visions of his dead wife, sometimes at crucial moments that define his leadership. This image of the protagonist and antagonist, placed side by side, emphasizes the value of perspective to the audience who will follow their respective journeys in the fictional world of a zombie apocalypse. The Walking Dead and the Story Sync application accompanying its live 
broadcasts (where this ad is featured) quite helpfully engage in the rhetoric of what it means to "see" well and how point of view shapes the events of the narrative.

While it is important to mention key events in the narrative that shape this overreaching discourse of "eyes" and "seeing," this chapter features a close, rhetorical analysis of the transmedia associated with The Walking Dead and other shows and not the show itself. Even more important to my purposes is analyzing what it means to engage in perspective taking, and how pop culture may help us find new ways to approach this culturally lauded skill. The overall thrust of this argument returns repeatedly to the rhetoric associated with the act of seeing and the development of observational powers during engagement with second screen applications. Transmedia in the form of second screen applications serves as the content that helps illuminate in today's world how that rhetoric operates and how the act of "watching" is being transformed on and through television's primary and second screens.

\section{Changing the Way We Watch}

In essence, second screen applications change the way we are watching television in terms of material conditions. As Breeanna Hare explains, "Whereas we simply watched one screen in the era of The Cosby Show, some of us would be at a loss if we couldn't have our laptops out while also viewing Modern Family." It used to be that when people gathered to watch a show, they would do so in large groups around one central monitor. Conversation happened organically among those watching, and it often continued the next day at work, where employees or students would discuss the last night's events with their coworkers around the water cooler or with their fellow students at the lockers. Scholars discussed this phenomenon in cultural studies during the last two 
decades of the twentieth century, noting, generally speaking, that these conversations were indicative of a common cultural currency, thematically linking groups of people to the experience of watching a narrative unfold over weeks and months (see Williams; Buckingham; Fiske; Lembo).

With the use of mobile applications on phones and tablet computers, a viewer may now watch television and converse with others simultaneously. To do so requires that the viewer "syncs" her/his device with the narrative unfolding on the television screen. In order to activate the applications, the viewer must turn on the television and allow the program to "listen" to the broadcast in its "live" transmission. For example, as the app below "listens" and hears an episode of NCIS: Los Angeles (as seen on the right side of the screen shot below), the interface states that "you are successfully synced."

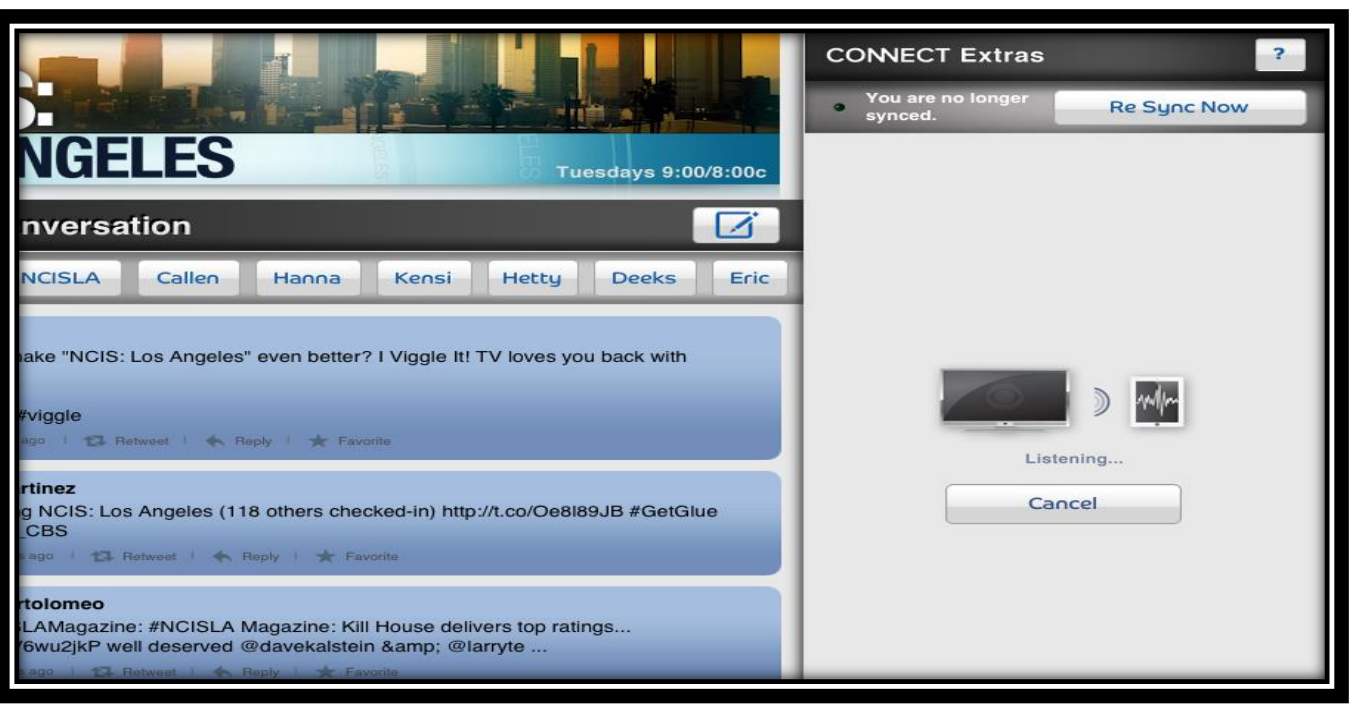

Fig. 3: NCIS: LA Connect App: "Listening” to Live Broadcast

The listening done in the images above is being done by the machine, or the syncing device itself. The notion of "listening" represents a human activity, but its process is mechanized. The processes that follow act in a similar manner. Once online, viewers may use the touch pad to answer questions or polls, as well as engage in live conversation 
feeds with other viewers. In the past, fans of TV shows, when interested in taking their passion for the narrative to an online forum, would have often used computers separately from television. To write their thoughts about an episode on a listserv or a forum, they turned the television off in one room and entered their office to type a response. The two processes of watching and conversing online were mostly separate. To synchronize viewer reactions and plot events in a live viewing, the viewer now has to consider "watching" as an active process where call and response, or user participation is the normal activity. In today's world the material conditions needed to experience narrative include two screens in harmony with each other rather than one watched in isolation. This also facilitates a guided journey through the eyes of characters in the ensemble, all of whom view problems and relationships from a different point of view.

To analyze the syncing process as it unfolds on second screens like the laptop, tablet, or mobile device, I will first explain why the act of "watching" has gained more attention in our culture recently. Then I will compare the act of syncing with the experience of other live events such as a sports game, a classroom lecture, and a community gathering. After a close analysis of how viewing and syncing "live" have transformed the process of engaging with a fictional world, I will provide an argument for Burkean identification ${ }^{14}$ acting as a major persuasive force in our experience of narrative. Then I will discuss the limitations of identifying with characters who often represent a specific way of life rather than allowing a more diverse ensemble to share points of view with the audience. While calling attention to these moments of consensus,

\footnotetext{
${ }^{14}$ Again, for an explanation of how I use Burke's concept of identification, see Chapter 1.
} 
I will, in conclusion, revisit the prevalence of perspective shifting as a common trope in today's television narratives.

\section{What it Means to See: Emphasis on the Individual}

The reasons behind this examination of identification and the act of "seeing" stem from what I perceive to be a preoccupation with sight and observation in our culture that has reached its culmination in the years following September 11, 2001. In 2010 the Department of Homeland Security launched a campaign whose billboards and posters could be found on all manner of public transportation and large arenas of public gatherings. The campaign slogan contained simple but enigmatic words, reflective of a post-9/11 mentality of fear: "If you see something, say something." The "something" to which the slogan alludes is the suspicious activity that might characterize a terrorist attack. We are instructed to "see" our surroundings in such a way that we might possess the power in ourselves to stop a dangerous foe or warn the public of impending disaster. The DHS outlines the official purview of this effort on their website:

If you see something suspicious taking place then report that behavior or activity to local law enforcement or in the case of emergency call 9-1-1. Factors such as race, ethnicity, national origin, or religious affiliation alone are not suspicious. For that reason, the public should report only suspicious behavior and situations (e.g., an unattended backpack in a public place or someone trying to break into a restricted area) rather than beliefs, thoughts, ideas, expressions, associations, or speech unrelated to terrorism or other criminal activity. Only reports that document behavior 

shared with federal partners.

What is interesting about this project is its emphasis on the public's ability to observe and describe behavior that is threatening, or to determine what is "reasonably indicative of criminal activity." This campaign assigns each individual the role of individual private detective, able to discern the mundane from the extraordinary. DHS asks and believes that each person possesses the cognitive ability to look beyond factors of race, faith, and ethnicity to determine how the actions of others may place lives in danger. Rather than reacting to disaster after it happens, which is often the case when we feel empathy, this example asks us to keep watch and to follow a procedure of behavior that could save lives. According to the DHS, one person's point of view, when used properly, could mean the difference between life and death.

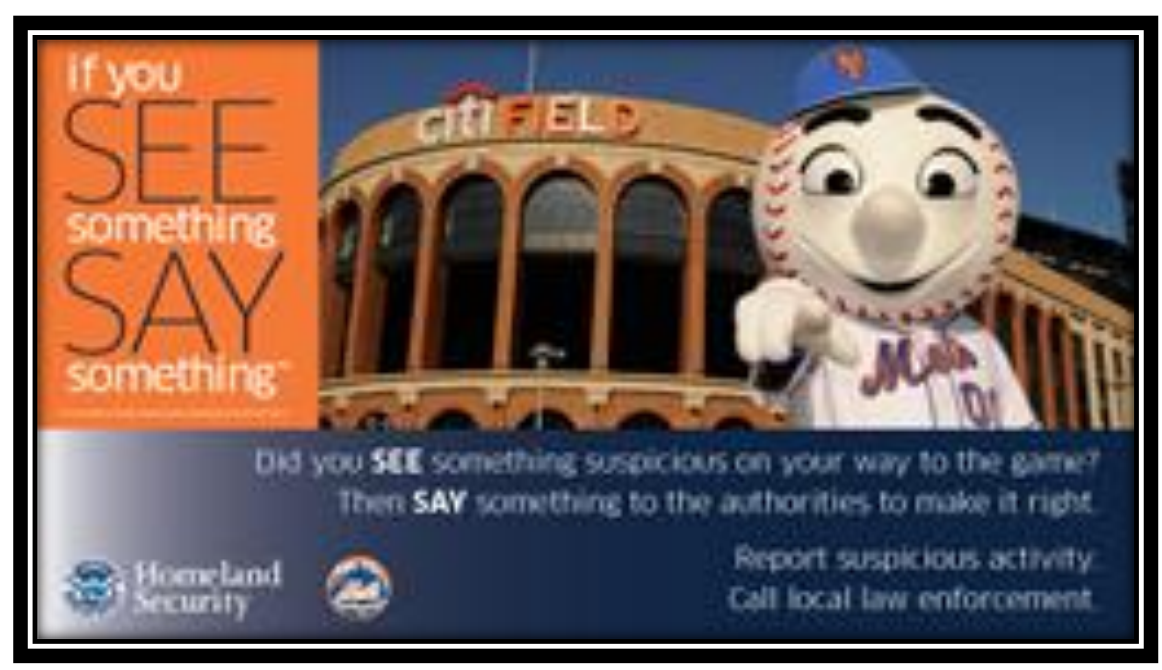

Fig 4: Advertisement for the "If You See Something, Say Something" Campaign 
In the picture above, we see how the baseball, representing the New York Mets ${ }^{15}$ and anthropomorphized as a giant "watcher" of sorts, points his finger to command us to speak up if we witness suspicious conduct. This command is punctuated by the baseball's large, wide eyes and towering presence in comparison with the stadium behind him. What is notable here in this picture is not the message that we might someday all be capable of detecting terrorist activity and be capable of standing watch against dangerous influences in public spaces, although such a possibility is interesting. But I specifically point out this message from DHS as an example of the rhetoric that accompanies the request for vigilance and the act of watching. These words-"if you see something, say something"- -highlight a cultural preoccupation with the power of individual's sight to effect change.

\section{What it Means to Sync: Emphasis on the Group}

But perspective taking involves more than just watching our surroundings. It requires a certain imaginative power to transcend one perspective and then imagine what it is like to think like another, while also maintaining a sense of self. To "sync" our viewing with others who are experiencing the same narrative at the very same time is a powerful act of consensus-building among people whose cultural, racial, and economic backgrounds may differ. This is different from seeing "something" as an individual defender of the public, as the advertisement from the Department of Homeland Security suggests. As Bronwyn T. Williams argues alongside Amy Zenger in Popular Culture and Representations of Literacy, pop culture narratives have a way of reflecting dominant ideologies about literacy and education, creating a loop in which pop culture and meaning

\footnotetext{
${ }^{15}$ The Mets as a team seems especially appropriate in this case since they are clearly associated with New York City, where 9/11 took place.
} 
making are both informed by and inform one another (14). It is evident from these applications that the notion of "seeing well" is being promoted as something a "smart" viewer is able to do but also something that happens with groups of people who become stakeholders in a fictional world. Narrative is now made successful by how well the audience may not only enjoy or passively relate to characters but by how well they actively identify with them by being able to assume other points of view. By invoking the ideas of identification with characters and the images of eyes and point of view, the second screen reinforces how valuable observation as a skill is to communication, especially when it involves a large number of viewers acting in concord.

Indeed, the use of the term "sync" to describe the procedure of "enhancing" television seems to be used across all of these devices, if not by direct name, then by the action of "listening" to the television content and starting the stream. This procedure highlights the active process of watching: both are verbs suggesting we do rather than simply watch. Another valuable point is the connection between the word "sync" and the homonym "sink," due to the nature of what the applications are asking us to do. While watching television used to be, in many cases, a solitary process, the applications here are asking us, metaphorically anyway, to "sink" into a larger pool of participants in order to engage in perspective taking as a community. And as we align our perspective with a larger group, this is where the word "sink" becomes potentially dangerous. By "sinking" too fully into a mode of "group think" where the producer guides our understanding and perspective taking of any given narrative, we may lose track of how we construct our own meaning.

\section{Concerns about Exploitation}


Therefore, I am not trying to ignore the fact that the apps discussed here are transmedia designed for and by media corporations to enhance viewing but also to build consumer loyalty to a franchise. In fact, I call attention to this matter by using the epigraph by Burke that begins this chapter. Cooperation among fans and producers often leads to what we would call exploitation, or commercial gain. If enhancement of narrative leads to purchases or consumption that benefits that corporation, this fact does not take away from the ways such apps raise questions about storytelling and how it has changed in the face of new media. It happens in spite of this participation in a consumer society. In this matter I side with John Fiske in his famous text Reading the Popular when he says that shopping "can never be a radical, subversive act; it can never change the system of a capitalist-consumerist economy. Equally, however, it cannot be adequately explained as a mere capitulation to the system" (27).

The motives I concern myself with in these apps are the persuasive ones, ones that garner the viewer's attention and help enhance narrative commitment to a given series. But I share the opinion with visual rhetoric scholars James Elkins and Barbara Stafford who note that visual texts are often misappropriated by well-meaning teachers as cultural studies objects that will corrupt or brainwash us into activity we do not understand. An advertisement showcasing women's perfume does not have to be approached with an eye for how the company is "luring" us toward buying perfume without our conscious approval. This is all to say that advertising and televisual culture sometimes receives the brunt of our fears about living in a simulated, commercial society. According to Jean Baudrillard in his famous essay on the simulacra, we are surrounded by a collection of simulated and purely commercial set of signs with no potential for authentic discourse. 
This view of the modern world is similar to the position of postmodern theorist Frederic Jameson, who stresses the commercialization of society has prompted the "transformation of reality into images" (1860). Jameson and Baudrillard's observations about the commercial world shed light on how understanding the rhetorical structure of a syncing program is often coupled with fear of materialism and indulgence in a commercial society.

Baudrillard's most recent published comments on reality television echo his concerns about the increasing screenification of our world: "If everything ends up being visible, ... the crucial point nevertheless is to succeed in creating out of this extreme disenchantment of life, out of this loss of any symbolic space, an object of contemplation, of awe-struck observation and perverse desire" (10). Again, Baudrillard's position is one of absolute pessimism, driven by the spectacle of reality television and the celebration of banality he sees in Western culture. His pessimism, certainly, has some basis in truth: as Mark Deuze describes, "we have arrived at a crucial time when an unmediated life is inconceivable-even impossible" (28). Deuze explains that we are now "looking at the world through the interface of the avatar," where "the premise of a media life seems to turn people into gods" (more on this idea of avatar and embodiment will be discussed in Chapter Four) (29). Therefore, it may be easy (but altogether slippery) to move from his condemnation of humanity's "perverse desire[s]" to a more global condemnation of what viewers seek when they watch fictional worlds unfold on their screens. While this concern may guide us toward a more ethical and grounded treatment of what we analyze in media studies, that same concern should not, I argue, overshadow any other creative and surprising processes transpiring between viewer and text (the show or the sync or 
both). I would not, however, go as far as to say, like Fiske, that "traces of radicalism are to be found in the way [commodities] are consumed and the needs that underlie their consumption" (27). I do not approach syncing as an activity that could foster subversive tactics by consumers. In fact, syncing sometimes limits any opportunities for subversion of textual analysis. In its limitations, however, are essential lessons about how reading and writing are evolving as public practices.

\section{What it Means to Watch "Live"}

Although live viewing has decreased with the advent of delayed online viewing through Hulu, Netflix, or downloadable video at iTunes, the ratings for television still remain based on a live audience. Because of this fact, the "syncing" application is ultimately designed to keep a viewer in his/her seat during a live broadcast. Time has become a significant factor in how we interpret television and its genres. We are accustomed to seeing the situational comedy wrap up any problems the characters face in the final minutes of the half hour. We often can predict that in a murder mystery the killer will be discovered in the fourth act of the hour, or in the last fifteen minutes of the program. Time shapes our expectations for how a narrative will present itself within the constraints of the network air time it is given. Jennifer Gillan, in her case study on the television show 24 and Fox News, makes it clear that an increased awareness of time helps maintain a certain alertness and sense of danger in the viewer, especially in the aftermath of the $9 / 11$ terrorist attacks. One example she cites to support this claim is the presence of the "continuous looping news crawl" we see at the bottom of our screens (114-15). The crawl, I would suggest, is one form of syncing that audiences have become accustomed to. They are learning to watch and listen to the main text as well as an 
ancillary message beneath it in order to feel as if they are constantly informed of the world's events.

To be clear, a broadcast is not "live" in the sense that it is being produced at that moment. Almost all of television (except reality programming like talent competitions) is taped in advance. Only recently have we heard the phrase "watch it live" make a comeback in our entertainment culture. Consequently, the app now features activities that remind us of other activities we enjoy doing "live," such as participation in a classroom (a classroom based ideally on a favorite subject rather than a dreaded one), basketball and football games that are monitored by a ticking clock, and "checking in" to a community gathering or meeting place. I will show how each part of the app mimics these parts of life, helping us to see the value in experiencing narrative live.

AMC Mobile describes Story Sync's function as a second screen experience in terms of it being "a LIVE, interactive experience that allows you to vote in snap polls, answer cool trivia questions, and re-live tense moments via video clips during the premiere broadcast of the latest episode." The word "LIVE" in all caps, as the first adjective to describe the experience, echoes what Krista Fleckenstein says when she describes the digital systems of meaning in our world as being part of a "permeable ecology of information pathways" (9). The sentience of the "sync" illustrates how a "flow of information" may help a user and the producer of this app "create each other mutually" in a symbiotic manner (7). Because the apps are "living" documents, as the app store describes them at www.apple.com, they are always changing and exchanging methods of communication. The ability to play a part in shaping a "live" document makes a viewer feel more involved in the creative process of transmitting narrative to a large audience. 
But being a "live" experience means more than transmission. It means experiencing a cultural event in the very moment it happens. Television narrative is filmed in advance, but the application gives us the impression we are viewing something as it is being unveiled for the first time. Here is where it is important to think about procedural rhetoric as opposed to simply visual rhetoric. A ticking clock, a live counter, is posted in the right corner of AMC Mobile's sync app, showing the viewer exactly how many minutes and seconds will lapse between one syncing activity and the next. The act of this procedure communicates the point of view of attending a live performance where something unpredictable is always just a moment away. More specifically, I would also argue that this ticking clock and the idea of a live performance invoke images of sports games played for points before a stadium of excited fans. The clock also conveys a sense of high stakes by reminding a viewer that each minute in the "game" of narrative is important. A moment away from the screen at the wrong time will cause the viewer to get "out of sync" with the action. Likewise, the idea of "counting down" builds suspense in us as we watch events unfold.

Methods of retaining viewer presence during live presentations include syncing methods that even govern the commercials on the applications viewers use. Every part of Story Sync's rhetoric works toward concretizing specific themes that will continue to echo in the viewer's mind throughout the episode. 


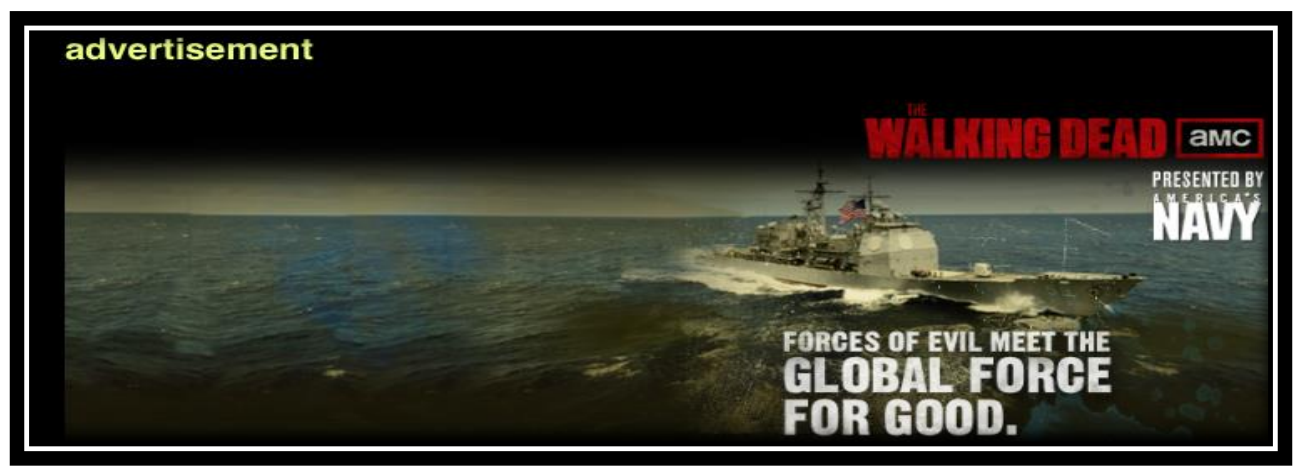

Fig 5: U. S. Navy Advertisement during The Walking Dead Story Sync

For example, if watching The Walking Dead, viewers are likely to see visual ads during commercial breaks for the armed forces, usually featuring a theme of good overcoming evil. See the example above from the U. S. Navy: the colors of the interface reflect the color scheme of the world of the apocalypse in the narrative: the design is army green and dark red, the colors of militaristic living and bloody encounters with zombies. Every design choice on the app reflects the encounters with danger that the characters on the show face, yet the viewer is safely ensconced in her/his own home while touching a screen.

With Falling Skies, the app prompts viewers during commercials to solve puzzles with images of the characters' faces on them. As seen below in the screen shot of the Falling Skies app, these mismatched squares, if put together properly within a short

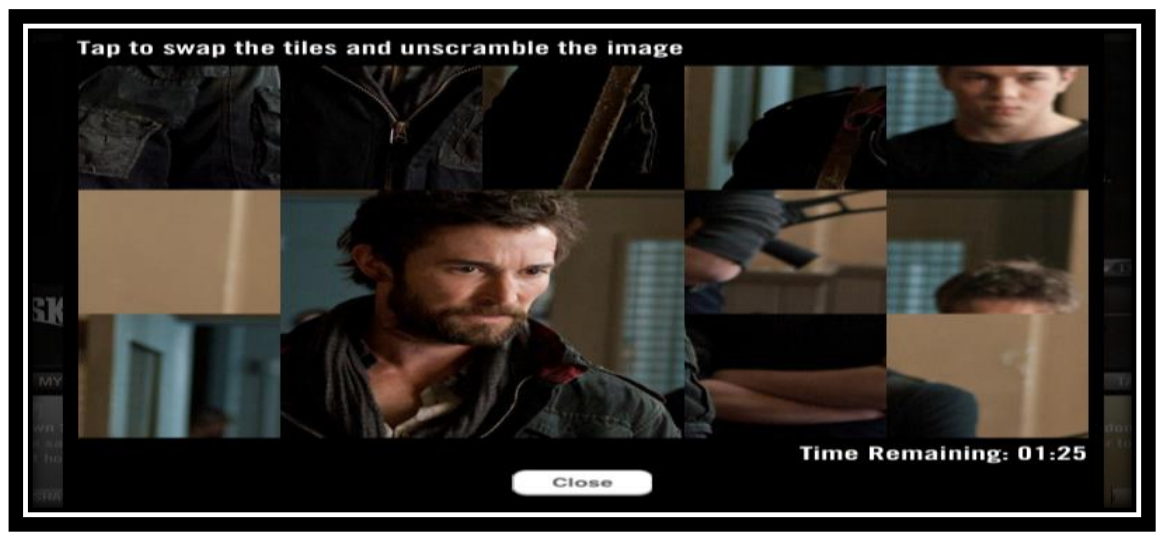

amount of time, reveal a 
Fig 6: Interactive Puzzle Game on Falling Skies App during Commercial Airing key moment in the dialogue or action of the show's content. Again, here we see the emphasis on timing someone's participation, making the act of watching a game rather than just a passive activity. The countdown of time at the bottom right hand corner looks identical to the ticking timer associated with other applications like Story Sync. The ability to "see" well, to see how pieces in a puzzle fit together, makes a viewer "win" the game. The puzzle piece activity reveals an emphasis on seeing how well details in each square align with the borders of other squares, again contributing to the idea that sharp observation skills are needed to be successful.

\section{"Schooling" the Viewer}

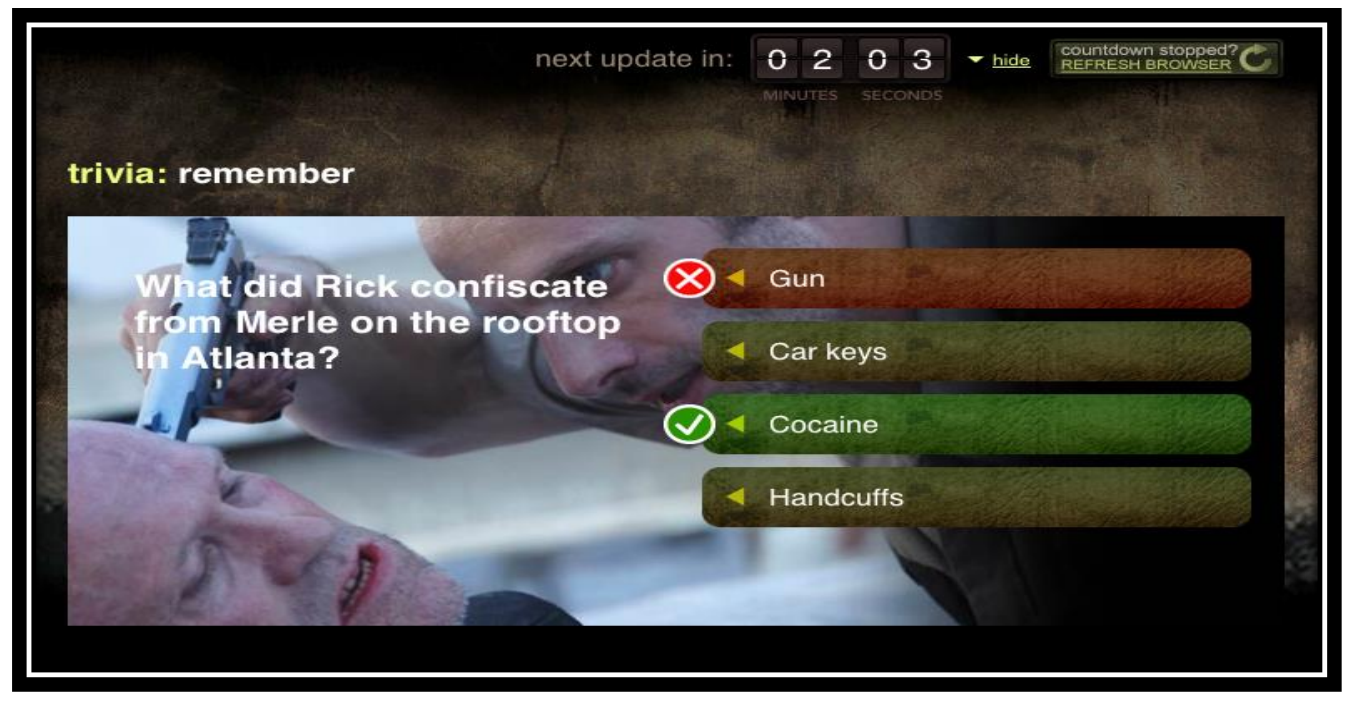

Fig 7: Quiz Question for Fans from AMC Mobile's The Walking Dead Story Sync

Testing the viewer is now a standard part of the syncing process. When syncing activities occur, Story Sync for AMC Mobile varies the content from a trivia question about past seasons, to a prediction question about a favorite character, and then to a fun 
fact about the filming of a current episode ${ }^{16}$ What is especially interesting here is how the rhetoric of these questions and their formats borrows from the twenty-first century classroom. Therefore, the connections I see deal specifically with how syncing presents multiple-choice items in a quiz format, how it highlights and points us toward important concepts, and how it provides textbook knowledge of the fictional world so that we may apply such knowledge to future viewing practices.

A green check mark appears when your answer is correct, and a red $\mathrm{X}$ signifies an incorrect choice. When some items merely require the viewer to vote on an outcome or evaluate a character's action, the answer does not get labeled correct or incorrect, but the results of the audience poll get displayed on the interface so that viewers may see if their answer is in the majority or not. Correct answers to trivia help the viewer feel as if s/he belongs to a knowledge community where mastery of reading/viewing texts is something of which to be proud.

\footnotetext{
${ }^{16}$ At the time of this project's completion, the former application GetGlue, now called tvtag, advertises its purpose in similar terms. In a recent email campaign, tvtag explained to former GetGlue users what their mission would be: "For every moment of a TV show, tvtag gives you a 'digital water cooler' — a place for you and others to react to what you're watching. With tvtag, you can vote in polls, comment, and even caption or doodle on an actual moment from the show to then share with friends on Facebook and Twitter." The idea of testing the viewer plays a role in the marketing: "With tvtag, answers are right at your fingertips: cast info, show trivia, and real-time trending searches from other tvtag users. And better yet, you never have to leave the app to find your answers!" More to come on GetGlue (tvtag) in Chapter Three.
} 


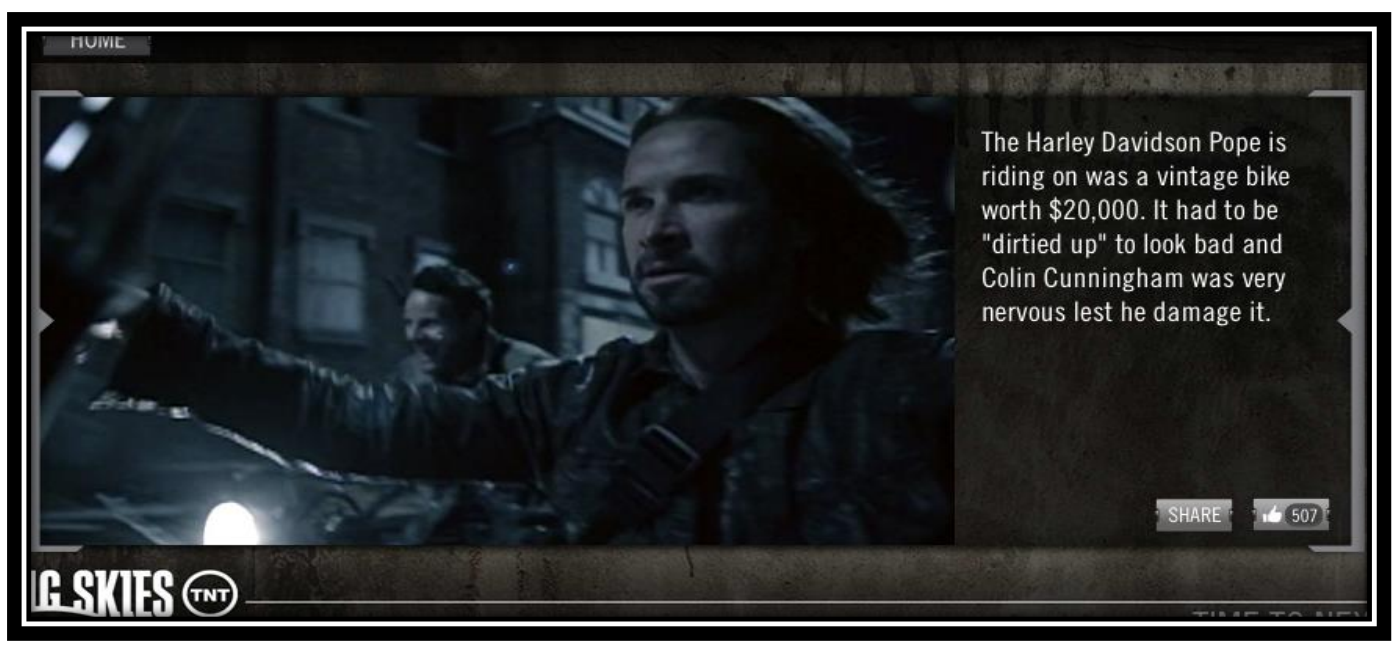

Fig 8: Facts about Production on Falling Skies App

Learning the secrets to the making of props, costumes, and camera work on the show also help the viewer experience the role of proprietor of the show's intimate details, thereby reinforcing the sense of belonging. It also creates a community of experts. Thorough knowledge of the fictional world also enables the viewer to respond more effectively to questions of prediction about the plot, as well as questions about what characters should or should not do.

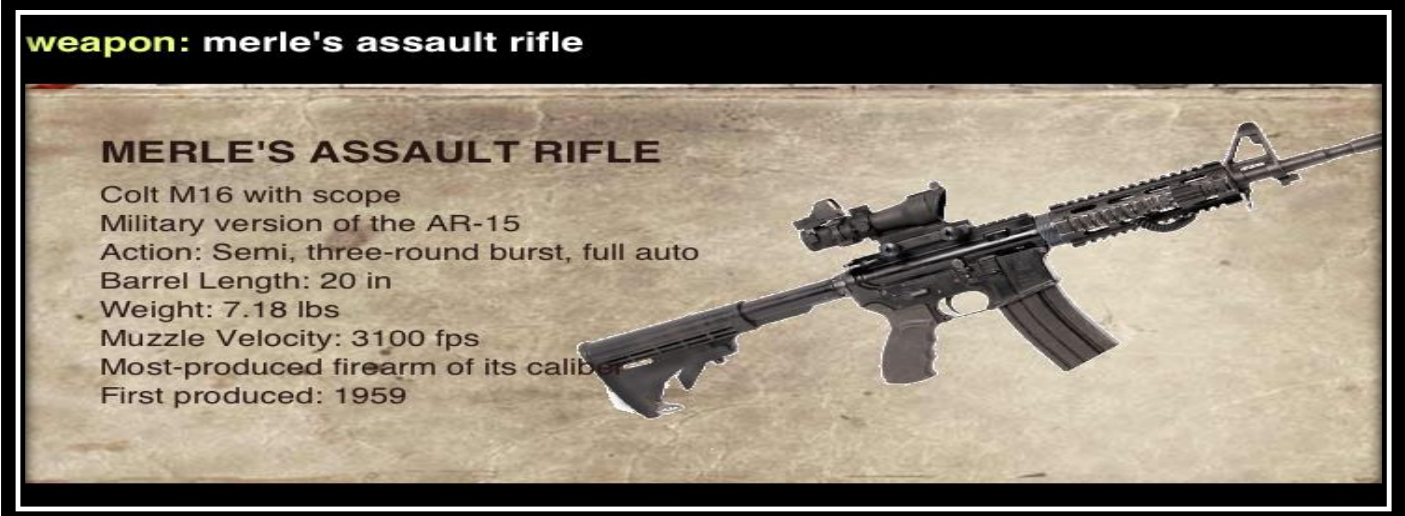

Fig 9: Facts about Production on AMC Mobile's The Walking Dead Story Sync 
By becoming experts about these fictional worlds and the details within them, we as viewers are encouraged to do what Jason Mittell notices fans are doing more often, which is "drill down" into a narrative rather than "spread out." But because we are now being given specific tools and facts through which to drill, we may be limiting the viewers' independent learning processes and searches for answers that take more serendipitous routes through the information world. This "schoolification" of pop culture has implications for how we see others constructing meaning. While scholarship has highlighted how gaming can influence learning environments and workplaces of the twenty-first century (see Gee), I would say that syncing is primary example of how classrooms, with quizzes and right or wrong answers testing fans' knowledge, influence new media. The relationship is more reciprocal than we might have imagined.

Yet a more concrete and material connection between the twenty-first century college classroom and these syncing applications exist. Within situations where professors must lecture to hundreds of students at once, never knowing for certain who is engaged or involved in the learning process, tools called clickers are used to "monitor attendance" and "spur classroom discussion that is not dominated by a vocal few" (Rashid). Clickers allow students to anonymously enter answers to quiz questions as a lecture continues and to see immediately the results displayed on a large screen. Like the quiz questions displayed in the screen shots, quiz questions displayed for clicker use often indicate the correct answer with a green check mark and the wrong answers with a red 'x.' Conclusions to preliminary research studies on the use of clickers in college classes suggest that such tools help academic performance and encourage interaction with the teacher (Mayer et al. 56). They, like the syncing questions, direct student attention to 
specific ideas and themes that are considered most important in a given amount of content. In her presentation on new media at the Conference on College Composition and Communication, Anne Francis Wysocki mentioned that the paratactical design of websites like Facebook have created (student) writers who may avoid distinguishing between main ideas and supplementary ones, since information is constantly being fed to them in a steady stream of updates, all of which are equal in status. Creating opportunities for them to "sync" the main ideas of the teacher with their own reading directs them toward creating a hierarchy of ideas rather than losing track of the outline of the lesson.

Other comparisons between college learning and the use of Story Sync are worth mentioning. As I stated in the Introduction, Johnson sees composition textbooks and video game manuals as having many traits in common. Johnson explains that "many game manuals, and especially those for role-playing games, offer back story—sometimes quite vivid and absorbing descriptions of the gaming world and its history.... [These manuals] read[] like entries in any cultural dictionary" (64). Story Sync also acts as a portable study guide or manual for television narrative. This positioning of the syncing device as a guide raises important questions about how viewers choose to explore the fictional world in which they choose to immerse themselves. For example, media scholar Henry Jenkins has made an explicit connection between college research writing and television viewership. In 2006 he noted that college students love the practice of spoiling endings to shows like Survivor. One student said that the practice of spoiling is akin to the research "digging" he is asked to do in college: "I like to look at primary source information. I like to find official manuscripts of an event. I like to find out who were the 
people there, what did they see. I want to hear it from them. That's part of my love of spoiling. I like to dig to the bottom" (53). This love of extra information, of digging to the bottom, seems to be a major part of Story Sync's presentation now. However, as seen in the screen shots above, the app does most of the work for viewers by providing all of the information at the audience's fingertips.

It is fair to say that often fans of a given narrative used to dig on their own for supplementary information about characters, settings, and history. Some, of course, still do. Jason Mittell relays a quotation from The Wire creator David Simon to critic Emily Nussbaum, in which he cites the value of creating television in an information-based culture: "If I can make you curious enough, there's this thing called Google. If you're curious about the New Orleans Indians, or 'second-line' musicians-you can look it up." What makes the relationship between a narrative and the audience special, according to reader-response critics, is that it creates many blanks or gaps through which the audience gets to construct meaning rather than consume it. Syncing expands on Wolfgang Iser's reader-response theory of the "Interaction between Text and Reader" by creating more structural and social boundaries for the gaps occurring between viewer and creator of narrative. Iser famously notes that gaps "function as a kind of pivot on which the whole text-reader relationship revolves" (1527). "Communication in literature," he says, "is a process set in motion and regulated, not by a given code, but by a mutually restrictive and magnifying interaction between the explicit and the implicit, between revelation and concealment" (1527). Since large gaps may leave audiences unable to identify with characters and worlds that make little sense to them, syncing provides material that helps guide how we watch and facilitates a collective experience of viewing texts. This 
procedure creates a matrix of understanding for the viewer rather than letting the viewer construct the matrix her/himself, a process that can be isolating or frustrating, as seen in the audience reaction to St. Elsewhere's finale, as discussed in Chapter One.

\section{Building Community}

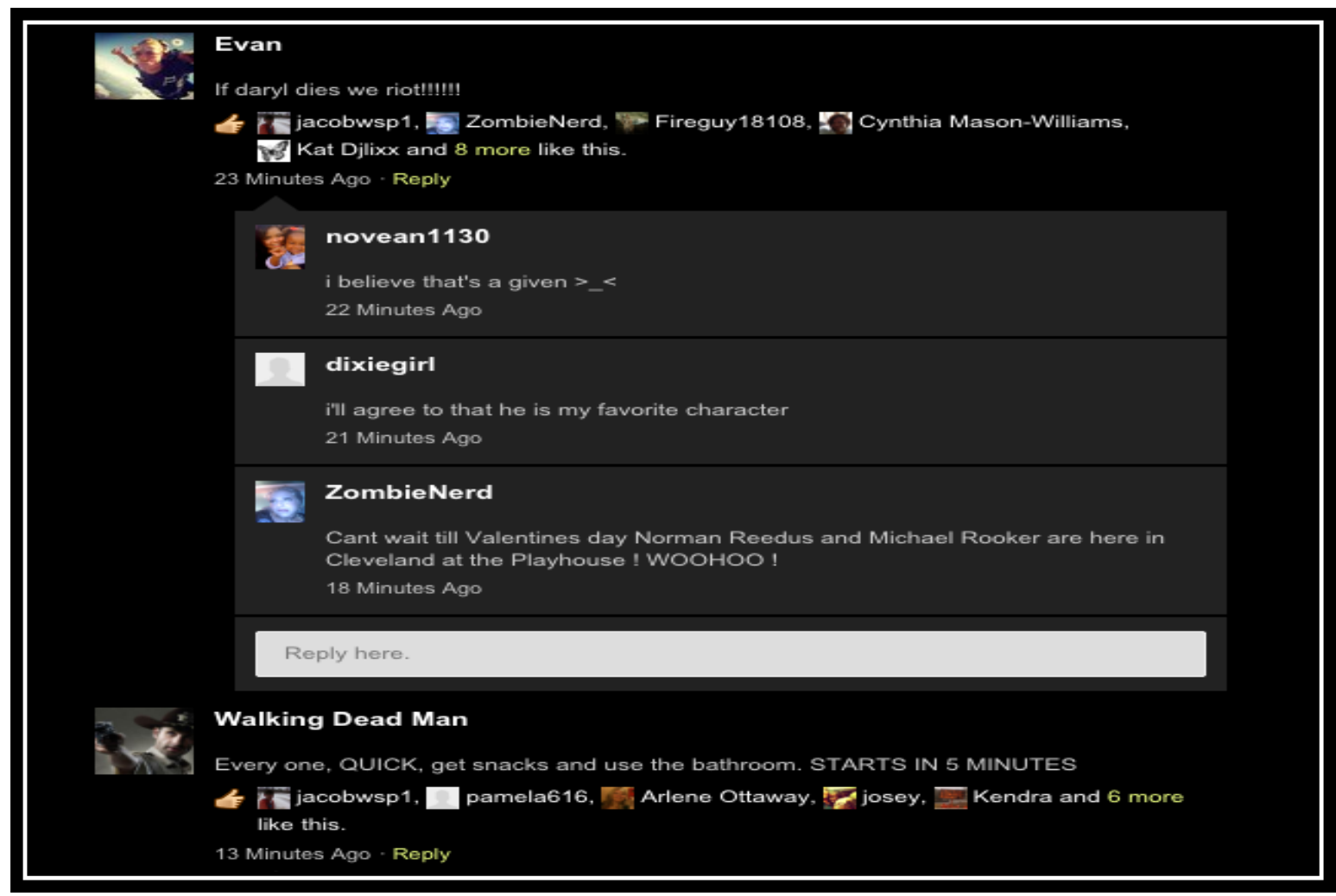

Fig 10: Live Feed during AMC Mobile's Story Sync of The Walking Dead

The second screen application also encourages social interaction with other fans.

When a viewer is waiting to see the next syncing item, s/he may click on the live conversational feed that accompanies syncing items. The live feed preceded most syncing applications in its design. Indeed, most ideas about syncing stem from producers watching the fans gathering on "watch and chat" network websites (Hare). Now this separate interface, organized as a subfolder on the tablet screen of the syncing application, shows fans talking back and forth about characters and ideas in real time. 
Above we see how the viewer - the "I"- - has become the "we" of a collective fan community. User Evan proclaims that if his favorite character Daryl dies, "we riot!" Other users quickly agree that they feel the same way. Individual viewing practices have now been transformed into what appears to be a public outcry over possible dangers that Daryl faces in the world of The Walking Dead. Also, at the bottom of the screen shot, user Walking Dead Man commands, “Every one, QUICK, get snacks and use the bathroom, STARTS IN 5 MINUTES.” This conversation feed simulates a neighborhood meeting of friends, who act in concord as they enjoy their favorite show together.

While producers often choose the hashtags on live feeds that govern conversation among viewers, viewers themselves often use their own methods of expressing their love for a narrative. The full nature of these "live" conversations will receive more attention in the next chapter. However, for now, this practice may be exemplified best in fan campaigns designed to retain loyalty to a series or prevent it from cancellation. When viewers heard that Bryan Fuller's series Hannibal was in danger of being cancelled due to low ratings, the fans rallied around the hashtag "\#EattheRude" in order to show their support. Here again, the relationship with the network and the fans who love its programs is reciprocal. The phrase "\#EattheRude" had been used in earlier marketing strategies associated with promoting Hannibal, but it had since been retired in favor of the simple \#Hannibal hashtag that Fuller and others had asked viewers to use on Twitter. Fans brought the phrase back, and as they did so, the producers and writers also promoted "\#EattheRude" as the official tag associated with the series on the night of May 16, 2013. Here again we see how, just as the classroom and the syncing app inform one another, the 
producers and fans also exist in a reciprocal bond where they borrow and forward one another's ideas through a live conversation of thoughts about narrative.

This part of the app's rhetoric, the live conversation feed, seems the most important to the networks. Most of the other major networks and some cable channels$\mathrm{ABC}, \mathrm{NBC}, \mathrm{CBS}, \mathrm{TNT}, \mathrm{CW}, \mathrm{TBS}$, and others--have apps that function in simple, streamlined ways, some just using a live conversational feed synced to the microblogging service Twitter or hosted independently. In most cases, the major features of these apps is the access to the Twitter feed and the occasional supplemental information about the background of the episode. In the next section, I will discuss more of what it means to “join the conversation" as a TV viewer/social participant.

\section{Identification in Narrative and Sync Devices: Concerns about Consensus}

Identification represents an activity of sharp observation and imaginative perspective taking. It may also represent the process of filtering reality through a specific person's point of view. In syncing applications the work of assuming identity is tied to decision making and proactive movement through a given fictional world. Again, because I am not speaking of the rhetoric of empathy but of the persuasive nature of shifting points of view, I visualize this act of role play as a step toward a specific goal, not as a temperature reading of our emotional depth and sensitivity levels as audience members. By syncing into a character's role, we sync with the community of viewers who watch the program but also the fictional world of the show.

Perspective, as Willie van Peer and Seymour Chatman explain, is the "spatiotemporal coordinates of an agent or observer; figuratively, it signifies the norms, attitudes, and values held by such an agent or observer" (xxiii). Without studying the art 
of perspective taking, narrative loses its "capacity for transferring experience" (xxiv). As I discussed in Chapter One, the nature of taking on the body to understand a new identity or position has already been described by Brendan Keogh, who explained how the $M * A * S * H$ episode "Point of View" encouraged him to imagine what it was like to be a disabled soldier. B. Malen also explained how taking on Tony Soprano's body would grant new meaning to the ending of The Sopranos. Indeed, representations of perspective taking do include the use of an avatar or digital body in some forms of new media. But previously, video games were the main area in which this form of embodiment was studied in new media. The rhetoric surrounding identification items on syncing applications frequently begins with "if you were , then what would you do?" and is often followed by four choices. Sometimes the viewer is not asked to place her/himself directly in the shoes of another but is asked to pass judgment on a character's decision"Rick's choice to ___ was ___ _-with audiences again choosing an answer that they think best describes the action (foolish, wise, cruel, supportive). However, frequently we are asked to place ourselves directly in Rick's shoes and decide what is best in a given moment of narrative.

As we recognize in the "If You See Something, Say Something" campaign against terrorist activity, the ability to recognize another's motive as dangerous and then to act against the fulfillment of that motive could save lives. Van Peer and Chatman are not as dramatic about the power of narrative perspective to rescue those in peril, but they stress repeatedly that the issue of point of view is part of public policies and policy analyses (xix). Spaces like "the press, the doctor's office, corporate headquarters, and capital buildings" all include confrontations, be they benign or malignant, between points 
of view of those in power and those who see themselves as subject to power (xix).

Perspective taking, while creative and productive when done as an exercise, also reifies dominant ideologies and cultural backgrounds at the expense of more diverse points of view. That is, we may explore perspective taking all we wish, but in the end some would say that we only assume the perspective of a person who is most like us. Rather than such a position hurting my overall thesis here, I see it as an illuminating and challenging part of engagement with narrative. The tensions between finding our way into the body of a wounded soldier in $M * A * S * H$ or understanding Tommy's autism in the snow globe scene in St. Elsewhere and the act of aligning ourselves with the white, adult, protagonists of most narratives create valuable discussion points for how point of view may be manipulated.

Although in Burkean terms (or new rhetoric) the word identification has often been studied as a persuasive and even manipulative maneuver that suggests a degree of sophistication on the part of the speaker, the idea of "identification" receives more negative press in literary studies. The word, like empathy, is often associated with using emotion rather than intellect to interpret narrative. Yet not all scholars see this as the only way to engage with narrative. For example, Faye Halpern does not approach identification from a rhetorical angle, but her argument in College English is worth noting for its defense of what has typically been called "reading badly." Halpern's aim is to establish how and where we might recoup the process of "identification" in the academy since it is often maligned as the sign of an uncritical reader of texts. Using texts by Harriet Beecher Stowe and Herman Melville, Halpern shows how sentimentalism is an unavoidable but also an even productive aspect of interacting with certain dramatic 
material, especially from a political stance. Rather than asking readers "What I Would Do in That Character's Place" it might be more helpful, she argues, to consider "How do the racial/gender/class politics of the piece intersect with mine?" (570). This approach might address Peckham's concern about the process of seeing from multiple perspectives being too grounded in middle class ideologies, as I mentioned in Chapter One. To quote him more fully this time:

The higher one's social class, the more varied the roles one is required to play, simply because members of the higher social classes find themselves in more varied social circumstances than members of the working class do....[H]igher social class members travel more, are exposed to different languages, different environments, and different modes of being. (72-73)

It is fair to say that the expense of travel, whether in the form of a summer spent abroad in Europe or family vacations to Asia, is limited to the upper and middle class; and such a limitation benefits students from such families and puts the working class student at what some might call a disadvantage. Perhaps television narrative set in different countries and across multiple locations could help students who rarely travel explore different perspectives. Yet television narrative is limited in its portrayal of different languages, races, and cultures, as I will show, since producers choose the identity markers of their characters and encourage us to accept them without much interrogation of why certain races, genders, or classes receive more representation than others. While primetime programs have made moves toward creating more diverse casts (Lost's Korean couple Sun and Jin spoke in their native tongue and were understood only through subtitles, a 
transgender character now plays a significant part in Glee's fourth season, and the list goes on), we must still acknowledge that such portrayals are subject to producer scrutiny and approval. I will unpack this problem in more detail in the coming paragraphs.

\section{Identification and Additional Concerns}

But first, I should add that even Burke notes some problems with identification. While he sees one of the major parts of persuasion to be the process of identifying with audiences, he also offers more ethically suspect ways that identification may function. In The Rhetoric of Motives he addresses the politician, who although being a "misanthrope," manages to identify his character with "mankind-loving imagery" (36). In this sense, the process of identification becomes a product of sophistry, in the pejorative sense of the word. However, Burke qualifies this negative example with the idea that while the politician appears to be falsely presenting himself, there "may be honesty in the assuming of the role itself; and the overplaying may be but a transition into a different medium of communication, a way of amplifying a statement so that it carries better to a large or distant audience" (36). Burke also mentions the example of a shepherd who, while protecting and acting on behalf of his flock, may still align part of his identification with the business interests that seek to "rais[e] the sheep for market" (27). Here again, as the title of his book suggests (Rhetoric of Motives), Burke considers both content and the motive behind it in order to analyze the art of role playing in speech and performance. He demonstrates his ambivalence toward those who master the art of deceiving others, yet he also sees the value of identification as a procedure that helps us meet a communication goal. 
It would be difficult not to project motivation on to a set of visual images designed by producers to "enhance" television viewing experience. This does not have to mean seeing the producer-designed apps as solely capitalist, manipulative, and corrupting influences. But what is somewhat unique about asking viewers as a collective whole to identify with one main character is that identification, a process that used to be primarily a private moment in the mind of a reader or viewer relating to a favorite character, has now been co-opted by producers as a public exercise in understanding the telescript. The request to see from a different point of view becomes a communal enterprise, one in which everyone using Story Sync may temporarily indulge. The idea of everyone identifying communally with one voice seems to promote the idea, again, of a specific narrative to follow rather than a host of options through which to explore a fictional world. While individual interpretations of narrative always exist, Story Sync pushes us toward a more consensus-oriented interpretation of television.

\section{Group Dynamics and Examples from Syncing}

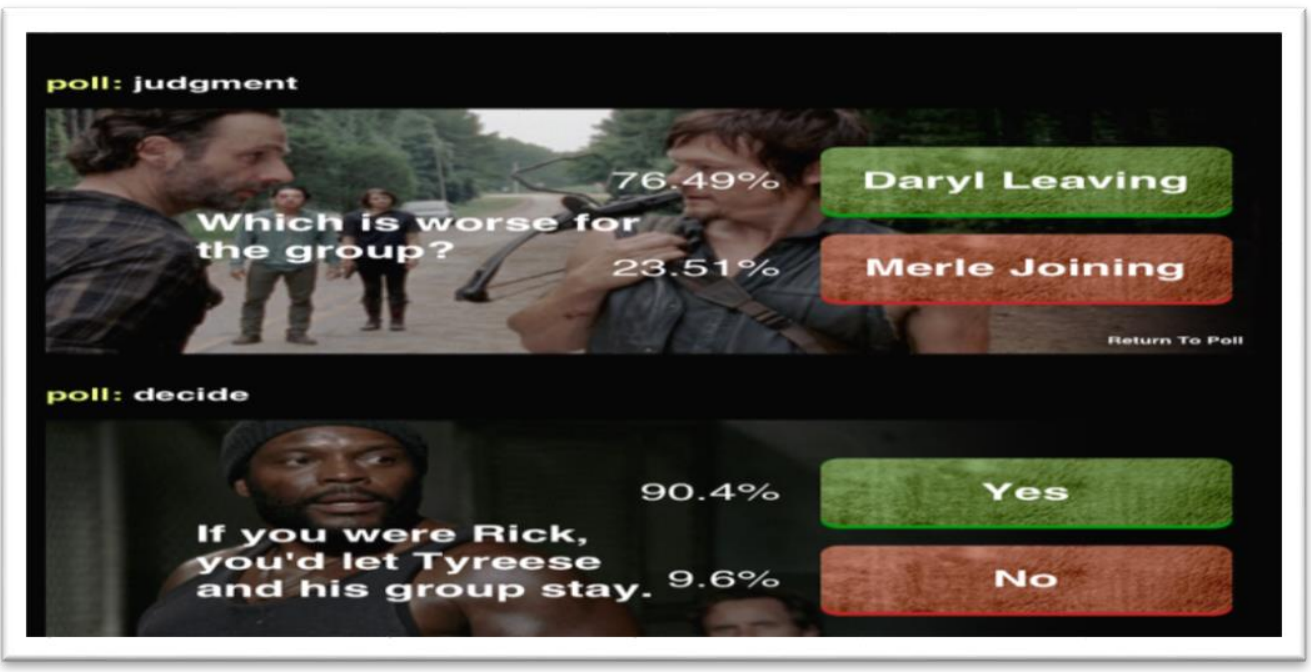

Fig 11: Audience Polls for The Walking Dead Story Sync Application 
Even the narratives themselves place a great deal of emphasis on the power of people to survive in groups rather than as individuals. The first step in identification is to see yourself as a member of the ensemble that inhabits the fictional world. In The Walking Dead, the fictional world on television and the information on the second screen always returns to the idea of group strategy and how best to lead others to safety in a time of crisis. Group dynamics will make or break the process of surviving the zombie apocalypse, and Story Sync ensures that the viewer is continually reminded of the group's welfare. The common word in polls on Story Sync is, in fact, "group." Viewers are asked to decide and judge who deserves to stay with the group of survivors. Much like reality TV, where a member of the cast can be voted off the island or rejected from a contest, users get to choose who they wish to stay and go. Although the choice may or may not agree with the narrative direction shown on the television, the dual screen technology enacts a procedure that makes the answers feel just as important as the information on the primary large screen. Once users choose their answers, they may weigh their opinions against other audience members using Story Sync. Like the characters featured in the app, users are a part of a group, too, but this time they are part of a live audience, almost as if they shared a movie theatre together. The emphasis is on a shared experience during which feedback matters and is displayed publicly. Again, this type of activity goes beyond visual rhetoric and creates a procedural rhetoric - through polling and live results on the screen—during which users may feel a sense of belonging. We also see the information above presented as a dialectic, the kind that Burke describes when he speaks of identification and argument, just as it was in the mywatchbegins.com site. We are asked to choose one of two sides rather than note the 
nuances involved in any given situation. In doing so, we become passionate about the side we choose and find ourselves allied with others in order to experience that feeling of belonging. The procedure behind choosing an answer on the syncing app includes seeing two possible solutions rather than many. While we might first argue that this dichotomy reduces a visual experience to ultimatums rather than complex decision making, the sync creates this form of questioning to enable the viewer to return to the screen as soon as possible. It would not make much sense to ask a four-part essay question of viewers if such a task took them out of the world of the narrative altogether.

We would be remiss not to recognize that sometimes people are faced with choices, where they must select from only one of two alternatives, sometimes with very limited time. The sync pays homage to those kinds of dialectic moments in our lives, asking us how we might handle the situation. Perhaps we are not asked to place ourselves in the characters' shoes as much as we are asked to see the narrative as a living, active current inside which we might get caught. By choosing what to do, we are making the story our own, but we aren't necessarily entering someone else's head in the strictest sense. Instead, it seems that we are asked to make a temporary body shift to suggest ourselves as avatars, or players in the course of the narrative. It is not that person's psyche that is important as much as it is their positionality inside a pseudo-reality. 


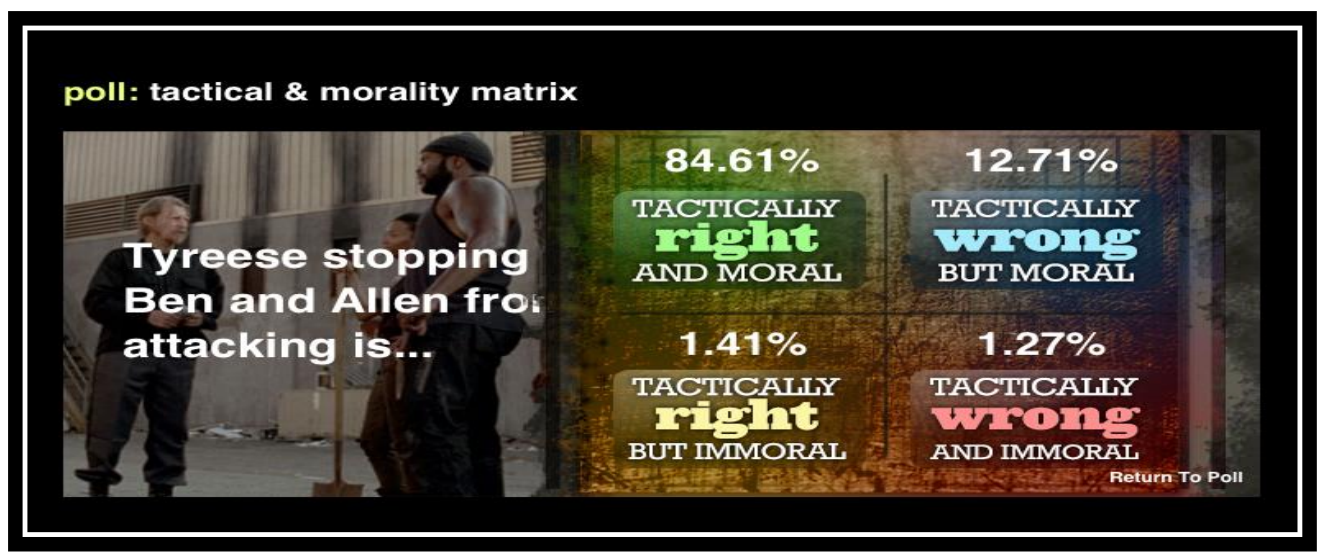

Fig 12: Evaluation Question from AMC Mobile's Story Sync for The Walking Dead

On the image above, we can see how the writers of The Walking Dead have acknowledged that simple yes or no answers, or a dialectic model in the Burkean sense, sometimes do not work in an apocalyptic world. The "smart" viewer may be able to discern not only that more than two alternatives are needed when trying to survive dangerous situations, but that the decision that is best for the group tactically may not be the best morally. One major point of analysis in The Walking Dead is how characters change in extreme survival situations and how their previous codes of morality no longer apply to the eat or be eaten world in which they live. The identification process here is not with one specific character's point of view but with the code of behavior that an entire world represents. To be able to distinguish between tactics and morals is a skill that the app expects of viewers who watch this particular program. 


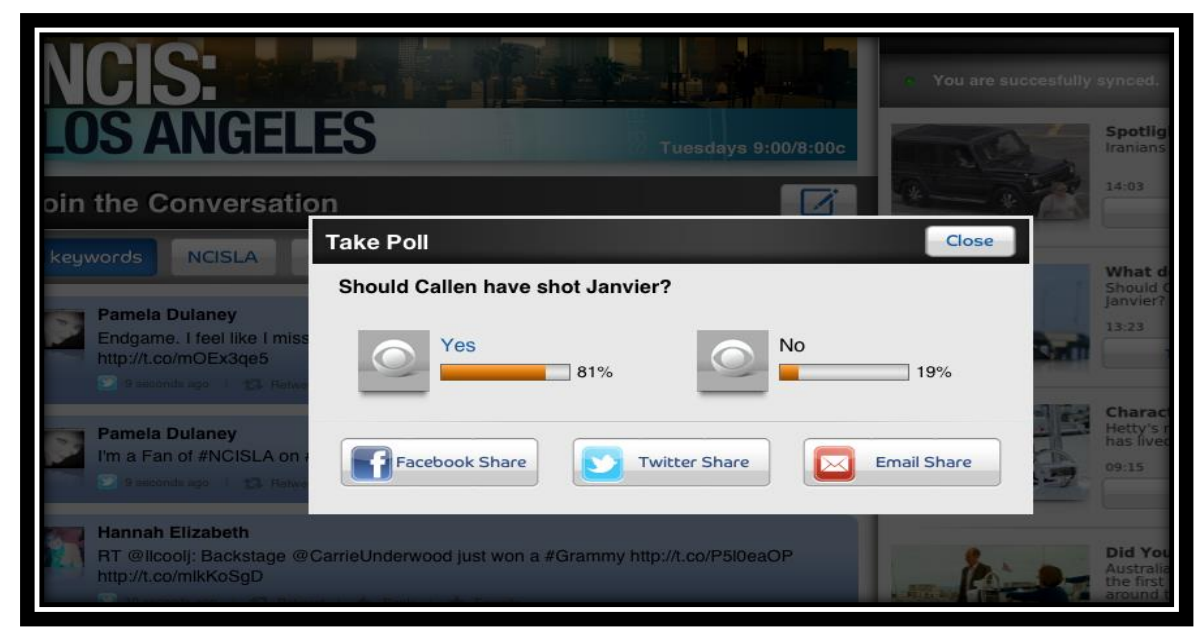

Fig 13: Evaluation Question from NCIS: LA Connect App

As a point of comparison, NCIS: LA Connect does something different. The question above about shooting a character shows, once again, how a dichotomous structure encourages viewers to participate in yes and no answers. The level of vocabulary on the AMC app is difficult in comparison to NCIS's direct question about shooting. Words like "tactical, morality, and matrix" suggest that our views of the characters' actions on The Walking Dead will contain conflicting but sophisticated notions of what is best for the community of survivors. This show, after all, includes an after-show named The Talking Dead, whose host Chris Hardwicke incorporates words like "theorize" in his discussions with a panel of celebrity visitors. Hardwicke and others associated with producing this show create an environment almost academic in their devotion to the series, one that viewers feel privileged to participate in.

While the app for NCIS is concerned quite directly with whether a character should have shot another, the AMC interface avoids such black and white assumptions by asking audience members to admit when a choice is immoral but justified due to the apocalyptic conditions. Those at AMC urge viewers toward ambivalence rather than binaries, although they do so under timed conditions. Instead of simply agreeing or 
disagreeing with a plot point or the character decisions made, viewers of The Walking Dead may support part of a decision and still disagree with the ethics or morals involved. Still, such decisions made when synced are made in seconds. While in real life a person might have the gift of time on her/his side to make a life-changing choice, the characters on the show facing zombie attacks do not always have this luxury and, therefore, in order for us to more accurately identify with them, neither do we.

\section{Identification with Protagonists on the First and Second Screens}

The problem with identification, however, is that the characters we often are asked to align ourselves with are the white, middle-aged male protagonists, especially in the case of dramatic television. Such a gaze is limiting if we wish to imagine a world where identification helps us understand people from different races, religions, gender orientations, or socioeconomic backgrounds. On both cable and major network channels, the hero is almost always a man, sometimes tortured by mistakes or flaws, but dedicated to making a terrible situation better for those involved.

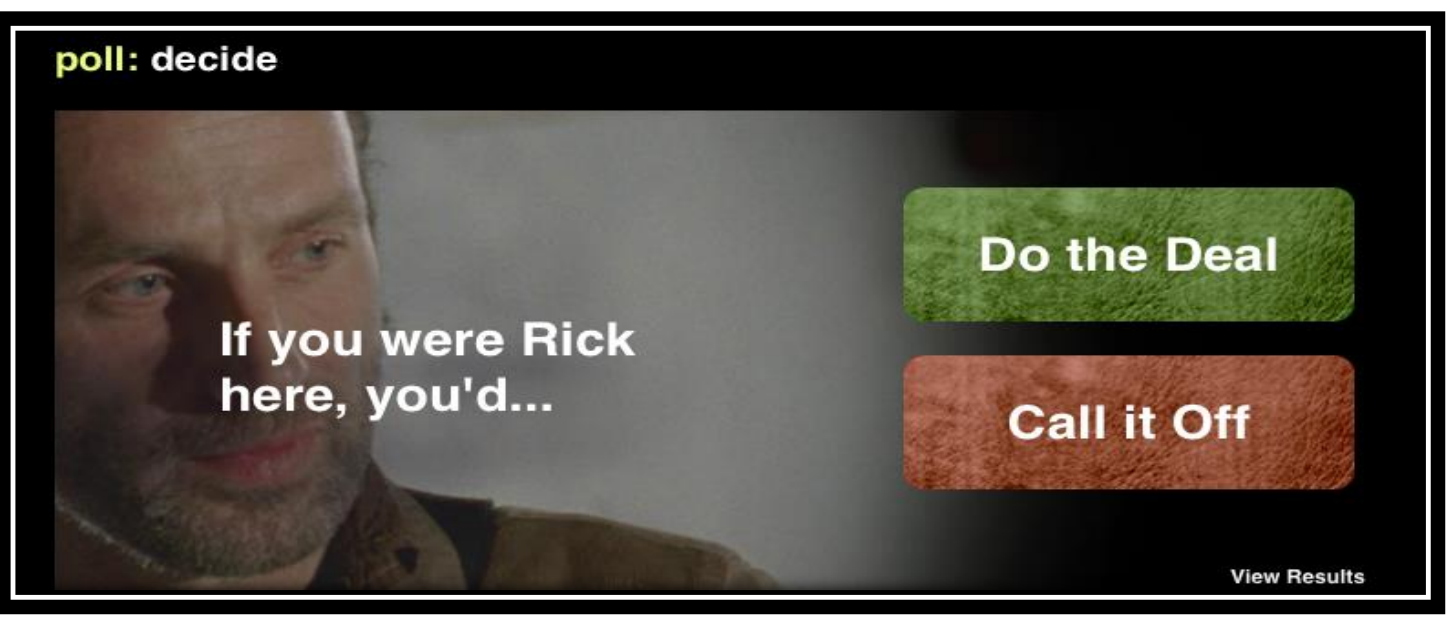

Fig. 14: "Audience Poll: Decide" for AMC Mobile Story Sync for The Walking Dead For example, the questions above from my The Walking Dead screen shots typically refer to Rick Grimes and his view of the apocalypse. Rick, a troubled, white, 
middle-class sheriff with a wife and child, is the everyman with whom viewers are asked to identify. Even the main image of "An Eye for an Eye," which advertised the coming season, featured Rick's eye as prominent in the image, with the other eye coming from another white middle-class male character, the Governor. This image- the extreme closeup of the eyeball--has been true in television's recent history, as an iconic shot from the show Lost was the opening sequence in which white middle-class doctor Jack Shepard opens his eye to find himself stranded on a mysterious island. In both Lost and The Walking Dead, women play key roles in the ensemble, but their vision or perspective comes secondary to the vision of the male lead.

Building on ideas from Wolfgang Iser and his reader reception theory, Cornel Sandvoss, in his work on fandom and fan practices, has already established that loyal viewers or readers of a fictional world are often complicit in making the text they love something that is more neutrosemic than polysemic (representative of a singular vision rather than multiple meanings). In other words, as fans rework or remix a world to suit their own points of view, they ignore parts of a mythology in favor of others, and they align the perspectives of characters to fit their versions of the world. The term neutrosemic is used pejoratively by Sandvoss, who, argues that "[i]f aesthetic value is based on transgression and estrangement, the reading of fan texts strives for the opposite: familiarity and fulfillment of expectations" (30). I would extend Sandvoss's point to say that producers of narrative also have a similar opportunity to create a neutrosemic viewing experience in which we focus primarily on dominant racial and cultural representations in order to ensure viewer comfort and loyalty. 
For example, in interviews associated with the launching of the History Channel's first scripted series Vikings, the writers/producers explain how their narrative will be filtered through a familiar lens of Christianity and morality, even though the majority of characters in the ensemble follow pagan beliefs. While most characters in the show are white, their pagan beliefs create a gap in viewer understanding, since most rituals and sacrifices associated with the Vikings are many centuries old. Therefore, the writers created a character with whom they thought we would feel comfortable: a Christian monk named Athelstan, whose capture and enslavement to the Viking community would become the point of view through which we would learn about these "strange, exotic people."

During the episode called "Sacrifice," Athelstan's point of view is literally the one we follow throughout most of the major scenes. When he samples food or drink during a pagan festival that causes his vision to grow hazy due to intoxication or ingestion of hallucinogenic materials, the camera becomes blurry and out of focus, creating a feeling of motion sickness in the average viewer who is trying to follow along. It also creates the feeling of uneasiness, or discomfort, so that we as viewers sense that the world we inhabit is "Other" rather than reflective of our own society. In other words, the idea of a white, male cast, although typically identifiable by most audiences, was not enough if those characters were associated with non-mainstream religious practices whose sacrifices to the gods included human beings. Because these characters worship gods other than the Judeo-Christian one and commit what we consider unspeakable acts of violence, the writers chose not only to create a white male character, but one whose Christian values would more likely align with the Western world's sensibilities. 
The same is true for Game of Thrones and the accompanying transmedia website mywatchbegins.com, which I discussed in more detail in Chapter 1 . While most characters in this narrative are hardly practicing any religion we can easily recognize since the show is based in a fantasy world, we still understand what the men in the Night's Watch resemble: a band of monks who wish to pledge their lives to a higher power or cause. Although we as website visitors hardly wish to become monks who live outside a world of pleasure (after all, the website itself is a reflection of our material interests), we may still indulge in a perspective that we believe reflects our own moral struggle and our own (white male) selves. ${ }^{17}$

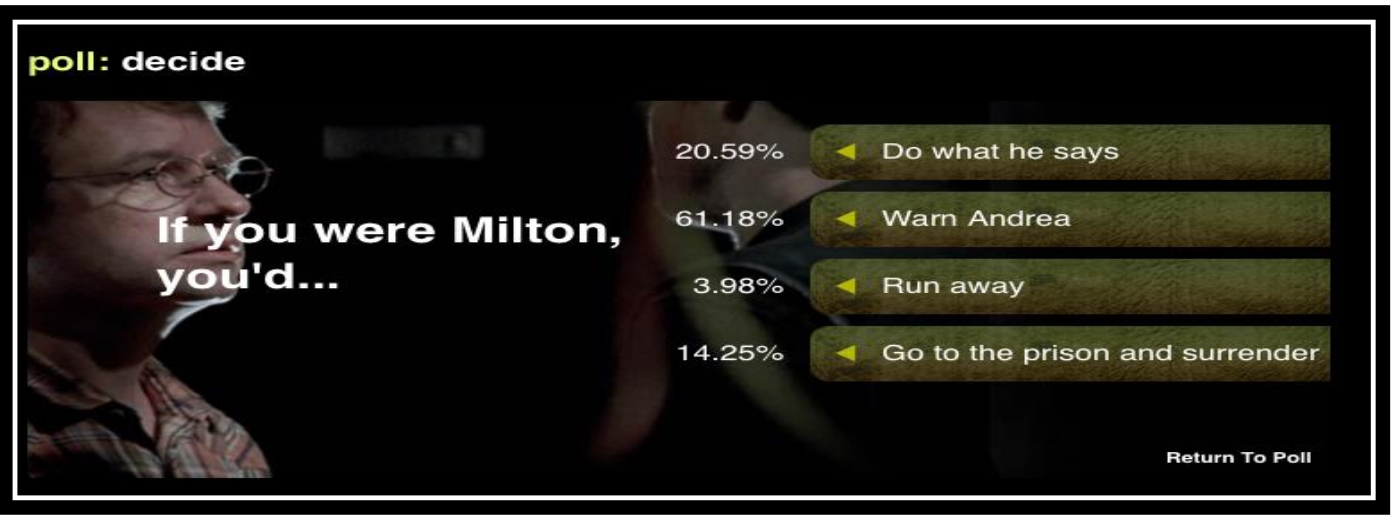

Fig 15: "Audience Poll: Decide” for AMC Mobile's Story Sync of The Walking Dead Sometimes the supporting male characters in an ensemble also offer insight that reinforces this concept. Here again, in the above shot from The Walking Dead, we see

\footnotetext{
${ }^{17}$ This is not to say that there are no shows with strong women in the lead roles. At the time of my writing, shows known for featuring strong but flawed women (either physically or emotionally) included Nurse Jackie, The Big C, Grey's Anatomy, Scandal, and others. At the time of this research, Shonda Rhimes, showrunner of Grey's and Scandal, did not use syncing programs to accompany her narratives. The producers of Nurse Jackie do, and I show an example in the final section of this chapter. Shows like Orange is the New Black, hosted by streaming services such as Netflix, do not have "live" airings but upload all episodes at once, so they do not utilize the second screen model. My argument is not a media studies project in which I attempt to prove that women are ultimately marginalized in television narrative. But I do believe it is safe to say that while many stories do feature women in prime-time television, they are often not as plentiful as the number of stories featuring men as leads.
} 
that although the identification question does not center on Rick Grimes, the supporting character in question, Milton the scientist, is the focal point of this syncing item. Milton is the Governor's unhappy assistant, occasionally trying to defy his leader for the good of his community. In this poll, we are asked to imagine what Milton will do in response to being told by the Governor to harm another character. Milton's profession again is middle-class; he is an educated man who is conducting scientific tests on zombies to determine the nature of the infection that has caused the apocalypse. He is also an interesting representative of literacy, from his glasses and plaid buttoned shirt, his makeshift laboratory, and his constant pursuit of answers to questions about the human body. What is fascinating here is how Milton is perceived as someone who is always questioning the fabric of reality, someone then who typically would be associated with what Bruner refers to as "a willingness to construe knowledge and values from multiple perspectives without loss of commitment to one's own values" (Acts of Meaning 30). Therefore, Milton as educated scientist is a character worthy of identification. The role embodies the very act of seeing from multiple perspectives while also reinforcing dominant images of the white middle-class male who possesses this talent. To learn how to see from multiple perspectives, we must model our cognitive habits after those characters who have already mastered the art of it.

Indeed, Milton as a resident of Woodbury, a small suburban town that has somehow managed to remain virtually intact, despite the zombie apocalypse, lives a life we all might envy if the world lost most of its resources and utilities and left us all to fend for ourselves. He has a nice home and lab, and he can imagine within the walls of this town that the world has not ended in disaster. His suspension of disbelief becomes 
something we can imagine in ourselves if we were caught in a predicament like his. He also finds himself serving the most powerful and evil character in the franchise, but he still resists committing fully to a nihilistic code of behavior in which people must eat or be eaten. Milton, as identifying supporting character, represents someone like us who has to continually revise his ethical stance in order to survive, but he still manages to make a valuable contribution to society through research. Likewise, we as viewers believe in a world where hard work and innovation will lead to a successful and comfortable life, despite the disasters that befall the rest of society. Bronwyn T. Williams and Amy Zenger, writing about depictions of literacy and education in film, argue that such character portrayals cannot be ignored. I would extend their argument to apply it to television narratives like The Walking Dead.

Films are a recognizable but idealized and intense view of life and culture. By studying them we attain a sense of what we want to have happen in life as well as a view of what does. We have all at one time or another wished life were more like the movies. That the metaphor of Hollywood as a "dream factory" has become a well-worn cliché does not mean that movies have lost their power to portray as well as shape our desires and anxieties. (168)

Viewers may comfortably identify with Milton, the curious scientist who is both flawed and heroic, because he represents their own desires and anxieties about living in a dangerous time and having to make difficult choices. Life becomes like TV as we imagine our knowledge of the show making us just as essential to the audience as Milton is to the community of Woodbury. 
This is all to say that although strong female characters in both ensembles are present, they are often not the focus of the questions in which we are asked to imagine ourselves in a character's shoes. Questions on Story Sync that address the female characters and their backgrounds certainly occur and often. However, they are not typically framed, at least in the network shows discussed in this chapter, as “identification" moments for viewers but rather as study questions or items about how women advance the plot.

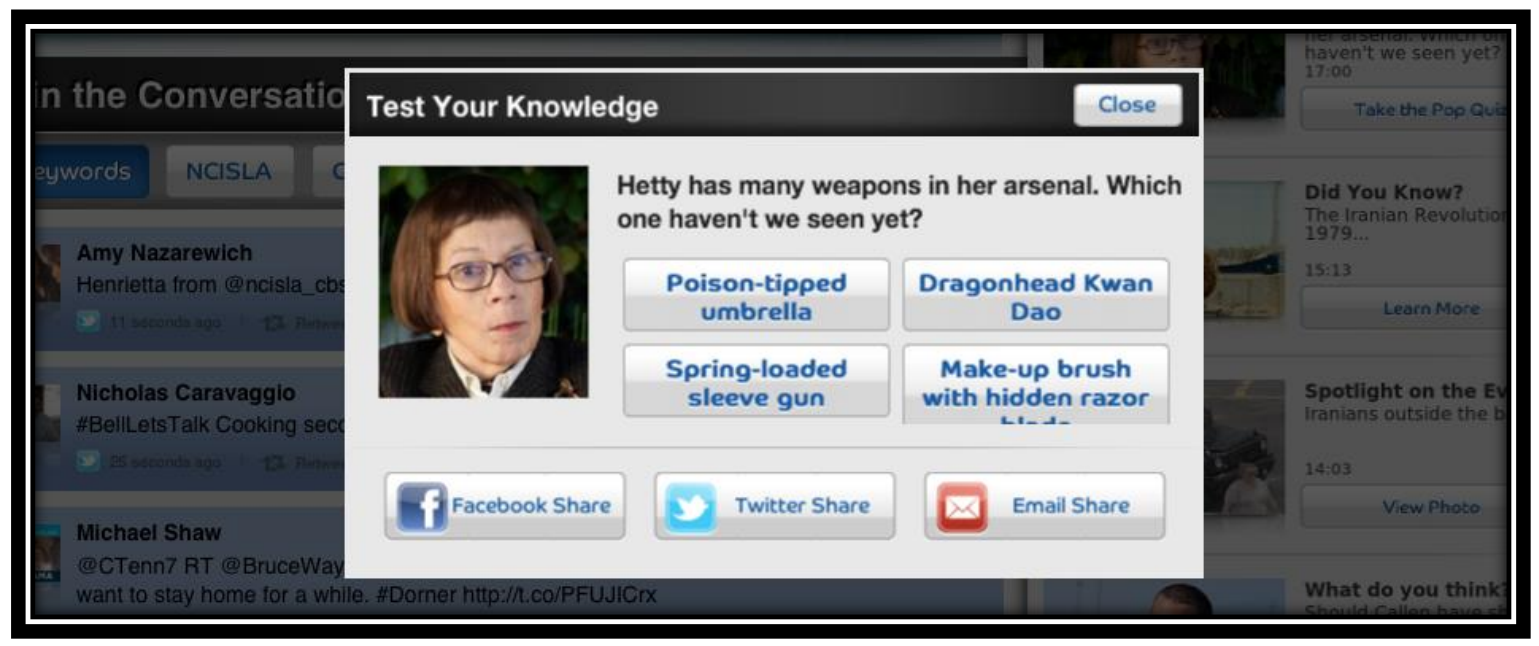

Fig 16: "Test Your Knowledge" on the NCIS: LA Connect App

An example from NCIS: LA Connect reviews the information about a female character in a similar fashion, but this time the item asks a direct question. However, note that even though the question refers to a woman, its content centers on what might be interpreted as the male-oriented discourse of weaponry and violence. In previous images from Story Sync $^{18}$, we may also consider how the information about guns and motorcycles represent

\footnotetext{
${ }^{18}$ As someone writing in the specific seasons of Spring 2013 and Fall 2013, my research often returns to television narratives that aired at that particular time and were available for viewing on basic cable. This certainly leaves some room for future investigations of gender representations on premium channels and how second screen programs either reify or subvert expectations about these representations. I do manage to locate an example from one premium show on the following page, yet this example was selected without
} 
a hyper-masculinized world, despite the expectation that often in the genre of science fiction and horror most action centers on violence and physical struggle. Most of the "backstage" information about the props used by actors focuses on the weapons they carry (Merle's gun) or the vehicle driven (like Pope's motorcycle in Falling Skies).

While apps do exist for shows featuring a female protagonist, the questions on a substantial number of syncing programs showcase women's emotional experiences and faults rather than high-stakes moments during which life is endangered.

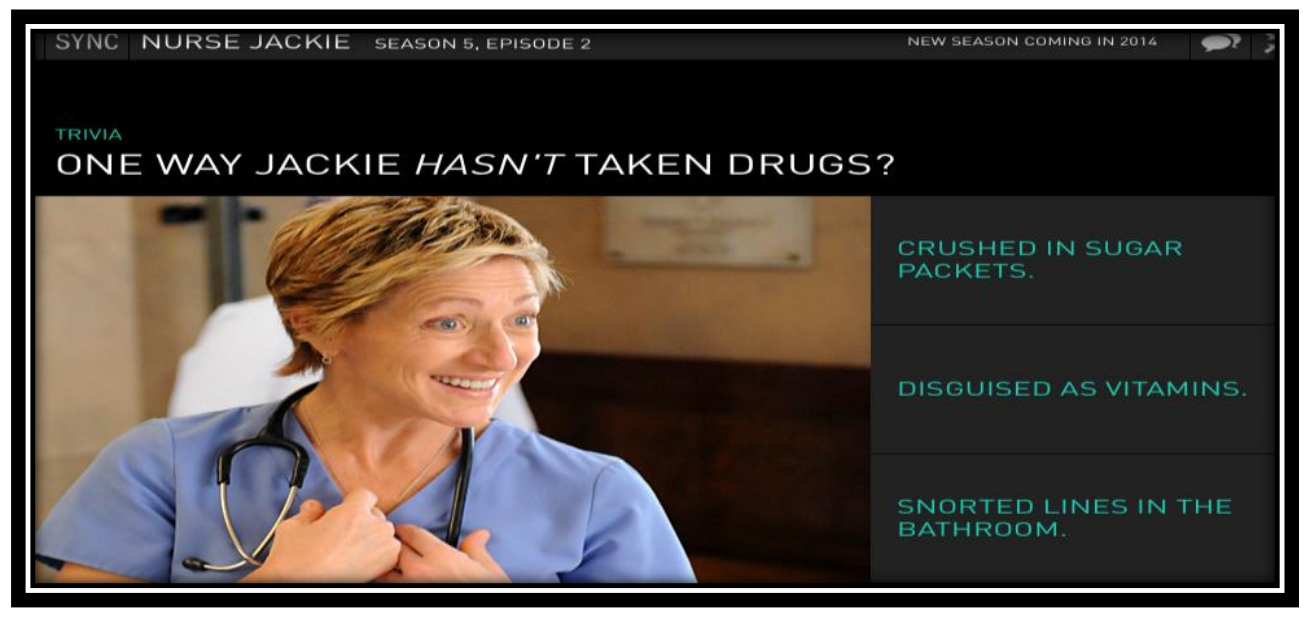

Fig. 17: Showtime Sync for Nurse Jackie's "Luck of the Drawing"

For example, above is an image from syncing an episode of Nurse Jackie, which features the lead's addiction to pain pills. What we may have is simply a matter of difference in genre. With comedy, the characters' mistakes, for good or ill, receive more attention than their moments of leadership since the audience expects to follow the plight of a funny, yet struggling lead character. Even in the shot above, we see the actress Edie Falco grinning despite the messages of drug addiction surrounding her on the sync app's trivia question. Nevertheless, we are not asked, at least through the syncing app, to identify

the option of live viewing to accompany it. Still, I use this example to illustrate a point that I argue is worth exploring about gender and identification. 
with Jackie in the manner we are asked to identify with Rick. In dramas like The Walking Dead, characters like Rick may struggle, but that struggling is set against a backdrop of apocalyptic proportions, thereby creating the illusion that women's struggles are more personal and, therefore, forgettable. Certainly more work on such shows is necessary to gain a larger sense of how Story Sync will continue to represent men and women in different ways and encourage identification with the male perspective.

It may be safe to say, however, that, in general, television narrative does not change the nature of individuals to congregate with other individuals who share their same values and backgrounds. Perspective taking, however frequently it is invoked, often returns to the normative standards of white, male, middle-class America. It is interesting to recall that when identification and understanding broke down in the cases of St. Elsewhere's Tommy and The Sopranos' Tony, we were dealing with characters who, although white, were not mainstream representatives of American culture. Tony as Italian-American mobster and Tommy as autistic working-class boy are a bit outside of the average television viewer's realm of experience. Therefore, I return again to another example of how a character--again white, male, and middle aged--caused some controversy to the identification process during a show that premiered in the spring of 2013. In this case, the audience was asked to identify with a man who could identify with others, but these others often represented the most deviant members of society.

Indeed, the process of identifying with a male protagonist is sometimes more difficult than just imagining oneself as the leader of a group. Bryan Fuller, showrunner of Hannibal, based his entire vision for the show on the process of a man trying to see the visions of criminals so that he might retrace their steps and fully comprehend their 
motivations before they murdered again. This character did more than assemble clues and imagine possibilities. He could actually reconfigure the violent moments prior to killings and position himself bodily and emotionally in the minds of those who had committed the acts. As many expected, this procedure did not always translate well to the screen, nor was it without some controversy (a station in Utah refused to air Hannibal due to its violent imagery, most of which occurs through the character's mind). Therefore, the NBC network provided a document associated with the release of Hannibal that allowed audiences to "sync" their experience with the script writers so that they could understand the nature of why violent acts were being portrayed in the manner that they appeared onscreen. NBC released the actual script from the pilot episode--including actual photographs from the show, set design renderings, and lists of props--that could be downloaded and reviewed by viewers in their own homes. Much like a teacher who provides a script for students who are required to learn Shakespeare, those at NBC wanted their audience not only to watch but to study the execution of the protagonist's violent thoughts as they were brought to life. While this act of making the script available is not the same as making a concrete app that guides and directs a person's viewing (although there was an app available for this show in international markets), the decision to let the public read it is surely tied to processes of "syncing." If viewers needed help understanding creative decisions made in the pilot, which was beautifully but bizarrely shot in most parts and highly subjective due to being immersed in the protagonist's thoughts, they could read along while watching the pilot a second time.

Again, the character at the heart of the narrative is not too different from St. Elsewhere's Tommy, not because he is autistic but because his methods of thinking 
border on neuroatypical, or divergent from expected brain patterns and responses to stimuli. In the opening sequences, the script's notes explain how this character, an FBI profiler named Will Graham, positions himself inside the body of another person, in this case a killer, so that he might reconstruct the events of a gruesome death scene:

Will Graham takes a breath, exhales, then closes his eyes.

\section{A PENDULUM}

It swings in the darkness of Will Graham's mind, keeping rhythm with his heart beat. FWUM. FWUM. FWUM.

\section{ON WILL GRAHAM}

His eyes are closed. The PENDULUM is now outside his head. It swings behind Will, wiping away in its wake the gush of arterial spray from the wall. FWUM. The PENDULUM swings on the other side of the window, wiping away the OFFICERS and POLICE CARS in front of the house. FWUM. The PENDULUM swings across the stained carpet lifting the blood. FWUM. The PENDULUM swings across the blood spattered SECURITY KEY PAD and the rustcolored dried drops vanish. FWUM.

(NOTE: The PENDULUM is a stylistic device, our REVERSE METRONOME rewinding Will to a TIME BEFORE THE MURDERS.)

The crime scene has now been decriminalized in Will's mind.

Will Graham opens his eyes and stands, turns and walks BACKWARDS toward the front door (which shows signs of a violent forced entry), opening it behind him, backstepping outside before closing it again. CAMERA REVEALS THE DOOR IS NOW PRISTINE, PRE-FORCED ENTRY. (Fuller 2)

Despite all good intentions to make the pilot accessible to viewers, we might imagine how viewers could miss the presence of the "fwum" or swishing noise and how it was meant to act as representative of Will's circulatory system. Because the auditory imagery of the circulatory system is unfamiliar, some who watch the show might be content to tune out the sounds accompanying this particular scene. This syncing document leads them to understand in a more informed way how the artistic vision of this show was realized. Likewise, it might be difficult to recognize that the pendulum was acting as a time-keeping device. It seemed that Bryan Fuller, the writer, was doing his best to enact a 
form of prosopopoiea (in imagining ourselves as Will) that could be translated to viewers, but that translation had been a bit hard to digest in light of all the stimuli the opening shots revealed. This decision to make the script a PDF accessible to all viewers encourages them to "re-watch" and revisit the details they might have previously misinterpreted or missed altogether. This situation is unique because it builds on the idea of multiple viewings rather than the premise that live viewing is the only way to enjoy second screen applications or materials. The script, like the materials in a student's notebook at school, could be read and studied so that a viewer could gain expertise in the area of production and point of view.

Finally, this person making procedure, one that Fuller describes happening in Will's mind, is not too different from the procedure of a viewer trying to sync her/his own vision with Will's mind as the pilot progresses. While Will is trying to imagine what it is like to be someone else, we are imagining what it is like to be Will. The pendulum, lights, and noise are supposed to help us do this. Here we see embodiment of point of view as something that does not exist in terms of decision making but in terms of being able to reconstruct the totality of another's imagination. Indeed, the show focuses on how indulging in this much "syncing" with another person is actually incredibly traumatic for the protagonist. Not surprisingly, the characters describe Will as having "pure empathy," a word I mentioned earlier as being sometimes associated with pain and retroactive methods of feeling another's suffering. This pilot episode actually demonstrated how the idea of seeing something and saying something could go too far.

What the pilot does achieve, I argue, is another highly sophisticated procedural approach to what it means to shift perspectives, and the supporting documents that guide 
our syncing or understanding further illustrate the importance of perspective shifting to the artists and creators. In some of today's most current programs on television, the rhetoric of what it means to see and see well continues to permeate the design of narrative and help us reconsider how we address the skills of observation and perspective taking in civic discourse. The relationship between pop culture narrative and methods of learning or acquiring knowledge act symbiotically to produce a viewing public that is prepared to "say something"--and say something well—when they "see something."

\section{Syncing in the Future}

The details associated with how our eyes see, and how we read and write as a result of what they see, is a part of the learning process that continues to fascinate scholars. Like syncing applications that seem to point us toward a specific way of watching, new technologies described by Chris Anson and Robert A. Schwegler are available that may help us physically study the act of seeing and "create more accurate maps of what we look at while working with text" (153). Anson and Schwegler suggest that if we learn, through using eye tracking software, how college students "see" text and respond to it, we might be able to study "the processes students use to read and examine source work and what they do with that material in their own writing" (166). While such studies would be illuminating, I cannot help but thinking that attempting to concretize the acts of reading and writing into procedures could easily lead to attempts to control such processes.

I will speak in more detail about pedagogical implications of the syncing mechanism in my final chapter. For now, I will conclude by saying that even when observation or syncing leads us to identify with those most like us instead of those who 
are different, critiquing our alliances with characters challenges us to expand notions of perception and how they might be limited. Kenneth Burke has already noted in Permanence and Change that every "way of seeing is also a way of not seeing" (49). Choosing a perspective to honor often means slighting others, but I propose that finding ways to be mindful of this practice in the future may be key to being a better observer. In their chapter on "A Pedagogy of Multiliteracies," the New London Group defines the process of stepping back and analyzing dominant ideologies as "Critical Framing." In the classrooms of tomorrow, instructors will likely be helping students "denaturalize and make strange again what they have learned and mastered" (34). To engage in Critical Framing is to include the "social and cultural context of particular Designs of meaning" (35) in any given moment of discourse, written, seen, or spoken. As I state earlier, such processes may be overdone in the attempt to get students to pierce the veil of consumerism and become skeptical of all visual media. Instead of doing so, Critical Framing looks at the context of a given rhetoric and explores the impact of culture on meaning. By examining how we "sync" our perspectives with a television audience through applications for mobile devices, we have a place to start such conversations about identity portrayal among characters. As we look at how characters become the focus of identification exercises, we may, in time, see how such practices could apply to our encounters with narrative.

When we trust that what we see and say are valuable contributions to the transmission of narrative, we "join the conversation" that producers design for us, and we do our best to make it our own. In today's world, the conversation surrounding perspective taking continues to build momentum both inside and outside formal learning 
environments. In the next chapter I demonstrate that the momentum stems not only from syncing our viewing interpretation with others but also from the ability to converse with others in rapid dialogue that is often choreographed but not fully controlled by producers. I will show how "join the conversation" as a directive encourages viewers to write, and write often, during the broadcast of a television narrative. For example, the presence of "trending topics" on microblogging sites like Twitter opens up more possibilities for viewer discussion to occur "live" during a broadcast. To be specific, what the producers do in order to ensure viewer engagement is to provide writing prompts and organizational strategies through which to establish and maintain constant dialogue on a live feed. This dialogue ensures that the hour we spend syncing may also be supplemented by rapid discussion during which we verify that members of the viewing community identify just as readily with characters and ideas from the fictional world as we do.

Identification as a tool of persuasion becomes a gateway through which we consider other perspectives with more attention and imagination. New media creations like the syncing application help us in this process. Through aligning our positions with fictional characters, we experiment with ways of seeing the world that may often resemble our own, but perspective taking as an active, creative process may influence us to move slightly beyond what is comfortable into a less stable or recognizable world of ideas: the world of fiction. 
CHAPTER THREE

\section{FOLLOWING THE LEADER: CHOREOGRAPHING CONSENSUS AND CONVERSATION IN LIVE TWEETING}

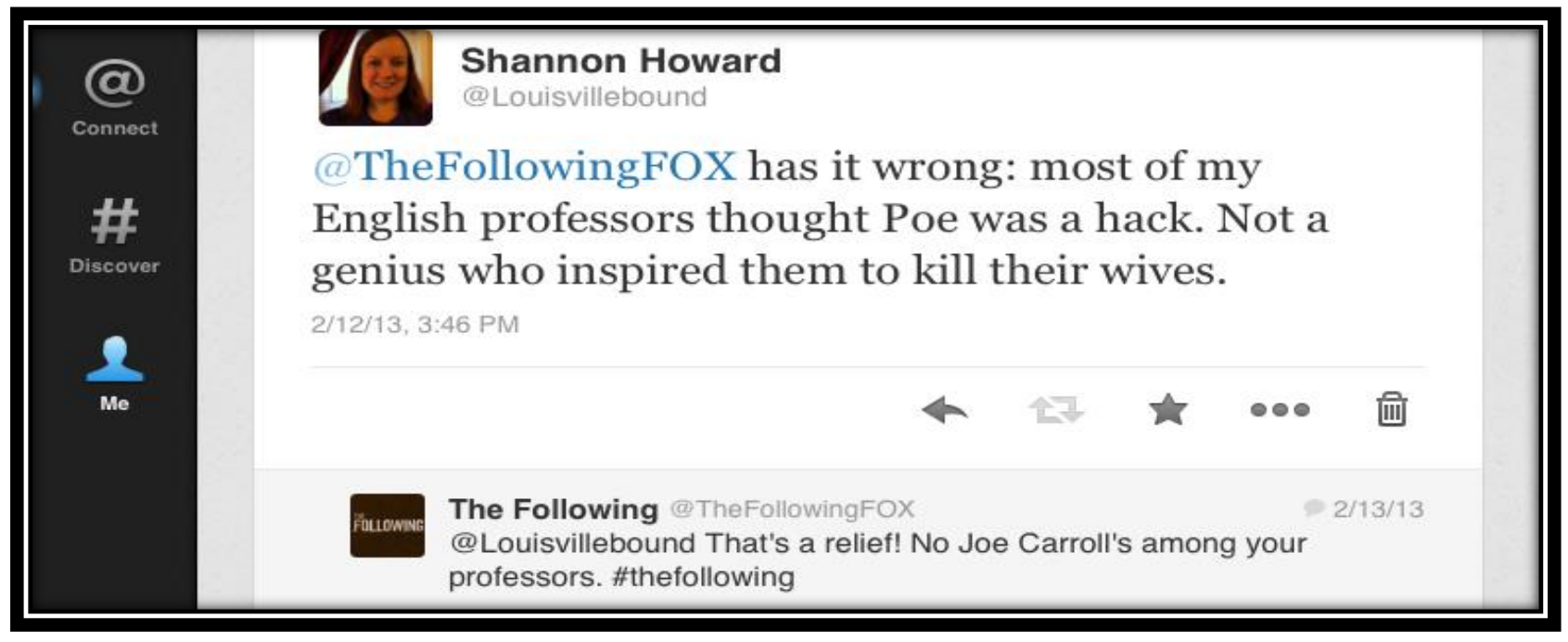

Fig. 18: My conversation with producers from Fox Television

This past spring my dislike of Fox Television's drama The Following led me to post a tweet about how silly I thought the show's focus on Edgar Allan Poe was in the context of the plot. In this narrative the villain is an English professor who is inspired to kill based on the works of Poe. When I posted these words on the microblogging website Twitter-“'Sorry @TheFollowingFOX, English professors think Poe is a hack, not an inspiration for serial killers"--it was a only a matter of hours before I saw a response. The Fox Television writer or member of the production team wrote back, "Good! No Joe Carrolls among your professors!” 
They mention Joe Carroll, the villain or killer in The Following, in order to remind me that while I am a critic of what they do, I still share the same references and participate in the same world by responding to the characterization of the show's villain. They also follow the statement with their show title and a hashtag (or label) that promotes their show. Like the act of ordering a "grande" at Starbucks and using their terminology to describe my coffee, I cannot escape using the characters and the fictional world in which they have been introduced to make my point. More frustratingly, I become complicit in encouraging the language and conversation around The Following to return to academia, where most of their plot strands revolved in their first season. Viewers from the world of academia would have easily found the portrayal of Joe incredibly disturbing. As an ex-professor of English, serial killer Joe used Edgar Allan Poe as inspiration to start his own cult of young followers and to perpetrate a subculture of violence toward women. His lack of morals or common sense once again thrusts the humanities scholar into a position to be mocked. By giving the @ theFollowingFOX a chance to remark on the professors at my school, I have allowed them to remind my own followers and their followers how important Joe Carroll as a character has become to our thinking.

Of course, this simple interchange can and will be dismissed by most. Perhaps it does not indoctrinate me into a narrative as much as it reminds me that my use of @ theFollowingFOX handle (account name) remains under some form of surveillance. However, while it is easy to see this tweeted response as humble and friendly, a power differential still exists between the Fox writer and me. To be specific, I will never know the author of the words or the face associated with the account "TheFollowingFOX", but 
they or s/he know(s) my name, my picture, and my city of residence. ${ }^{19}$ Our relationship remains one where their observation signals a continual watch over those interested in their program, but the one doing the watching may remain essentially anonymous. I will be telling them where I live, while their location and identity remain hidden. More importantly, while the media enables the possibility of response, it remains true that any response invariably follows certain guidelines. These new forms of transmedia and the producers behind them, I would argue, choreograph viewer involvement in such a way that they promote certain, preferred conversations about the fictional world.

I mention in Chapter Two that one of the oldest forms of "syncing" is the live conversation section on the apps. I also explained how some apps mainly consist of the live tweeting option, occasionally supplemented by trivia or fan quizzes. The idea of "live tweeting" a television show has become more and more prevalent during today's broadcasts. Turn on any channel at random, and often you will see a phrase or word at the corner of the television. That phrase will have a hashtag designating how to "join the conversation" online with other fans who are watching at the same time. Other viewers, as I've mentioned, may discover how to "join the conversation" by following instructions on their syncing applications.

By asking fans to tweet, producers are instructing them to sign into Twitter, enter a reaction or thought about the show in 140 characters, and then post this statement publicly. The statement, if truly part of the discussion, will include what is called a "hashtag": a simple phrase or promotional statement associated with the show's themes

\footnotetext{
${ }^{19}$ It is important to note, however, that one can have a Twitter account where such details are hidden. I reveal these matters by choice. However, Twitter is a medium where many users opt to use their real names and personal information for professional networking purposes.
} 
or plots. For some narratives, the hashtag consists simply of the show's title (e. g. \#thefollowing). Other producers prompt viewers to use an inside joke that only those invested in the narrative will truly understand. For example, Hannibal's writers/producers establish hashtag phrases like "\#eattherude" and "\#feedyourfear" as an homage to the show's most infamous character, who is a cannibal. If enough people use a certain hashtag, the phrase then becomes a potential "trending" topic regionally, nationally, or even internationally. Twitter users need only glance to the left of their computer or tablet screen to see the trends of the hour updated almost every few minutes (Facebook began to add trending topics to its own feed in early 2014, perhaps due to Twitter's success in this area).

Those who "join the conversation" often share their love for the fictional world they are enjoying at the time; in other words, such feeds usually consist of praise for the creators, writers, and actors in the given program. When we invest in a fictional world we enjoy, we join other viewers in talking about and appreciating the plot and characters we all share in common. Sharing things in common with a large group can bring people closer together. It can also, accidentally and sometimes purposefully, hinder the individual expression of conflicting ideas. It is not that radical to imagine that enjoying narrative through live feed participation often leads to consensus. By looking at the live dialogue occurring online among viewers, particularly on Twitter, I wish to pose these questions: How do producers and showrunners foster a spirit of consensus among viewers and fans? In what ways do these live feeds take on meanings of their own once transmitted virally on the Internet? 
In this chapter I consider the rhetorical strategies used by different groups to establish consensus and govern dialogue among viewers as they interact online. The blogging and commenting of viewers that signals their membership to a certain viewing community is a direct product of how they wish to identify themselves as fans and would-be proprietors of a fictional world. Statements they make about the show are persuasive: they often beg others to watch if the ratings are low, they register shock and anger at a cliffhanger and hope others feel the same, or they praise an element of the narrative that others may then choose to forward. Strategies employed by producers of live feeds suggest that viewers should follow their lead, but audience members do have ways of establishing their own version of consensus and serving as models to the very producers and writers who govern circulation of transmedia. Unlike the syncing applications, participation in the live feed involves more reciprocity between viewers and those in control of the franchise.

I have already argued in Chapter Two that viewers of narrative find that while producers encourage them to take part in participatory enterprises like a live feed on Twitter or answer quiz questions via mobile application, they are experiencing a preferred reading of the text they see on television. This is not to say that such contact is always insidious or treacherous. Talking about narrative now, depending on where we post or publish, establishes dialogue among not only other audience members, but potentially the creators, writers, and actors of a given narrative world. A narrative twist in a TV show, one lasting only seconds, may grant an instant opportunity to post a reaction witty enough to be reposted or retweeted by hundreds of other viewers or even the producers themselves. Our interchanges convince us, for a moment, that big-time money 
makers behind franchises are interested in cultivating relationships with the average viewer. This process is what Justin Hodgson has described previously in the journal Enculturation as a world of "interactive spectacle." Hodgson says that one of the differences between small and big screen cultures is the amount of control producers exercise over the big screen, while viewers have more creative freedom over the small one often used on tablets or laptops (he is talking mainly about YouTube), but I would disagree, and argue that we are seeing just as much producer involvement with small screens, particularly mobile and tablet devices designed to act as supplements to the main narrative on television. These producers foster consensus among viewers by encouraging their audience to join the conversation, engage in reciprocity, and invoke a common code of "token" meanings.

\section{Conversation and Consensus in Writing Groups and Communities}

Most of what is happening in live feeds is the improvisational and organic flow of words and meanings among strangers and people in different positions of power. At this point, before analyzing more data from the world of live feeds, I review and reflect upon the work of scholars who have wrestled with the idea of the writer's agency as it exists within collaborative groups both online and off, particularly in fan communities and in the college writing classroom. As early as 1992, Henry Jenkins asserted that "heated disagreements" over any one television character or episode in group forums or discussion boards are "rare," that a "high degree of consensus shapes fan reception" (Textual 95). The typical response to naysayers or, as some call them, "hate watchers," is to suggest that they not join the conversation at all. It is common to hear a user on a given website or forum simply say, “If you don't like [this show/story], why are you even on 
here?" Today's fan communities themselves train their newcomers carefully to follow the often unwritten rules of discourse that are perpetuated in online conversations about a given fictional world.

While not specifically writing about fan communities of narrative, Julia Davies in "Hello Newbie" addresses this point when she describes how members of a Wiccan community online are enculturated into specific ways of conversing that honor the principles of their lifestyle. She says that the "coherence and cohesiveness" of the online writing group is characterized by "the repeated citation of the same names across many guest books; the way they vote for associated sites in various online polls; their listing of links to each other's sites on their home pages; as well as their referencing of each other's contributions to discussion boards" (217). Rhiannon Bury also detailed the public and private correspondence occurring among women who formed and maintained the David Duchovny Estrogen Brigade, a group that splintered off from the more male-centered discussions of the show The X-Files and sought to make a cyberspace where women would feel welcome not only to discuss Duchovny but to debate more serious topics. In her project she notes that women, while open to one another's thoughts and interested in debating the major plot and character points of shows they love, also seek a certain consensus when interacting online. Because they are afraid of appearing as mere "fangirls" instead of serious writers, they often judge one another quite strictly on how well their fan fiction adheres to the world of canon and to standard English (Bury 41). Likewise, in her presentation at the Thomas R. Watson Conference on Rhetoric and Composition in 2010, Emily Hooper discussed how members of an online Lost forum became so protective of their favorite show and the conversations generated by its 
content that they often found ways to silence naysayers who wished to converse about the plot's weaknesses. Sometimes the response was simply to shun or ignore the online poster's contributions to the discussion. Most active users on the forum knew that the appropriate presentation of self includes the use of a Lost-themed avatar, screen shots to illustrate the details they reference, and the nod to inquiry, or the posing of a question at the end of their post to signal an interest in conversation. Above all, an appreciation for the show's plot and characters was expected throughout the display of these discursive moves.

In classroom settings, scholars have frequently wrestled with how to keep the acts of writing and conversation free from the specter of uncritical consensus. Kenneth Bruffee explains how collaborative learning, or small group work, grew out of a concern that students were not willing to ask for help in order to adjust to the standards of the college classroom. Loosely defined, Bruffee describes the consequential implementation of group writing as "a form of indirect teaching in which the teacher sets the problem and organizes students to work it out collaboratively" (398). Within these groups, Bruffee says that students acquire the "normal discourse" of the university, or "the basic qualification for acceptance into that community" (404). The most important byproduct of this activity is the conversation that occurs among members of small groups of learners.

But as this group writes and learns together, it grows more difficult for members to play devil's advocate with one another, just as it becomes difficult for online writers to express discontent or dissensus in the discussion forum for a given television show. It also becomes more difficult for writers to think outside the academic standards that they 
are encouraged to embrace, just as it might become difficult for someone to write and/or oppose a producer's vision of narrative. Most groups operate under the umbrella of agreement and groupthink that may stifle the progress of learning. Bruffee does caution that it is important to "teach the use of these tools [of normal discourse] in such a way so that students can set them aside, if only momentarily, for the purpose of generating new knowledge, for the purpose, that is, of reconstituting knowledge communities in more satisfactory ways" (410). In other words, we may wish to embrace "abnormal" discourse at times because we see consensus as the enemy of reconstituting knowledge and creating a dynamic community (410). Likewise, John Trimbur, responding to the ideas of Bruffee, works through the notion of consensus by explaining that it can be "a powerful instrument for students to generate differences, to identify the systems of authority that organize these differences, and to transform the relations of power that determine who may speak and what counts as a meaningful statement" (442). Trimbur wishes to emphasize that consensus need not signal the end of negotiation but rather the culmination of it through the exchange of ideas. He is particularly wary of the term "abnormal" discourse as a romanticized notion of the individual rebelling against the group's way of thinking. Instead, he argues, the notion of abnormal discourse should be a way to "analyze the strategic moves by which discourse communities legitimize their own conversation by marginalizing others" (449). In this sense, Trimbur's idea of abnormal discourse contains echoes of the New London Group's concept of Critical Framing, where the idea of stepping back and considering social context of a given act of reading or writing helps students and others gain the necessary perspective on ideologies they take for granted. 
Andrew Kopp proposes that we work on helping writers see the value in exploring divergent perspectives not just as an exercise but as a way to challenge the language that gives us easy answers. That is, we recognize the consensus that surrounds us in order to move beyond it and become "tolerant of profound uncertainty and empowered to perform with invented authority within indeterminate social situations" (227). The "distanced and apathetic perspective from which we customarily regard the world," as he says (228), is an inheritance that we would do well to transcend. In this point Kopp assists me in bringing this chapter back to the idea of perspective shifting. In consensus, perspectives often sink beneath the power and conservatism of one voice strong enough to align them all to its cause. The challenge is to recognize that alignment as a point of critical inquiry and not to dismiss all social networking for what some consider its tendency to engage in banal exchanges. Within the work of consensus is the valuable lesson of how identification and role play may create, perhaps not dissensus in the face of consensus, but avenues through which to push against conservative approaches to texts.

To return again to online activity associated with narrative, I stress that consensus need not be tainted by the image of consumer dupes all acting in concord to promote a franchise without critical attention to content. Bronwyn T. Williams explains in Shimmering Literacies that one of the valuable parts of viewers joining forums in online spaces is that, as one of his chapter titles suggests, "everyone gets a say." By "everyone gets a say," he does not mean that there aren't certain standards of discourse implicit in how viewers are supposed to conduct themselves when interacting with others about the narrative. He notes that most audience members participating in discussions online often 
privilege a certain type of writerly presentation - one that shows evidence of copy editing, careful research of the show's mythology, and intertextual references to other stories in that genre of storytelling (54-57). What is fascinating, to Williams, about this sense of privilege is how closely it connects to the goals of a writing classroom, where novice writers are often reminded frequently to be aware of audience and to use persuasive evidence to support points. Of particular interest to this project is Williams's focus on the quoting and responding techniques some online posters exercise when responding to ideas about narrative. The cutting and pasting of ideas among users shows attention to citation that resembles what Twitter does in microform on its own site. When users on a forum wish to respond to someone's post they reproduce the original quote with their own idea beneath it in conversational mode. As Williams explains, "It is possible to see how knowledge from different individuals increases in value as it is combined with others' ideas as participants build their ideas from the ideas of others" (55). This reference to a collage culture of online material gestures toward the kinds of "conversation" and participation on live feeds I wish to highlight--specifically the activities of checking in, forwarding, and responding.

\section{The Tokens of Consensus: Participation through Checking In, Forwarding, and}

\section{Tagging}

To begin, the new method of "checking in" to a show, as if it were an actual geographical location, initiates consensual sharing of time and online space among viewers who have agreed to participate in the same fictional world. The application GetGlue provides this opportunity for viewers to "unlock" online stickers and badges 
when they notify their social networks that they are watching a certain episode. ${ }^{20}$ These stickers often feature an actor's head shot and the title of the episode, along with the words "You have just unlocked" accompanying the sticker's image.
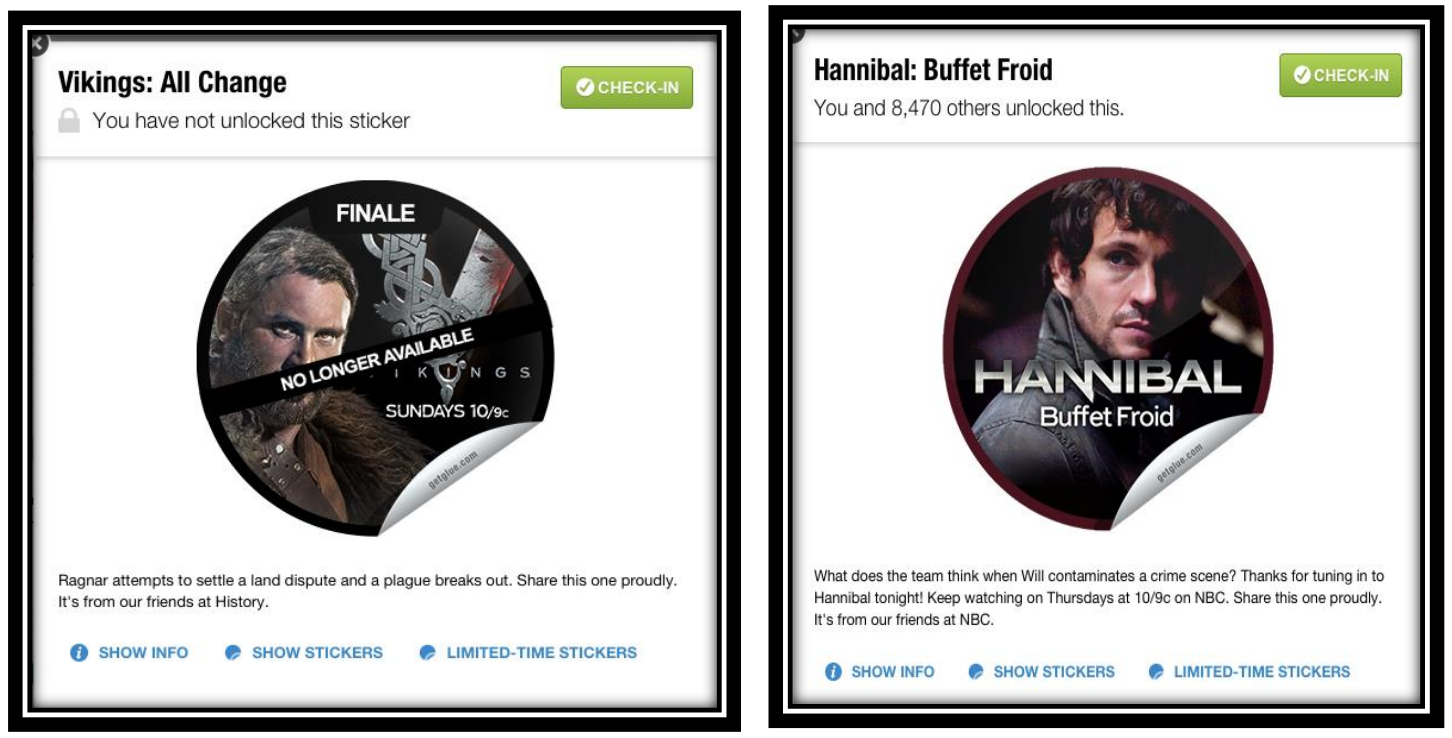

Fig. 19: Vikings Check-in Sticker

Fig 20: Hannibal Check-in Sticker

The word "unlock" reinforces the idea that to participate, one must have the right "key" to enter a privileged space. The notion of unlocking, like syncing, also connotes physical action in the place of passive consumption. Being able to "unlock" something involves the physical insertion of information or objects into a surface that is normally off limits. The number of those who have "checked in" is constantly updated, making each person aware of how large the community is growing as watching progresses. Viewers may check in before, during, or even after the show airs; this act does not always signify a live viewing. However, if a viewer waits too long or attempts to unlock the sticker prematurely, that badge of participation will not make itself available (see the Vikings sticker above, which I did not unlock before or after the show aired). This strategy on

\footnotetext{
${ }^{20}$ At I completed final edits to the defense version of this manuscript, GetGlue changed its name to tvtag.
} 
behalf of the social network GetGlue reinforces the need to engage in viewing a narrative as soon as possible, even if a person does not see the show live. By checking in, we agree that the program we are watching is worth our time, and we are proud to show that we have "unlocked" the opportunity to experience this particular fictional world. It is a form of consensus among viewers who wish to communicate that one show is preferable over others. By unlocking an episode, we are, again, "syncing" our participation with those who have proudly displayed their badges of checking in, too.

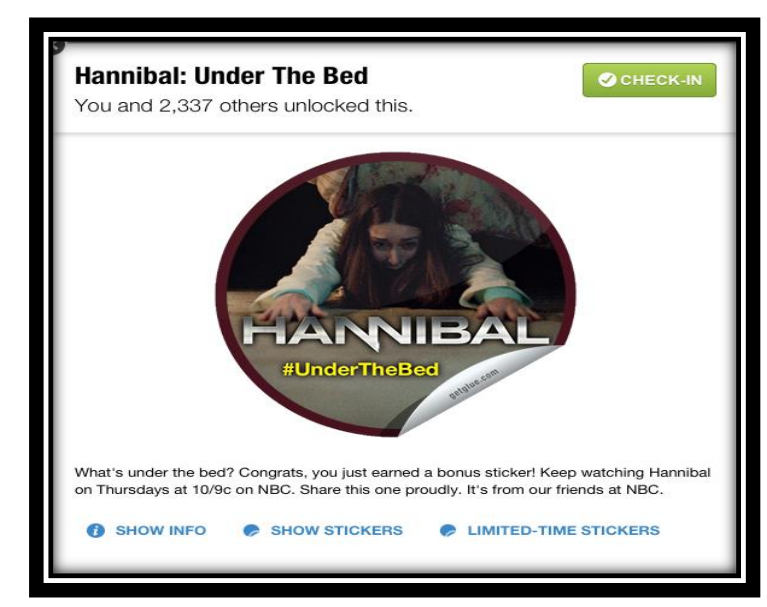

Fig 21: Bonus Hannibal Sticker

Sometimes the application allows users to unlock a bonus sticker if viewers enter the correct code when logged in to GetGlue. The code is often a hashtag associated with plot points from the current episode. In the case of this sticker below, a girl was in danger from someone hiding under her bed in an episode of Hannibal. By enter the hashtag \#underthebed, I earned an extra badge of participation. The act of unlocking a special virtual sticker may seem peculiar and banal in appearance. ${ }^{21}$ When questioning just what a sticker might accomplish rhetorically, it is easy to be dismissive and to have trouble discerning how GetGlue maintains a loyal following based on the act of earning these

\footnotetext{
${ }^{21}$ At one stage in their marketing, GetGlue would mail actual stickers to fans who collected a certain amount of virtual stickers through their given accounts. They no longer engage in this practice.
} 
virtual tokens of participation. According to Leon Mayhew, who uses the term token rather pessimistically in The New Public, "tokens" act as simulacra (Mayhew draws heavily on Baudrillard in his argument) that sometimes result in empty meaning, since by "token" we suggest that the part representing the whole loses its signification over time, the same way that an image ceases to represent something authentic in a world entirely simulated and commercialized. Mayhew's discussion of the token is grounded in a history of advertising that he traces from the nineteenth century to the present, where he says that the "dominant principle" guiding the changes throughout these years was "the rationalization of persuasion" (189). Persuasion, he argues, has become entirely "instrumental" in its presentation (190), which suggests that when practices like "checking in" occur, the sticker, or badge, we download to display our participation is one that holds little value. This idea does not surprise most of us, since we may already conclude that a virtual sticker, as a sign of fan currency, is rather silly and purposeless.

Still, stickers, these small images with no monetary value, have some form of power to communicate consensus and, even more importantly, the growth of a fan's presence in a virtual world surrounding narrative. GetGlue's tokens of involvement continue to appear in live feeds and in apps where users congregate to share what they are watching at any given time. Reasons for its popularity may vary, of course. First, the sticker renders the fictional landscape of a vast mythos shrinkable and obtainable. Also, the face on the sticker becomes a point of identification for the viewer. The placement of the image on a Facebook, Tumblr, or Twitter profile page signifies a kinship with a fictional character similar to the kinship displayed when people share photos with friends and tag their names. Finally, as I will discuss in later sections, we might take a different 
view of how an object (however virtual or small) may begin in human hands to operate in one traditional and mundane fashion but then become transformed through the unpredictable circulation of its meaning throughout the online world. The ways in which these stickers communicate allegiance with a fictional world suggest that "tokenism," while considered an intellectually bankrupt model of meaning making according to Mayhew, may require some reconsideration as a valid form of group solidarity.

This notion is not foreign to the study of creating a public. While the "check in" may initially seem too simple or mundane to represent participation, it helps to know that Michael Warner, in his famous study of the formation of publics--or gatherings of people around a similar interest, belief, activity, or location--says just "showing up" may constitute a person's membership into a community. He explains that being a part of the community does not have to indicate significant cognitive activity but just the voluntary choice to belong: "It is even possible for us to understand someone sleeping through a ballet performance as a member of that ballet's public....The act of attention in showing up is enough to create an addressable public" (88). In other words, physical presence signals the commitment to the group even when emotional and intellectual energy lags behind it. When checking in, others report to the same virtual location as we do, and the watching process transpires as a community, even if some members of that community eat dinner, fall asleep, or surf the internet while viewing the narrative. The process of identification still occurs, regardless of our actions after we download the sticker. When we check in, we see upon its surface the one fictional face representing the whole 
narrative - a face that, as a small sticker, becomes the rallying point for those who follow the story and for the world of the story, too. ${ }^{22}$

\section{Retweeting/Reblogging}

Tokenism may also take the form of reblogging or retweeting. Some producers ask their fans simply to "retweet" or "reblog" news about the show as it begins. By retweeting (reblogging) information, a user chooses to forward a message that was written by someone else. Once forwarded, the message has the potential to become viral, since the users who read it may then choose to retweet the message in turn. Bloggers on Tumblr practice this same technique, choosing to reblog favorite images and statements about the narratives they love. Often, those on Tumblr will add a reaction or statement to the things they reblog. However, on Twitter, the procedure of engaging in retweeting includes the strict limitation of space: only 140 alphabetic or symbolic characters are permitted per single post.

The act of retweeting and reblogging speaks to what Jim Ridolfo and Daniélle Nicole DeVoss in the online journal Kairos have termed "rhetorical velocity." As I explain in Chapter One, rhetorical velocity takes into account the speed at which information is exchanged and interpreted, so users or viewers at all times must make decisions about how they will present their ideas in order to predict how they might be remixed by others. This is particularly important to the process of a "live feed" that occurs during a television broadcast. Rhetorical velocity takes into account "distance, travel, speed, and time," all of which intersect with online networking practice, since a

\footnotetext{
${ }^{22}$ It is difficult to say whether the face on the sticker represents part of the "preferred reading" approach that I discussed in Chapter Two. From my experience, stickers do not necessarily indicate the specific character who will receive the most screen time in the plot. Sometimes a minor character appears on the sticker, one whose presence in the episode is not that pivotal to the narrative.
} 
tweet that originates in the United States may easily be read and retweeted by someone across the world in a matter of minutes. By considering the rhetorical velocity of something we post in Twitter, we strategize where a statement we make is going to end up. We have a future-oriented vision of our words reaching a given audience, but often the network itself acts so unpredictably that the results far exceed what we initially plan. I will discuss this idea of the network "acting" on its own in a later section of this chapter.

While producers behind these narratives may not be using the term "rhetorical velocity" to describe the process of a live feed, they do recognize the value of having messages about their programs circulate rapidly. Therefore, in many cases, they have established creative approaches to retweeting. Shows like Bates Motel and Hannibal ${ }^{23}$ employ descriptive language or puns that accompany this request: "retweet if you've made a reservation at the Bates Motel" or "retweet if you're joining us at the dinner table for Hannibal.” Like@TheFollowingFOX's references to their serial killer Joe Carroll, these phrases and terms are meant to engage the live feed participant in using the language associated with the show's narrative. The letters "RT" signal that a message has been forwarded without commentary. Some who forward tweets will also add the letters "MT," indicating consensus in the form of two letters standing for an often heartfelt "me

\footnotetext{
${ }^{23}$ Most of my examples in this chapter are drawn from Hannibal (and occasionally Bates Motel, Vikings, and Walking Dead)mainly due to scheduling purposes. At the time I was composing this chapter, the late spring of 2013, these shows were among the few on television that were still airing new episodes and, consequently, new online marketing strategies for audience participation.
} 
too."

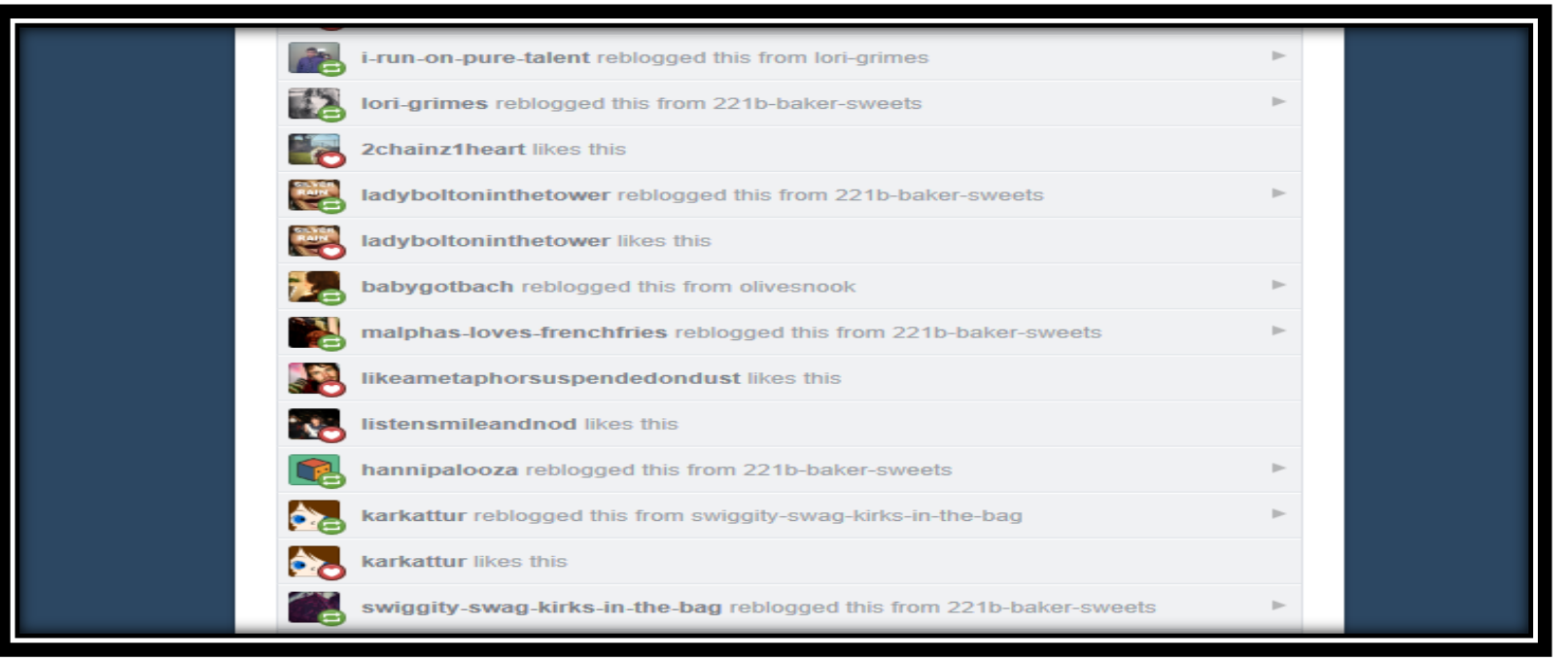

Fig. 22: Reblogging and Liking a Post on Tumblr

In live feeding on Twitter, the chain of forwarding is not clearly specified. This style is different from that found on other networks like Tumblr, a microblogging site that also features pop culture enthusiasts, perhaps even more prominently. As I have discussed previously in "Everything Old is New Again: A Barthesian Analysis of Tumblr," if we examine how fans interact on Tumblr microblogs in such live conversations, we often find genealogical listing of forwarded information below the blog entry, as seen in the above shot. Tumblr's marking of chronology and regularity of visitor comments build upon one another in vertical trees of meaning that resemble a record of users lurking or reacting to the content. Tumblr, seen as a genealogical tree of meanings connected among users, creates an image of dialogue at work, something that is often hard to see in sharp focus on another site like Twitter that truly does limit the number of characters in a post. I will discuss Tumblr more fully in Chapter Four.

Joseph Harris in Rewriting: How to Do Things with Texts describes this chain of forwarding as a rhetorical strategy that is characteristic of argumentation. I would go 
farther and say it also facilitates the building of consensus. Forwarding, according to Harris, accomplishes four actions: writers use it to illustrate, authorize, borrow, and extend. While Harris's strategies have the goal of helping students use forwarding to build their own ideas, ${ }^{24}$ my own discussion of forwarding focuses on the more literal way in which text is circulated virally. When a tweet is forwarded to others, it is literally borrowed from the original author and sent forward through a list of new users to be read. It is also a product of "authorizing," or invoking "the expertise or status of another writer to support your thinking" (39). Harris describes authorizing as a practice that is often a "straightforward and routine form of intellectual housekeeping" (44). When a viewer retweets the statement of a producer, s/he uses the producer's status to lend weight to her allegiance with the fictional world she enjoys. She also shrinks the distance between her and that producer by showing how one button, one click of a keystroke, may connect the average fan to the people in charge. This feeling of connectivity is part of the rhetorical strategy of not just watching television but getting others to invest in a narrative she prefers. But retweeting may also work in the opposite way. When a fan's message is retweeted, that viewer realizes her statement or idea is being authorized by others. For example, showrunner Bryan Fuller is consistently retweeting and forwarding links to fan art associated with his show Hannibal. By complimenting these artists and also endorsing their work to the public, viewers receive more traffic on their own pages and the affirmation of knowing they have received "official" support from those in charge of the

\footnotetext{
${ }^{24}$ I am not using Harris with the goal of applying Twitter feeds directly to classroom instruction. Instead, I use Harris and other compositionists to establish a symbiotic relationship in which new media and writing studies both inform and are informed by each other. In my concluding chapter, I will discuss how new media in the form of these apps might have implications for how we learn both inside a classroom but also outside it.
} 
narrative. In one response to a fan who wrote him and sent him artwork after the airing of the first episodes, he exclaims, "I want to hang it in my kitchen!" In another response, he simply says, "Very cool!" and retweets the work of another artist who loves his show. While not speaking about Twitter specifically in his explanation, Michael Warner characterizes this form of circulation as one of the defining characteristics of a "public": the presence of "the reflexive circulation of discourse" (90). Power is both borrowed from those in control of the narrative and also received from others in the community at any given time.

\section{Tagging as Tokenism}

A new public practice exists of using the part to represent the whole. Hashtags, or single words and/or short phrases, stand in for an entire mythos upon the event of a live airing of television narrative. Hashtags, like the stickers on GetGlue, represent not only alliance with a show but also alliance with the particular characters who would say or do things in support of this thing. To return to an early example I mentioned, the phrase "eattherude" stands in for the entirety of the Hannibal fictional world, and it also creates identification with the franchise. Like the story syncing that prompts viewers to differentiate between the tactical and moral actions of characters during a zombie apocalypse, the phrase "eattherude" suggests paying homage to a vigilante system of eliminating those in society who are considered too discourteous to live. Such circulation of the phrase or words is free advertising, but it is also a way in which fans identify one another as they seek to have conversations (more on this soon). With the tags like the “walkingdixons” representing a given episode's narrative arc, we support fictional characters like the Dixon brothers from The Walking Dead in their homosocial bonding 
as they hike the Georgia forest in search of safe refuge from zombies.

The Walking Dead AMC

@WalkingDead_AMC

\#FightTheLiving is trending! Let's keep it up!

pic.twitter.com/Hsxa4OR8HC

3/24/13, 8:38 PM

United States Trends - Change

\#MentionSomebody YouWantToMeet

\#IfIWonAMillionDollars

\#IDontPlayWhenitComes To

\#Fight Theliving

\#LiesIveToldMyParents

FGCU

Put God

Fig 23: Trending Topics on March 24, 2013: The Walking Dead hashtag "fighttheliving” Another hashtag for The Walking Dead featured the emphasis on a conflict between the characters living in different locations: \#fighttheliving. Above we see how this hashtag became a viral presence. Those who follow a trending hashtag then may have the opportunity to see how popular a given narrative world has become for viewers in living rooms all across the country. The method of live tweeting suggests an indexing system that also allows a given reader response set of thoughts to be archived and remembered.

Hashtags deal specifically with economies of information. That is, people who are reading the live feed during narratives do not have time to post or read more than 140 characters at a time without being pulled outside of the fictional world and losing track of the story they see onscreen. In this sense, Twitter remains the perfect platform for engaging with others who love the same fictional worlds. With more time permitting or with access to a "pause" button through DVR viewing, an audience member may choose to "live blog" instead of "live tweet," thereby putting a little more effort and time into the product on a site like Tumblr. However, the hashtagging system works quite differently on Tumblr, as I will discuss in more depth when I address the issue of reciprocity. Users 
tagging entries on Tumblr want to be archived and researched, but they also use tagging as a humorous writing exercise, resisting the strict classification practices of Twitter and creating a system that cannot be easily authorized or duplicated by others. Here the practice of archiving is more of a trope that may be subverted to gain attention for one's clever play on words, a parody of the source material, or a deliberate distortion of standard English practices and spellings (e. g. the hashtag of \#waterudoing as opposed to \#whatareyoudoing). Here we see more opportunities for independent interpretations of plot and character rather than guided formulas for interactions with others. Tumblr does not act simply as a platform for dissensus, since the users there are just as concerned with proper ways to garner followers and earn their respect. Still, the notion of tokens standing in for greater feelings and reactions to narrative applies.

whatifiaminsane +

Did I just gain a follower because I started tagging the stuff I reblog? Ô.o Perhaps it wasn't such a bad idea after all. Let's see how long I can keep it up $\mathrm{xD}$

\#really?? \#i mean seriously \#these are just fucking nothings \#but if you like it

Fig. 24: Tumblr Microblog Entry about Tagging and Popularity

Indeed, some Tumblr posts are remembered based on the quality of the humorously written tags, and not for the actual message contained before them. It is not entirely uncommon to see users reblog other users' tags as a way to signify how enjoyable they are to read. Above the blogger is asking if the notion of tagging has improved her popularity on Tumblr. More important, however, is her use of humor in the tags themselves. She shows how incredulous she is about the importance of adding something 
so small to the overall content of her blog. The tags in a sequential row-“"\#really? \#imeanseriously \#thesearejustfuckingnothings — represent the same disbelief a newcomer might feel after visiting Tumblr for the first time. The phrase "thesearejustfuckingnothings" echoes the notion of Mayhew's idea of the tokenism of such objects.

Yet Mayhew, for all of the assistance the word of token permits, still holds to the same belief that Baudrillard, Jameson, and others have expressed about a world saturated in symbols. Token often means something absent, empty, or meaningless in the face of the circulation surrounding it. I would counter this idea with the notion of hashtags possessing what Ian Bogost has described more positively as the referential and ontographical power of images and things. By ontography, Bogost means that we study the way something is depicted and exists outside its initial appearance and use. Known more popularly as object oriented ontology, or OOO, this branch of philosophy and rhetoric concerns itself with an appreciation (simply speaking) for objects, juxtaposed with human activity or existing separately. In accepting the views of OOO, we acknowledge that our human point of view may only accomplish so much in the face of how things exist in the world. One way he explains ontography, which is closely related as a term to ontology, is to say that ontography is sometimes the oppositional force to minimalist art. Things multiply and become infinite, sometimes in strikingly "inefficient ways" (59). Lists are a major example of how objects and words bump up against one another to cause some chaos. In a live feed of postings on Twitter or Tumblr, different statements and ideas consistently bump up against one another in chronological but, otherwise, somewhat haphazard order. 
While it may seem that I am adding a different lens to my study of these digital platforms, the ideas of object oriented rhetoric and procedural rhetoric are connected in important ways. Both exist under the same philosophical and epistemological umbrella. The study of processes and the study of objects in networks and in circulation both inform and are informed by each another. The idea is to explore a circulatory system that, through metamorphosis and transformative states, comes to represent more than just a product or an originary motive from the human mind. This system supports both linear and disruptive journeys through meaning. Through process we consider that things operate partially due to human intervention but also partially through combinations and juxtapositions of moving parts that cannot always be predicted. See the screen shot below, featuring one user's humorous post of her own dashboard on Tumblr:

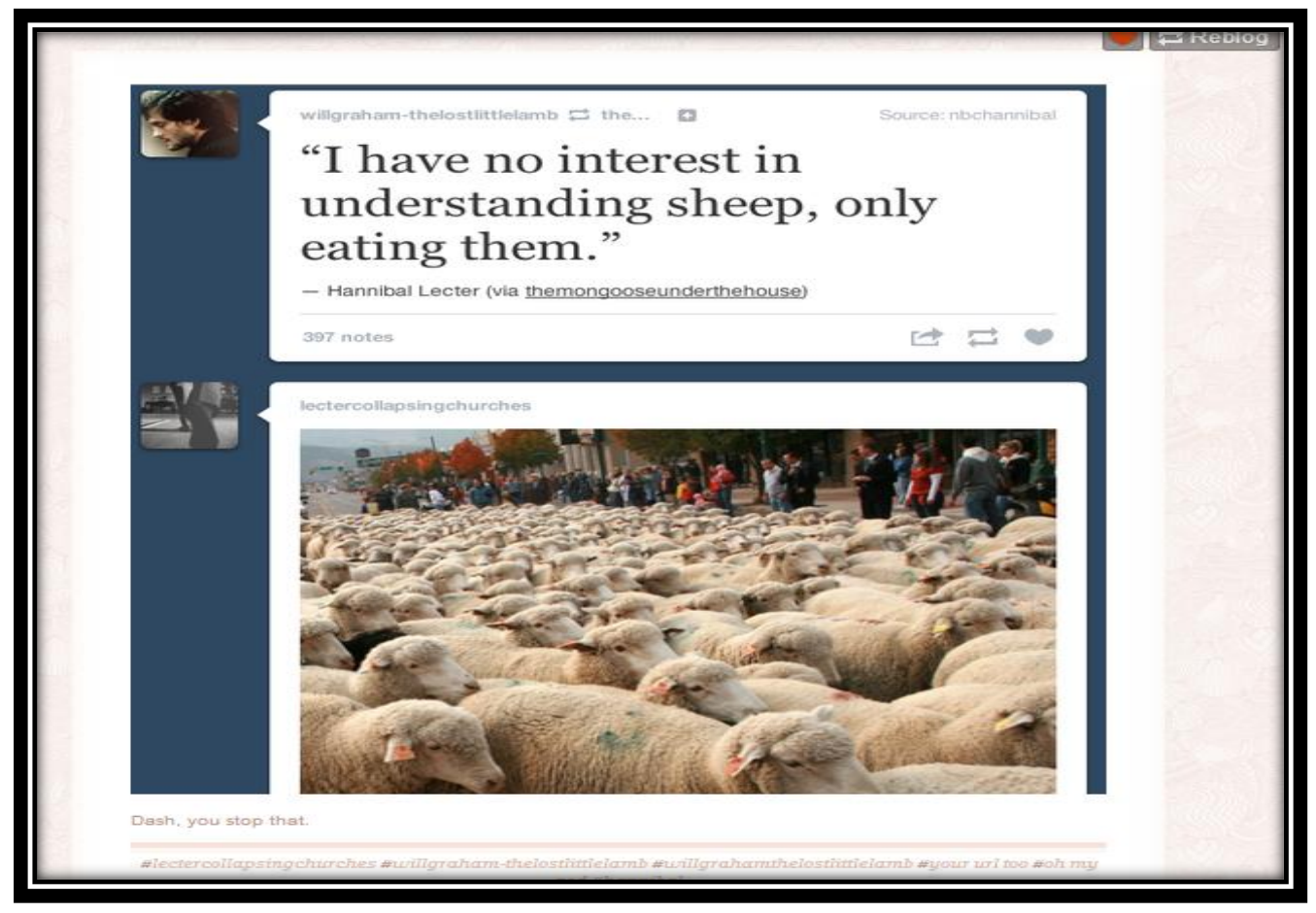

Fig. 25: "Dash, you stop that," by thehobbesgirl after two entries create a parody on her feed. 
Like Facebook, Tumblr consists of a news feed in which all recent blog posts appear in a vertical scrolling dashboard of information and images. The blogger above takes a snapshot of how her dash features two authors' separate blog posts, which, when immediately following each other on the screen, act as parody. The role player here called "thehobbesgirl" (more on role play in Tumblr in Chapter Four) sees humor in how her dashboard places one user's reference to a line from the television show Hannibal just above the pictorial representation of the same moment in the live airing of the narrative. She speaks to the dashboard feed as if it is sentient rather than part of an online social network by saying, "Dash, you stop that." What I wish to stress in this picture is that while we may as humans control what we post on our individual pages, the process of archiving these posts in a news feed, according to a specific order we control, is not always possible and, therefore, lends itself to unpredictable and enjoyable juxtapositions of writing and imagery. Although humans developed this system and the algorithms behind it, the ultimate result is surprising to "thehobbesgirl," providing humor in the midst of a dark narrative moment about cannibalism and humankind's resemblance to a herd of animals.

It is important to note that "thehobbesgirl" is part of a fandom, and the blogs she follows post writing and imagery connected to the show she enjoys. The sheep and the line from the television drama both originate from the same master narrative- the post with a picture of sheep is from "lectercollapsingchurches" (another nod to the character), and the other post originates from "willgrahamthelostlittlelamb" (same franchise). Therefore, the juxtaposition that the blogger notes in her screen shot is not as unpredictable or unexpected as we might initially observe. Still, the way that these texts 
bump up against one another in ways that we do not plan informs the way we see writing develop in our contemporary world. Such compositions are often motivated by a common love for story but remain products of an aleatory system.

If we look at the hashtags on Tumblr, we may reconceptualize the humorous listing of expressions and words as an example of OOO, where labels have started to possess a life force all of their own, as they are passed virally from user to user. I would stress that the directive to "join the conversation" holds value due to this reconsideration of the token, which includes a more creative and inspirational way to conceive of how small units of meaning may possess universes of possible iterations and circulatory power when reblogged or forwarded. In this sense, the words that producers ask us to use may be instructing us to converse in a preferred way that shows our mutual appreciation and love for the narrative, but the way we combine and arrange these terms creates something that could be considered new and generative instead of simply a "new rhetoric of presentation, featuring hyperinflated rhetorical tokens" that "inhabit distintegrating social worlds" (Mayhew 282). ${ }^{25}$

\section{Creating Consensus through Joining the Conversation}

However, if we consider hashtags and Twitter exchanges as objects that offer infinite possibilities, then the idea of conversation may seem a bit disorienting. While OOO focuses on the potential of non-human units to create new and surprising connections, conversation as we call it is usually a mark of human enterprise.

\footnotetext{
${ }^{25}$ I should clarify that while Mayhew is chiefly concerned with advertisers in his argument, I find his work applicable here because the use of hashtags in television marketing is now a common trend, and the directive to "join the conversation" is an extension of the kind of promotional activities he discusses in The New Public.
} 
Conversation typically refers to an oral phenomenon, one that is often ephemeral and improvisational in its design.

But when the word is used to describe writing practices, sophistication and purpose enter into the act of dialogic communication, and the notion of "fitting in" becomes more integral to participation. Scholars have long used the term conversation to connote membership within a small community of experts in a given field, or the people contributing to an ongoing body of information about the epistemological nature of a given topic or subject. To put it plainly, the term in academia is often associated with status. By using conversation to describe the ability to lend one's voice to a certain group, the word still acts metaphorically and also serves as a gatekeeping term that distinguishes those capable of adding to the discourse and those who are not ready to do so.

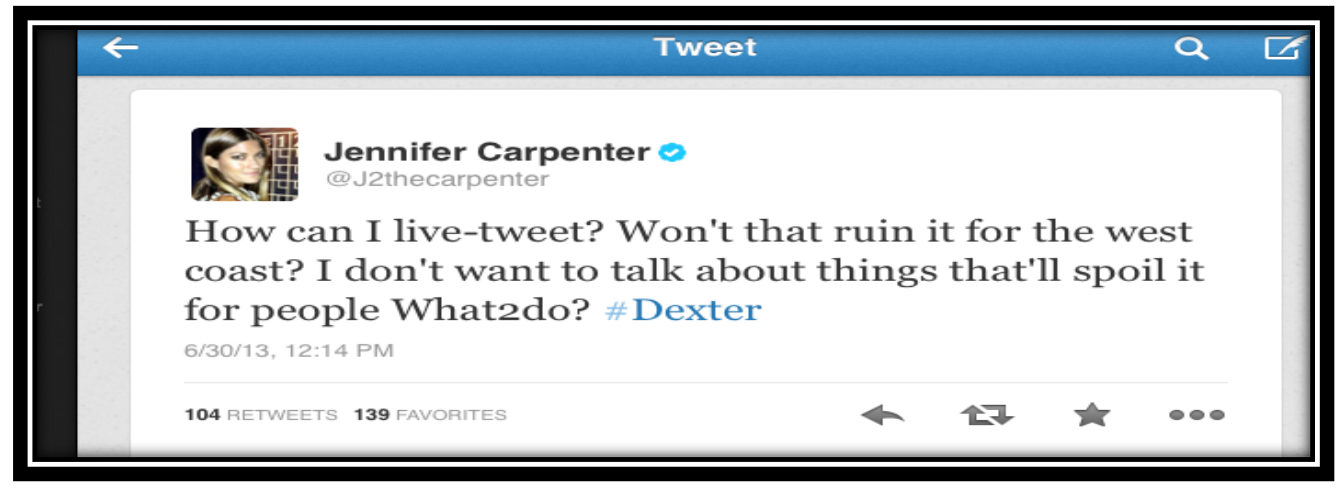

Fig. 26: Actress Jennifer Carpenter's Query about Live Tweeting

Even in the world of digital conversation, certain rules govern discourses surrounding pop culture and narrative. Above is an example of how a lead actress on Showtime's Dexter worried that her participation in the live tweeting conversation might be disruptive or conducted in a way that is inappropriate. 


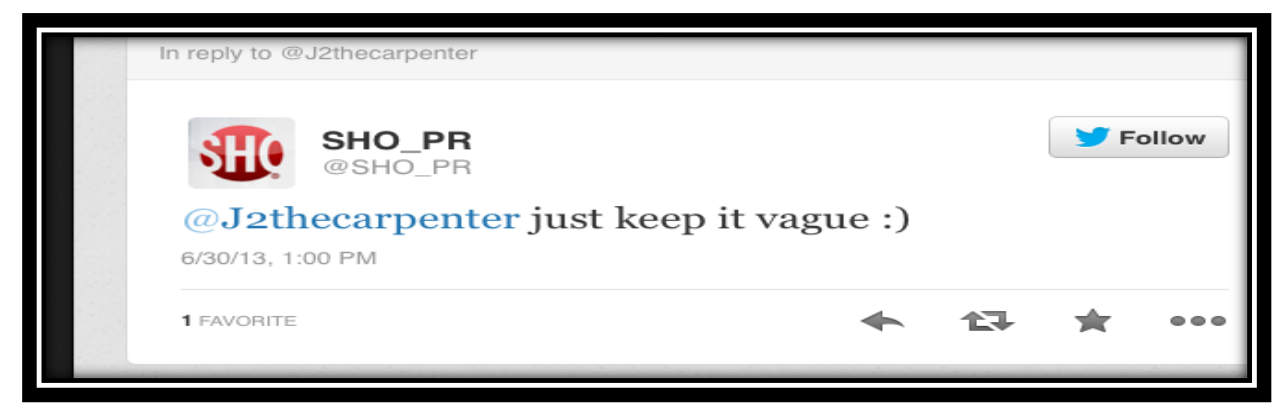

Fig. 27: Showtime's Response to Carpenter

As the conversation among Carpenter's fans continued, Showtime's Communication Team actually responded to her question via their own tweet with advice on how to proceed once the show aired. In this sense, the communications writer here advises Carpenter to participate but to avoid specific events or character references that might spoil the episode for those watching on a later time slot. As they illustrate above, the conversation has specific guidelines and practices that ensure everyone's narrative experience is positive and respectful. What Carpenter illustrates in her interchange with Showtime is the practice of what Kenneth Burke refers to in his famous parlor analogy as waiting to join the conversation before putting one's "oar" into the flow of dialogue. In The Philosophy of Literary Form, he describes the scene of dramatic action and dialogue in these oft-cited words:

Imagine that you enter a parlor. You come late. When you arrive, others have long preceded you, and they are engaged in a heated discussion, a discussion too heated for them to pause and tell you exactly what it is about. In fact, the discussion had already begun long before any of them got there. ... (110)

The situation with Carpenter differs somewhat because the Showtime team does pause long enough to instruct her in how to "live tweet" the premiere of the show. Nevertheless, 
by asking and waiting first, she shows respect to those fans who began conversing and tweeting long before she joined their conversation online. By waiting to live tweet rather than boisterously cluttering the Twitter feed with spoilers, Carpenter proves that she is not only a loved actress but a respected member of the online community as well.

These comments from scholars and from Showtime are not far removed from the sentiments behind building affinity groups ${ }^{26}$ among fans online. To be a good communicator, a "newbie" on a live feed or forum will often wait to "put his or her oar in" and gather some information about how status is conveyed on those already on the inside. The difference is that producer-run affinity groups want to increase their numbers and let as many members into the group as possible. In most cases, their main concern is increasing the viewership, not judging the capability of each fan to prove his/her worth as a conversationalist. But the producers do encourage a certain form of fan activity, one that often involves its own vocabulary terms, inside jokes, and specific topics for discussion. James Paul Gee explains how affinity groups work in what he calls "new capitalism":

The business creates (or socially engineers) certain practices that ensure that employees or customers gain certain experiences, and that they behave and value in certain ways.Many companies today—for instance, the company that makes the Saturn car-create activities around which their customers come together as an affinity group (proud owners of Saturns). These people attend social gatherings across the country (e.g.

\footnotetext{
${ }^{26}$ Another popular way to refer to these kinds of gatherings is to call them communities. Yet the word affinity group has been helpful for many scholars because it allows people to think of the group as less homogeneous. To some, the term community suggests that individuals within share the same socioeconomic backgrounds and ethnic roots.
} 
club meetings, Internet chats) that create an allegiance to each other as coparticipants in these practices. (107)

This notion of a co-allegiance through such practices is key to how consensus is built and is the foundation for creating avenues through which everyone feels able to enter the conversation. Agreement in conversation is the typical stance for most people in an affinity group of this kind. This is why it is common to see producers label their fans with an affectionate, all-inclusive label to signify their interest in a given world. In the case of Bryan Fuller and his producers, the term Fannibal was used to constitute the world of fan activity surrounding Hannibal. It is here we experience what Kenneth Burke might call "ethical confusion," since this form of participation leads us to "find our own patterns of thought in the texture of events outside us" (214). In other words we participate in a world that reflects what we love and wish to discuss, and the rest of reality begins to fade as we return, again and again, to a discourse that supports our favorite things and narratives. We look for our "external counterparts" (215) or fellow viewers/fans to support our allegiance to a certain fictional world, just as the car owner years ago had seen her/himself in the Saturn lifestyle and in its social extensions. ${ }^{27}$

But Richard Rorty, upon whom Bruffee and Trimbur rely in their scholarship, does make a more optimistic point about the role of consensus in conversation. He explains that the "notion of culture as a conversation rather than as a structure erected upon foundations" creates an alternate paradigm from consensus building and group think, as strangers come together to learn from one another and recognize that they must interpret what the other has to say based on each individual's frame of reference, which

\footnotetext{
${ }^{27}$ At the time that James Paul Gee wrote this article, Saturn was a relatively new car company, set on establishing new traditions for car ownership. In 2009, Saturn's dealerships closed.
} 
can never be wholly deconstructed (Rorty 319). This is where the practice of tokenism works its rhetorical magic. In conversations taking place on microblogging sites like Twitter, a person need only look for the requisite hashtag to realize that $\mathrm{s} / \mathrm{he}$ is standing alongside others who are thinking about the same narrative as s/he is.

\section{Bellringers}

In the hours before a show airs, producers notify viewers (at least those who are following them) that if they wish to participate in the "conversation," they should use a specific hashtag and open their Twitter feed at the beginning of the hour. Once the hour begins, producers will use specific questions about plot or character in order to "jump start" dialogue in a live feed.

I argue that these prompts often serve as "bellringers," as they are often called in the school classroom. In a class, teachers will often display a question on a projection screen to which students will write a response, freestyle, for about fifteen or twenty minutes. Such responses are often shared in class or just kept as part of a writing journal that remains private. The idea is to get students writing and generating ideas. It also encourages, like the clickers I mention in Chapter Two, the notion of good attendance and the need to be on time for the beginning of a session. Likewise, producers signal the start of the conversation by asking questions on a live feed that will prompt discussion as the show continues. 


\section{HistoryVikings}

What do you think are Lagertha's fears? \#VIKINGS 4/28/13, 10:06 PM

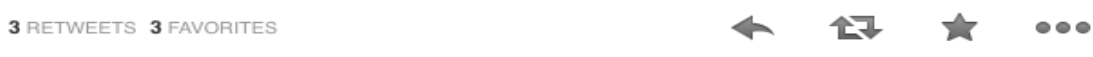

Michele Soti@Schellers

@HistoryVikings Ragnar finding a new woman

Mikaela Luketic@SwimmerMKL96

@HistoryVikings children

Jacqueline Dreyer@MonsterFactory3

@HistoryVikings That \#Ragnar will discard her b/c she mite b barren. Power doesn't have room 4 love

Fig. 28: Opening Writing Prompt for Vikings on Twitter

As seen above, the live feed asks a question six to ten minutes into the broadcast, often timed to appear when the first narrative break occurs. As the credits roll after the first six minutes of a teaser opening, audience members might be tempted to switch their channel or to leave their seats. The conversation starter urges them to remain in the world of the narrative instead and to enter conversation. Again, the question's construction and timing resembles a teacher's own attempts to keep her students occupied and engaged, especially as the agenda for the day begins.

The tweeting continues up until the hour of the episode ends. Most of the social media involved in the live tweeting process feature a final question in which the producers ask the audience to reveal their favorite part of the episode they have just seen. During most airings, the final question, like the one posted by the producers on April 28, 2013, reads: "What was your favorite part of tonight's \#VIKINGS?" This question prompts audiences to reflect upon what they have just witnessed in order to think more seriously about the events that affect the characters from week to week. More importantly, we witness how consensus is built through conversation. While viewers may 
differ in their choice of favorite scenes, they are still participating in a dialogue where the idea of a favorite scene is a given. Rather than simply ask, "What did you think about tonight's episode?", which could allow for criticism and or admission of dislike for the events that occurred, producers have ensured that the participation process here centers on everyone sharing positive experiences from their narrative engagement.

\section{Posing of Research Questions to Showrunners}

Showrunners also make themselves available to viewers on live feeds so that if questions arise, the fans might directly pose these questions to those in charge of creating the narrative. What this practice does is encourage what writing textbooks like The Curious Reader call a "spirit of inquiry." Questioning is a major component of learning to think critically. Rhetorically speaking, we consider someone a good scholar if they are able to pose good research questions to frame a subject of investigation.

The questions viewers pose often range from the banal to the serious. They question the direction of the plot, but they also question the costume of the hero and ask if he will appear without his shirt on in future episodes. Showrunners must strike a balance between honoring such questions and weeding out the extra static. Sometimes showrunners prefer the humorous question to the serious one if it helps illustrate more of their "backstage" personality and "insider" joke telling persona. At other moments, they will try to maintain focus on the show's narrative direction in order to keep viewers occupied with the content of the given episode. They also tease future developments and reward those who ask questions with information others might not receive if they were not participating on the live feed. 


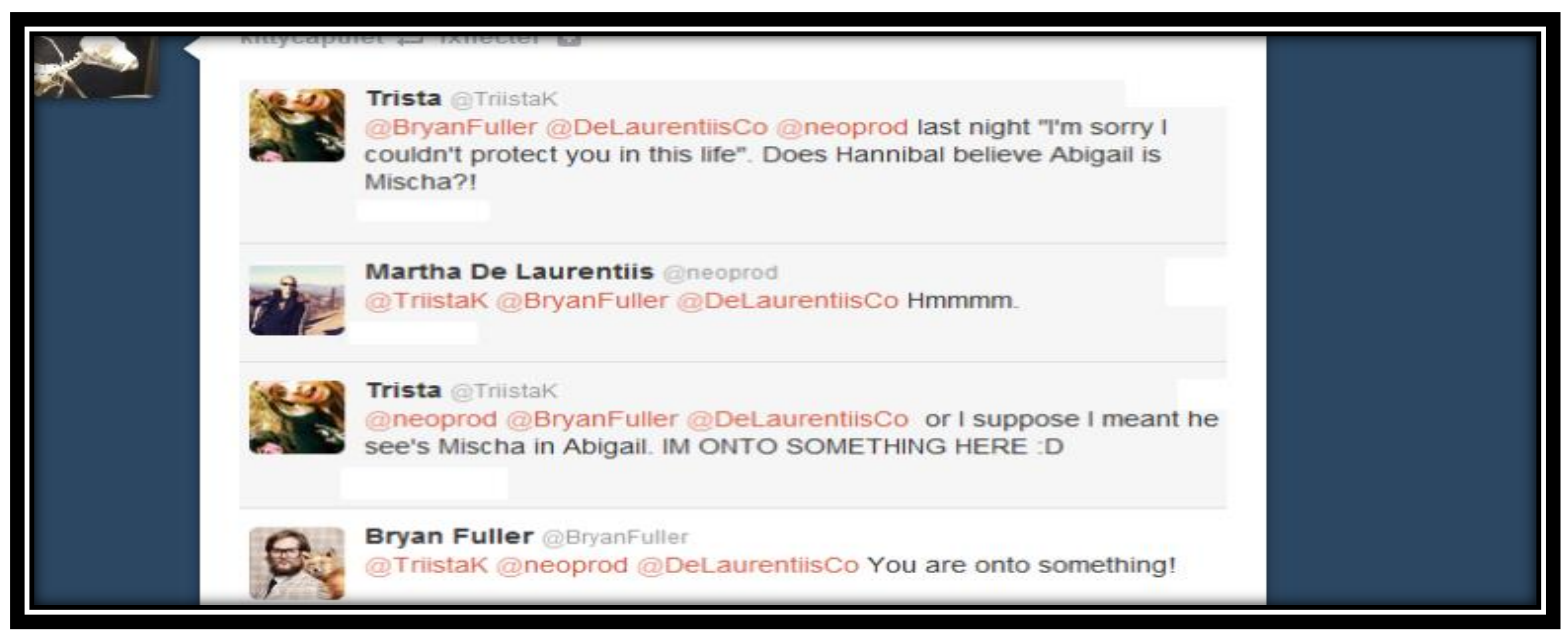

Fig. 29: Conversation with Producers and Showrunners about a Hannibal episode

Above Bryan Fuller reifies a fan's thoughts about a plot detail on Hannibal by telling the viewer that she is "onto something" [sic]. In just a few words, Fuller acknowledges and respects a viewer's thoughts about why Hannibal might be grieving over his lost sister. To get the attention of those who are being contacted by potentially thousands of fans, a writer must choose 140 characters with great awareness of the community's audience but remain vague enough to keep them unaware of the resolution. A main constraint is the need to ask a probing question and allow room for a succinct answer in 140 characters, since most live feeds happen on Twitter.

Standing somewhat in opposition to the idea of OOO and its multiplicity of meanings found in circulating objects, Geoffrey Sirc's article "Serial Composition" praises the simplicity of minimalist efforts in art and music and extends his aesthetic study to consider what writing might be if we were more open to small, serial bursts of prose that functioned as tools of meaning. He argues that the "Internet-based style" we have to teach (70) may help us return to a minimalist approach to seeing textual moments as parts rather than wholes, which may possess more craftsmanship than we originally thought possible. Such is the case when a person is faced with crafting a microblog entry 
like a "tweet" on a live feed, especially one that might be chosen by a producer or writer to forward to other fans. Value exists in crafting a small part of something, however brief and tokenistic it may initially appear.

Naysayers of this practice of speaking in 140 characters have valid points about the limitations inherent in communicating through live feeds. While producers in live feeds ask viewers directly to "join the conversation," they then display certain topics as the trend for the night. In the example below, we see that the team behind The Walking Dead wants us to talk about the show online according to their whimsical title "Walking Dixons," describing two brothers who are wandering alone in the woods. As the hour of television goes on, producers urge people to keep tweeting so that the title "walkingdixons" or \#thewalkingdead becomes a trending topic nationwide. Our impressions of other characters get lost in this process. Our experience of The Walking Dead is reduced to the discussion of two white male brothers rather than allowing interchange about the rest of the cast. The points of view of other characters are suppressed in favor of predicting what Daryl and Merle Dixon will do to repair their relationship and how they will survive in the woods alone.

Rather than dwell on a point I have already made, which is that we do privilege a certain masculine, middle-class, Caucasian perspective in our enjoyment of narrative, I would rather establish how tweeting about such characters under the guise of "joining the conversation" might be problematic. By fostering an exchange of ideas on a live feed we are dealing in brief and random expressions of thought rather than sustained dialogue about the show. This idea of conversation is reduced to what Erik Ellis, in his discussion of template writing in composition, calls "terse, trenchant exchanges" (65) of persuasive 
writing rather than complex rhetorical debates where ideas may be more fully explored. While Sirc finds valuable work done in these small units of text, Ellis and others have worried that moments of conversation reduced to microblogs or template statements hinder cognitive work. Minimalists like $\operatorname{Sirc}^{28}$ might have much to note about the question and answer format below:

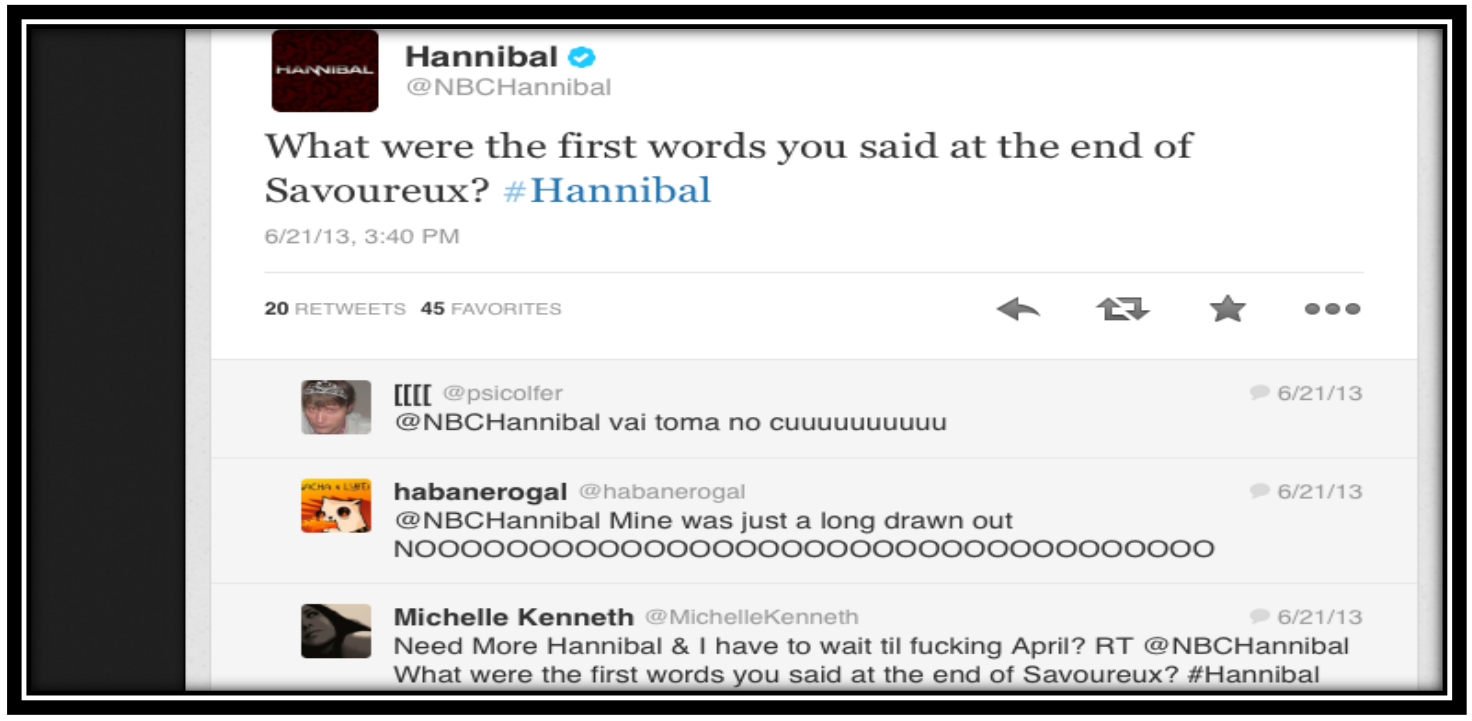

Fig.30: Reflection Question after Live Broadcast of a Hannibal episode

With only 140 characters with which to respond, people do not have time to engage in a sustained analysis of the show, but the question did not ask for such a response. It merely queried the audience for initial reactions. However, if we look closely at the shot, we might notice that two languages are at work here in the response: English and Spanish. In Chapter Four, I will explore in more detail how viewers from different cultures, while engaging in identification practices, become more aware of perspectives foreign to them.

\footnotetext{
${ }^{28}$ Another writer calling attention to this minimalist approach is Christopher Johnson. His recently published Microstyle: The Art of Writing Little addresses the importance of the economic use of words and how short messages have become essential parts of communication in our culture today. While he considers the art of writing little to be a complex act of message crafting and would not necessarily see the above exchange as "artistic" or "meaningful," the connections made between fans and producers through multiple languages and cultures cements a relationship to narrative that might not have burgeoned otherwise. That cementing happens through a small number of alphabetic characters and words.
} 
Still, initial reactions, even in diverse languages, do not produce an extended discussion of ideas and themes of a narrative.

Phyllis Benay, in her review of the writing textbook They Say/I Say says that encouraging others to converse in a strict template mode of dialogue creates a false impression of what conversation is supposed to be. Like the live feed, the templates in They Say/I Say that train students to see academic writing as what I might describe as lines from a given script suggest that communication may be choreographed and controlled rather than generated organically. She offers a review of the text that highlights these limitations:

While I agree that the twists and turns of academic writing are highly complex and require practice, I am also convinced after fifteen years of teaching expository writing that these moves are intrinsically connected to increasingly complex ways of thinking, which becomes evident through increasingly complex rhetorical structures. The difference between socalled seasoned writers and the unseasoned one is not just the process of ... absorbing academic moves, but the acquisition of more complex cognitive platforms.

Absorbing more cognitive platforms is not always an intuitive move for those simply trying to enjoy narrative, although I would argue that the "schoolification" activities on syncing apps and elsewhere suggest otherwise. This is not to say that viewers are lacking in cognitive ability. Not at all. But the goal of narrative is often to enjoy the flow of the story and to share the love for it online. Twitter does not allow room for complex cognitive engagement: the length and viral nature of the expressions there counter the 
possibility of an in-depth conversation. However, relationships still form among the small parts of a dialogue based in consensual thoughts about narrative. And with relationships come exchanges of power and information that make Twitter similar to a gift-based discourse community of giving and sharing.

\section{Building Consensus through Reciprocity}

Reciprocity builds consensus among those in power and those on the receiving end of things: it minimizes the disconnect created by the amount of power that the producers have. Furthermore, when we are responsible to a community, we should be giving them something as well as them giving us something. Building what Ellen Cushman has described in her ethnographic scholarship as a "network of reciprocity" (380-81) among those in cultural power and those who exist without it helps each party achieve needed goals. While Cushman is not discussing digital work on Twitter but rather her idea of a rhetorician's ability to enact social change in literacy studies (372), her research, along with research on fan reciprocity in different media (see Hellekson, Pearson) assists me in showing how reciprocity governs online spaces as well as offline ones.

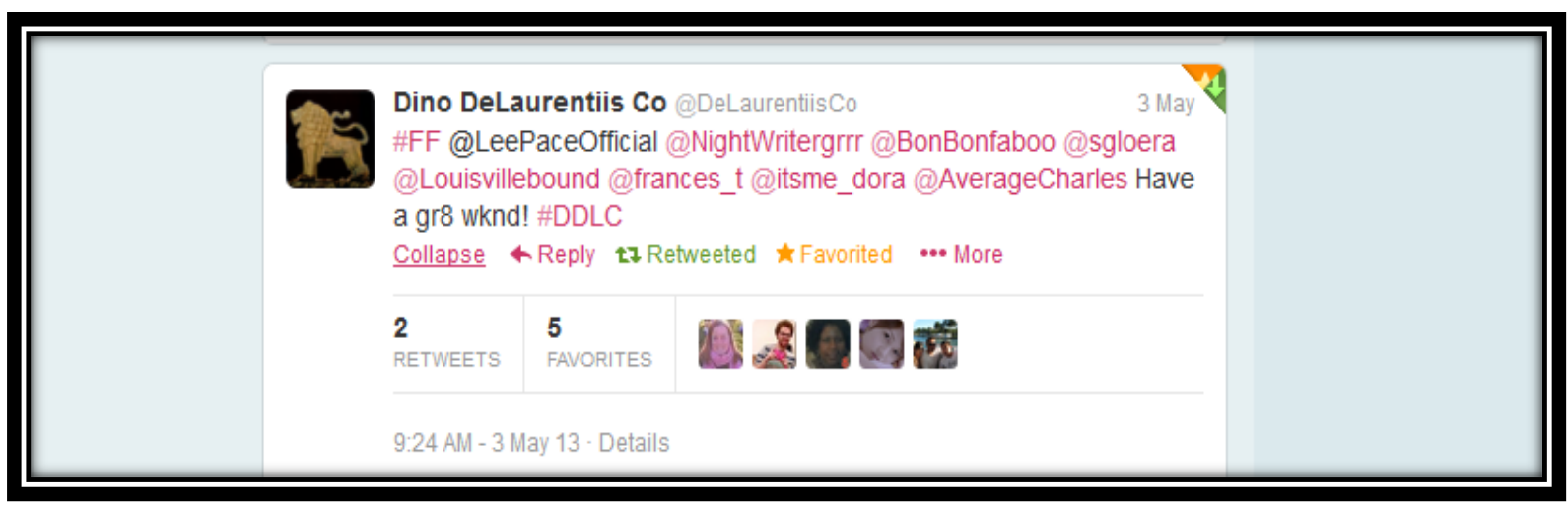

Fig. 31: Producers of Hannibal Participating in Forward Friday on Twitter 
To offer a primary example of how reciprocity between fans and producers operates, I would refer to a personal experience I had in which I was following Hannibal producers Martha DeLaurentiis and her husband Dino DeLaurentiis. My tweets praising her show and her work on helping the show come to fruition were reblogged and even "favorited" by her in the early days of the show's airing. Due to the context—-some of us were the first fans of the show—we received a lot more attention from producers because their amount of digital fan mail was considerably smaller than it is now. In terms of reciprocity, however, I would not say that having my words reblogged by a producer was on equal footing with my gift of support. But what was on equal footing was the Forward Friday recommendation that included my Twitter handle. Within the world of microblogs like Twitter and Tumblr, the idea of recommending other people's work is prevalent to these subcultures. In order to gain more followers, it is important to secure digital sponsorship from those who have more power or influence on the digital community. The Forward Friday trope happens every Friday and gives users this chance to recommend people to follow. By being featured on these producers' Twitter feeds, I was being "authorized" by one of the main caretakers of a franchise that I had grown to love. Here my actions as fan led to reciprocal care and attention to my efforts through a promotion of my own scholarly and personal tweets. Furthermore, my own name was placed right beside famous actors, as if I was just as famous as those who had made a name for themselves in television.

We may see reciprocity at work in other ways, too. For example, most shows have characters who are portrayed by others on Twitter. This practice often develops independently of the showrunner or producers, but in today's world of interaction, the 
wall separating the two groups is often brought down. Some Twitter users actually role play characters from the shows and then participate actively with producers in these question and answer sessions. The entire Twitter account becomes an act of prosopopoiea, or ancient rhetorical person making. By entering the conversation as members of the fictional world, a new dimension in dialogue opens up among fans who wish to take the narrative seriously.

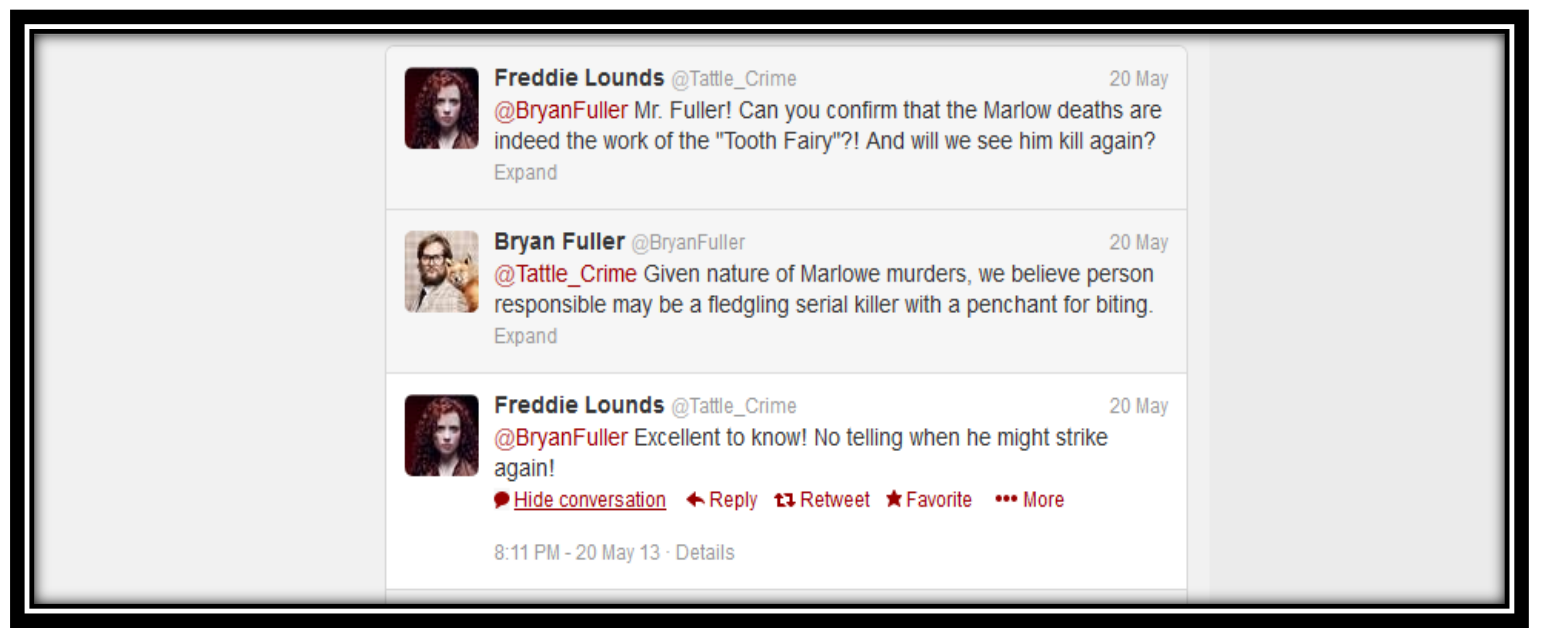

Fig. 32: Showrunner Bryan Fuller's Conversation with Role Playing Fan

For instance, showrunner Bryan Fuller chose to engage one role player on his own Twitter feed, a character playing the reporter Freddie Lounds in Hannibal. When the actress behind the account asked questions about the show's murder cases, Fuller answered the question, not as a showrunner talking to a fan, but as an insider reporting the information on a crime. Rather than sitting on the sidelines and watching the fan activity around his given fictional world develop, he decided to play ball, so to speak, with those who loved the show enough to engage in a modern form of prosopopoiea. Rather than surveil or attempt to control the creation of this person's Twitter account, he authorized it for everyone to see. At the time of composing this chapter, this same role player had set up subsequent interviews with producer Martha de Laurentiis and guest 
actress Kacey Rohl from Hannibal. This correspondence suggests that the team behind this show is dedicated to the idea of reciprocity: if fans will retweet and authorize the show to others, then the producers will do the same for them. Furthermore, not only are the producer and fan worlds colliding here, but the world of narrative and metanarrative blend seamlessly to hint at future plot events in the show discussed above.

Similar reciprocal movements by producers and viewers occur on Tumblr, where the culture of fandom encourages a tagging process similar to that on Twitter. Like tags on Twitter, these words that follow the hash mark '\#' are placed strategically at the bottom of a blog entry to make the content searchable to those interested in the same idea, hobby, or story. ' Yet tags on Tumblr, rather than being efficient markers of conversation, often act as satiric and nonsensical comments on emotional reactions to narrative. To be clear, it is common, or a mark of consensus, to find tags that read like the following: \#whyisntitThursdayyet (if a viewer is excited about a show), "sorryimnotsorry" (when posting something potentially embarrassing), or "ijustcant" when emotion overruns the ability to describe how s/he feels about a certain plot twist. These things aren't trending on Tumblr. Tumblr blogs often include such humorous tags in order to maintain a large group of followers and to gain attention. If all of the user's tags are serious, the blogger runs the risk of appearing too serious to participate and, thus, feels the need to give in to consensus by adopting the community's dedication to humor. 
nbchannibal

TWENTY FOUR HOURS UNTIL SAVOUREUX

It's almost time for your final appointment. .

\#Hannibal \#NBC \#Television \#*maniacal laughter* \#*escalating maniacal laughter*

31 notes

Fig. 33: NBC Hannibal Tumblr Page with Parodic Tagging

Those responsible for the Tumblr account for the show Hannibal actually adopted this approach in their own posts, thereby reinforcing the consensus already surrounding the way rhetoric works on Tumblr. Those behind the account knew that to properly identify with fans on this particular social network, the ability to see humor in all things, even dark moments, was important to gaining their respect and attention. Therefore, tags on the Hannibal posts included such humorous gems as “\#maniacal laughter" and "escalatingmaniacallaughter" (as seen in the blog post below), and other references to the plot in a parodic tone. The tone the Tumblr moderator adopts is one that easily melds with the other users who interact on this particular website. By mimicking that tone, those in charge of social media for Hannibal are engaging in what Mikhail Bakhtin describes in his theory of fiction as the "multiplicity of social voices" (263). The tags utilized on the Tumblr blog show an awareness of audience common to this form of social communication online. 


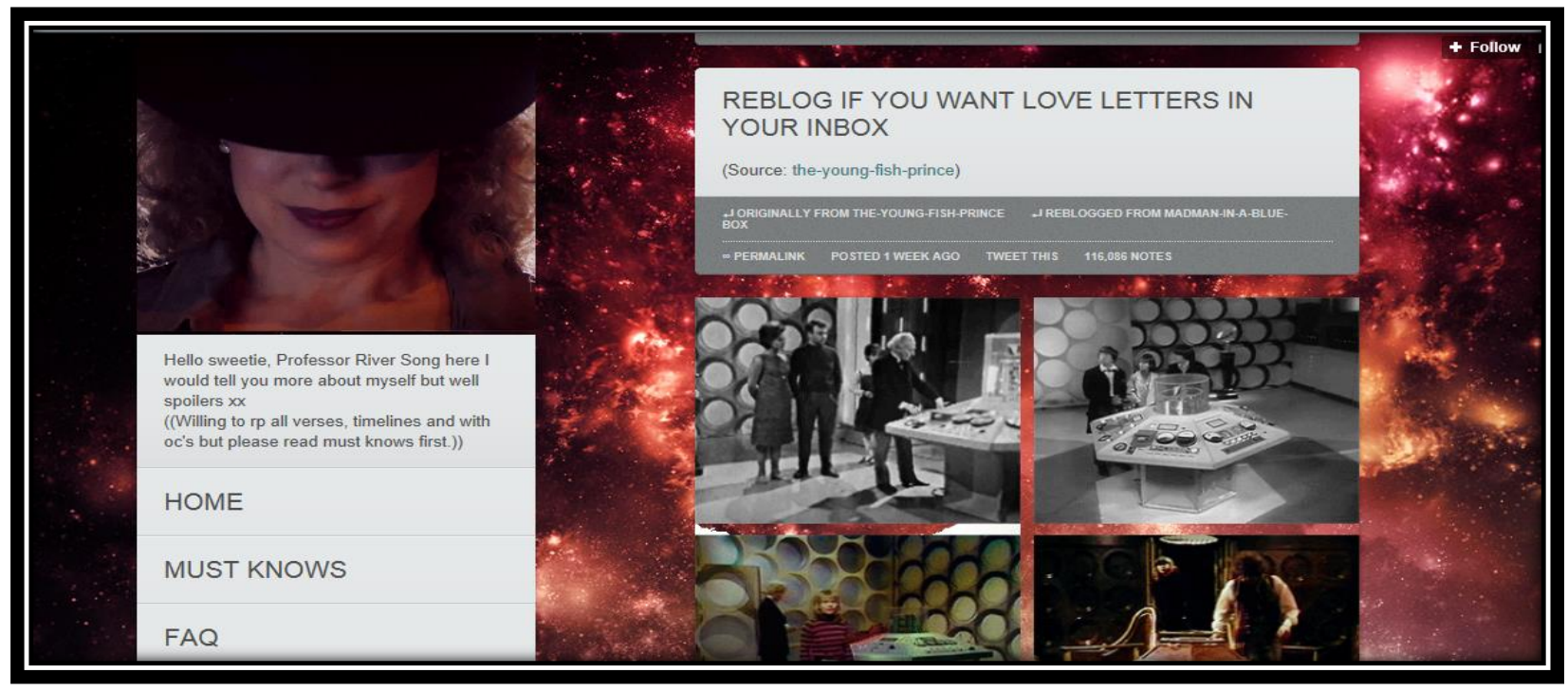

Fig. 34: Tumblr Page of Dr. Who Role Playing Blogger (used with permission)

Like the producers, the hosts of blogs on Tumblr often implore visitors to their sites to "ask them anything," and they will respond in the voice of a fictional character. Joining the conversation then may often be the result of merging discourses-narrative with argumentative - as a fan might jump from one window inside which s/he portrays a character through role play on Tumblr to another like Twitter inside which s/he might debate the plot points on a forum or live feed. In many cases, joining the conversation means merging and mixing the acts of prosopopoiea with close readings (or viewings) of the narrative. Here, the viewers assume the mantle of perspective shifting all on their own, crafting blogs in which the characters from the shows may interact with the general public and reconceptualize and reinforce the fictional world they love. Above is a screen shot from a character featured in the new Doctor Who series. As we see in the image, Professor River Song, the fictional identity sponsoring the blog, is willing to engage in conversation with anyone who wishes to address her character, including those who do 
not exist within the world of Doctor Who. She invites others to leave her messages, and she in turn says that she will leave "love letters in [the] inbox" of those who forward or authorize her blog through circulatory reblogging. The blog is a mix of images, text, and dialogic encounters with other characters and writers, both in and outside the world of the show.

The role playing activities on Tumblr and Twitter become constitutive processes, ones that help online writers identify actively as members of a fandom. Maurice Charland, in his seminal study of constitutive rhetoric among the Quebeçois in 1987, explains that to understand the full nature of how people feel this sense of belonging, we must consider what he calls the "radical edge" of Burke's concept of identification, which is that Burke "moves toward collapsing the distinction between the realm of the symbolic and that of human conceptual consciousness." "Social being," as Charland summarizes is ultimately "textual" in nature (137). I would concur, and say that while I find the River Song blog interesting as an example of someone experimenting with identity, I am not as curious about the person behind the blog as I am about how the text takes on a life of its own and is circulated among those who choose to engage in dialogue with the writer. But rather than set myself up in opposition to those who interview or study the blogger as the site of inquiry, I would say that Charland in his study of constitutive rhetoric (and Burke as an extension) make the theoretical move that helps explain how ethos becomes conflated with the product of writing. Neither may exist without the other. Through the study of the blog's text and imagery, we learn about what kind of role player this $D r$. Who fan: one who is committed to generating a faithful and enjoyable perspective on the canonical text while also encouraging participation. The social nature of this blog is 
constituted by the presentation of image and text identifying River Song as a participant in the world of narrative. In Chapter Four, I will discuss more examples like River's in order to understand how embodiment of perspective becomes a trend of fan activity that has received less attention than one might expect.

Here we drift away from the idea of producer-based strategies of building consensus into the realm of fan agency and creative writing based on their interests. Yet because the writers and producers engage these fictional personas in dialogue, as I showed with the example of the reporter Freddie Lounds and producer/writer Bryan Fuller, the circulation of these fan blogs becomes part and parcel of the sanctioned world of structured readings and writings associated with the program. The user who makes the blog for River Song is also advocating a preferred reading of her own, and while she may assert her own creative approach to the story and the character, the amount of followers she gains will often be determined by her fidelity to the narrative and her skill engaging in prosopopoiea.

As we already know from research, fan activity associated with these narrative worlds also affects and is affected by the writing that is done in the academy. Kevin Roozen in "Fanficing Through Grad School" highlights how one college student used these combined processes in earlier forms of fan activity. His case study of Kate features an English graduate student whose interests in fan drawings and fiction fueled her ability to organize and identify major themes in the works she studied for her comprehensive exams. By borrowing from the perspectives of her fictional world(s), she improved her ability to argue about text in high stakes situations like those of her exiting comprehensive essays for her degree. This project looks at how the process is reciprocal: 
not only do fan activities influence the ability to prepare for cognitively challenging tasks, but the cognitive challenging tasks of the classroom have also infiltrated the discourse conducted by these producers. Today's showrunners challenge their viewers to engage in conversation on an extremely sophisticated level, even though much evidence here also suggests that parody and humor play a significant role, too. As I showed in Chapter Two with my analysis of Story Sync, the presence of testing and evaluating knowledge of viewers is here to stay. Now if viewers wish to show themselves worthy of joining the conversation, they must demonstrate the creativity and familiarity with the narrative that will earn them social capital.

Likewise, joining the conversation online through live feeds often requires a viewer to balance imagination with reason in ways that are highly constrained: 140 characters allowed only, including the required hashtag indicated to signify inclusion in a community discussing a particular fictional world. This act of identification on the part of viewers helps clarify why the actions of "unlocking" participation and tweeting responses are so valuable. By aligning themselves with a particular fandom, viewers experiment with their own identities and the methods through which they express them, often under producer surveillance but also, as expected, on their own.

Furthermore, the procedural nature of live feeds creates new meanings out of originally discrete units of information. Through the circulation of fan activity online, different parts of a conversation sometimes coalesce like a typical encounter between two or more individuals, but often they create unexpected meanings that cannot be predicted. While these actions are grounded in human enterprise that resembles the efforts involved in establishing various public groups, the words and phrases spread throughout these 
networks result in creative combinations of meaning that may surpass the original, unitary existence of one line of 140 characters. Creating a public means relying on circulation to achieve the goal of bringing people together.

Consensus among these individuals in fan and viewer communities is common. Often viewers become afraid or excited about plot events at approximately the same times. Nevertheless, consensus sometimes prevents people from being able to shift perspectives and see problems or world views from a different orientation than their own. Once a part of a community where everyone is discussing the same characters (\#walkingdixons) or themes (\#eattherude), we tend to avoid the work involved in learning to "see something and say something" more alien or less comfortable than our own perspective. Baudrillard describes the effect of television as creating an event out of a non-event that ultimately succeeds "in completing a fantastic operation of directed consensus building, a real power grab" (28). Like he indicates in the opening quotation from Chapter One's epigraph, "the televisual universe is nothing more than a holographic detail of global reality." But if it is a holograph, is it still possible that the dialogue and activities featured inside that holograph reveal new ways to encounter narrative and to reconsider the establishment of consensus? My answer would be yes.

This tendency toward consensus does not discount that exciting and challenging methods of identification are being used to help us invest in a narrative. We now live in a world where producers and role players talk openly with each other. Actors in television series are often online as we watch their work, and they write their own tweets about the process of filming their scenes, giving us a chance to learn "backstage" secrets to the construction of a fictional world. These activities formalize what fans have been 
experimenting with for decades, the notion that their writing and questions might be discovered or honored by the makers of a story.

With this formalizing comes the construction of new spaces inside which to explore identification. While we may have always tried to identify with the protagonist (or other role) in a movie or television, we did so within our own minds. Now we engage in multiple worlds as we view a narrative unfold: we physically sit in our living rooms or offices, we emotionally follow characters through the world of the screen, and now we also mentally challenge ourselves by interacting with the characters, writers, and producers themselves on another platform, perhaps even multiple ones (e. g. a tablet computer and/or mobile phone). The image of today's viewer consists of an audience member who is tweeting to "join the conversation," watching to see what will happen next on the television, and following a syncing application to experience a guided reading of the events that transpire. It may not be news that we live in a participatory culture, but what is new are the methods through which we are invited to participate and the explicit emphasis on identification to do it effectively. Even when we engage in conversations that trend toward consensus, our keyboard strokes and sentences often contain evidence that we are able to imagine multiple worlds and multiple subjectivities.

In her study of online ranking forums for college instructors and students, such as Rate Your Professor and Rate Your Students, Sara Biggs Chaney establishes how important it is to theorize how economic, social, and cultural forces come into play when thinking about people interacting in a common online space, where they compose evaluative statements and public displays of irritation. Chaney's work focuses on trafficking in a more combative realm, certainly, where people may gather to express 
negative views, but her approach to studying such digital exchanges of opinion is informative. Her argument returns to the salient point that our public forums are continually shaped by commercial interests (205). TheFollowingFOX 's tweet in the opening story of this chapter reminds us of this fact. The world of the narrative may survive only in a world of high ratings and successful promotion of a franchise. To ignore such forces of economic pressure would be irresponsible in studying the interactions of viewers and the producers who wish to ensure those viewers' loyalty.

What is productive, though, is to also call attention to the continued learning curve of reciprocity in which viewers and producers have begun to participate. Despite a commercial motive of sustaining viewership, the showrunners and producers of television narrative produce texts that encourage identification strategies to continue and increase, and such strategies constitute a public whose primary economy is not based solely in the exchange of hard cash but on social capital and the intellectual ability to role play different points of view.

As this analysis continues, the continuum of producer control shifts considerably from greater to lesser: Story Sync application use being the most controlling and guided direction with which to approach a live viewing, to live feed participation, in which producers and viewers meet one another in the middle, influencing and being influenced by one another, and finally to an extended look at independent role play and embodiment produced solely by avid fans in this next chapter. The idea of our bodies being actively engaged in the process of identification may not seem surprising in a world increasingly made up of avatars and profile pictures on networks. However, the idea of the human form being manipulated to argue for the legitimacy of a narrative world is still important 
to consider, especially since fans are becoming more creative in their ability to adopt the perspectives of their favorite characters. Nevertheless, the next chapter will still focus on how producer and writer influence play a part in the work fans do. Viewers who are devoted to a fictional world will ensure that others know just how loyal they are to that world's continued existence as it is seen in the eyes of the writers and producers. 


\section{CHAPTER FOUR}

\section{TEXTS AS BODIES, BODIES AS TEXT: ROLE PLAY AND THE RHETORICAL PRACTICES OF IDENTIFICATION}

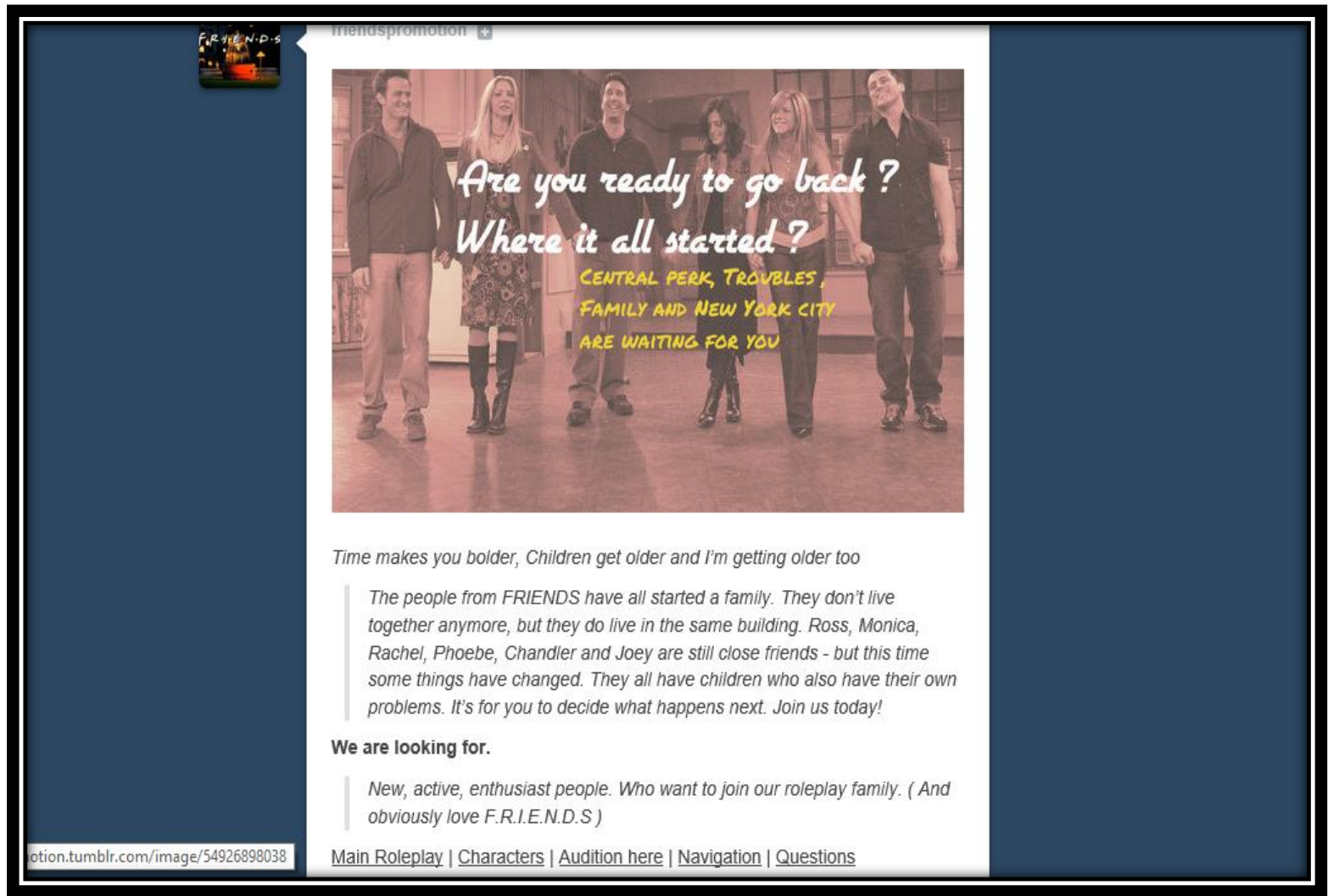

Fig. 35: Promotional blog entry for role playing community for the sitcom Friends

In the above screen shot, we see a promotion for an online role playing group that bases its writing on the 1990s situational comedy Friends. Looking at the content, we note that this specific group sets the role playing activities after the narrative's canonical ending: writers are asked to imagine the future of the main characters' lives. The post includes a reference to joining a "role play family," which implies that participation leads not just to sharing a love for this narrative but also to finding a new, close circle of fans 
for support and communication. Words like "family," "enthusiasm," and "love" reveal what most would consider an affective response to this narrative that aired on NBC for ten years. Yet a closer look at the ad reveals that role playing with this group follows logical steps and requirements, the first of which is the application, or "audition," process.

Like a business that seeks new employees based on certain qualifications, the administrators of this group list what traits they value in their participants: "new, active enthusiast[sic] people," people whose very embodiment suggests loyalty and devotion to a franchise through thought and action. The blog post includes a link to an audition page where the applicant(s) may see further requirements. Upon clicking on the link, information is requested, with a statement to "please make sure you have read the rules before applying." Rules include baselines for how active and professional the group must remain. For example, players who are offline for three days or more are asked to resign participation, and posting or submitting to the blog must appear "neat," which requires learning how to operate Tumblr's cutting and blogging commands so that the information is organized in a specific fashion. The application then asks for information such as name, age, time zone, level of activity online, previous role play experience, desired character choice, second desired choice, and even a writing sample, in the form of several paragraphs.

I argue in this chapter that role play blogs and related character profiles may be viewed not only as affective responses to beloved narratives or experiments in personal identity but also as examples of procedural rhetoric and living, evolving bodies of text that replace physical bodies once forwarded through viral circulation. As I discuss in 
Chapter One, I am using Ian Bogost's definition of procedural rhetoric found in Persuasive Games, which is defined as "the practice of using processes persuasively" (17). In terms of Tumblr users, procedural rhetoric helps characterize their efforts to build ethos through manipulating text in systematic ways. Games and role play share similar traits of allowing players to take on different social and economic roles than they possess in life (746). While text generated on these blogs often circulates and evolves outside of the author's control, the text, as it lives and moves within the blogging platform, embeds the author in ways that alter her perspective of the world. This dissertation project has been a rhetorical study of producer-designed second screen applications, entertainment company blogs, and live feeds of audience commentary as "living documents" of persuasion--how they shape and/or guide narrative meaning for viewers, and the ways in which they use character identification or point of view to ensure deep engagement. From these programs and digital sites we find ways that empathy and attention to shifting points of view are becoming a more integral part of how we conceptualize meaning. In this chapter, my attention falls primarily on the subject position of the fan as s/he engages in role playing characters, or identifying with them in the most imaginative sense. First, I will explain how Tumblr functions uniquely as a social networking site and how its activities receive a different analysis than those in previous scholarship. Then I will explain how this site and others support a new model of identification through the circulation of text apart from the body. I return then to the emphasis on the subjectivity of the blogger and to the cross-cultural implications of co-authorship on a digital platform. With all this in mind, I conclude by reminding us that the role players' actions reinforce some of the ideas I have established about producers and storytellers: mainly that there is 
a master narrative to which we owe allegiance, and that we are stakeholders and conversationalists always complicit in shaping its progress. Role play activity returns often to the original site of power--the showrunner/producer's design.

\section{The Text as Body}

Before addressing challenging questions regarding embodiment, central features of digital role playing deserve some explanation. Literacy scholars, mostly focused on students in primary and secondary schools, have taken note of online communities centered on fan fiction writing, role playing, and video game avatars (Black; Gee; Warren; Johnson; Williams). Paul Booth in "Rereading Fandom" discusses Myspace users' profiles that are based on characters from television programming, and highlights the power of these fans to identify with television characters and "become proprietors of their own textual spaces" (520). Booth explains how the process works: users adopt a role from a television show (or movie, book, or game) to impersonate, and they connect online with others who support their portrayal. In the process, they establish a blog for their character, often by selecting a celebrity's head shot for the profile picture. Myspace, which features attention to favorite books, movies, and music as part of the information on a user's profile, allows for substantial room to play with the notions of what a character likes and dislikes. In essence, the body of the character is represented by the face seen in the celebrity photo but also by the lists of hobbies and interests.

On a minor level, we might find role play on Facebook or other networks where quizzes online tell us which character from a given story we identify with most; these moments are designed by fans as well as producers. Social networks like Myspace and Facebook allow us ample space to show off our quiz result to a given public and to 
constitute ourselves in the world of the story's design and message. Just recently, days before I finished this project, I took a quiz on Facebook that informed me that I did not just identify with Haymitch Abernathy from The Hunger Games but that I was Haymitch. Such quizzes display our results firmly in large font for others to see and discover what role in a given mythos they fit best (a link follows the results to direct new users to the quiz). In this case I am told that I "am principled and independent, "a loner," and "have my own way of doing things." This result pleases me so I feel the need for my own followers to know my kinship with the character, perhaps because he is a memorable one on screen as well as in the book series (see Williams's "Which South Park Character are You?" for other examples). Some applications allow users to transform their photos to appear more like a character in the fictional world. Producers behind The Walking Dead games and applications also invented a way that fans could "dead themselves." See my

result below:

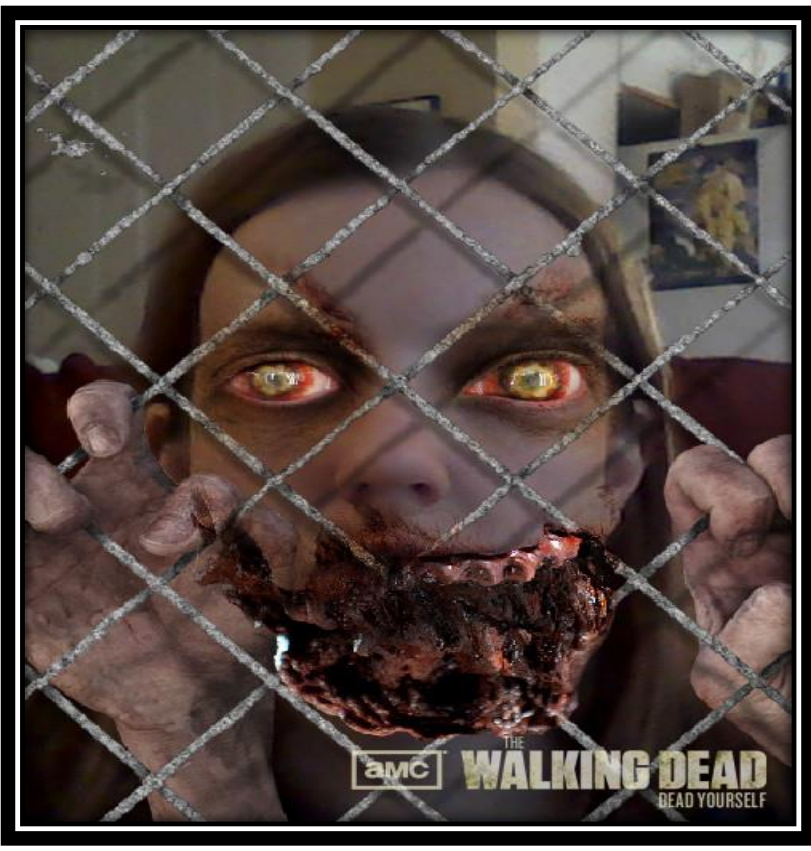

Fig. 36: The Walking Dead "Dead Yourself” Application 
By embedding myself in the narrative, my body shows complete transformation characteristic of the zombies in the television show. Here we see the body as a living text meant to advertise and promote a certain mythos to others. The producers are the ones here who do all of the work in making my face appear like a zombie, but in the role play examples I will share next, the bloggers are the ones to assume the lion's share of the identification process.

Indeed quizzes and "dead yourself" applications take little time and effort. But role play involves significant research and preparation. This experimentation with characters begins the process of thinking critically and imaginatively about narrative details and the idea of claiming the character as a living subject on the digital page. It also allows complete immersion in a different perspective (through identification) and facilitates multiple opportunities to experiment with text. Laura R. Micciche explains that the act of "play" in writing tasks

means that fictional elements are valid aspects of critical writing. Play involves performance, critical engagement with texts, considerable rhetorical skill, audience awareness, capacity to negotiate voice and tone, and an understanding of social relations - pragmatic, rhetorical knowledge, in other words. In addition, play entails wonder, curiosity, idealism, hyperbole, and imaginative leaps—an expansive horizon that purposefully exceeds predetermined limits. (182)

While Micciche does not speak of play as role play, this description fits the activity happening on Tumblr. Role play features similar intellectual work: seeing from different points of view, negotiating different languages, and managing social relations are 
required to produce an ensemble of characters (or users) able to interact and make meaning together. Also important is how play "exceeds" the limits we are able to construct and imagine, allowing for productive disruptions in what we accept as true and normative.

This approach will differ from previous studies and even from my previous chapters. Angela Thomas's Youth Online: Identity and Literacy in the Digital Age ties online role playing directly to what we might call the interior negotiation of a person's identity. Like most studies on youth literacy, the definition of identity relates to the way the user perceives her or himself when thinking and writing in a variety of roles. In other words, Thomas notes that young people role play to find out more about the kinds of personalities and images they wish to project as they grow older. In one of her interviews, she quotes a girl who, after selecting a physically appealing avatar, says, "I think I look like I come from a dolly magazine cover!" (124). Here Thomas illustrates how the writer finds joy in her image selection because it represents an ideal and reconstructs her as worthy of circulation on a magazine cover. I depart in some ways from Thomas's approach by placing more emphasis on the text and not on the author's thoughts as motivating elements of the rhetorical event. While rhetoric may never be fully divorced from motive, role play blog entries as blocks of text, once published, interact with other entries on the Tumblr dashboard, or feed, in ways that we may not always predict. Why the blogger chose a specific photo soon becomes irrelevant. Other readers, at any point in the role play enterprise, may reblog, forward, or interrupt the text they see on their screens, just as those who edit a wiki page may change content. Coupled with this unpredictability is the procedural approach employed by role players who, like the 
Friends moderators who require a writing sample of their potential members, wish to represent themselves as professionals.

Role play blog posts are living documents, which means they may be continually revised as they circulate. In this sense, the blog posts are similar to the data that I examine in previous chapters. However, in this chapter, the term means two things: the tendency for the document, or written role play narrative, to evolve; and the actual ways the role play text or website stands in for a person's body. In this process, we experience challenges to identity, reading, and writing that do not support a model of consensus as put forth by producers. More than pictures or videos or costumes, alphabetic text, in the form of threaded discussions, encapsulates the role play experience and the lives of fictional characters and departs significantly from the terse exchanges on Twitter. While the founder of Tumblr, David Karp, intended for his microblog design to share concise bits of information, film, and images, most users on this network have chosen to compose lengthy posts (see Howard), and many are by role players co-authoring threads.

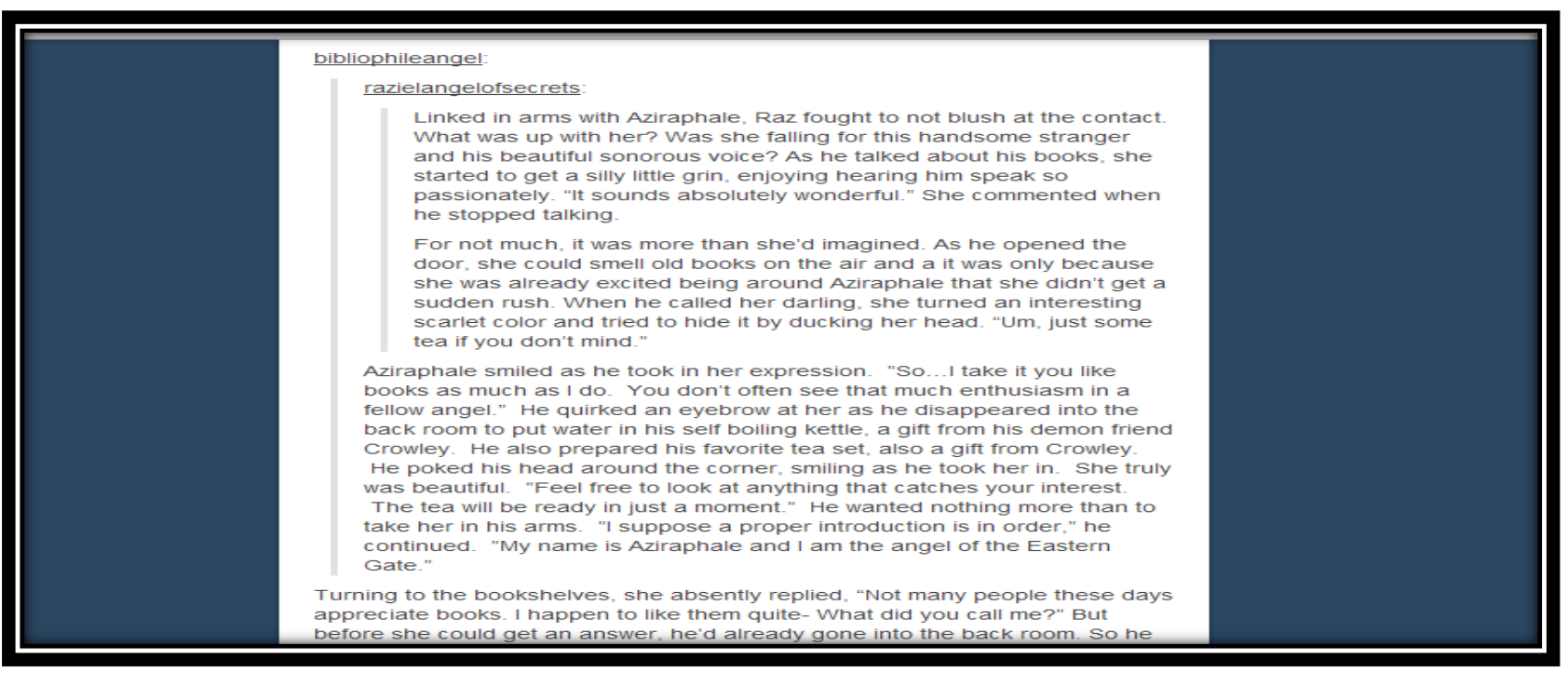

Fig 37: Role play between razielangelofsecrets and bibliophileangel on Tumblr. 
Above we see the role play in process, with a specific textual interchange between two Tumblr users. Their user profile pages state that azielangelofsecrets is a role player from the show Supernatural, and bibliophileangel is a role player who portrays an angel from the book Good Omens. Grey lines, vertically binding each entry's left margin, show the dialogic nature of this activity and the way that text constitutes a connection between two players. When each player is ready to respond, s/he types directly under the first section of text, and then selects the "reblog" command. Over time, the replies create a pyramid of a narrative, slanting to the left as it grows in length. Although it cannot be seen above, azielangelofsecrets tagged bibliophileangel at the post's end as a way to help the other player remember it is her turn (similar to the Twitter method of hashtagging). This discursive move is helpful since most role players use the "search" function to track their user name; it also hails the role player as co-author and valued participant, embedding that writer's contribution in the scene. These lines and tags indicate that the practice of scene work in role playing is a procedural one, organized and archived in a specific manner. Its contents reflect more than the desire for entertainment.

I argue that subjectivity in Tumblr is bound up in these grey lines and words that embed each role player's contribution and invite further response. Drawing from contemporary critical theory, we may find tools that give clarity to the idea of text operating in a similar role, where subjectivity extends outward to encapsulate thoughts and connections in the form of material, viral documents. Explicating the work of philosophers Gilles Deleuze and Felix Guattari, Brian Massumi describes the collision of different points of view in a way that encapsulates my argument about text as circulatory and dynamic: 
Thought perception is always real and always of the outside. The thinkingperceiving body moves out to its outermost edge, where it meets another body and draws it into an interaction in the course of which it locks onto that body's affects (capacities for acting and being acted upon) and translates them into a form that is functional for it (qualities it can recall). ... Thought-perception reaches into things, launches them up through the atmosphere of language, and in the same motion returns them, altered, into the depths of matter. (56)

This idea of thought perception grounds itself in a notion of external circuitry and the ability of language to function and become an ambassador for the subject. Katherine Hayles might remind us, as we read material like these growing Tumblr threads, that we operate in a reality where "the boundaries we impose on the world" and our notion of the body as central "prosthesis" (26) do not always take into account that the subject, especially as represented in text, "is an amalgam, a collection of heterogeneous components, a material-informational entity whose boundaries undergo continuous construction and reconstruction" (27). Anne Francis Wysocki and Kristin Arola echo this view with the following observation about media and our relationship with it in today's world: "our bodies," they argue, "are not fixed" but "mutable." They further explain, "We come to be always already embedded — embodied—in mediation" (4). The media we encounter become less about outside forces and more about constituting reality. Likewise, Massumi helps articulate how interactions that require simulating a different perspective (although that particular activity is not named here) feature more than just fan imaginings but the capacity for thought to transmit affect, connection, and embodied 
conversation. The procedure of acting as if we see from someone else's point of view (role playing a character) bases itself in the external production of meaning and its capacity to gain velocity, ${ }^{29}$ to be "launched" up.

Before moving forward in Tumblr, I detour and shift to an important example that encapsulates how textual artifacts "live" on the page and constitute the bodies referenced on them. It also illustrates the ideas of Hayles, Wysocki, and Deleuze and Guattari alike: that subjectivity is embedded in text in ways that decades ago might have surprised us. This section addresses text found on RateYourProfessor.com: a student-driven blog of evaluations of college professors. Walter White, the protagonist from the criticallyacclaimed show Breaking Bad, appears in this screen shot below. User comments and ratings suggest he is a real instructor at the University of New Mexico in Albuquerque rather than a fictional character in a television show. Someone has played the role of student, evaluating him for the public.

\footnotetext{
${ }^{29}$ I would extend Jim Ridolfo and Danielle Nicole DeVoss's concept of "rhetorical velocity" (discussed in previous chapters) by stressing that no matter how much we attempt to plan for the destinations and receptions of our work through careful awareness of audience, the "launching" of each text is unpredictable.
} 


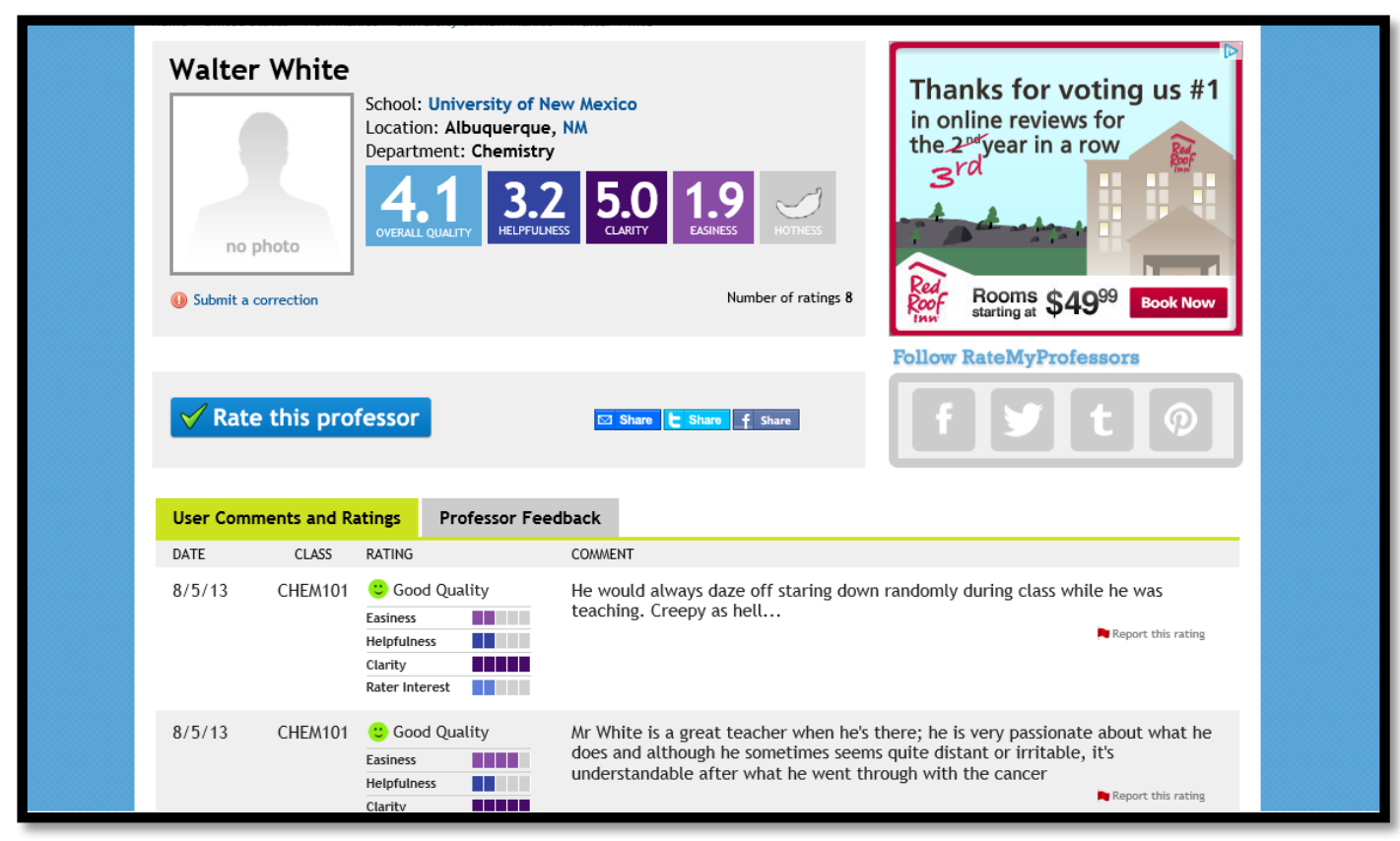

Fig 38: Rate Your Professor profile of Walter White, a character from Breaking Bad.

As seen above, the famous teacher and meth dealer Walter White, like others on Rate

Your Professor, is ranked according to different traits like "clarity" and "easiness." His

placement at the university makes sense narratively because he pursued advanced

graduate study and worked to patent his own company before he pursued high school

teaching. Students then commenting beneath the entry qualify their rankings according to

the events in the fictional world. ${ }^{30}$ The author(s) bridge the gap between the fictional and

the real and embed this profile in the architecture of this website so that future visitors to

the site, especially those not familiar with the show, will think Dr. White is an actual

instructor.

\footnotetext{
${ }^{30}$ It is important to remember that even this student feedback about White may not actually be from a student, but from someone acting or role playing the part of a student. The writer's true identity is hidden, and the source is represented as anonymous. In this increasingly circulatory world of text, the anonymous writer gains a power that s/he did not possess in the past. I will discuss this in more detail in the sections to come.
} 
The nature of Walter's profile here illumines the process by which identification both negates and validates the physical body/subject in the form of textual messages. Walter White's embodiment on this page is absent. We see no photo of the actor or character but only a grey, faceless shadow. Yet the button that offers us a chance to "rate this professor" brings him into our sights, and the fact that his origin is fictional no longer matters. The ability to provide user comments and circulate a message about him is what remains important. What is also notable: I myself may upload an image if I choose to do so. Yet I (and perhaps the other writers who crafted this profile) find this information much more compelling when not accompanied by a stock image from the television show. Most professors on Rate Your Professor are actually represented by the grey shadow avatar. To give him a recognizable face would actually call attention to his fictive origin.

By framing White as a member of the faculty, the sentences describing him legitimate the value of the fictional world through the evaluative language that typifies most other ratings of professors. The writing on Rate Your Professor is descriptive and even serious here, especially when the one of the writers notes that White's irritable nature is "understandable after what he went through with the cancer." ${ }^{31}$ Because the page may be edited by anyone, this changing profile becomes another example of a living document. It is also highly procedural. The Rate Your Professor site determines how and where to post evaluative feedback and is designed to measure performance based on numbers averaged from user input. With White's entry, the anonymous writers take a

\footnotetext{
${ }^{31}$ In the world of Breaking Bad, Walter White becomes a meth manufacturer due to rising health care costs associated with his cancer treatment, and this user cites this specific plot development as commentary on what kind of teacher he would be during that time.
} 
website designed to help actual students make course selections and reterritorialize it to allow a space for play. For Deleuze and Guattari, the idea of machines and bodies acting in concord, or at least reterritorializing and deterritorializing one another, projects a world in which selves are always multiple and connected. But such multiplicity of selves does not mean that the world has become simply one large stage of performances. Instead, they argue that "[i]f desire produces, its product is real" (26). The multiplicity of selves is tied to material products and circulations; therefore, Walter White of Rate Your Professor becomes not just a conduit between the fictive and the real but the real itself, thanks to the text written there.

\section{Role Playing and the URL}

The Walter White example amplifies, through visual presentation, how alphabetic text moves the fictional toward the real through the work of role play. I now return to Tumblr with attention to a smaller textual artifact: the role player URL. The URL's alphabetic text represents the role player more than a photo or avatar. As most know, URL stands for Universal Resource Locator and acts as an address, locating the work of writers and designers on a particular site. To reach the website of a particular player on Tumblr, we must enter the user's name as a prefix before tumblr.com. The URL and the user's name become synonymous. Therefore, "roleplayerJane.tumblr.com" is also "roleplayerJane" in any correspondence online. I argue this is different from Facebook or

other social networking sites where the address does not replace the name of a particular person's website. For example, on Facebook, my address is Shannon.howard1, not Shannon Howard. The address chosen to precede the tumblr.com address is unique in that the handle signifies both a location online and the subject that initially catalyzes the 
living documents, just as the body in the physical world locates itself spatially in day to day life and becomes the animator of conversations and meaning. ${ }^{32}$ Role play starts with interactions among various URLs (or users).

Indeed, many role players will invite feedback about their URL's reputation. In such a request, they ask for what status, if any, the user's name has in the Tumblr role playing community. This invitation is open to both anonymous users (more on this to come: another example of how alphabetic text is privileged is the frequent invitation to provide anonymous feedback) and other bloggers established in the community. This desire for widespread popularity is not surprising. Henry Jenkins, Sam Ford, and Joshua Green discuss the circulation of messages in their most recent work Spreadable Media: the main thesis is that "if it doesn't spread, it's dead" (1). The very notion of calling such text "dead" brings me back to my point about living documents: text that moves is text that lives. One post on Tumblr stated the following: "Reblog if you are proud of your URL." User madaraswife earned 16, 578 replies ("reblogs" or "likes") from this post within twenty-four hours. The ability of this one sentence to circulate 16,000 times in such a short time shows how quickly text takes on a living force of its own.

The URL legitimates each writer's presence and frames him or her as a specific type of player whose contributions differ from others. This is important since role players often choose the same character to portray. For example, after the airing of NBC's Hannibal, many Hannibal Lecter role play blogs sprung up on Tumblr as a homage to

\footnotetext{
${ }^{32}$ As Debra Hawhee, building on the ideas of Fredric Jameson, astutely observes, "the bind for body theorists is that bodies become a problem when they come to "stand in' for subject positions" (7). I do not consider myself a body theorist, and my use of this term is more literal throughout this chapter. However, even as someone who does not typically operate within body theory, I, too, find the term slippery when considering how easily it is conflated with the subjective mind here. For more information on how theorists define subjectivity in relation to embodiment in culture, see Jameson and Massumi.
} 
Mads Mikkelsen's portrayal of the character. The URL afteryourdeathormine has a different online reputation than the URL lectercollapsingchurches, which bases its text on the back story of the character's obsession with the destruction of faith and on the organizing symbol of structural debris. The user explains: "I see this idea of the church collapsing as feeding into the image of a fallen angel. This blog features a journey of transformation rather than a stagnant portrayal of Lecter." Here the writer's words shows that the player has read the character's back story and creatively "launched it up" for discussion and interaction. This is different from "afteryourdeathormine," whose introductory material about the same character features medical disclaimers and attention to the character's position as a psychiatrist. She says, "I am not a medical professional. I am not certified to offer medical, psychiatric, or personal advice in any way. This is a roleplay blog_-based off a manipulative, abusive, charming character, whom I do not own or in any way represent." ${ }^{33}$ Her page even offers links to various crisis hotlines for those with mental illness. While authorial intent may never be known, the presence of her disclaimer suggests the user's awareness of rhetorical velocity and the possibility of repercussions. The URL carries with it the responsibility of how text is "launched" into circulation.

\section{Muns, Muses, and Anons in Role Play}

Wayne Booth has famously described the "confrontation" of different ideas from different viewpoints as something akin to a crisis of logic rather than faith. He says, "When I enter the place where you dwell and have your being, I bring with me ways to

\footnotetext{
${ }^{33}$ I often refer to role players with the pronoun "she" since most role players on Tumblr are women. See Thomas. For more information on how women construct online communities around popular narratives, see Bury's Cyberspaces of Their Own: Female Fandoms Online.
} 
some degree alien, and the results of our meeting will always provide what looks like evidence for those who want to claim total indeterminacy of meaning or the permanent impossibility of understanding" (Critical 341). Booth's concept of "the place you dwell" is also important here. Perspective taking involves both mental and physical processes since the simulation of other views cannot be divorced from the body. The way we shift perspectives is closely tied to the "place" where we "dwell," both inside our heads and also within the spaces where we interact with others.

Role players, depending on the "place they dwell" in their creative processes, will compose alphabetic and visual texts based on whether they write "in character" or "out of character." Their crisis of faith stems from the performances, often in stark contrast, between the character they portray and the author behind that role. Bloggers differentiate between the character they play and the real life persona who creates the character by using the appropriate terminology. The actor or blogger is called the "mun," short for the "mundane" projection of the embodied, real world writer. The fictional character is referred to as the "muse," thereby hearkening back to the classical term designating the spirits who inspired great myths and stories. These words help users organize events and writing prompts that allow them to connect with other role players. For example, the tradition of "Munday" refers to the frequent photographs posted of the real world bloggers on the Monday of every week. Mondays often include blog posts where the user will promise to post videos of her/himself answering questions about the character played; or answer personal questions about her/his age, favorite things, and real world work/student status. 
This classification system highlights how important the difference between fiction and reality is to most role players. It also creates a division of self not too dissimilar to what viewers who watched Herman's Head experienced when they watched a protagonist weigh problems from multiple perspectives in literal terms (see Chapter One). This division is a site of complex identity negotiation and important to note from an ethical perspective since many characters portrayed on Tumblr are narrative agents who break the law, hurt others, or generally represent "evil" motivations and actions. Thomas Newkirk has explained in Misreading Masculinity that those who engage in such activities are quite aware of how their make believe activities speak rhetorically to others, and how those activities might be read as indicators of actual behavior. In his study of children who play games or write stories featuring violent scenarios, he found through interviewing them that they, on the whole, saw distinctions between the real world and the fantasy world (106-13). Although most of his subjects in this project were young boys, the same approach to separating the real from the fictive exists as these bloggers classify text produced by the muse or the mun. Identification as a procedure guides the role player through distinguishing between the body operating behind the computer screen and the body of text circulating as a representation. The negotiation of reality between mun and muse recasts what seems to be a purely performative act as a composition of multiple "dwelling" places, as Booth describes.

In contrast, the site of dwellings for some writers is literally erased, which supports my argument that text itself, divorced from any particular subjectivity or URL, sometimes holds more sway over the role play platform than the authors whose identities are clearly marked. It may seem obvious to state that a person who writes with no claim 
to title or image is operating outside constructions of identity, but this is the case on Tumblr and on other sites like Omegle ${ }^{34}$ where the marketing focuses on attracting users who wish to interact with the text of strangers. The "ask" function on Tumblr includes an "anonymous" option so that even those with identifiable user names may hide them by checking the option to pose information without leaving a name behind. For example, bloggers who wish to receive feedback on their writing will issue calls to "anon readers." The URL liverandchianti posted the following message as an invitation: "Go on ANON and tell me what you think of me. I do not want to know who it is, at all. Don't tell me who it is, don't give me hints, don't say your screen name. Tell me exactly what you think of me. Don't sugarcoat things. Don't lie. If you hate me, tell me why. Tell me what I'm doing wrong. If you like me, tell me why." These anons provide valuable writing prompts to help the role players engage in creative writing tasks. They also expose the player to potential risk, since the absence of a subject's name or face means that vindictive or hateful messages are sent in addition to productive ones. These moments of tension are part of participating in procedural rhetoric.

\footnotetext{
${ }^{34}$ Omegle is a free online chatting site where people may have conversations as anonymous participants. Participants are called "Stranger" when engaging in dialogue with others.
} 


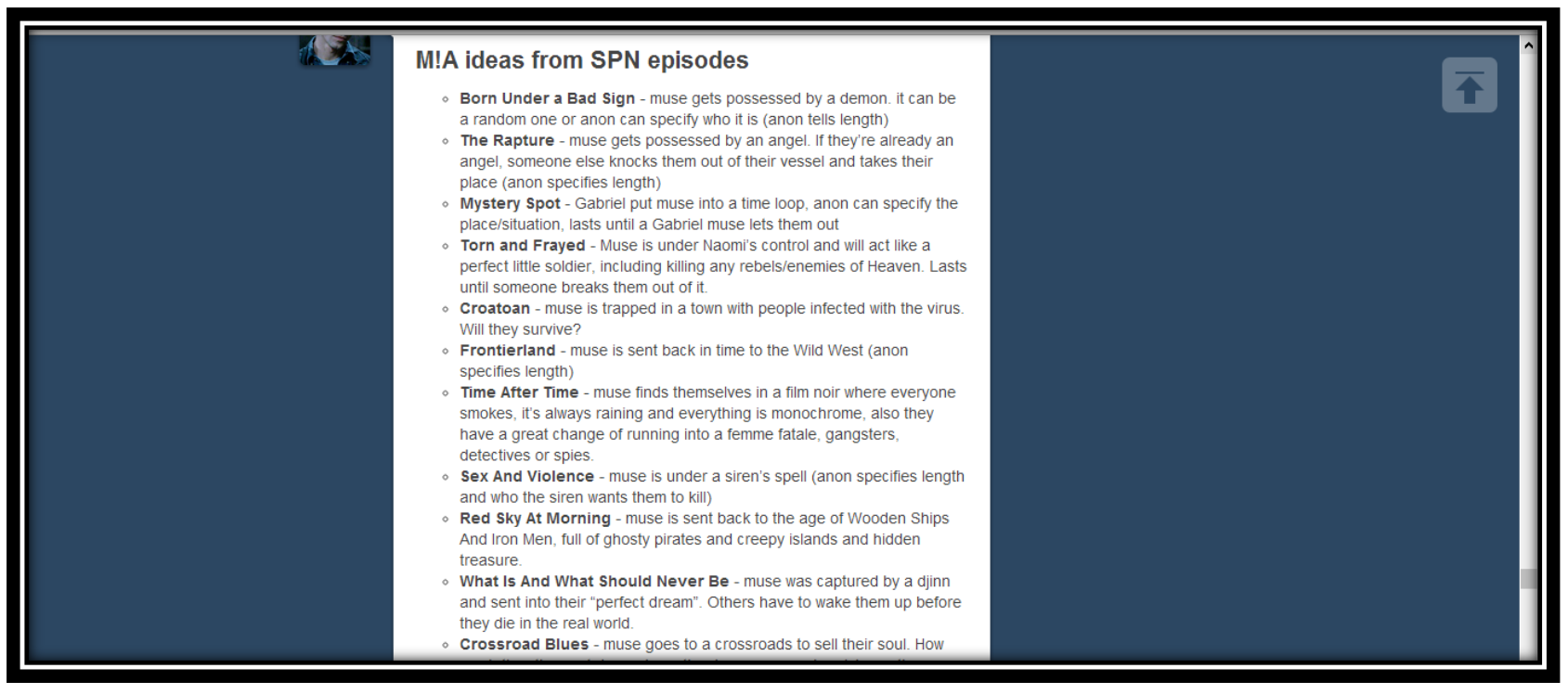

Fig. 39: Example of Magic Anon Writing Prompts from URL michiferangst

As Bogost explains, procedural rhetoric "motivates a player to address the logic of a situation in general, and the point at which it breaks down and give way to a new situation in particular" (740). This "new situation" that Bogost refers to may be illustrated with the screen shot above. By requesting that anons send what is referred to in that community as "M!A" posts, or "Magic Anons," the regular pattern of role play is disrupted to allow for challenges the player may not have anticipated. These posts set up obstacles for the role player to confront, which are usually described in terms of physical harm or disability to the human form. Examples include the practice of making the character blind for twenty-four hours, causing them to suffer an allergy, or having them follow directions of another person due to mind control or hypnosis. In these exercises, the writer must maintain the identifying characteristics of their role while also meeting the strict procedures of the "M!A" task. Here we may understand how textual procedures substitute for physical encounters in ways that embed the faceless user, whose gray shadow of a face resembles the icon of Walter White on Rate Your Professor, into a 
system of circulating messages. Sent by an anonymous writer, the commands are taken seriously rather than dismissed as signs of cowardice or insecure writing ability. The faceless user, who has not claimed a subject or specific body for her or himself, acts as controller over the role player's fictional persona, thereby creating revelatory moments where the power of writing (as procedure) to enact change will eclipse, at least temporarily, the power of the writer.

\section{The Body as Text}

While the anonymous, circulatory, and disembodied blog entries characteristic of role play give us plenty of room through which to explore how text may eclipse the physical body or subject in Tumblr, it is not always productive to ignore the presence of the embodied author. Therefore, as a former participant in these communities, I refer to my own impressions of writing and imagining narrative in order to establish a tension between the nature of the text circulating on Tumblr and the instigator or creator behind it. When doing so, I provide a subject that feels, remembers, and analyzes its own activity. Further, I provide a moment of disruption (much like those in Bogost's framing of procedural rhetoric) inside which I bracket off the more pseudo-objective rhetorician stance and reveal personal testimony in which text, blogged and circulated, helped reconstitute my identity and provided me with a successful cross-cultural shift in perspective.

The motivations behind my participation in online networks were mainly two. When I joined my first role playing group, I was dealing with the death of my father. This group allowed me ways to find a supportive network of people outside my usual communities of school and family. The group gave me a specific kind of support that was 
appealing: at any given hour of the day or night, someone was always online and available to chat. It also informed my approach to this scholarship. I am not the first to use life events to supplement academic writing and to round out my portrayal of media participation. Williams, in Tuned In, links his examples of media participation to similar life events through anecdotal moments. His study of how television and the teaching of writing influence each other is accompanied by stories of how television marked specific moments in his family's life:

I have had the TV on while I wrote checks, folded laundry, and, yes, even while I graded student papers. And when I was first out of college, alone and working in a new city, I put the television on for company just as my father did hundreds of miles away, where he sat, disabled, in his bedroom waiting for my mother to get home from work. (11)

The gentle incorporation of life events into the research project assists in explaining how the researcher's subjectivity was formed during his authorship of his book. It does not change the main fact that once these words were published, years ago in 2001, the writer would not be able to predict the circulatory power of them in this section of the dissertation in 2013. He might be able to project the influence his work would have on future students or speculate that the work would reach an academic audience interested in studying vernacular literacies. Still, the actual knowledge of where and when this text would be circulated remains an impossible prediction for all writers. Text still acts as the main mover, but it gestures toward embodied life beyond the page, helping establish a fascinating tension between what may be considered textual life and lived experience. 
Massumi argues that Deleuze and Guattari speak to subjectivity in a way that reflects this tension. Their description of subjectivity links the idea of the organ without bodies and the circulation of text to the phenomenon of personal experience. According to them, Massumi explains:

The "I" does not inhabit the body, but is attached to the place of enunciation. It insinuates itself into the body tapped for possession by the “one" haunting the premises. I mouths one's words. Every body has as many "I"s as there are "ones" in the world it moves through. The first person only repeats here and now what the anonymous third person of the abstract machine has already said elsewhere in the mists of time, and will undoubtedly say again.

In this imagery are machines, repetition, and movement, all linking back to the notion that discourse circulates at all times, even when we perceive our own experience as personal and unique. It does not discount the fact that the researcher who loses a parent views herself as an "I" seeking solace in a time of stress and grief. What it does offer is the potential for that "I" to generate meaning and participation through media--media that, in turn, creates opportunity for the "I" to "launch" text out of grief and have it land in unexpected ways. The death of a parent remains a personal motivation for entering a role playing community, but this sorrow and grief, once manifest in writing and public community, acts as a catalyst or originary place of energy in a larger system of meaning and exchange, rather than serving only as autonomous life events contained in my memory. 
Another reason I was drawn to online role play was that I had missed my experiences in theatre. As a former theatre major in college, intern in a professional theatre company in California, and as a regular volunteer in community theatre both backstage and on, I had found my most productive years of life were those in which I had theatre as a hobby. Role play as a theatrical enterprise has always had implications across multiple disciplines for me - education, psychology, rhetoric and composition, and literature. In performing the work of identification, two different subjects find commonalities that link them, in Burke's view, persuasively. The theatre also presents its message through actors who embody other subjects, linking their own human experiences to a new fictional subjectivity that may or may not initially have anything in common with her/him. Role play gave me the chance to imagine and create in ways that theatre had offered in the past. In their critique of psychoanalysis, Deleuze and Guattari rely heavily on the notion of theatre as a metaphor for previous ways of conceptualizing reality but find limitations in it as a concept. Theatre as "a model of production" points toward a "lack" (306). If all role play is simply performance, it is "reduced" then to a space with little value; it becomes an absence rather than a site of textual energy (306). The text generated in these online spaces does the opposite: it becomes a living document subject to growth and change.

In this next personal anecdote, I hope to more clearly illustrate how text, produced by a subject, often has more influence on that same subject after it has been subject to rhetorical velocity. Thomas and others might have us think about identity as it is initially shaped on a network when authors have the digital space to explore roles. I would use this next example to extend their thinking. I believe that the text gains power as it is 
reblogged, extended, and co-authored with other writers. It does not gain power just

because we cite or honor its positive attributes. It gains power by changing the author as a subject, not just at the beginning of thought and creative process but beyond the end of publication. ${ }^{35}$

By co-authoring a narrative on Tumblr with one woman, whom I will refer to as Carla, ${ }^{36}$ I had the opportunity to negotiate two different language backgrounds as living texts. I also had the chance to explore the process of identification in ways I did not anticipate. Carla is a native Spanish speaker who is also fluent in English, and she and I wrote or collaborated several times a week. While Carla had been speaking English since she was a small child, she still acknowledged weaknesses in idiomatic understandings and shifts in tenses. Still, her command of the English language was admirable, and it inspired me to reciprocate by learning Spanish. She mentioned frequently that by writing with me she learned new words to add to her vocabulary, and I felt that the process might work similarly for me.

Writing in two languages gave me insight into different perspectives, a process that I had often claimed to research (especially here in this dissertation) but had not fully

\footnotetext{
${ }^{35}$ Scholars might find such a point obvious because they already know what it means to be cited and recirculated, perhaps sometimes in ways that they appreciate and in other ways they don't. However, the average blogger, especially one engaged in role play, may not have conceived how multiple subjectivities intersect in ways that make rhetorical velocity a process that affects not just the alphabetic characters on a page but the author's character as well. I believe such moments have implications for how we teach intersubjectivity and the "conversation" among different authors in scholarship. More on this in the Conclusion.

${ }^{36}$ I informed Carla (a pseudonym) that she plays an active role in the fourth chapter of my dissertation. Our partnership is one I wish to protect; therefore, any direct quotations or statements from her writings will not be included since they would be searchable on Google and lead back to her blog. Heidi A. McKee and James E. Porter in "Feminist Research Practices in Cyberspace" explain that while the National Endowment for the Humanities may allow for us to consider all blogging text as public, a more nuanced approach takes into account relationships, consequences, and degree of privacy involved in the personal lives of writers (157-58). I follow their lead by speaking of Carla's work and my own in a more abstract manner than I do in the sections of textual analysis preceding and following this part of the chapter.
} 
put into practice myself. Through investigating moments of digital rhetoric, I find the need for lived experience to supplement and enhance my theoretical observations; otherwise, my work as a writing teacher remains incomplete. In writing threads with this blogger, I became aware of which constructions in English were most troublesome for her as a bilingual writer, and such knowledge gave me new insight into the struggles of composition students whose native language is not English.

To challenge myself to learn Spanish, I set my own page instructions and menu options to Spanish so that I had daily practice, even if only subliminally, with words that referred to the Tumblr commands of blogging, reblogging, following, and liking. In this sense, I commanded the network to embed me in a culture of writing and reading dissimilar to my own. My blog entries then described the date and statistics of each entry in Spanish. For example, if I blogged something a day ago, the time signature at the bottom of the entry would read "hace 1 dia" as indication of when my post first appeared. My search box at the top of the page commanded me to "buscar" (look for) other blogs I might show interest in. When others would like or reblog my entries, the words "le gusta esto" and "reblogueado esto" appeared ("liked" or "reblogged" this) beneath the posts. Through immersing myself in these phrases, I became used to seeing the Spanish representation instead of the English one, and, therefore, Spanish became a living discourse through the procedures I set in place on this site.

These examples did not mean that working with another language, and coauthoring a story with a Spanish speaking partner, was a procedural one that could be controlled the way my own blog's commands could be controlled. This practice of blogging with someone whose native language was Spanish meant using what Suresh 
Canagarajah calls the "let it pass" principle to work in my co-authoring activities (19). By "let it pass," Canagarajah means that "if an interlocutor comes across an item that she feels is incorrect or unintelligible, she moves on with the conversation rather than attempting to correct, judge, or walk away from the interaction" (19). Williams, responding to Canagarajah's work, notes this practice as being common online: "Participants in online fan forums that draw people from across cultures do not generally correct each other's language use or assume cognitive deficiencies because of variations in language use" (256). Carla confessed that while she formally consulted an English dictionary for some words I wrote, she also followed the context to make some allowances for gaps in knowledge. From these improvisational moments in the production of text, language failed to operate in a procedural manner and became dynamic and fluid.

Certain linguistic constructions merged. After reading and writing with Carla, I found myself adapting her English discourse, writing a construction such as "didn't liked" rather than "didn't like" since Carla often struggled with the past tense in English and rendered both the auxiliary verb and the main verb the same in agreement. I understood this form of writing as one I had learned about in my studies on multilingualism: a form of writing that included what might be called an error in Standard English terms but not a careless mistake (see Lu). It was a construction that, through repetition, I acquired temporarily, although I often caught it in my scholarly writing before I completed my copyediting. In Booth's terms, I caught myself somewhere between the place where I "dwell" and the place where Carla "dwells" in her composing and thinking. In a sense, I confront a crisis of faith in which I recognize that the Standard 
English I am accustomed to using may break down upon understanding the perspective of another and be replaced by a new, alien system that alters the text I produce.

In these moments when I lapsed into “didn't liked," I recognized Bogost's framing of procedural rhetoric to be accurate: that such rhetoric does account for moments of disruption rather than moments of secure and linear steps. It also prompts a reexamination of the subject's beliefs, or deliberation (516). Bogost describes games that are designed with fallacies and incongruities in mind so that the player must rethink what s/he normally takes for granted about how the world works (more to come on this in the Conclusion). In this case of role playing with Carla, I should stress that while negotiating language was dynamic and improvisational, the two of us still adhered to the rules set forth by most role play communities. Those structures, while seemingly invisible at times due to our increasing attention on language learning, still framed our experience and brought a degree of order to the unpredictable nature of cross-cultural interactions.

Most importantly, role play helped me experiment with text while also seeing from multiple perspectives. Even as the words changed from English to Spanish, my own life in the "mundane" world (recalling my earlier discussion of muns versus muses) featured English discourse; therefore, it is tempting to say that my identity did not change as I began to learn Spanish verbs. Instead, my text was simply evolving into a set of two language constructions that multiply my opportunities to narrate and communicate with others. However, such a claim cannot be supported. My engagement with Spanish did allow me not only to experiment with text but to reposition myself as someone dedicated to becoming bilingual. As I sought to learn more Spanish, and I began to follow Spanishspeaking Twitter and Tumblr accounts, the number of posts in my online feeds that were 
in a language other than English increased. The Spanish vocabulary I learned on Tumblr transferred to my comprehension of text in real-world situations. And in those moments where I recognize Spanish in daily life, I enjoyed identifying (at least in my own mind) as a bilingual, even though my progress in such areas is slow and I am far from worthy of the label. I share this experience to stress how language, while operating virally and independently, still returns to the subject and leaves her changed. The text we coauthored in this digital space rebounded upon and altered my authorial presence as well as my perspective on the world.

This experience happens for others on Tumblr, and it ideally constitutes role players in a matrix of multicultural possibilities. The notion of finding a role play "family" now means substantial work in decoding foreign turns of phrase and overcoming barriers to understanding in order to share the "love" of a narrative. Not only are role players chosen based on their writing abilities (see the Friends requirement of a multi-paragraph sample to audition), but they are also judged on their ability to speak more than one language. Below is an example of how one role player created a fan music mix for another role player with song titles in Lithuanian in order to honor a character's 
heritage:

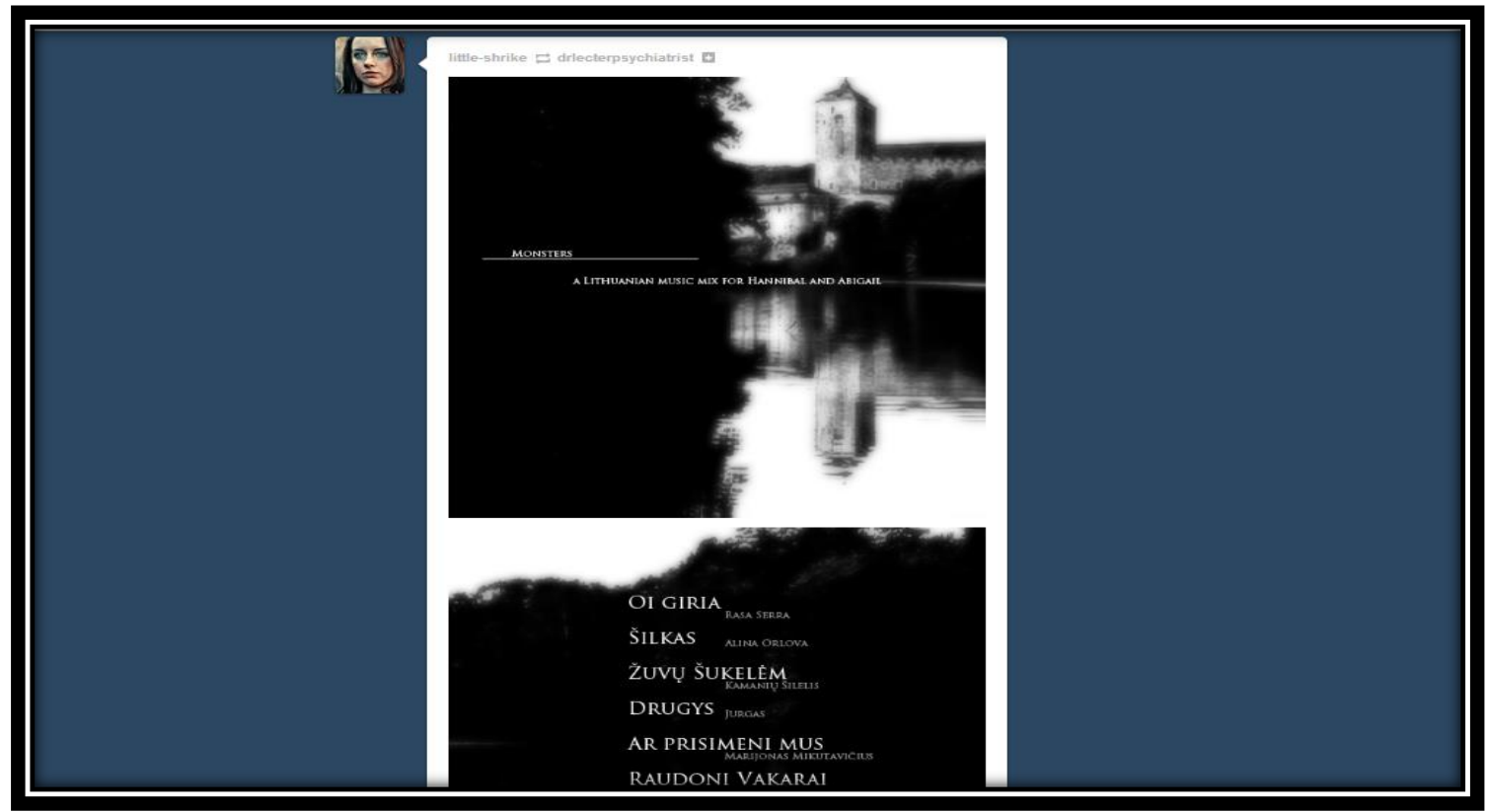

Fig 40: URL little-shrike reblogs URL drlecterpsychiatrist's fan mix for Hannibal

Blogger little-shrike reblogs a post from drlecterpsychiatrist in the above screen shot. Its contents feature the cover art and music selections that fit her own character Abigail Hobbs and her relationship with Hannibal Lecter in the show Hannibal. The title of the mix is "Monsters: A Lithuanian Music Mix for Hannibal and Abigail." In the Thomas Harris novels, Lecter as a character hails originally from Lithuania. Therefore, the songs and artists are featured above in Lithuanian to show how the original creator drlecterpsychiatrist is familiar with both the NBC television series Hannibal (as Abigail is only a character in this version of the narrative) but also the book Hannibal Rising that explains the early years of Lecter's life.

By translating and presenting text in a language other than English, I argue that drlecterpsychiatrist works to layer multiple critical approaches to narrative: the desire to make thematic choices that fit a character or characters' points of view, the graphic design necessary to make the blog appealing in terms of art, the effective synthesis of two 
different canonical texts, and the respect paid to the source texts about the protagonist's knowledge of multiple languages. The ability to speak more than one language on Tumblr as a role player showcases both the level of commitment to a character and the intellectual work with which a blogger engages to challenge herself. Indeed, role players acknowledge the challenge some bloggers face when English is not their first language. The following post compliments such writers:

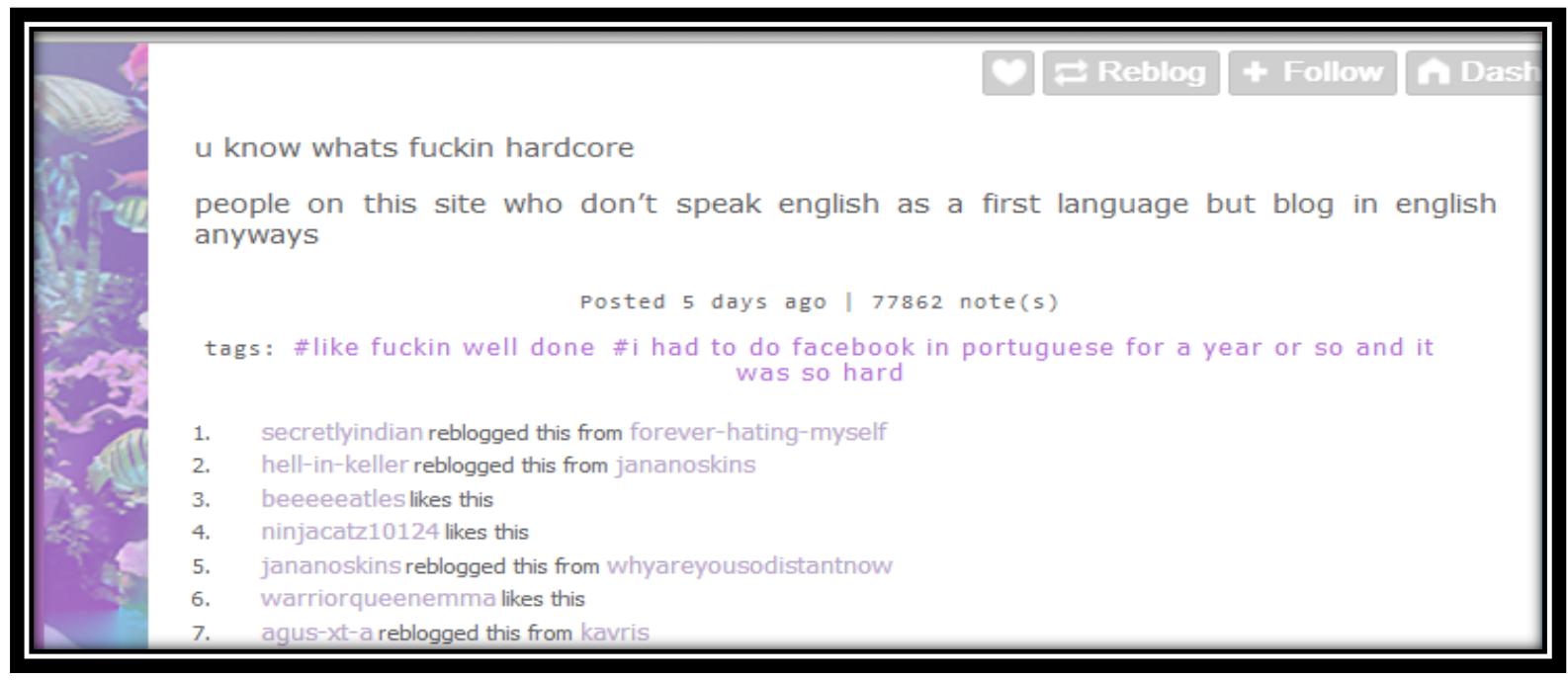

Fig. 41: Blogger fefarielle praises English language learners on Tumblr.

Looking at the information above, we see that user fefarielle believes that a blogger who writes in English even when English is not her native language is someone who is "hardcore." She acknowledges in her tags beneath the statement that "I had to do facebook in Portuguese for a year or so and it was so hard." This post, while a simple text message without punctuation or graphic design properties, was reblogged on Tumblr, at the time of this shot, 94, 631 times. This circulation occurred within three weeks (the blogger originally wrote the post on August 19, and I retrieved it again on September 2). What is also important to notice is how the text alone is not receiving praise. The people behind the text, the ones who are "hard core," are worthy of attention for the work they 
perform both online but also offline, where they practice and hone their ability to speak in more than one language. In other words, the author receives as much praise for the process behind the text as s/he does for the text itself. In examining these role play posts as living documents, it does benefit us to remember how personal effort and practice help produce textual artifacts worthy of publishing and forwarding. Still, the number of reblogs listed below the entry illustrate how the message lives in its own way on each separate person's page.

\section{Role Play as Influenced by Producers}

So far I have first discussed the textual properties of Tumblr role play blogs and then secondly analyzed my own cross-cultural experience on the site. This data features less guided writing and reading and more activity borne from individual role players. Nevertheless, the influence of producers and showrunners cannot be ignored completely, as bloggers often imitate these corporate entities in their own designs. To be clear, producers, thus far, have not engaged role players on the Tumblr platform, although some marketing staff work to maintain official Tumblr accounts in honor of certain shows, something I gestured toward in Chapter Three in a discussion of tagging and forwarding. But the influence of franchise developers and producers may be felt in the activities that role players design for their blogs and for their followers. In essence, the role player, when gathering a large number of followers, wishes to maintain the same level of narrative engagement with her/his blog that the showrunners and producers of the television narrative want to encourage during live feeds and syncing apps. Therefore, the blogger designs conversation starters and writing prompts that invite even those who are 
not role players to send in trivia questions and to seek attention from the fictional character whose URL is featured there.

What this behavior does suggest is that the influence of large organizations and corporations on our own love for narrative may not avoided entirely. Even in a community of role players, who design their own plots and versions of the characters, all bloggers still pay homage to the studio executives and producers who originally wrote and conceived of the fictional world. While they are not as eager to promote one preferred reading of their threads, they do often endorse and forward moments of consensus, particularly when inviting feedback. Tumblr bloggers often respond to writing prompts or questions typically if they have something positive to say to the role player. Critics remain largely silent, avoiding confrontation even in the form of anonymous feedback.

In the most basic of reblogs, the desire to be seen and heard is evident. Role players are aware of what Burke has already described in terms of the process of identification: "And often we must think of rhetoric not in terms of some one particular address, but as a general body of identifications that owe their convincingness much more to trivial repetition and dull daily reinforcement than to exceptional rhetorical skill" (Burke, Rhetoric 26). These daily reinforcements may come in the form of polls, questions, and trivia questions, just as they do in Story Sync. For example, user beverlykatzonthecase reblogged a post in which she asked the following: "In the middle of a conversation, my muse begins to cough up blood. How would your muse respond?" The prompt asks for a specific reaction in which her role play character and another person's character will engage in an inciting moment that could lead to a short or long 
scene. Most of these prompts include questions and scenarios that challenge their abilities to stay in character during a given situation. While such moments certain become trivial when repeated, the circulation of these texts suggests that role players are seriously concerned with the power of "belonging" and how rhetorical it may be (Rhetoric 28).

Some references even call to mind the idea of a narrative series that is either in progress or not. As such, role players who must leave the online world for a given amount of time will announce that they are going on "hiatus," a word that is also used to describe the down time between television seasons.

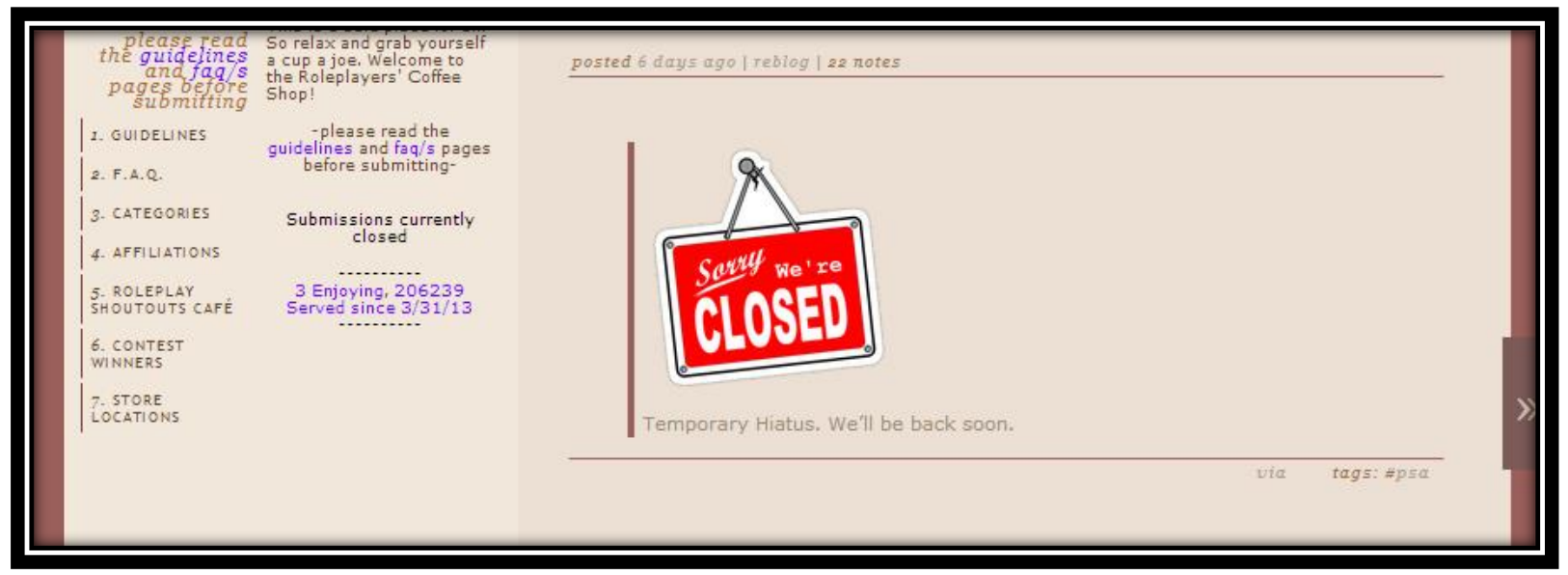

Fig. 42: The roleplayerscoffeeshop blog indicates that their blog will be on hiatus.

Above the screen shot indicates with a closed sign that the moderators or bloggers behind the site roleplayerscoffeeshop will be offline and, therefore, on a "temporary hiatus." The closed sign as a visual statement accompanies the news to draw on the idea of their blog being a space resembling an actual coffee shop where people gather to discuss ideas and write about their favorite role play activities.

Tumblr users often create participatory activities similar to those found in transmedia: online quizzes that allow visitors to their blog to vote on characters and ideas from their role play scenarios, requests for visitors to explain who they "ship" (or pair 
romantically) with the role player from the wider universe of role play blogs, and invitations to create music that matches their muse's tastes. Role players on these sites design their blogs to attract visitors and, consequently, followers. These followers are often role players in the same narrative, although exceptions may be made (it is not that strange to see an elf from a J. R. R. Tolkien fantasy novel writing a role play scene with Sherlock Holmes). While there is virtually no producer control, visitors to these pages may easily discern homages to the producers and creative minds behind the narratives. Television shows like Fox's Glee include activities now where one fan or viewer may win a prize for entering contests or becoming "fan of the week" (or Gleek of the Week) by posting responses to the show's page on Facebook. Likewise, role players have central blogs where "shout outs" to their favorite characters and players are archived. Like producers and writers who honor a "fan of the week," certain blogs also sponsor giveaways and prizes when they reach a certain number of followers (this practice occurs often when URLs reach a certain number of followers like 300 or 450).

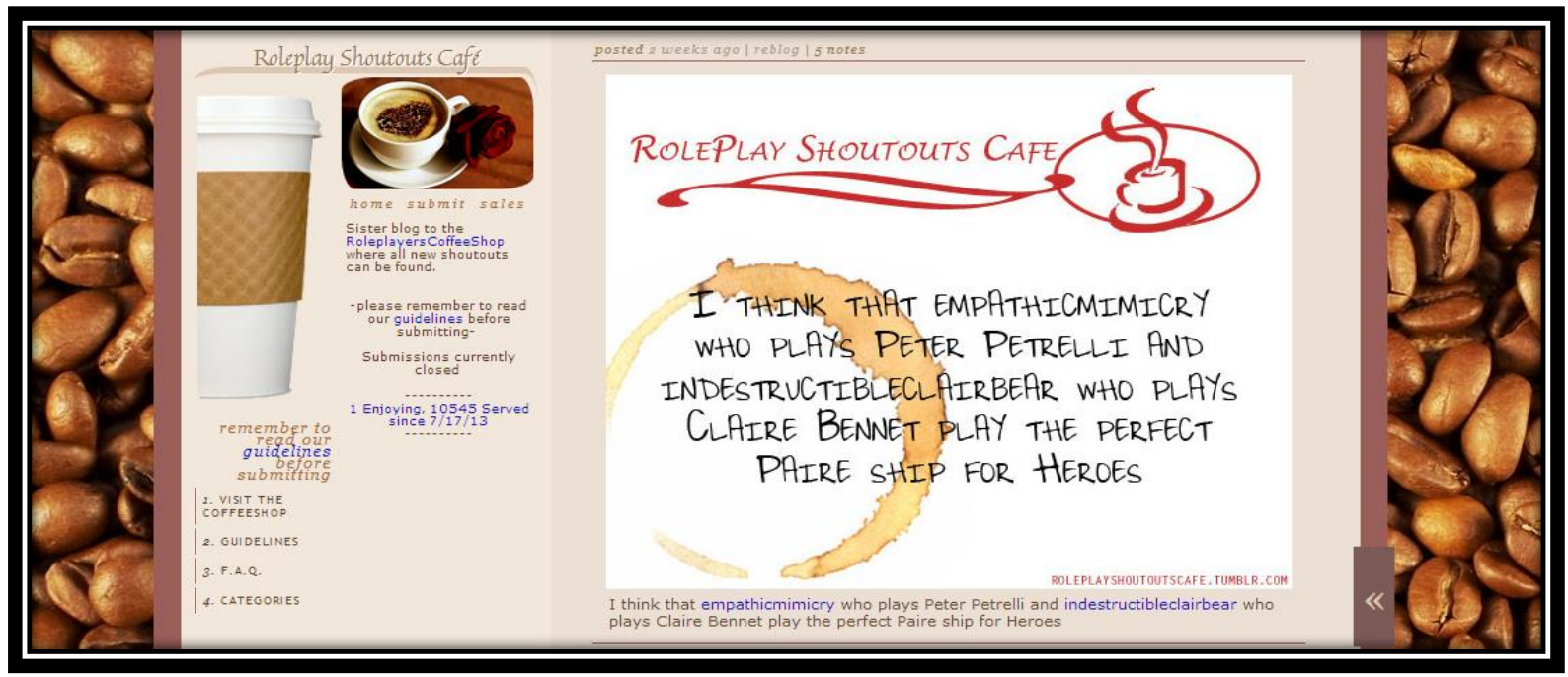

Fig 43: A "shoutout" blog post dedicated to two role players from the Heroes fandom 
Above we see how someone anonymously praised the two role players from the Heroes franchise for being a perfect pair. With shout outs, the goal is to tag the two bloggers so that they become aware of the compliment, but more importantly, a shout out might lead to increased traffic on a site, since many people follow the roleplayerscoffee looking for quality portrayals of their favorite characters from television. Like the Forward Fridays of Twitter, these statements authorize certain accounts and constitute them as important Tumblr accounts to monitor.

\section{Tweets}

$$
1 \text { new Tweet }
$$

Fig. 44: Studio promotion on Twitter of the new Starz television series The White Queen Role players also post promotional blogs to advertise one another's work. These posts resemble the official company tweets and messages send from studios. For example, above we see how the producers behind the Starz television show The White Queen promote their show on Twitter. Even though I do not follow WQueen_Starz (the official handle of the show), I still find this message (or tweet) at the top of my live feed because the people behind it have paid for a promotional placement. It becomes, much like the dialogue between myself and @ theFollowingFOX in Chapter Three, an inescapable encounter with a story world that I do not even support. Furthermore, the message invites participation and feedback. By saying "retweet if you know it pays to 
have influential friends," the producers urge those reading the text to respond by forwarding and endorsing their narrative world.

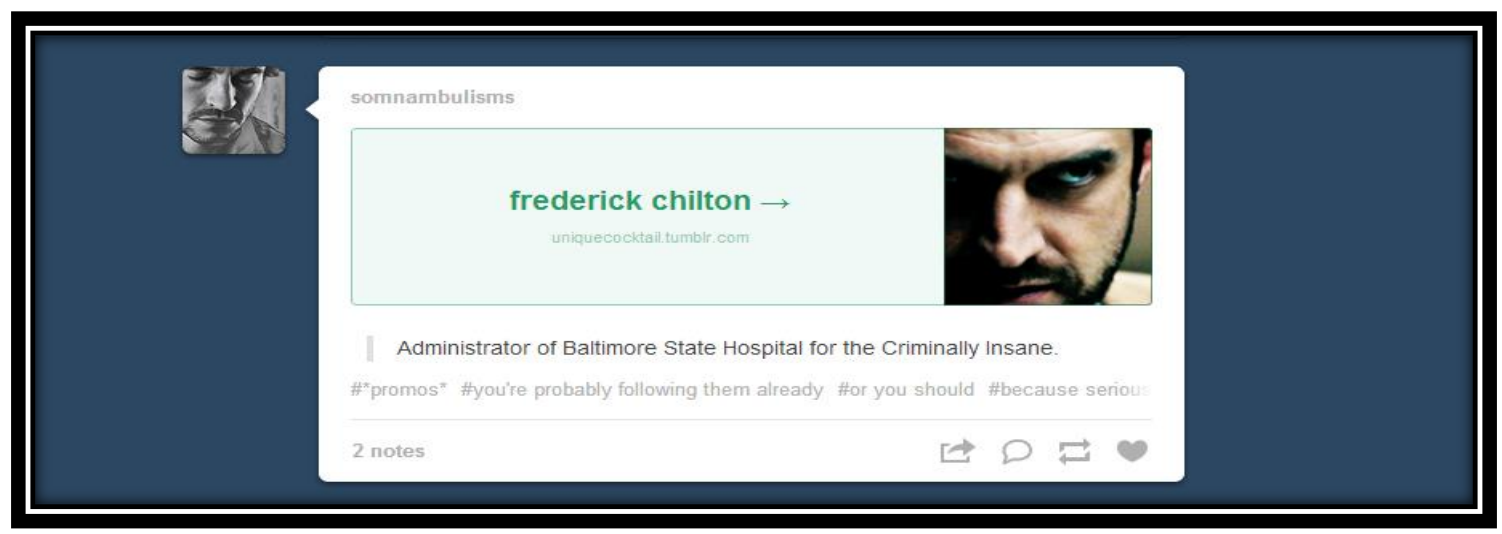

Fig. 45: Role player somnambulisms promotes role player uniquecocktail on her dashboard.

Above URL somnambulisms from the Hannibal fandom promotes URL uniquecocktail from the same fandom by providing a direct link to the blog. In this sense, members of the community act as one another's sponsors, as they ensure that the blog in question gains increased circulation and attention from others. Above we also see that the blog, while represented by an image to the right, one of the actor who plays Frederick Chilton on Hannibal, is not the only place our eyes are drawn. Beneath the arrow and name of Frederick Chilton is the proud URL address of the role player in question.

We might argue that this need to collect followers is not too different from the television system of measuring a show's success by numbers through Nielsen ratings. The numbers of people who watch a show live still determine initial signs of success, even in the age of computer and streaming technologies. Quantitative measures would seem outdated, since growing fandoms often acknowledge that loyalty, not numbers, determines the success of a narrative on television. However, the number of followers to a blog, not the number of visitors or "likes" a blog receives, still acts as the major 
indicator of cultural capital on Tumblr. Again, this reinforces the concept that writing only "lives" in circulation; without increased viewer traffic, the future of the blog's activities may be curtailed or abandoned due to lack of interest. It also nods to a somewhat posthuman view of the world, where numbers and quantities are measured more often than the voices of the warm bodies behind them.

Bogost argues that numbers alone do not measure what symbolic wealth might be found in the way games are engaged, and I extend his view to include these role play moments. He provides an overview of how assessment efforts in schools, advertising, and public policy all return to the process of numerizing our actions (507-12). His argument counters the power the numbers by explaining how procedural rhetoric works to counter them:

But as I have argued, procedural rhetorics can also challenge the situations that contain them, exposing the logic of their operations and opening the possibility for new configurations. Accounting for such results is impossible from within the framework of the system a procedural rhetoric hopes to question; the currency of such a system is no longer valid. (Bogost 512)

I spend this moment on numbers to foreshadow a limitation I introduce in my final chapter: the limitation of using qualitative research in place of quantitative research. The selection of these blog posts supports my agenda and my experience as it existed on Tumblr and extends to include examples that act as supplementary resources for that experience. Yet within the world of Tumblr is this reliance on numbers of followers and this belief that the higher the number, the more quality the role play or the blog. Existing 
without numerical measures means measuring our worth by other means, such as discursive analysis (Bogost 515), a method I use throughout this project.

We may gather from these activities that the decision to practice identification online comes with increasing responsibilities to the audience. The success of a URL remains heavily dependent on the promotions and feedback provided to it by both close allies and by anonymous readers and writers. It is not enough for the role player to practice identification as an individual hobby, although some still do so. For many, the activity is bound up in notions of narrative engagement with the role player's site and the amount of traffic a site receives. Without circulation and a host of URLs with which to engage in dialogue, a blogger's role play site remains what we might call a "dead" document online: one with no potential for animation or evolution.

\section{Conclusion}

Digital media scholarship has not yet paid much attention to how the cultural work of identification now occurs in the tense and dynamic space existing between procedural habits designed by humans and circulatory nature of online systems. While there have always been critical and reflective writing practices among fans, the posts on Tumblr speak to a renewed interest in procedural rhetorical strategies designed to make text circulate in a productive manner. Role play is also a major example of how imagining the world from multiple perspectives leads to cross-cultural inquiry as well as

the dialogue necessary to learn and grow as a writer. This site differs from Myspace and Facebook in that it supports a construction of the self as circulated text, with the URL handle signifying identity more than images of favorite things or lists of personal interests. 
Earlier I stated that I depart from Thomas's approach by placing more emphasis, at least at first, on the text as a living document and not on the author's thoughts as motivating elements of the rhetorical event. What works best in the analysis of Tumblr is to remember that the circulatory text motivates its authors to think differently about identity. While Thomas and others ask questions about writer identity as it exists during the planning and creation stages, I would argue that it is just as important to ask questions of what happens to writers after their text has circulated and then returned.

Intersubjectivity as a process becomes heavily dependent on the work of meaning production in text form and on the capacity to create a living message, one that does not ossify or close itself off to multiple ways of thinking and responding. While text circulates and multiple perspectives are entertained, the work of the text does not melt or merge with other texts but maintains some distinguishing features different from the texts produced by others. ${ }^{37}$ In other words, the diversity of text production means that different points of view still exist, even in a world where bodies, metaphorically speaking, act as extensions of machines in the form of alphabetic text. Each message is still different from the next one. And to imagine what that other text-producing machine uses as motivation to generate its themes and ideas is to perform a rhetorical act necessary to engaging intellectually with others.

Again, we cannot wholly divorce ourselves from the notion of the authoring subject even if that subject remains classified, at least on Tumblr, as the mundane persona adjoining the more animated and creative muse. In this sense the words "mun" and "muse" become particularly telling. Bloggers seem to think of their real world persona as

\footnotetext{
${ }^{37}$ Helpful to my thinking here is the concept of Mikhail Bakhtin's heteroglossia, which he discusses in "The Discourse of the Novel."
} 
the more mundane part of their existence while the role they play inspires them, like a muse. Yet moderators on these role playing sites still search not only for writers who produce quality work but for writers whose enthusiasm as "muns" (as seen in the screen shot from the Friends example) impregnates each textual moment. Thinking about the "mun" as a trustworthy and ethical player becomes integral to building trust among a cast of like-minded writers. Nevertheless, there is still room to study the act of forwarding as a disembodied event and a prime site for where valuable identification work takes place. The most useful places to view this process in action are digital ones, where meaning lives, evolves, and mutates to fit the needs of a community that circulates it.

The idea of imagining multiple futures and possibilities for characters through writing blog posts must first involve the willingness to see from another point of view. As Bogost explains, "Once a procedural rhetoric advances a new logic that a subject interrogates, it no longer remains possible to feign ignorance about that logic. Like love and revolution, procedural rhetorics persuade through intervention, by setting the stage for a new understanding unthinkable in the present" (754). As I mention previously, Massumi describes a process that is similar to the work of shifting perspectives when he describes how "thought-perception reaches into things, launches them up through the atmosphere of language, and in the same motion returns them, altered, into the depths of matter" (56). Although the procedures of role play in online spaces like Tumblr must be flexible enough to adapt to different cultures and languages, they still codify the acts of identification in ways that suggest awareness to the disembodied nature of text as it represents the author and is "launched up" into dialogue. Nevertheless, we return to the subject to find that while text has been "launched up," it has also returned to its 
originating point to transform its creator and dissolve the line between the mun and the muse, thereby making what Bogost calls this "new understanding" possible. 


\section{CONCLUSION}

\section{IDENTIFICATION AS A RHETORICAL STRATEGY AND CONSIDERATIONS FOR THE WRITING CLASSROOM}

In an article for The Guardian, science fiction writer Neil Gaiman explained that

fiction has benefits for creating and leading in an innovative society. In the piece, we hear the traditional homage to empathy, as Gaiman stresses that fiction "allow[s] us to function as more than self-obsessed individuals." But reading just a few lines after that statement comes the part of his argument that is more germane to what my purposes in this project have been. He explains that fiction helps us to discover that the world “doesn't have to be like this. Things can be different."

He follows this with a concrete example of how narrative has permeated the cultural boundaries of new arenas in our age:

I was in China in 2007, at the first party-approved science fiction and fantasy convention in Chinese history. And at one point I took a top official aside and asked him Why? SF had been disapproved of for a long time. What had changed? It's simple, he told me. The Chinese were brilliant at making things if other people brought them the plans. But they did not innovate and they did not invent. They did not imagine. So they sent a delegation to the US, to Apple, to Microsoft, to Google, and they asked the people there who were inventing the future about themselves. 
And they found that all of them had read science fiction when they were boys or girls.

Here Gaiman links the work of enjoying narrative to innovation and potential to create or build. Whether or not we agree that such an argument of causation is valid, we still acknowledge that imagination and the cultivation of it creates room for more options when solving problems. Such cultivation of imagination, as expressed in the example above, is something, it is safe to suggest, that we hope to find in an intellectual public as well as inside the classrooms of our universities. While we are privileged to experience what some have called a "golden" age of television narrative, the power of stories to help us imagine alternate realities has always been important.

The identification process, for many viewers or readers, is what makes these moments of narrative immersion so powerful. I argue that the identification practices accompanying the enjoyment of narrative help shape our experience and create opportunities in which we may shift our perspective and imagine alternate answers to questions or problems. Such an ability is valued in the public arena as well as at home with our favorite book or television program. Each generation confronts issues that require discussion and attention and, in turn, finds themselves charged with the creation of solutions. To be sure, today's public issues of health care reform, environmental preservation, and same-sex marriage are just a few ways people today might try to understand multiple points of view. Such examples of role play as a means of persuasion are not new. As I introduced in Chapter One, the practice of prosopopoiea dates back to ancient Greece. Crowley and Hawhee explain that the work of this activity helped public communicators to "create conversation that gives clues about a person's response to 
situations" (239). This idea of conversation as a means to perform intersubjectivity will be helpful to me in the pages to come. In this last section I will explain how we see identification at work in public argument and how it often involves the use of both pathos and logos (in this case, procedural rhetoric). This emphasis on civic argument has implications for how we approach the act of teaching writing. Therefore, I will conclude by showing how identification as a tool in teaching argument could be a more prominent part of our writing classroom ecology.

I begin with an example of civic argument that invokes pathos as its main platform for persuasion by way of prosopopoiea. In this case I seek to show how identification works in traditional texts as well as pop culture. David Kirby in the nonfiction Death at Sea World asks the audience to identify with a killer whale in order to prove how oppressive captivity must be for sea creatures held in large amusement parks for entertaining the masses. In it he places us directly into the role of a swimming whale at sea:

Your family senses something is not right. They begin turning away from the boat, which has never before gotten so close. Your mother issues a shriek. Danger! Flee! Now! Confused and gripped with terror, you make a run for it, trying to catch up....

Then you are stopped. You kick your flukes furiously, trying to propel yourself through the water, but you cannot swim. You realize you have darted directed into the lacy curtain. So has your entire family. (Kirby 80) 
The words, taken from the second person point of view, are meant to thrust the reader into the identifying role of cetacean so that the audience will recognize the terror associated with being ripped from a natural habitat and separated from family. Certainly this particular passage is easy to interpret in terms of its political agenda. We know from its content that the author wants us to view reality in terms of animal rights and environmental concerns. The pages prior to this passage contain sentences like, "The sunsets are spectacular" and "You are a happy little whale." On the heels of the scene above, however, are such heart-rending comments as "What is going on? Where is your mom?" The section of the chapter goes on for seven pages, until it concludes with the event of a killer whale seizing a trainer's foot and dragging her to the bottom of a pool. This event is not helping us understand a fictional world as much as it is helping us reenact a tragic moment in the history of sea park management in the United States. Therefore, it illustrates how we experiment with perspectives not only to talk about our favorite stories but to make an argument about what we consider ethical. Writers or speakers often employ identification to make their audience feel point of view more strongly and to appeal to pathos.

More recently, as I explain in Chapter One, blogger Liza Long used identification to grab her audience's attention when she announced that her experiences with her mentally ill son made her feel like "Adam Lanza's mom.”

We engage in the act of prosopopoiea in order to imagine the feelings of other subjects and, in the case of the whales or Long's mentally ill son, become advocates on their behalf. These experiences often stir negative emotions of fear and disgust. However, many experiences with narrative involve the opposite feelings of joy and suspense, often 
at the same time we confront fear of the unknown. While identifying may lead to concrete steps of action or simulating multiple solutions to a given problem, it is also certainly bound up in pathos. The work of the role player, the blogger, the viewer---their participation in online platforms stems from a love of story. However, this ability to love and enjoy does not discount the serious work of identification and how it calls for a discerning mind.

\section{Procedural Rhetoric}

Logos plays a significant role in these persuasive moments, just as pathos does in Kirby's example. This is where the idea of procedural rhetoric becomes helpful as a lens to identification. Procedural rhetoric takes into account the emotional and logical implications of being changed through the input of data. While we initially view the word procedure with an eye for disembodied, linear steps to solve a problem, Ian Bogost sees it as the process through which we change our point of view permanently. To do so, means feeling and thinking our way through an activity so strongly that we view the world with different eyes. His work centers on studies of games that, through their processes, convince the player to see a social problem differently than s/he originally conceived it. In this sense, it is not that different from Kirby's attempt to have his readers see through the eyes of a whale. The main factor separating Kirby's passage from the video game is the input of data by the reader.

At one point, Bogost likens the analysis of gaming and its ability to persuade to the work of Judeo-Christian rhetoric, where a homily led by a preacher operates in a "conceptual space" in which the parishioner "might reconfigure his personal life" (734).

Faith, argues Bogost, is based on a certain agreed set of artifacts and messages (or 
scripture). These tools prompt others to consider how to act beyond the church service. The pastor need only call upon these items to pull his audience into a state of deliberation about their lives. Similarly, games, with their own artifacts and messages, produce spaces for deliberation (732), and I would extend this to say that transmedia in the form of live feeds and apps does the same. Once the session or live viewing is completed, the opportunity to see the world differently presents itself to the player or viewer. It is not that apps persuade us to do something differently at that moment in time. Procedural rhetoric "produces deliberation, which implies neither immediate assent nor dissent" (Bogost 732). The transfer of the game's lessons occurs over time and with specific reflection. Therefore, when social media prompt me to answer a question about narrative on Twitter, I am not persuaded in one specific way to act differently or to take on a point of view in the truly embodied sense. But I am deliberating on the importance of character and plot in ways I might not have if the question had not been posed. In this sense, I am being persuaded of the significance of certain elements of narrative and allowing myself to be constituted in a social activity surrounding that narrative. Over time, those moments combine to make me a stakeholder in the narrative's outcome and a willing supporter of the protagonist.

In my project, the material conditions often required to enter these digital conversations and deliberate on narrative are the mobile applications and/or social networks that we take with us into the various settings of our lives. This form of data, it may be suggested, best represents where our culture is headed in terms of communication. These forms of technology have crept into our life activities without any substantial demands on our skill level or time. The apps discussed here are simple study 
guides or simple data representations and require little training to operate. For example, I began with the weather application that connected the weather of Game of Thrones to the weather in our home cities. Such a statement "As in Louisville, so in Winterfell" marks the atmospheric conditions locally but then broadens imagination to take in the potential setting of another world. When the subject is asked to identify with something new and unrelated to the daily life in which s/he lives, deliberation takes place, however temporary, and such deliberation becomes a marker for future changes in perspective. Over time, checking the weather and syncing one's home experience with Winterfell's climate has an impact, however small, on how we conceptualize reality. Identification as a means of persuasion is an additive and cumulative process.

\section{Classroom Implications}

This cumulative process has implications for how we learn. My attention now moves to the procedural quality of how student writers approach tasks of deliberation and how they unfold in the classroom. Students make up a significant part of the population that currently enjoys role playing, blogging, and viewing complex narratives on television (from secondary school on through nontraditional adult members of a university program). When students put these games and blogs aside at school, teachers often ask them, in formal settings where they will be evaluated, to shift their perspectives in order to understand someone else's point of view and represent that view fairly in words and in speech. This is especially something we ask of first-year college writing students who are engaged in "critical thinking initiatives" that prompt them to approach contemporary issues with discernment. If so, does the process of prosopopoiea as seen on Tumblr, Twitter, or Story Sync have anything to offer us as instructors of writing 
students? What kind of academic value might we find in an activity that allows people to feel intensely as if they are in the shoes of their favorite characters?

In a recent thread on the Writing Program Administrators listserv, Irvin Peckham explained, as he does in Going North, Thinking West, how teaching students to put emotion aside and deal in "pseudo-objective" and/or "depersonalized" language fall victim to middle-class ideologies where one version of rational thinking is supported as better than others. My response to his observations would be that we unite the work of perspective shifting as it is described in academic discourse to the work of narrative and find productive ways to tie the two together-ways that engage writers in procedural activity that appeals to the public's definition of hard work and dedication to a task. The role players in the Friends example that began Chapter Four advertised that they wanted writers who would be both "enthusiastic" but also consistently present; three days of absence from the work of role play would be grounds for dismissal. It would be difficult to view such rules as indicators of a mindless enterprise. Still, in Shimmering Literacies Williams explains how pleasure is often associated with "nefarious" matters of wasting time or engaging in mindless activity (174). He further explains that critics from all political backgrounds find reasons, especially in the academy, for being suspicious of anything that might prey on our passions and thus result in an "ignorant and vulnerable population" that cannot articulate their points of view clearly enough to enable any sort of productive intersubjectivity work to take place (174).

I do think that the processes associated with character identification, besides giving us interesting models in pop culture with which to experiment with text, do have implications for how we teach the act of dialogue or research in writing. I also believe 
this process may be infused with both logos and pathos alike, since the art of conversation is one that is dynamic, unpredictable, and emotionally charged. Here I move from the example in Death at Sea World and the text of narrative to the material of the university freshmen writing class, where narrative texts like the Kirby one above may be incorporated into the curriculum ${ }^{38}$ liminally but rarely substitute for an argument-based syllabus that requires a research paper as its cornerstone project. In other words, the study of what happened at Sea World, while captivating and persuasive, does not often replace the "stuff" of academic writing, in which the point of view remains, as Irvin Peckham says, a "pseudo-objective" and unemotional enterprise. Identifying with a killer whale-in a book, movie, or TV show--may not receive the same attention, in most cases, as the attention to proper citation, bibliographies, and possible reading of journal articles.

Upon observing an instructor last spring who was teaching English 102, the Intermediate College Writing class at my university, I was fascinated by how she involved students in seeing from multiple perspectives. The assignment that day was to create a cartoon strip, based on the interchanges of two scholars who held different opinions. Inside that strip, the perspectives of each would be represented in speech bubbles. The teacher encouraged students to consider whether the scholars, as the figures

\footnotetext{
${ }^{38}$ Most universities encourage teachers, particular writing teachers, to adopt a book in common that raises questions about identity, the American dream, and/or current issues in the news. Often, while such books are not engaging us in the kind of fictional work that Game of Thrones does, they still anchor their examples in a discernable narrative or plot. At the time of this research, my own school had adopted This I Believe. When I had taught freshmen English my first year at this same institution, the book chosen for discussion was Freakonomics. This practice of using contemporary texts to inspire writing shows how hard it is to sometimes divide the work of narrative and reading with discernment and the production of writing. As Story Sync and other programs show, the ability to read well allows us to enter the conversation with more gravitas than it would if we did not view or read with some degree of sophistication.
} 
in the cartoon, were "agreeing, building on each other's claims, or calling each other out." Students then exchanged their drawings and commented on one another's perspectives as artists, thereby increasing the levels of awareness that meaning always comes from different points of view. What impressed me most was the teacher's discussion after the activity ended. She stressed that while the genre of a cartoon may appear, to some, to be silly and inconsequential, the work of representing differing perspectives was anything but. She argued that engaging in this process was, in effect, a translation activity rather than a goofy exercise.

In 2006, another activity occurred in my own classroom that featured the experimentation with multiple perspectives. I had my students, who were reading The Great Gatsby, set up Livejournal accounts (a free blogging service) as specific characters from the novel. As we read and discussed this work of literature, they were in charge of maintaining their site according to the events transpiring on the pages. At the end of our unity on Gatsby, each student would give a presentation and answer questions about the writing done on this role playing journal. I was using role play as my available means of persuasion. By requiring that students see from another perspective featured in the novel, I hoped to convince them that the literature I required them to read was important, dynamic, and, above all, still a "living" narrative. Further, I hoped to constitute them in a set of subject positions that spoke to this very concept. Within this activity were many opportunities for emotional and affective exploration of character. I even required students to dress as their characters on the final day of this particular unit. Humor, excitement, frustration, and enjoyment were among the many reactions to literature in my class on those days. 
Upon initial observation, it may seem that the two anecdotes above have little in common. One takes place in a post-secondary world of a general education requirement at a large public university, while the other occurs in a private high school classroom. But the intent behind the class activities of both instructors (myself and the other college teacher) is the same: we use activities to convince students that writing and reading are living, dialogic enterprises meant to be taken seriously. While digital technology plays little part in the composition of the cartoons in the university example (although it is certainly multimodal), it plays a significant part in the shaping of the second story based in high school. To role play in my class, students had to establish accounts on a free blogging service, pick an image that represented their character (a famous actor usually), and enter descriptive narratives about their fictional lives. This assignment resembled the work of role players today on the site Tumblr, only these students did not create these blogs on their own but under my direction and, of course, with the aim to make a good grade.

We might initially understand how identification plays a role in the literature class, where students role playing as characters engage more deeply with a novel's themes as a result of their participation. But what is the work of identification in writing, and how does the first example speak to it? This type of activity — the one with the cartoon featuring multiple scholars in conversation-occurred in a spring semester composition course that culminated in a research paper. To help students do what we in composition call "enter the conversation" (see Graff, Birkenstein, and Durst), faculty may engage in a number of class exercises and homework tasks to build students' confidence in representing other people's points of view. Indeed, at this same university-my home 
institution--one of the four major traits of "critical thinking" for undergraduates is the ability to "situate a claim or argument in a larger context and acknowledge that there are other perspectives or interpretations of evidence" (University of Louisville Critical Thinking Rubric). Our composition director, upon presenting the findings of a general education assessment administered in 2010 at this same institution, said that students struggle most with this ability to enter conversation with other perspectives in research and writing assignments. According to a memorandum sent to Academic Deans in 2011, assessment of 1093 student artifacts revealed that out of a maximum score of 4 , the average was lowest -2.39--for the skill of "showing awareness of multiple points of view” (General Education Curriculum Committee Office of Assessment Results). Furthermore, an assessment of the writing program at the University of Kentucky, found online at the WPA Council website, concluded with similar findings. Among the learning outcomes for Kentucky's first-year writing course was the need for students to both “develop perspectives that take into account various forms of evidence and points of view" and "engage in a range of writing activities to explore and express their experiences and perspectives" (emphasis mine). Ongoing analysis revealed that "students appear to be less able to engage in sophisticated analysis, to establish a strong sense of ethos, to use supporting evidence effectively, and to evince an awareness of multiple perspectives on a given topic."

What this data suggests to me is that somewhere between the activities we use to involve students in shifting perspectives and the actual outcomes we measure, students are not feeling confident about their ability to balance multiple points of view in written compositions, especially in inquiry and research-based writing tasks. Because teaching 
students how to entertain multiple perspectives is a challenge, instructors choose varied methods to meet this goal. While some teachers ask students to role play a dialogue between two people or more people who represent oppositional sides to an arguments, others assign textbooks like They Say/I Say: The Moves that Matter in Academic Writing because such texts focus explicitly on template design and the ability for novice writers to "enter the conversation" with particular signal phrases and signposts in writing ${ }^{39}$. Peter Elbow's famous "believing and doubting" game, originally explained in the Appendix of Writing without Teachers has been used frequently in composition classrooms to facilitate practice of this ability to see more than one point of view.

The producers behind Story Sync and Twitter live feeds often make the same discursive moves toward simplicity of conversation in order to let audience members enter the viewer conversation quickly and effectively. In Chapter Three, I address Burke's metaphor of the parlor found in The Philosophy of Literary Form. Ellis reminds us that in Burke's version of the conversation metaphor, the conversation in the parlor is, as he literally says, "unending," one that "never arrives at a final destination" (65). But how do conversation as a writing metaphor and the idea of identification intersect? To begin, we might look closely at one article that explains research as a conversational enterprise. This article is the first in the textbook titled Writing about Writing, a book

\footnotetext{
${ }^{39}$ Such templates include the following formulas for relating new ideas to previously articulated ideas, or the additive model of knowledge: "Her argument that is supported by new research showing that ." (8). Also, template design is built to highlight the student's role as conversant in a dialogue with other scholars: "I disagree with X's view that because, as recent research has shown, "(60). In other words, the "moves that matter in academic writing" as Graff, Birkenstein and Durst call them (see book jacket), are the formations of sentences in which what "they say" previously comes in direct contact with what the student, or the "I," will say now. This bestseller then prompts students to practice the art of conversing with multiple perspectives using readings from politics, economics, pop culture, and sports.
} 
designed to introduce writing students to some of the most central arguments and ideas in Rhetoric and Composition. Stuart Greene says,

Argument is very much a part of what we do every day: We confront a public issue, something that is open to dispute, and we take a stand and support what we think and feel with what we believe are good reasons. Seen in this way, argument is very much like a conversation. By this, I mean that making an argument entails providing good reasons to support your viewpoint, as well as counterarguments, and recognizing how and why readers might object to your ideas. The metaphor of conversation emphasizes the social nature of writing. (10)

Greene lucidly states what many textbooks and template exercises take pages to explain: the work of argument is to converse, not simply prove someone right or wrong. This clear path through the muddy territory of teaching researched argumentation in the writing class does not remain clear for long, however. The very work of entering into conversation takes practice, a great amount of practice. Greene also cites Burke's parlor metaphor in his article, explaining that "every argument you make is connected to other arguments" (11). Now we have a note about the viral and additive nature of this process of writing. The idea of using conversation in viral and additive places like microblogging sites seems less strange after considering that the work in such places is quite similar to the work we hope to do in teaching the research process.

Still, Burke's parlor metaphor and the questions on Story Sync about identifying with a protagonist are pieces of rhetoric that exist on different platforms and for different audiences. Burke's explanation of how knowledge builds over time and the work of The 
Walking Dead producers who ask audience members to identify with Rick are not written for similar purposes. Yet part of the processes behind each suggests an emphasis on productive intersubjectivity. By productive intersubjectivity, I mean to say that knowledge acquisition happens by way of encountering other mind sets with the idea of furthering understanding rather than shutting it down. The parlor metaphor is built on an image of multiple communicators existing in some degree of concord, even in times of disagreement. A community forms out of the shared desire to advance knowledge. Certainly this also raises questions about the role of consensus. Attending to different perspectives should not result in univocal conclusions, and I address this concern with the use of Twitter hashtags in certain live feed conversations. In an ideal situation, knowledge should not result in consensus but productive opposition and extension as well as agreement. Even as consensus results from some producer-led activity, we still see evidence - on Twitter, Tumblr, Story Sync--of a new parlor forming through digital networking, one that is additive and ongoing.

Some writing teachers and scholars rely heavily on Burke's metaphor (see Harris; Graff, Burkenstein, and Durst; Greene) to explain how writing an argument works. The thesis statement central to most argumentation results from opposing, defending, or extending the ideas of previous writers who held opinions about the topic at hand. It is not that difficult to conclude that school and second screen applications are two sites of writing that may not easily intersect. While this project studies the rhetorical nature of applications and networks and is not pedagogical in design, I believe a careful study of live feeds could have implications for how we incorporate the conversation metaphor and the notion of collaborative thought into our teaching of others. Bogost's first part of his 
definition of procedural rhetoric deserves attention again; he explains that such rhetoric is "the practice of persuading through processes in general and computational processes in particular" (17). Encounters with Bogost, Hayles, and Deleuze and Guattari invoke references to the living, dynamic nature of such processes and encourage us to look beyond the singular author and focus on the network of encounters that shape any perspective.

Research as a way of teaching abstract concepts like intersubjectivity often fails, not because a student or teacher does not strive to honor the intellectual work of shifting perspectives, but because few examples of nuanced, complex dialogue exist that might help us nudge students toward a better understanding of the living nature of voices in contact. Embodiment is often absent in projects where written research attempts to capture multiple points of view. The sources or citations used to support an argument become afterthoughts rather than representations of various subject positions or prime movers in a conversation. Such problems often appear in the most creative and engaging composition classes. I would then argue that this moment of trouble in a classroom might benefit from the use of narrative in which different points of view reveal themselves throughout popular culture narratives or through the kinds of transmedia that Jenkins and others describe in Chapter One. For example, television episodes like "Bad Blood" from The X-Files and "Four Corners" from ER (as well as other examples mentioned in Chapter One) might be incorporated into the classroom-incorporated as prompts for discussions that address intersubjectivity and fair representation of secondary sources. Student reactions to these narratives could be blogged or tweeted to mimic the live feeds that support evolving conversations during broadcasts. Such narratives go beyond 
template teaching like the kind found in textbooks to show how different points of view are not easily captured through a formula. Textbooks are less apt to capture the work involved in intersubjectivity than cultural texts, and I include Death at Sea World as one such cultural text worthy of adoption into a curriculum. The pathos used by Kirby reminds us that the whale, as a representative of the embodied author's campaign against animal harm, has a vivid, active role in shaping our imagination of a current debate in our culture. The voices within the Burkean parlor are not just conversing but having a "heated discussion," which suggests that pathos and logos are intertwined in the work of exchanging perspectives. Such "heat" stems from a passionate dedication toward persuading others to see from our own point of view.

Not all writing classrooms incorporate templates, but it is fair to say that a large number of college English departments possess mission statements or educational objectives that mention the words "perspective" and/or "point of view" in conjunction with critical thinking initiatives and attention to scholarly discernment. Moments of teaching students to "believe" and "doubt" are helpful in the process of learning how to see beyond one point of view, but they again return to binaries and columns of beliefs that do not enter dynamic conversation but act as lists or ideas that, rather than acting upon or on each other, simply remain parts of a static whole.

Teaching attention to nuance and the ability to simultaneously entertain and oppose a given idea from another point of view is difficult, even when templates point the way with suggested phrases or transitional words. What we see in the narratives of television today is a careful, complex treatment of ideas and events that often involves the 
perspectives of an entire cast (see Lost). These perspectives overlap, align, extend, contradict, question, and inform one another in ways that textbooks cannot easily capture.

The apps that accompany such narratives and facilitate dual-screen experiences are not too different from the activities some teachers are adopting in the classroom today. While I speak mainly about writing classrooms, these examples have interdisciplinary implications. As I mentioned in Chapter Two, the use of iClick, a technology that allows students to vote or respond via a clicker and then see their results tallied on a large screen, is common in some large lecture settings. The idea of iClick is to simulate a more participatory and dialogic classroom, despite the large numbers of those in attendance. Additionally, instructors have been experimenting with live feeds and Twitter use both during and after their classroom meetings. One need only Google the terms Twitter and classroom to see dozens of blogs dedicated to teaching instructors how to use microblogging tools to facilitate conversation. The teacher tweets announcements or asks questions, and the students may be prompted to respond. Writers like Christopher Johnson and Geoffrey Sirc note the importance of learning how to pack meaning into discrete chunks of information. Because the way we read is changing to reflect more Internet-based skimming and brevity of information, we should be training students to adapt to this new form of textual interchange (70-72). Hayles refers to this practice of reading as "hyper reading," and she explains that it brings about "cognitive and morphological changes in the brain" (42). The ability to move quickly across and within texts that are short but viral in nature plays a significant role in reading and writing. 
College instructors are also allying themselves with producers to create transmedia experiences. In September 2013, for example, AMC's The Walking Dead included links to a massive online open course offering based on its narrative of the zombie apocalypse. Led by professors at the University of California at Irvine, the class would teach its members survival skills needed to confront future disasters. According to UC Irvine's press release, “[T]his MOOC represents a unique level of experimentation in teaching and learning by formally infusing an academic syllabus with contemporary media. It's also the first time a technology firm, entertainment company and major university have collaborated in this way." The eight week course involves multiple disciplines, with lessons originating in the fields of social science, mathematics, physics, and public health. The entertainment company's move toward using university spaces and methods to sanction and enhance a narrative world speaks to a larger cultural trend in which identifying with stories leads to new knowledge--knowledge that provides resources through which to imagine multiple futures and develop problem-solving tools to meet those futures. Digital rhetoric again acts a constitutive force for helping subjects unite in a common love for story world via the simulation of different points of view.

Online participation, whether in a massive open course, a blog, or in Twitter helps people see writing as a dynamic conversation. When the topic is narrative, the conversation is often guided by the work of identification. While such technologies assist in the learning process, they also raise questions about the making of consensus and the desire to have students act in concord. Like the producers who prompt viewers to answer what their favorite part of the night's television airing was, teachers may not initially realize how live feeding and prompts push their students toward a preferred 
perspective of learning. Certainly teachers know that technology creates situations of surveillance and that monitoring students online comes with its drawbacks. Yet I argue that the more salient concern is the adoption of dual-screens as a tool to bring all members of a population toward a preferred reading of a lecture or idea as presented by the person in charge.

At this time, as we learn how to adopt and use these tools, reflexivity and careful consideration of how these tools are being used is necessary. Such a statement may seem like common sense. To most scholars with a background in Rhetoric and Composition, the call for reflexivity in pedagogy is nothing new. Yet because apps are relatively new technologies, we are often so entranced by their capabilities that we may miss the underlying production of consensus that lurks in our classrooms. The teacher who asks her/his students to "live tweet" a homework reading, a live presentation, or a class lecture, may unwittingly place a certain expectation on that student to be positive, conservative, and neutral in response so that the culture of the classroom becomes one view of how learning takes place. As we assign a given hashtag to our class section, we do create boundaries for participation not only by assigning one title to the activities taking place but also by creating another version of template use. Students may also resist our desire to grade or monitor the things they say on popular platforms like Twitter, since many of these conversational spaces are ones they are accustomed to working in without being assessed or critiqued. Twitter's capacity to generate messages in 140 characters or fewer, and its public, viral nature echo the need for students to "enter the conversation" in ways similar to those advocated in books like They Say/I Say. Books like They Say/I Say teach valuable lessons but should be supplemented by a careful, nuanced study of how 
perspectives shift and present themselves in more complex ways. Likewise, instructors who align themselves with commercial interests (the UC Irvine professors and The Walking Dead MOOC) will confront their own set of questions about the value of grooming new fans under the auspice of teaching students survival skills in end times. Such activity, when designed as part of the transmedia associated with promoting a narrative world, deserves what the New London Group refers to as Critical Framing (see Chapter Two).

\section{Ethical Implications for Contemporary Apps and Narratives}

These ideas about writing mentioned here in this project first begin with considerations about general audiences of narrative (one that consists of all ages), and then consider the implications of how such audiences may be learning and writing in ways that inform our practices with students. Now I leave the classroom once again to make final conclusions about how identification has become a common practice in our culture at large.

Although the idea of fiction prompting us to imagine different realities is not new, it is not as common to think of writing and conversing with others as doing the same. But I would make the case that writing ideally functions in a similar manner, not just in the classroom but beyond it. For example, John Duffy, in his presentation at the Thomas R. Watson Symposium this past year, explained that writers (and particularly scholars in Rhetoric and Composition) might consider taking up the charge of adopting Aristotle's intellectual virtues as a foundation of their work and especially consider them in our relationship to audiences. 
Writing involves ethical choices because every time we write for another person, we propose a relationship with other human beings, our readers. And in proposing such relationships we inevitably address, either explicitly and deliberately, or implicitly and unintentionally, the questions that moral philosophers regard as ethical: what kind of person do I want to be? How should I treat others? How should I live my life? For writers, these questions may be rephrased: what kind of writer do I wish to be? What are my obligations to my readers? What effects will my words have upon others, upon my community?

To say that writing involves ethical choices is not to suggest that Story Sync and Twitter conversation prompts are striving to make us better people through asking us to identify with characters. But the choices of who we choose to identify with and how we identify relate to the questions listed above in Duffy's passage. Although producers may not be aiming to help us answer such questions as "how should I live my life?", their activities speak to a cultural trend in which public writing and reading practices involve imagining life from another person's point of view. As we imagine these different perspectives, we gain a better sense of how we might wish to live our own lives and, consequently, how we might practice discernment in communicating fairly with others. Certainly such goals are often found in the mission statements of universities and colleges, where marketing experts must distill in concise sentences the educational objectives of training a student for the larger world of employment and civic duty. But outside the walls of those institutions, programs like Story Sync and social networks like Twitter and Tumblr are also trafficking in similar ideas. 
In analyzing these networks and applications with attention to ethics, we realize that producers neglect some perspectives. As I explained in Chapter Two, the protagonists in a large number of primetime network and cable television shows are white men. While writing this conclusion, Alyssa Rosenberg published a column in which she stated that if the U.S. was represented solely through primetime television characters, race and gender would appear radically different. She presents this list of figures as indicators of the homogeneity common to television narratives and as signs that the fictional populations in these narratives skews in favor of one dominant point of view:

-Half the population would be white men.

-Five percent of the population would be black men.

-Just 1.9 percent of the world would be Asian or Latino men.

-Overall, 57 percent of the population would be men.

-34 percent of the world would be white women

-3.8 percent would be African-American women

-And 3.8 percent would be Latino or Asian women

While Rosenberg admits that her figures here are "rough" and that she is no media scientist, the trends suggested by these numbers offer some ground for conversation. Identifying with Rick on The Walking Dead becomes indicative of a larger motif in which the eye (again, see Jack Shepard from Lost) through which we repeatedly gaze at narrative events centers on the young, white, middle-class man.

I use this moment to transition and consider the future of these kinds of studies I am doing here. At this point, with Rosenberg's "rough" numbers listed above, I feel it 
necessary to speculate how future research on consensus, perspective, and other abstract concepts might be addressed with a different methodological approach in mind. Her argument, while based on quantitative data and more in line with social science approaches, makes a stronger case, at least to some of her readership, about how numbers speak more rhetorically than case studies representing a handful of narratives.

\section{Future Study of Digital Rhetoric and Closing Comments}

In this study the thick descriptions of these applications and social network live feeds include brief nods to posthuman ideas of disembodiment and the viral nature of information to exist outside the author's control. These descriptions, at present, are not accompanied by computational procedures and the ability to mine data that might better ${ }^{40}$ support certain arguments. Cultural studies projects may come to embrace the gathering of data, where aggregate numbers are pulled from Twitter feeds to determine degree of consensus based on the use of positive or negative responses to television narratives.

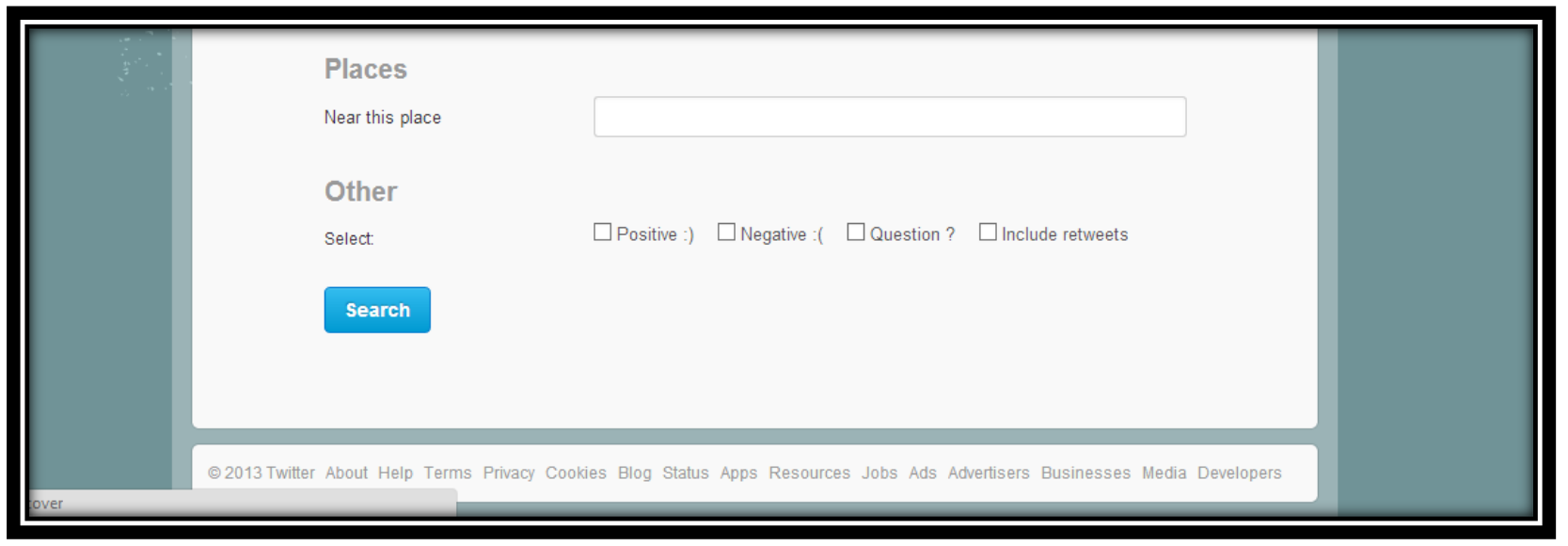

Fig. 46: Advanced Search on Twitter for Hashtag Information

\footnotetext{
${ }^{40}$ I say "better" with some reticence here. I do agree with Joanna Wolfe who says that numbers often appear to be indisputable facts and, as such, require closer study and framing than we now give them (see "Rhetorical Numbers: A Case for Quantitative Analysis in the Composition Class".) However, I am also certain many scholars are skeptical of arguments like those made by Rosenberg.
} 
For example, advanced searches on Twitter allow users to mine data to determine how many positive responses occur within a given hashtag's appearance. Above we see how entering items for a search allows us, under the category of "Other," to select positive, negative, question-based, or retweeted material. Such numbers speak to those who might wish to know how consensus is being formed in the appearance of key terms (e.g. the love of a character, the love a show's plot twist). While I still (obviously) privilege a close reading of specific revelatory moments in the work of digital rhetoric, and I see context as important to making arguments based on language, others may view the selection of examples as incomplete. The examples I share with readers here speak to my specific tastes as well as my position in the lower middle class (I cannot afford Showtime or other channels with subscription fees as a graduate student). To be sure, the process of text selection is always fraught with difficulty. One way to address the omitted genres or applications not mentioned in this work would be to mine more information across a series of platforms over a longer period of time. In other words, future studies like these may find some value in a computational stylistics model, in which the frequency of certain lexical constructions or themes appears across a season rather than simply within the occurrence of a few episodes or the narratives of basic network channels.

The Conference on Internet Research in 2013 featured speakers who addressed fan behavior in these exact ways. Because the program for this conference was made public, I was able to see how the study of live feeds on Twitter had embraced computational methods to analyze viewers' thoughts and habits. See this description of Italian panelist Fabio Giglietto‘s presentation: 
The paper presents what is, to our knowledge, the first study on a full season dataset of Twitter conversations about a TV genre. Starting from August 2012, we collected all the Tweets $(1,703,064)$ containing at least one of the official hashtags of the eleven political talk shows (607 episodes) aired by the Italian free-to-air broadcasters. We found a significant correlation between the Tweet-rate-per-minute during airtime and the audience of the show's episode. Furthermore, we demonstrate a technique, based on cluster analysis, aimed at identify key moment in a season. On this subset of contents, we applied qualitative content analysis to identify users' level of participation on the scale of access, interaction and participation.

Giglietto's approach to media studies and communication is different than the work in this project, and it remains different because I avoid the use numbers to discuss the many facets of how we identify with narrative worlds. My concern is not just that questions of writer identity may be lost in the analysis of the numbers but that the engagement with narrative is hard to analyze in terms of figures alone. As I explained in Chapter Four, Bogost stresses the value of discursive study in place of purely quantitative data when dealing with the work of gaming. The desire to see text exist outside the author's control is certainly worthy of consideration, yet from lived experience I recognize that subjectivity cannot be easily reduced to the viral exchange of information. My own desire to identify as a bilingual speaker showed how the manipulation of words in another 
language created opportunities for me not only to see language differently but to see myself differently as I moved through a world of text. ${ }^{41}$

The study of applications and networks that accompany popular narratives return again and again to the idea of constituting audiences in a specific culture. Not only do they raise questions about whom we identify with and how, but they echo a cultural preoccupation with sight and the act of seeing well. A campaign like the Homeland Security one focusing primarily on the idea of "seeing something" and then being propelled to "say something" reiterates how such messages beseech us to sharply observe our surroundings and possibly even place ourselves in the subject position of a would-be terrorist. Such an ability, I suggest, could, in part, be cultivated, or at least contemplated, through the critical study of transmedia that persuades its audience to identify with characters. "Rule-based representations and interactions," as Bogost says, "have unique persuasive powers" (10). Through the procedures discussed in the previous chapters, we learn to see the world as it might appear during a worldwide disaster (zombie apocalypse) and to champion that world as a worthy site of our study and participation. The questions that explicitly ask us how we would act if we were in the position of the protagonist are mounting claims about the value of that fictional world and nudging us toward a preferred model of conversation and participation. In the process of this consensus

\footnotetext{
${ }^{41}$ We may also remember that data mining is not a methodology first used by Internet researchers but has been in place through the study of various media: land line telephone surveillance and transcript study in courts is one such example, but the analysis of major works of literature to determine authorship through corpus stylistics is an even more prominent one in humanities work. Editors in The Henry James Review are currently working on a manuscript that features the systematic analysis of word usage and style changes throughout the corpus of Henry James's published novels and stories. The same cluster analysis that Giglietto mentions above appears in this analysis, too. Still, such techniques are not unique to this century or to this new fascination with digital communities.
} 
building, however, are lessons about intersubjectivity that are worthy of attention and interrogation.

The Story Sync application may soon be replaced by another immersive screen activity that engages audiences in an even more innovative manner. Certainly the tablet and mobile phones often functioning as second screens will be upgraded and, with these upgrades, will show even more sophisticated ways to engage in narrative and participate with other audience members. The use of handheld computers in the public and the classroom will soon, if not already, be the norm. Whether a viewer chooses to role play through a blogging platform or vote for a favorite scene in a given episode, the act of entering keystrokes and creating sentences in response to given narrative situations will continue to grow. Certainly each group of viewers, while watching their favorite narratives, has its own set of traditions and conversational moves. I have not meant to suggest that we can delineate one path of analysis through the exploration of second screen participation. Indeed, our study of these applications has been assisted here by critics in different subfields from object-oriented rhetoric and procedural rhetoric to the works of those currently engaged in constitutive rhetorical studies found in a recent edition of Rhetoric Society Quarterly.

A common thread running through all of this, however, is the fraught and everevolving term of digital rhetoric. While this project cannot account for all the vicissitudes of this term and the ways in which the term has potentially sharpened analysis or hindered it, my goal is for readers to see the importance of digital rhetoric as a living, changing method of composition through which multiple archives of messages and role play may provide insight on critical thinking processes. I believe this makes digital 
rhetoric valuable to the notion of academic conversation and writing because as teachers we hope to convince students that the conversation is always evolving and that they, too, have a voice in it as it changes and adapts to new periods of history.

In this project narrative has been the engine behind the push forward into new turns of conversation. I see narrative as the fertile ground upon which we are continually surprised and forced to grow and experiment with language. As people who are being asked more and more often to participate in its outcomes and to provide feedback to the writers behind it, we might understand even more clearly why it has the potential to infiltrate academic life and shape future arguments about student learning. Furthermore, to analyze it with an eye for how it helps us imagine other points of view is to open up possibilities in critical thinking and allow people of all ages to practice discernment in daily living and communication. Recently a friend confided that watching a show like Friday Night Lights while taking breaks during her the hardest parts of her dissertation process "did something akin to what religion does for others." This nod to pathos as a motivating force for logos (or the work of a thesis), similar to what Bogost describes when he mentions how Judeo-Christian theology provides space for deliberation, does not simply suggest that narrative inspires. It reminds us, I would argue, that narrative helps us deliberate. We may then pay closer attention to how our act of watching begins and how it continues. 


\section{REFERENCES}

Abbott, H. Porter. The Cambridge Introduction to Narrative. $2^{\text {nd }}$ ed. New York:

Cambridge UP, 2008. Print.

“About.” Afteryourdeathormine. 5 Aug. 2013. Tumblr. Web. 9 Sep 2013.

“About.” Lectercollapsingchurches. 3 Aug. 2013. Tumblr. Web. 9 Sep 2013.

“AMC, Instructure and UCI to Offer Multidisciplinary MOOC Based on 'The Walking Dead.'" UC Irvine News. Web. 4 Sep. 2013.

America in Primetime. PBS. Narr. David Chase, Vince Gilligan, Shonda Rhimes, et al.

Dir. Tom Yellin and the Documentary Group. 30 Oct. 2012. Netflix. Web. 30 Jan. 2013.

Anson, Chris, and Robert Schwegler. "Tracking the Mind's Eye: A New Technology for Researching Twenty-First Century Writing and Reading Processes." College Composition and Communication. 64 (2013). 151-71. Print.

“Are You Ready to Go Back? Where it All Started?” Friends-future-rp. Tumblr. 27 Aug. 2013. Web. 29 Aug. 2013.

"Bad Blood.” The X-Files: Season Five. Writ. Chris Carter and Vince Gilligan. Dir. Cliff Bole. 1998. Apple iTunes, 2011. Television.

Ballif, Michelle. "Writing the Third-Sophistic Cyborg: Periphrasis on an [In]Tense Rhetoric.” Rhetoric Society Quarterly. 28. 4 (1998): 51-72. JSTOR. Web. 19 Dec 2012.

Bakhtin, Mikhail M. "Discourse in the Novel." The Dialogic Imagination. Ed. Michael 
Holquist. Trans. Caryl Emerson and Michael Holquist. Austin: U of Texas P, 1981. 259-422. Print.

Ballenger, Bruce, and Michelle Payne. The Curious Reader: Exploring Personal and Academic Inquiry. $2^{\text {nd }}$ ed. New York: Pearson/Longman, 2006. Print.

Barthes, Roland. The Pleasure of the Text. Trans. Richard Miller. New York: Hill and Wang, 1975.

Baudrillard, Jean. "Simulacra and Simulations." Jean Baudrillard: Selected Writings. $2^{\text {nd }}$ ed. Ed. Mark Poster. 169-87. Stanford: Stanford UP, 2001. Print.

---. Telemorphosis. Trans. Drew S. Burk. Minneapolis: Univocal, 2011. Print.

Beauman, Ned. "Inside the Mind of St. Elsewhere's Tommy Westphall." The Guardian: TV and Radio Blog. Web. 22 Jan. 2012.

Benay, Phyllis. 2008. "Roundtable: Review of They Say/I Say: The Moves that Matter in Academic Writing." Pedagogy 8. 2: 369-73.

Black, Rebecca W. Adolescents and Online Fan Fiction. New York: Peter Lang, 2008. Print.

Bizzell, Patricia, and Bruce Herzberg. The Rhetorical Tradition: Readings from Classical Times to the Present. $2^{\text {nd }}$ ed. Boston: Bedford/St. Martin's, 2001. Print.

Bogost, Ian. Persuasive Games: The Expressive Power of Videogames. Cambridge: MIT P, 2007. iBook.

---. Alien Phenomenology, or What it's Like to Be a Thing. Minneapolis: U of Minnesota P, 2012. Print.

Booth, Paul. "MySpace Character Personas and Narrative Identification." Critical Studies in Media Communication. 2009. Academia.edu. Web. 27 August 2013.

Boothe, Wayne C. The Company We Keep: An Ethics of Fiction. Berkeley: U of 
California P, 1988. Print.

---. Critical Understanding: The Powers and Limits of Pluralism. Chicago: U of Chicago P, 1979. Print.

---. The Rhetoric of Rhetoric: The Quest for Effective Communication. Malden:

Blackwell P, 2004. Print.

Botwin, Michele. “WB's 'Creek' Hits Fan Pay Dirt with Dawson's Desktop Web Site.” LA Times. 12 May 1999. Web. 24 Jan. 2013.

Bruner, Jerome. Acts of Meaning. Cambridge: Harvard UP, 1990. Print.

---. Actual Minds, Possible Worlds. Cambridge: Harvard UP, 1986. Print.

Burke, Kenneth. Permanence and Change: An Anatomy of Purpose. Berkeley: U of California P, 1984. Print.

---. The Philosophy of Literary Form. Berkeley: U of California P, 1974. Print.

---."The Range of Rhetoric.” A Rhetoric of Motives. Berkeley: U of California P, 1969. 3-48. Print.

Buckingham, David. Children Talking Television: The Making of Television Literacy. New York: Routledge, 1993. Print.

---. Media Education: Literacy, Learning, and Culture. Boston: Polity, 2003. Print. Bury, Rhiannon. Cyberspaces of their Own. New York: Peter Lang, 2005. Print.

Canagarajah, Suresh. "Multilingual Strategies of Negotiating English: From Conversation to Writing." JAC. 29. 1-2 (2009): 17-48. Print.

Cazden, Courtney, et al. "A Pedagogy of Multiliteracies Designing Social Futures.” Multiliteracies: Literacy Learning and the Design of Social Futures. Ed. Bill Cope and Mary Kalantzis. London: Routledge, 2000. 9-38. Print. 
Charland, Maurice. "Constitutive Rhetoric: The Case of the Peuple Québéçois." The Quarterly Journal of Speech. 73 (1987): 133-150. Print.

Cope, Bill, and Mary Kalantzis, eds. Multiliteracies: Literacy Learning and the Design of Social Futures. London: Routledge, 2000. Print.

Corder, Jim W. “Argument as Emergence, Rhetoric as Love.” Rhetoric Review. 4. 1 (1985): 16-32. JSTOR. Web. 20 Dec. 2012.

Cushman, Ellen. "The Rhetorician as an Agent of Social Change." College Composition and Communication. 47.1 (1996): 7-28. Print.

Crowley, Sharon, and Debra Hawhee. Ancient Rhetorics for Contemporary Students. New York: Pearson/Longman, 2009. Print.

"Dash, You Stop That." thehobbesgirl. Tumblr. 52348309653. 18 Jun 2013. Web. 18 Jan 2014.

Davis, Julia. "'Hello, Newbie! **big welcome hugs** hope u like it here as much as i do!' An Exploration of Teenagers' Informal On-line Learning.” Digital Generations. Ed. David Buckingham and Rebekah Willett. New York: Routledge, 2006. 211-28.

Delagrange, Susan. Technologies of Wonder: Rhetorical Practice in a Digital World. Logan: Computers and Composition Digital P, 2012. Web. 12 June 2013.

---. “Wunderkammer, Cornell, and the Visual Canon of Arrangement." Kairos. 13.2 (2006). Google. Web. 24 Aug 2012.

Deleuze, Gilles, and Felix Guattari. Anti-Oedipus: Capitalism and Schizophrenia. New York: Penguin, 2009. Print. 
Dena, Christy. "Transmedia Practice: Theorising the Practice of Expressing Media in a Fictional World across Distinct Media and Environments.” Diss. U of Sydney, 2009. Google. Web. 12 Jan. 2013.

Deuze, Mark. Media Life. Cambridge, UK: Polity, 2012. Print.

“Did I Just Gain a Follower?" whatifiaminsane.tumblr.com. Tumblr. 16 June 2013. Web.

Dino DeLaurentiis Co (@DeLaunrentiisCo).“\#FF@LeePaceOfficial@NightWritergrrr @BonBonfaboo@sgloera@Louisvillebound@frances_t@itsme_dora@AverageC harles Have a Gr8 Wkend!" Twitter. Web. 3 May 13.

Duffy, John. "Reclaiming Virtue: An Ethical Discourse for Rhetoric and Composition."

Thomas R. Watson Symposium. Paper in Progress. Louisville, KY. 19 Oct. 2013.

"Don't just watch CBS. Sync!" CBS.com. Web. 2 July 2013.

Elbow, Peter. "The Doubting Game and the Believing Game-An Analysis of the Intellectual Enterprise.” Writing without Teachers. Oxford: Oxford UP, 1998. 147-90. Print.

Elkins, James. Visual Studies. New York: Routledge, 2003. Print.

Ellis, Erik. "Shushes in the Parlor: Reclaiming the 'Conversation' Metaphor.” In Disrupting Pedagogies in the Knowledge Society: Countering Conservative Norms with Creative Approaches, ed. Julie Faulkner, 60-76. Hershey, PA: IGIGlobal, 2012. Print.

“Endgame.” Interactive Sync. NCIS: LA. CBS. WLKY. Feb. 2013. NCIS: LA Connect App. Apple App Store.

"Eye for an Eye." The Walking Dead Season 3. AMC. Banner Advertisement on AMC Mobile. Web. 1 Feb 2013. 
“The Family Dog.” Amazing Stories: The Complete First Season. Writ. Brad Bird. Dir. Brad Bird. YouTube. 16 Feb. 1987. Web. 20 Jan 2013.

Feuer, Janice. Seeing Through the Eighties: Television and Reaganism. Durham: Duke UP, 1995. Print.

Fisherkeller, JoEllen. Growing Up with Television: Everyday Learning Among Young Adolescents. Philadelphia: Temple UP, 2002. Print.

Fiske, John. Reading the Popular. London: Routledge, 1987. Print.

The Following. (@TheFollowingFOX) “No Joe Carroll’s [sic] among Your Professors.” Twitter. Web. 12 Feb 2013.

Fleckenstein, Krista. “Cybernetics, Ethos, and Ethics.” Plugged In: Technology, Rhetoric and Culture in a Posthuman Age. Ed. Lynn Worsham and Gary A. Olson. Cresskill: Hampton P, 2008. Print.

“Four Corners.” ER: Season Eight. Writ. Jack Orman and David Zabel. Dir. Christopher Misiano. 27 Sep. 2001. DVD.

Fuller, Bryan. “Aperitif.” Hannibal. NBC. 2013. Google. Web. 9 April 2013. Transcript. ---. "Given nature of Marlowe murders, we believe person responsible may be a fledgling serial killer with a penchant for biting." Twitter. 20 May 2013. Web. Gaiman, Neil. "Why Our Future Depends on Libraries, Reading, and Daydreaming." The Guardian. 15 Oct. 2013. Web. 15 Nov. 2013.

“Game of Thrones--My Watch Begins.” HBO Marketing Campaign for Season Two. DinaMoe Interactive Media. Web. 1 Feb. 2013.

Gee, James Paul. "Identity as an Analytic Lens for Research in Education." Review of Research in Education. 25 (2001): 99-125. Print.

---. What Video Games Have to Teach Us about Learning and Literacy. Revised Ed. 
New York: Palgrave MacMillan, 2007.

Gillan, Jennifer. Television and New Media: Must-Click TV. New York: Routledge, 2011. Print.

Giglietto, Fabio. "Second-Screen and Political Talk-Shows: Measuring and Understanding the Italian Participatory Couch Potato.” Selected Papers of Internet Research: Conference on Internet Research. 2014. Google. Web. 10 Nov. 2013.

Graff, Gerald, Cathy Birkenstein, and Russel Durst. 2006. They Say/I Say with Readings: The Moves that Matter in Academic Writing. New York: W. W. Norton and Company.

Gray, Jonathan, Cornell Sandvoss, and C. Lee Harrington, eds. Fandom: Identities and Communities in a Mediated World. New York: New York UP, 2007. Print.

Greene, Stuart. "Argument as Conversation: The Role of Inquiry in Writing a Researched Argument." Writing about Writing: A College Reader. Ed. Elizabeth Wardle and Doug Downs. Boston: Bedford/St. Martin's, 2011. Print.

Hagood, Margaret. "Intersections of Popular Culture, Identities, and New Literacies Research." Handbook of Research on New Literacies. Eds. Julie Coiro, et. al. New York: Routledge, 2008. 531-52. Print.

Halpern, Faye. "In Defense of Reading Badly: The Politics of Identification in 'Benito Cereno,' Uncle Tom's Cabin, and Our Classrooms." College English. 70 (2010): 551-77. Print.

“Hannibal: ‘Buffet Froid’ Sticker.” Get Glue. 30 May 2013. Web. 30 May 2013.

“Hannibal: 'Under the Bed’ Sticker.” Get Glue. 30 May 2013. Web. 30 May 2013. 
Hare, Breeanna. "Twice as Much TV? How Networks are Adapting to the Second Screen.” CNN Entertainment. Google. 15 Sep. 2012. Web. 25 Mar. 2013. Harrigan, Pat and Noah Wardrip-Fruin. "Introduction." Third Person: Authoring and Exploring Vast Narratives. Cambridge: MIT P, 2009. 1-8. Print.

Hawhee, Debra. Moving Bodies: Kenneth Burke at the Edges of Language. Columbia: U of South Carolina P, 2009. Print.

Hayles, N. Katherine. How We Became Posthuman: Virtual Bodies in Cybernetics, Literature, and Informatics. Chicago: U of Chicago P, 1999. iBook.

---. How We Think: Digital Media and Contemporary Technogenesis. Chicago: U of Chicago P, 2012. iBook.

Heilker, Paul and Jason King. "The Rhetorics of Online Autism Advocacy: A Case for Rhetorical Listening."Rhetorics and Technologies: New Directions in Communication. Ed. Stuart Selber. Columbia: U of South Carolina P, 2010. 113133. Print.

“Hell on High Heels.” Prof-river-song-archaeologist. Tumblr. Web. 25 June 2013. HistoryVikings (@HistoryVikings)."What Do You Think are Lagertha's Fears?” Twitter. Web. 28 April 2013.

---. "What Was Your Favorite Part of Tonight's \#Vikings?” Twitter. Web. 28 April. 2013.

Hodgson, Justin. “Reculturalizations: ‘Small Screen’ Culture, Pedagogy, and YouTube.” Enculturation. 8 (2010). Web. 15 March 2013. 
Hooper, Emily. "From Epideictic to Deliberative Rhetoric: The Non-English Discourses of LOST.” Thomas R. Watson Conference. 15 Oct. 2010. Louisville, KY. Presentation.

Howard, K. Shannon. "Everything Old is New Again: A Barthesian Analysis of the Microblogging Site Tumblr.” Technoculture 2 (2012). Web. 28 Sep. 2013. ---. @louisvillebound. “TheFollowingFOX has it Wrong.” 12 Feb. 2013. Twitter. Web.

"Ice and Fire: Winter is Coming." HBO: Game of Thrones Weather Application. Home Box Office, 2011. iPad 2.

"If You See Something, Say Something." Department of Homeland Security. Google. Web. 25 Jan. 2013.

"I'd Love It If Even One Person Did This." Liverandchianti. Tumblr. 57167602706. 2 Aug. 2013. Web. 7 Aug. 2013.

"In the Middle of a Conversation. ..." beverlykatzonthecase. Tumblr. 60682544971. 8 Sep. 2013. Web. 8 Sep. 2013.

Iser, Wolfgang. "Interaction between Text and Reader." The Norton Anthology of Theory and Criticism. $2^{\text {nd }}$ ed. Ed. Vincent B. Leitch et al. New York: W. W. Norton, 2010. 1524-32. Print.

Jameson, Fredric. From The Cultural Logic of Late Capitalism. The Norton Anthology of Theory and Criticism. $2^{\text {nd }}$ ed. Ed. Vincent B. Leitch et al. New York: W. W. Norton, 2010. 1588-99.

---. "The End of Temporality." Critical Inquiry 29 (2003): 695-715. Print. Jenkins, Henry. Convergence Culture: Where Old and New Media Collide. New York: 
New York UP, 2006. Print.

---. Sam Ford, and Joshua Green. Spreadable Media: Creating Value and Meaning in a Networked Culture. New York: New York UP, 2013. Print.

---. Textual Poachers: Television Fans and Participatory Culture. New York: Routledge, 1992. Print.

Jinkins, Michael. "Intellectual Empathy." Huff Post Education. 18 July 2012. Web. 12 Jan. 2013.

Johnson, Christopher. Microstyle: The Art of Writing Little. New York: Norton, 2011. Print.

Johnson, Matthew S. S. "Authoring Avatars: Gaming, Reading, and Writing Identities.” Composing $($ Media $)=$ Composing $($ Embodiment $)$. Ed. Kristin L. Arola and Anne Francis Wysocki. Logan: Utah State UP, 2012. 60-71. Print.

Johnson, Steven. Everything Bad is Good For You. New York: Riverhead, 2005. Print. Journet, Debra. "Literate Acts in Convergence Culture: Lost as Transmedia Narrative." Rhetorics and Technologies: New Directions in Writing and Communication. Eds. Stuart Selber and Carolyn Miller. Columbia: U of South Carolina P, 2010. Print.

---. "Narrative, Action, and Embodiment: The Stories of Myst." Gaming Lives in the Twenty-First Century. Ed. Cynthia L. Selfe and Gail Hawisher. New York: Palgrave/Macmillan, 2007. Print.

Jurecic, Ann. "Empathy and the Critic." College English 74.1 (2011): 10-27. Print.

Keen, Suzanne. "Theory of Narrative Empathy." Narrative. 14. 3 (2006): 207-36. JSTOR. Web. 20 Dec. 2012.

Kennedy, George A., ed. Progymnasmata: Greek Textbooks of Prose Composition and 
Rhetoric. Trans. George A. Kennedy. Atlanta: Society of Biblical Literature, 2003. Print.

Kirby, David. Death at Sea World. New York: St. Martin's P, 2012. iBook.

Kopp, Drew. "The Risk of Rhetorical Inquiry: Practical Conditions for a Disruptive Pedagogy." Disrupting Pedagogies in the Knowledge Society: Countering Conservative Approaches with Creative Norms. Ed. Julie Faulkner. Sydney: IGI Global, 2012. 225-41. Print.

“The Last One.” St. Elsewhere: Season Six. Writ. Tom Fontana et al. Dir. Mark Tinker. 25 May 1988. YouTube. Web.

Lavery, David. "Lost and Long-Term Television Narrative." Third Person: Authoring and Exploring Vast Narratives. Pat Harrigan and Noah Waldrip-Fruin, eds. Cambridge: MIT P, 2009. Print.

Leake, Eric. "In the Words of Another: On the Promises and Paradoxes of Rhetorics of Empathy.” Diss. Univ. of Louisville, 2011. Google. Web. 11 Jan. 2013.

Long, Liza. “'I Am Adam Lanza's Mother': A Mom's Perspective on Mental Illness on the Mental Illness Conversation in America." Huff Post Parents. 16 Dec. 2012. Web. 20 Jan 2013.

Lu, Min Zhan. "Professing Multiculturalism: The Politics of Style in the Contact Zone." College Composition and Communication. 45 (1994): 442-58. Print.

Lucas, Janet. "Not Just a Feeling Anymore: Empathy and the Teaching of Writing.” Diss. Indiana Univ. of Pennsylvania, 2011. Google. Web. 11 Jan. 2013.

Lunsford, Andrea. "Writing, Technologies, and the Fifth Canon." Computers and Composition 23 (2006):169-177. Print.

Lynch, Dennis. "Rhetorics of Proximity: Empathy in Temple Grandin and Cornel West." 
Rhetoric Society Quarterly. 28. 1 (1998): 5-23. JSTOR. Web. 20 Dec. 2012.

Lynch, Jennifer. The Secret Diary of Laura Palmer. New York: Pocket Books, 1990. Print.

"Made in America." The Sopranos: Season Six. Writ. David Chase. Dir. David Chase. 10 June 2007. YouTube. Web. 28 Jan 2013.

Massumi, Brian. Parables for the Virtual: Movement, Affect, Sensation. Durham: Duke UP, 2002. Print.

---. A User's Guide to Capitalism and Schizophrenia. Cambridge: MIT P, 1992. Print.

McKee, Heidi A., and James E. Porter. "Rhetorica Online: Feminist Research Practices in Cyberspace.” Rhetorica in Motion. Ed. Eileen E. Schell and K. J. Rawson. Pittsburg: U of Pittsburg P, 2010. Print.

“M!A Ideas from SPN Episodes.” Michiferangst. Tumblr. 59597914824. 11 Sep. 2013. Web. 11 Sep. 2013.

Micciche, Laura. "Writing as Feminist Rhetorical Theory." Rhetorica in Motion: Feminist Rhetorical Methods \& Metholodologies. Ed. Eileen E. Schell and K. J. Rawson. Pittsburg: U of Pittsburg P, 2010. Print.

Mittell, Jason. Complex TV: The Poetics of Contemporary Television Storytelling. Media Commons P, 2012. 26 March 2012. Web.

---. "Narrative Complexity in Contemporary American Television.” The Velvet Light Trap 58 (Fall 2006): 29-40. Web.

“M!A: Romeo, Romeo.” Bibliophileangel and Razielangelofsecrets. 66666065855. 3 Sep. 2013. Web. 14 Sep. 2013. 
Mayer, Richard E. et al. "Clickers in College Classrooms: Fostering Learning with Questioning Methods in Large Lecture Classes.” Contemporary Educational Psychology 34 (2009): 51-57. Elsevier. Web. 3 March 2013.

Moberly, Kevin. "Composition, Computer Games, and the Absence of Writing." Computers and Composition. 25 (2008): 284-99. Science Direct. Web. 25 Jan. 2013.

"Monsters: A Lithuanian Music Mix for Hannibal and Abigail.” Little-shrike. Tumblr. 59995927611. 2 Sep. 2013. Web. 7 Sep. 2013.

Morley, David. Television, Audience, and Cultural Studies. New York: Routledge, 1992. Print.

Newkirk, Thomas. Misreading Masculinities: Boys, Literacy, and Popular Culture. New York: Heineman, 2002. Print.

"Normal Again.” Buffy the Vampire Slayer: Season Six. Writ. Diego Guiterrez. Dir. Rick Rosenthal. 12 Mar. 2002. DVD.

"Not to Startle You, But.” NBC Hannibal. Tumblr. 51747697811. 31 May 2013. Web. 7 June 2013.

Peckham, Irvin. Going North, Thinking West: The Intersections of Social Class, Critical Thinking, and Politicized Writing Instruction. Logan: Utah State UP, 2011. Print.

Phelan, James. Living to Tell about It: a Rhetoric and Ethics of Character Narration. Cornell UP, 2004. Print.

Ratliffe, Krista. "Rhetorical Listening: A Trope for Interpretive Invention and a 'Code of Cross- Cultural Conduct."” College Composition and Communication 51 (1999): 195-224. Print.

Rashid, Fahmida Y. "The Rise of Clickers Is Starting to Change How College 
Professors Run Their Classroom.” The Village Voice. 5 Jan. 2011. Google. Web. 25 Feb. 2013.

"Reblog if You Are Proud of Your URL." Madaraswife via Kisshimoto. Tumblr. 60196335619. 2 Sep. 2013. Web. 3 Sep. 2013.

Ridolfo, Jim, and Danielle Nicole DeVoss. "Composing for Recomposition: Rhetorical Velocity and Delivery.” Kairos: A Journal of Rhetoric, Technology, and Pedagogy. 13. 2 (2009). Web. 20 March 2013.

Rogers, Carl. A Way of Being. Boston: Houghton Mifflin, 1980. Print.

Roozen, Kevin. "Fanfic-ing English Studies: A Case Study Involving the Interplay of Vernacular Literacies and Disciplinary Engagement" Research in the Teaching of English. 44.2 (2009): 136-69. ProQuest. Web. 1 March 2013.

Rosenberg, Alyssa. "What the U. S. Would Look Like If It Mirrored the Characters on Prime- Time Network Television.” ThinkProgress. 28 Oct. 2013. Web. 12 Nov. 2013.

"Rules.” Friends-future-rp. 1 Aug. 2013. Tumblr. Web. 29 Aug. 2013.

Ryan, Mo, Erik Adams, and Myles McNutt. "The State of the Industry.” Talking TV with Ryan and Ryan. 30 Jan.2013. Soundcloud. Web. 31 Jan. 2013.

Sirc, Geoffrey. "Serial Composition." Rhetoric and Technologies: New Directions in Writing and Communication. Columbia: U of South Carolina P, 2010. 56-76.

Stein, Joel. “The New Greatest Generation.” Time Magazine. Vol. 181 (2013). Academic Search Premier. Web. 17 July 2013.

“The Suicide King.” Interactive Sync. The Walking Dead. 10 Feb 2013. AMC Mobile. Brightcove. Web. 10 Feb. 2013.

"Sacrifice." Vikings. History Channel. 21 Apr. 2013. Television. 
Sandvoss, Cornel. "The Death of the Reader? Literary Theory and the Study of Texts in Popular Culture." Fandom: Identities and Communities in a Mediated World. Ed. Jonathan Gray et al. New York: New York UP, 2007. Print.

Sepinwall, Alan. The Revolution Was Televised: The Cops, Crooks, Slingers, and Slayers Who Changed TV Drama Forever. Smashwords, 2012. iBook.

Stafford, Barbara. "Visual Pragmatism for a Virtual World." Visual Rhetoric in a Digital World. Ed. Carolyn Handa. Boston: Bedford/St. Martin's, 1996. 209-21.

"Superstar." Buffy the Vampire Slayer: Season Four. Writ. Jane Espenson. Dir. David Grossman. 4 April 2000. DVD.

"Tap or Swap the Tiles to Unscramble the Image." Falling Skies App. TNT. Web. 9 March 2013.

Thomas, Angela. Youth Online: Identity and Literacy in the Digital Age. New York: Peter Lang, 2007. Print.

“Twenty-Four Hours until Savoureux.” NBC Hannibal. Tumblr. 53404893625.20 June 2013. Web.

“U Know What’s Fuckin’ Hardcore?” Fefarielle. Tumblr. 586135374912 Sep. 2013. Web. 8 Sep 2013.

Van Peer, Willie, and Seymour Chatman, eds. "Introduction." New Perspectives on Narrative Perspectives. Albany: State U of New York P, 2001. ix-xxxv. Google Play Books.

“Vikings: ‘All Change’ Finale Sticker.” Get Glue. 5 May 2013. Web. 5 May 2013.

Warren, Katherine. "Who Are You Here? The Avatar and the Other in Video Game Avatars." Rhetoric/Composition/Play through Video Games. Ed. Richard Colby, 
Matthew S. S.Johnson, and Rebekah Shultz Colby. New York: Palgrave Macmillan, 2013. Print.

Warner, Michael. Publics and Counterpublics. Cambridge: MIT P, 2005. Print.

Williams, Bronwyn T. “'Which South Park Character Are You?' Popular Culture, Literacy, and Online Performances of Identity" Computers and Composition 25.1 (2008): 24-39. Print.

---."Multilingual Literacy Strategies in Online Worlds." JAC 29. 1-2 (2009): 255-58. Print.

---. Shimmering Literacies. New York: Peter Lang, 2009. Print.

---. Tuned In. Portsmouth: Boynton/Cook, 2002. Print.

Williams, Bronwyn T., and Amy Zenger. Popular Culture and Representations of Literacy. New York: Routledge, 2007. Print.

Weatherson, Brian. "Six Objections to the Westphall Hypothesis." Thoughts Arguments and Rants. 4 Oct. 2004. Web. 23 Jan. 2013.

Wolfe, Joanna. "Rhetorical Numbers: A Case for Quantitative Writing in the Composition Classroom." College Composition and Communication. 61 (2010): 452-75. Print.

“Worlds Apart.” Falling Skies App. TNT. Web. 9 Mar. 2013.

Yarow, Jay. "Apple's Advice for Developers Looking at the App Store.” Tech. Business Insider. 21 Oct. 2010. Web. 12 Jan. 2013.

Zillman, Dolf. "Mechanisms of Emotional Involvement with Drama." Poetics 23 (1994): 33-51. JSTOR. Web. 20 Dec. 2012.

Zunshine, Lisa. Why We Read Fiction: Theory of Mind and the Novel. Columbus: Ohio State P, 2006. Google. Web. 


\title{
CURRICULUM VITA
}

\author{
K. Shannon Howard \\ University of Louisville \\ 1218 S. Brook St. Louisville, KY 40203 \\ 251 510-5732 / kshowa02@louisville.edu \\ www.kshannonhoward.com
}

\section{EDUCATION}

University of Louisville. Ph.D. in Rhetoric and Composition, anticipated Spring 2014.

Dissertation: "“My Watch Begins"”: An Analysis of Procedural Rhetoric and Burkean Identification on Second Screens and Mobile Applications."

Committee: Bronwyn T. Williams (director), Karen Kopelson, Stephen Schneider, Matthew Biberman, Ellen B. Harrington.

University of South Alabama. M.A. in English - Literature, 2010.

Thesis: Joseph Conrad's Homosocial Bedroom and the Frustrating Search for Intimacy.

Committee: Ellen B. Harrington (director), Christopher Raczkowski, and Justin St. Clair.

Bread Loaf School of English. Continuing Education, Summers 2005 and 2006.

University of South Alabama. M.Ed. in Secondary Education - Language Arts, 1999.

Presbyterian College. B.A. in English and Theatre Arts with honors, summa cum laude, 1997.

\section{PUBLICATIONS}

\section{Peer reviewed}

"Establishing Dialogue between Theory and Composition Classrooms: A New Approach to Judith Butler's Gender Trouble via 'Moves [and Movers] that Matter' in Academic Writing." Pedagogy: Critical Approaches to Teaching Language, Literature, Composition, and Culture. Forthcoming 14. 3 (2014).

"Everything Old is New Again: A Barthesian Analysis of the Microblogging Site Tumblr." Technoculture: An Online Journal of Technology in Society 2 (2012).

\section{Chapters in book collections}

"Charles Gunn, Wolfram and Hart, and Baudrillard's Theory of the Simulacrum." Ed. AmiJo Comeford and Tami Burnett. Literature and Joss Whedon's Angel. McFarland, 2010.

\section{Non peer reviewed}

"Technological Redemption through Sound: An Auditory Journey through Dante's Inferno." 
Learning and Leading with Technology. International Society of Technology in Education, 2006.

\section{Encyclopedia/Reference}

"Elia Kazan." 100 People Who Changed American Entertainment. Ed. Robert Sickel. Greenwood Press, 2013.

\section{PAPERS PRESENTED}

\section{National Conferences}

"The Crossing as Constitutive Rhetoric: Balsero Identity in Art, Text, and Social Networking." Rhetoric Society of America. San Antonio, TX, 2014.

"Controlling the Underlife of Narrative Consumption: Story Sync, Guided Readings, and Classrooms of the 21st Century." Computers and Writing Conference. Frostburg, MD, 2013. "Paratexts as Policing Devices: How Transmedia Applications Control Fan Research." Popular Culture Association. Washington, D.C., 2013.

"The TV Superviewer Meets the Conversation Metaphor: Building a Research Scaffold from Multiple Points of View in Pop Culture." Conference on College Composition and Communication. Las Vegas, NV, 2013.

"Using ' $\mathrm{Y}$ ' to Solve for ' $\mathrm{X}$ ': Generational Discourse in Glee." Popular Culture Association. San Antonio, TX, 2011.

"Girls Following the Grail: the Gender Performance of Summer Camp through Arthurian Tradition.” Popular Culture Association. St. Louis, MO, 2010.

\section{Regional, Local, and Graduate Conferences}

"Inside the Theorist's Studio: Conversations and Theoretical Collisions in Judith Butler's Gender Trouble." Women and Rhetoric: Federation Rhetoric Symposium. Denton, TX, 2012.

"Closeted Bullies: Closeted Fans: the Digital Communities that Support Glee's Dave Karofsky."

Annual Humanities Graduate Conference on Fanaticism. Louisville, KY, 2011.

“The Search for Meaningful Apocalypse in Eaton's Inactivist and Are We Not Horses." Midwest Modern Language Association, St. Louis, MO, 2009.

"Serving Culture with a Smile: Restaurants in Zadie Smith's White Teeth." Midwest Modern Language Association, St. Louis, MO, 2009.

\section{Invited Talks and Workshops}

"Gender Studies Approach to Teaching and Writing: Karen Kopelson, Elizabeth Flynn, and Robert Connors.” English 602 Graduate Seminar. Louisville, KY, 2012. 
"Student Paper Comments as Dialogue for Conferencing." University of Louisville Composition Program Orientation. Louisville, KY, 2012.

"Branding Yourself: How to Be Searchable." School of Interdisciplinary and Graduate Studies. Louisville, KY, 2012.

"Camp Merrie-Woode for Girls and Gender Performance." Research Network Forum at the Conference of College Composition and Communication. Atlanta, GA, 2011.

"Effective Citation Methods for Essays." Enrichment Workshop on Behalf of the USA Writing Center. University of South Alabama. Mobile, AL, 2010.

"Sound Design in the English Classroom." Alabama Association of Independent Schools, Mobile, AL, 2006.

"The Age of Film Meets the Reading/Writing Connection." South Alabama Regional Inservice Center, Mobile, AL, 2004.

\section{TEACHING EXPERIENCE}

University of Louisville. Graduate Teaching Assistant, 2010-14.

University of South Alabama's Center for Healthy Communities. Enrichment English Instructor, 2010 .

University of South Alabama. Teaching Assistant, 2009-2010.

St. Paul's Episcopal School. High School Instructor, Fall 2000-2007.

Theodore High School. High School Interim Instructor, Spring 2000.

\section{COURSE INSTRUCTION AND DESIGN}

English 306: Business Writing, University of Louisville.

English 310: Teaching Literature to Non-Majors, University of Louisville.

English 105: Honors Composition, University of Louisville.

English 102: Intermediate College Writing, University of Louisville.

English 101: Introductory College Writing, University of Louisville.

English 101: Introduction to Composition, University of South Alabama.

World Literature: 10th Grade English, St. Paul's School.

American Literature: 11th Grade English, St. Paul's School.

Video Production: Elective Film Course, grades 9-12, St. Paul's School.

Introduction to Speech: Elective Communications Course, grades 9-12, St. Paul's School.

Introductory Dramatic Arts: Elective Arts Course, grades 9-12, Theodore High School.

Intermediate Dramatic Arts: Elective Arts Course, grades 9-12, Theodore High School. 


\section{ADMINISTRATIVE EXPERIENCE}

Henry James Review Fellow and Editorial Assistant, University of Louisville, 2012-14.

Assistant Director of Composition, University of Louisville, 2012-13.

Education Administration Internship at Berkeley Repertory Theatre, 2007-08.

Director of Upper School Awards Ceremony for Staff and Students at St. Paul's School, 2006-07.

Team Leader and Liaison for the Mobile Bay Writing Project, Summers 2002, 2004, and 2007.

SACS Committee Chair for St. Paul's School, 2002-03.

Director of Actor's Training Program for Youth, 1997-98.

\section{HONORS}

Barbara Plattus Award for Excellence in Graduate Teaching, University of Louisville, 2014.

Graduate Student Union Research Grant for Dissertation Work, University of Louisville, 2011.

Endowed Scholarship in English, University of South Alabama, 2010.

Outstanding Graduate Student Essay Scholarship, 2010.

Election to Phi Kappa Phi, 2009-10.

Outstanding Graduate Student Essay Scholarship, 2009.

Faculty Grant to Study at Bread Loaf School of English, 2005 and 2006.

Outstanding Graduate Student in Cultural Foundations of Education, 1999.

\section{SERVICE}

English Graduate Organization Executive, 2012-13.

English Department Book Sale Fundraiser Chair, 2013.

Panel Chair for Computers and Writing Conference, 2013.

Panel Chair for the Louisville Conference on Literature and Culture, 2013.

University of Louisville Peer Mentor, 2012-13.

University of Louisville Graduate Teaching Academy Member, 2010-11.

University of Louisville Watson Conference Hospitality Committee, 2010, 2012.

University of South Alabama's Center for Healthy Communities Tutor, 2009-10.

Junior League of Mobile, AL-Writer for League publication Folio, 2002-03.

Mobile Theatre Guild Board of Directors-Education Outreach, 2000-01. 